\title{
IntechOpen
}

\section{Changing Ecosystems and Their Services}

Edited by Levente Hufnagel

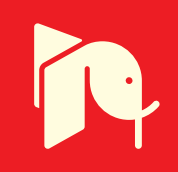





\title{
Changing Ecosystems and Their Services
}

\author{
Edited by Levente Hufnagel
}



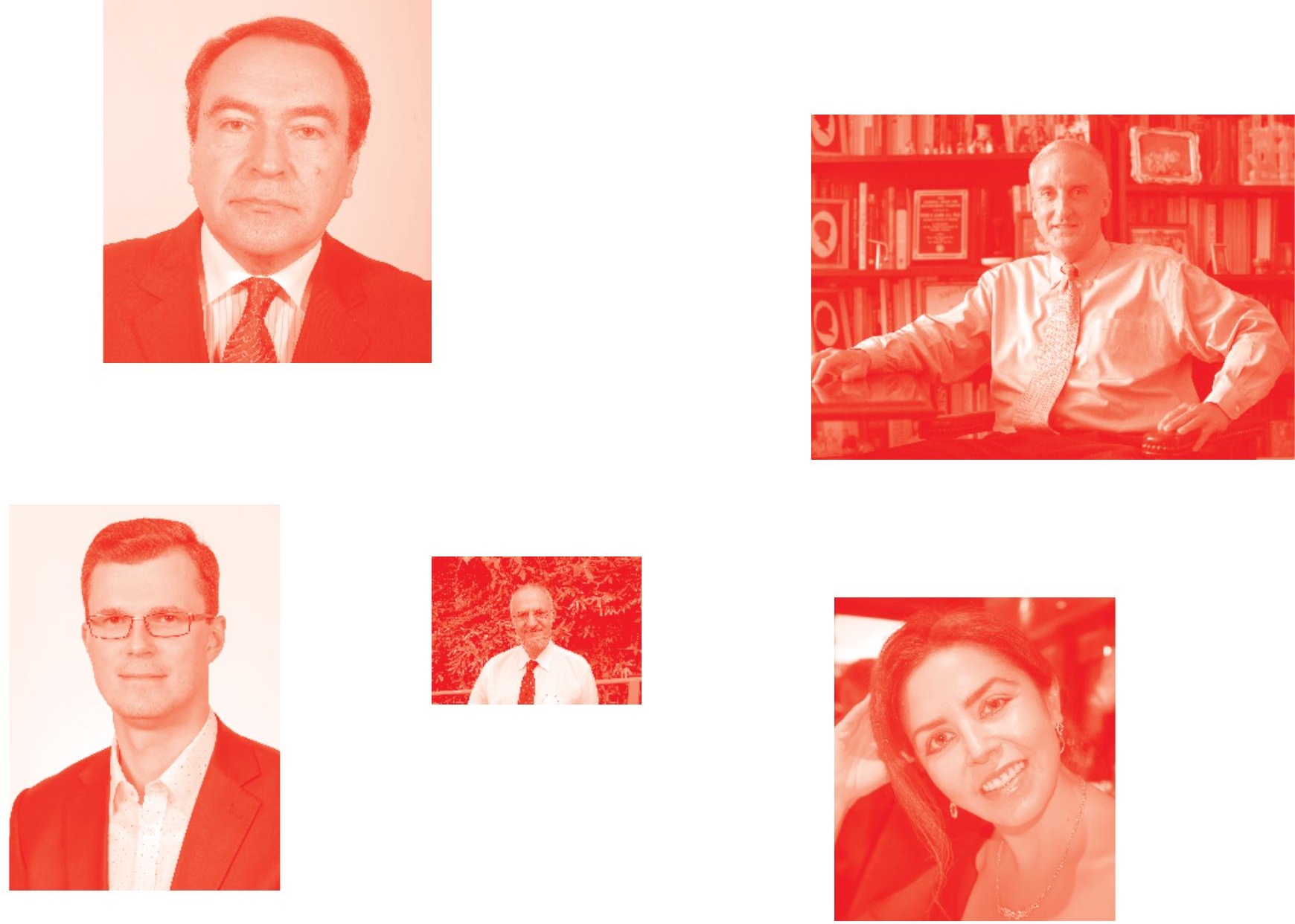

Supporting open minds since 2005
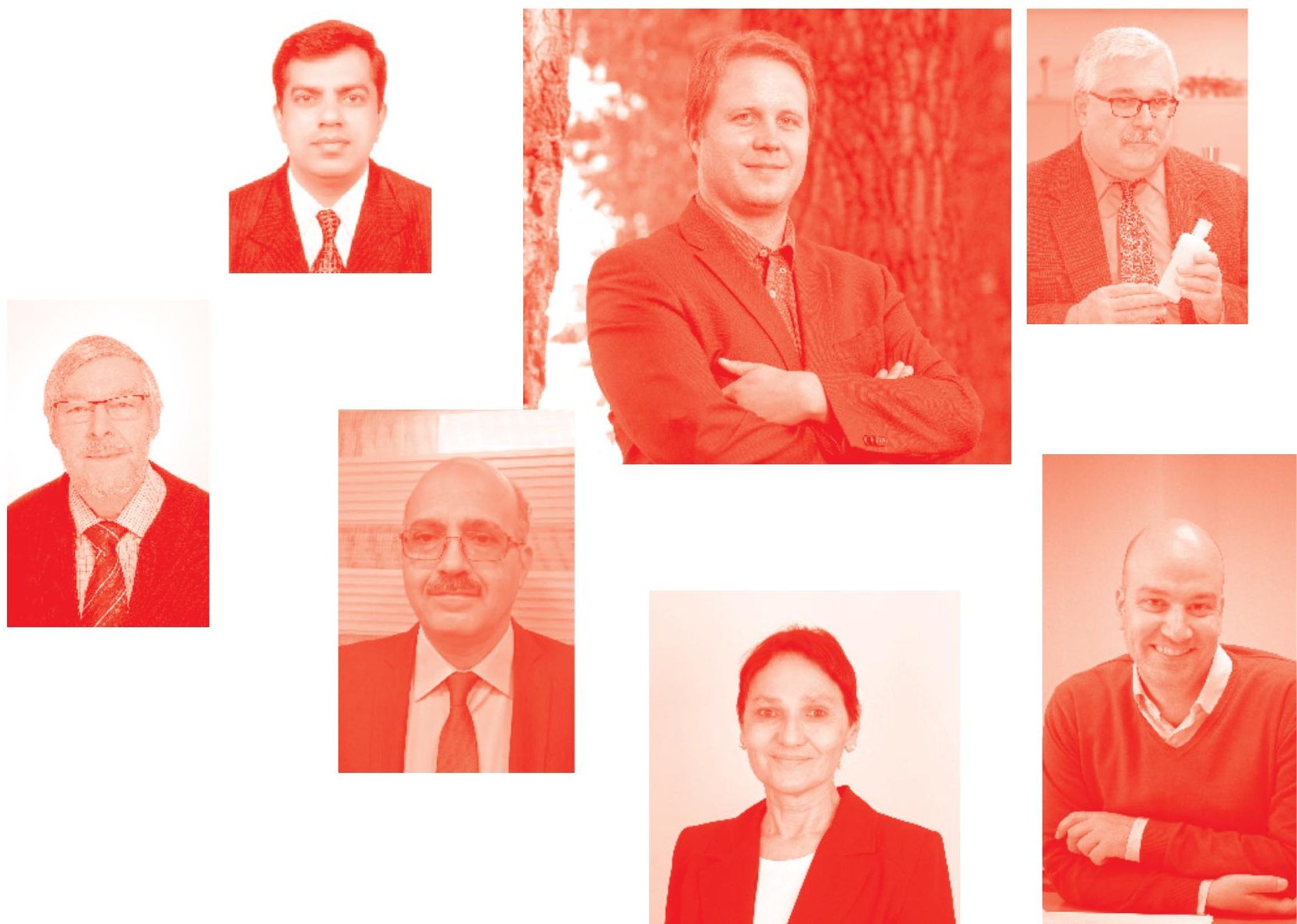
Changing Ecosystems and Their Services

http : //dx . doi. org/10.5772/intechopen. 82940

Edited by Levente Hufnagel

\section{Contributors}

Abdul-Rahman Dirisu, Michael Uwagbae, Tambeke Nornu Gbarakoro, Eman El Surtasi, Martins Aisien, Johnny Rotimi, Julia Ekenma Agwu, Vuyo Mjimba, Gamelihle Sibanda, Sylvia Mitchell, Kimani KitsonWalters, Achsah Mitchell, Levente Hufnagel, Réka Homoródi, Ferenc Mics, Melinda Pálinkás, Arnab Das, Acacio Navarrete, Marília De Souza Bento, Dayane Barros, Murilo De Souza Ferreira, Maria Bernadete De Amâncio Varesche, Janaina Do Carmo, Vania Neu, Rogério Hartung Toppa, Paula Benevides De Morais, Dawit Mulatu

( ) The Editor(s) and the Author(s) 2020

The rights of the editor(s) and the author(s) have been asserted in accordance with the Copyright, Designs and Patents Act 1988. All rights to the book as a whole are reserved by INTECHOPEN LIMITED. The book as a whole (compilation) cannot be reproduced, distributed or used for commercial or non-commercial purposes without INTECHOPEN LIMITED's written permission. Enquiries concerning the use of the book should be directed to INTECHOPEN LIMITED rights and permissions department (permissions@intechopen.com).

Violations are liable to prosecution under the governing Copyright Law .

\section{(cc) BY}

Individual chapters of this publication are distributed under the terms of the Creative Commons Attribution 3.๑ Unported License which permits commercial use, distribution and reproduction of the individual chapters, provided the original author(s) and source publication are appropriately acknowledged. If so indicated, certain images may not be included under the Creative Commons license. In such cases users will need to obtain permission from the license holder to reproduce the material. More details and guidelines concerning content reuse and adaptation can be found at http : //www . intechopen . com/copyright-policy . html .

\section{Notice}

Statements and opinions expressed in the chapters are these of the individual contributors and not necessarily those of the editors or publisher. No responsibility is accepted for the accuracy of information contained in the published chapters. The publisher assumes no responsibility for any damage or injury to persons or property arising out of the use of any materials, instructions, methods or ideas contained in the book.

First published in London, United Kingdom, 2020 by IntechOpen IntechOpen is the global imprint of INTECHOPEN LIMITED, registered in England and Wales, registration number: 11086078 , 7th floor, 10 Lower Thames Street, London,

EC3R 6AF, United Kingdom

Printed in Croatia

British Library Cataloguing-in-Publication Data

A catalogue record for this book is available from the British Library

Additional hard and PDF copies can be obtained from orders@intechopen.com

Changing Ecosystems and Their Services

Edited by Levente Hufnagel

p. $\mathrm{cm}$.

Print ISBN 978-1-83880-117-5

Online ISBN 978-1-83880-118-2

eBook (PDF) ISBN 978-1-83880-@77-2 


\section{We are IntechOpen, \\ the world's leading publisher of Open Access books}

Built by scientists, for scientists

\section{$4,700+$}

Open access books available

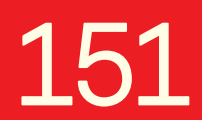

Countries delivered to
$120,000+$

International authors and editors

Our authors are among the

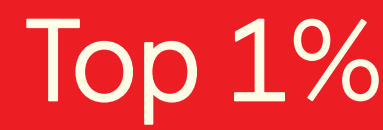

most cited scientists

Contributors from top 500 universities
$135 \mathrm{M}+$

Downloads

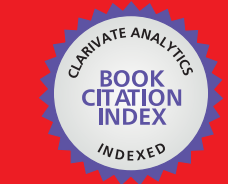

WEB OF SCIENCE ${ }^{\mathrm{MM}}$

Selection of our books indexed in the Book Citation Index in Web of Science ${ }^{\mathrm{TM}}$ Core Collection (BKCI)

\section{Interested in publishing with us? \\ Contact book.department@intechopen.com}

Numbers displayed above are based on latest data collected.

For more information visit www.intechopen.com 



\section{Meet the editor}

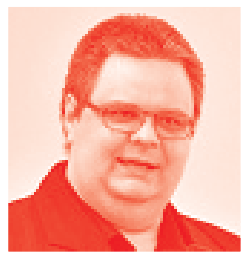

Dr. Levente Hufnagel is an associate professor and senior researcher at Szent István University, Gödöllő, Hungary, in climate change and ecosystem ecology, acarology, entomology, biogeography, biometrics, and ecological research methodology. He has more than 20 years of experience at leading Hungarian academic institutions teaching $\mathrm{PhD}, \mathrm{MSc}$, and BSc students from various social and cultural backgrounds. He has more than 200 scientific publications (in both aquatic and terrestrial ecological aspects of plants, animals, and microbes, at community as well as population level) and more than 900 independent citations. As a participant of several big ecological research and development projects, he has significant experience in multidisciplinary cooperations (with more than 180 coauthors in different publications). As the supervisor of several PhD, BSc, and MSc theses, and as editor-in-chief of an international scientific journal indexed by Web of Science and Scopus, he has wide supervising and editing experience. Dr. Hufnagel graduated from Eötvös Lorand University with a Master's degree in Ecology and Evolutionary Biology and a $\mathrm{PhD}$ degree in Hydrobiology. He also graduated from Szent István University with a PhD degree in Agricultural Science. 



\section{Contents}

Preface

Section 1

General Aspects

Chapter 1

Introductory Chapter: The Present Global Ecological Crisis

in the Light of the Mass Extinctions of Earth History

by Levente Hufnagel, Melinda Pálinkás, Ferenc Mics

and Réka Homoródi

\section{Section 2}

Specific Aspects and Case Studies

Chapter 2

Valuing Caribbean Biodiversity Knowledge

by Sylvia Adjoa Mitchell, Kimani A. Kitson-Walters

and Achsah Anna Mitchell

Chapter 3

Acoustic Habitat Degradation Due to Shipping in the Indian

Ocean Region

by Arnab Das

Chapter 4

Methane, Microbes and Models in Amazonian Floodplains:

State of the Art and Perspectives

by Dayane Juliate Barros, Marília de Souza Bento, Murilo de Souza Ferreira, Janaina Braga do Carmo, Rogério Hartung Toppa, Vania Neu,

Maria Bernadete de Amâncio Varesche, Paula Benevides de Morais

and Acacio Aparecido Navarrete

Chapter 5

Impact of Disturbances on the Biodiversity of Ijala-Ikeren Wetland

Ecosystem in Niger Delta

by Michael Aigbe Uwagbae, Abdul-Rahman Dirisu,

Tambeke Nornu Gbarakoro, Eman I. El Surtasi, Julia Ekenma Agwu, Martins S.O. Aisien and Johnny Rotimi 
Chapter 6

An Economic Valuation and Mapping of Pollination Services

in Ethiopia

by Dawit Woubishet Mulatu

Chapter 7

Biomimicry, Big Data and Artificial Intelligence for a Dynamic

Climate Change Management Policy Regime

by Vuyo Mjimba and Gamelihle Sibanda 


\section{Preface}

By the turn of the 21st century, humankind had fallen into a mass of global problems (global ecological crises), which endanger not only its welfare, peace, and development, but its survival as well. Now is the time to unite and address the issues of common concern; however, humankind has reached this era torn to 195 independent national states withno global organization to represent its common interests efficiently. Biodiversity crises (extinction of key species and the reduction of habitats) and climate change induce in each other a positive feedback loop, since through the biosphere, climate-regulating ecosystem services are weakened.

Research into temporal-spatial patterns of ecosystems on our planet, and especially biodiversity research into the recent biosphere, has a very important role in solving these problems.

This book consists of seven chapters. The first is a general text covering mass extinctions: the "Big Five" and "The Sixth", which are recent global ecological crises. This introductory chapter is followed by six specific case study chapters reporting on the frontiers of biodiversity research.

The next chapter is about Caribbean biodiversity. The Caribbean region is one of the world's hottest hot spots, with just over $10 \%$ of its original forest remaining. Of the 187 endemic mammals and birds in the Caribbean, at least 43 have become extinct over the last 500 years. Currently, it is estimated that 755 plants and vertebrate species are at risk of extinction.

Acoustic habitat degradation due to shipping in the Indian Ocean region is the topic of the third chapter. Science and technology advances have made the deepest depths of the oceans increasingly accessible, and we are realizing the challenges and opportunities that exist in the marine ecosystem. Marine species use sound or acoustic signals for numerous biologically critical functions, therefore they possess acoustic vision as they perceive the world around them through sound.

The next chapter covers methane, microbes, and models in the Amazonian floodplains. Amazonian floodplain ecosystems include open water and intermittent flood forest and agricultural systems with different water types. They are a significant natural source of methane in the tropics. The Amazon biome, especially the tropical rainforest, is one of the main contributors to the biogeochemical functioning of the terrestrial system, which also has an important role in global climate regulation of the biosphere.

The fifth chapter looks at the impact of disturbances to the biodiversity of a wetland ecosystem. This chapter is important because Nigeria has the largest mangrove forest in Africa and the third largest continuous mangrove forest in the world.

Also in this book is an interesting chapter on economic valuation and the mapping of pollination services in Ethiopia. An increasing amount of attention has been 
given to pollination ecosystem services, which have become a commonly mentioned example of how ecosystem services are economically valuable due to their linkage to world food production.

Despite the universally acknowledged, observed, and predicted adverse impacts of climate change, the slow and inadequate policies and responses to climate change mitigation and climate change adaptation practices present a quandary. As a result the closing chapter reviews big data and artificial intelligence for a dynamic climate change management policy regime.

Changing Ecosystems and Their Services provides a very interesting account of the frontiers in this area. I am sure that this book will be very useful for everybody who would lbenefit from insight into the recent problems of biodiversity research and ecology.

Levente Hufnagel, PhD

Associate Professor, Szent István University,

Gödöllő, Hungary 
Section 1

\section{General Aspects}





\title{
Introductory Chapter: The Present Global Ecological Crisis in the Light of the Mass Extinctions of Earth History
}

\author{
Levente Hufnagel, Melinda Pálinkás, Ferenc Mics \\ and Réka Homoródi
}

\section{Introduction}

Extinctions usually happen. They are part of the evolutionary processes. Like individuals, species also have a lifespan, which means that they go extinct naturally without any external forces over a period of time. It is called normal or background extinction rate. When the level of extinction is much higher than the background extinction rate, we talk about mass extinctions. Mass extinctions occur at different temporal and spatial scales. We consider both the local disappearances of frog populations and the Late Cretaceous impact event as mass extinctions. Mass extinctions may have different causes, but their dynamics and patterns are similar in many respects. During the Earth's history, several mass extinctions have extirpated species globally from time to time. These global mass extinctions usually have some external causes as number one triggers, such as climate change, volcanic outbursts, or impact events. We refer to the Earth's largest mass extinctions during the Phanerozoic as the "Big Five."

By the twenty-first century, mankind has fallen into the mess of global problems (into a global ecological crisis) which endanger not only its welfare, peace, and development but its survival and mere existence as well. It is the time of uniting and addressing the issues of common concern; however, mankind has reached this era torn to 195 independent national states without having an authorized global organization which would represent common interests of mankind efficiently.

Mankind forms a single family all over the world regarding its origin, and natural processes are basically global, since climate change, overpopulation, contamination of oceans, air pollution, and radioactivity do not know state borders. Science is also a global international activity, the common treasure and work of mankind.

The report Our Common Future published in 1987 by the World Commission on Environment and Development of the UNO defines sustainable development as the "development that meets the needs of the present without compromising the ability of future generations to meet their own needs" [1]. Sustainable society is a global form of operation of mankind aimed at but not yet realized, which ensures the survival of humanity, the long-lasting preservation of environmental and social living conditions, the protection of human environment (climate, atmosphere, water, soil, and biosphere), the operability of the biosphere and the protection of its biodiversity, the operation of the economy, the reduction of social tensions 
(inequality, famine, extreme poverty, crime, riots, terrorism, aggression, wars), the scientific and technological development as well as the rise of mankind, and the preservation and development of our natural and cultural heritage long-term (even through hundreds or thousands of years). The establishment of a sustainable society depends on macro-level (law, political will, consensus, public support) and micro-level conditions (affecting the everyday operation of individuals, families, companies and small communities). When scientists make an effort in order to save an endangered species $[2,3]$, they might not consider the complexity of the whole problem, which would make the work necessary.

The sustainability of the human society is endangered by global problems of our time, which are in close relationship with each other as well. Among global problems, overpopulation (global population explosion) has a central role, since more people have a larger ecological footprint, consume more, pollute more, occupy more space from natural ecosystems, and emit more carbon dioxide through their activities. Overpopulation directly intensifies global climate change, global biodiversity crisis, deterioration of the global state of the environment, and urbanization and reduces the extension of rain forests and natural habitats as well as the nonrenewable energy sources (fossil fuels, natural building materials, stock of water). At the same time, increasing population results in higher population density as well; this directly enhances aggression [4] and the risk of epidemics.

Global environmental crises appear at the macro-level (at the level of the society, mankind, and politics); they relate to each other on a large scale, in an interaction network. Global overpopulation results in biodiversity crisis, this reduces the climate regulation ability of the biosphere, and this results in climate change. At the same time, overpopulation contributes directly to climate change through energy consumption, combustion of fossil fuels, and the change of land use [5]. Climate change results in significant transformation of the biosphere $[6,7]$. Besides these, overpopulation directly results in social crisis, increasing aggression, as well as epidemics. Biodiversity crisis (extinction of key species and the reduction of habitats) and climate change induce each other in a positive feedback loop, since through the biosphere, climate-regulating ecosystem services are weakened. Overpopulation and social crisis are in a similar positive feedback loop, since it is proven that poverty and hopelessness increase the number of offspring. People living in poverty have nothing to distribute, nothing to base the future on; that is why many of them change from K- to r-strategy, trusting that some of their offspring will survive. Social crisis and public health crisis as well as social crisis and aggression (violence, crime, terrorism, riots, and civil war) are in a similar feedback loop. These interactions are shown in Figure 1.

Many scholars suggest that we are undergoing a global mass extinction. It is usually referred to it as the sixth mass extinction after the "Big Five." It is debated whether the global mass extinction is approaching [8], it has just begun [9], or it is in a more advanced stage [10]. The current extinction rates are about 1000 times the background extinction rate according to a recent study [8]. Three hundred twentytwo terrestrial vertebrate species have become extinct since 1500 [11]. Ceballos, et al. [10] studied 177 mammals, and they found that they have lost at least $30 \%$ of their geographical ranges and more than $40 \%$ of the species have experienced a range shrinkage above $80 \%$. Fifteen to thirty-seven percent of species are going to extinct based on mid-range climate change scenarios for 2050 [12].

The current/approaching mass extinction is different from the past mass extinctions, because a single species initiates the biotic crisis. Global population is increasing exponentially mainly because of the economic models based on growth and medical improvements. As a result, the human population is now over 7 billion. Not only the number of people causes environmental issues. Thanks to technical 


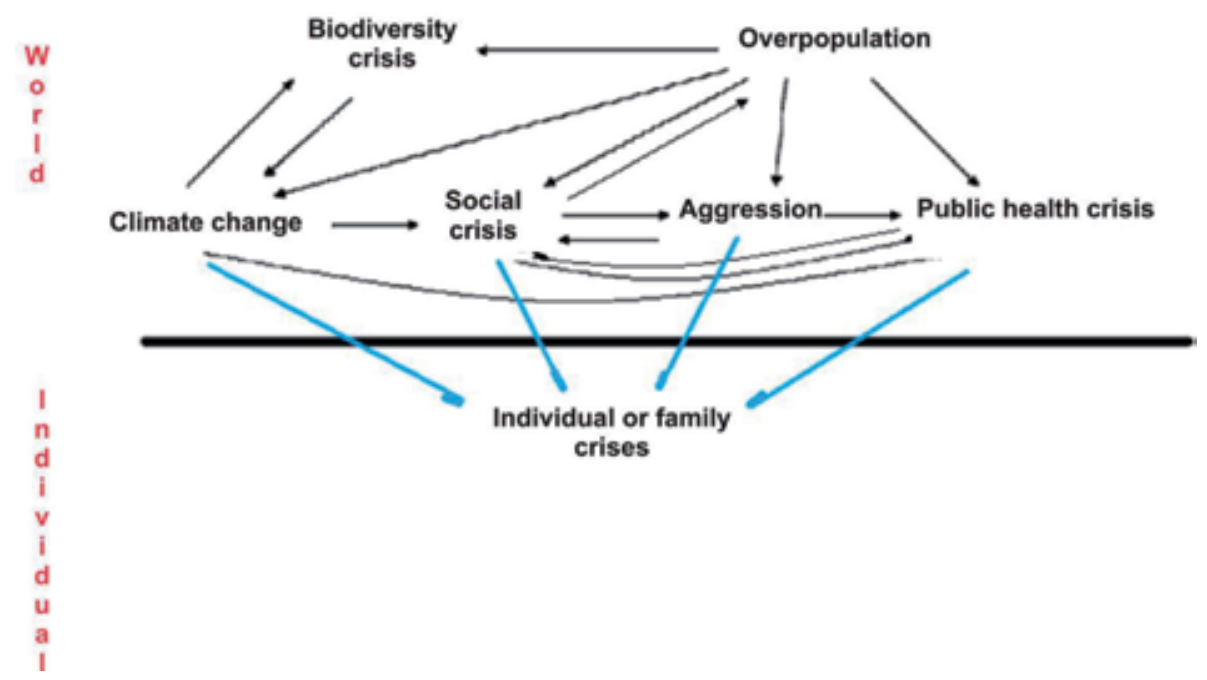

Figure 1.

Interaction network of global crisis phenomena and their relationships with individual crises. Black arrows mean macro-level connections, whereas blue arrows mean direct threats in individuals' life.

improvements and overconsumption, the humans' environmental footprint is continuously increasing, and as a result, it is not sustainable anymore [13]. The Earth has become too small for us. Direct anthropogenic effects (hunting, habitat destruction, pollution) are lowering the diversity and the abundance levels globally. Anthropogenic climate change as an indirect human effect poses challenges to the wildlife. Climatic changes are so rapid that plants and animals may not be able to adapt in the future, and eventually they will collapse. Climate change and direct human effects do not act independently but synergistically reinforcing each other's effects.

We consider the biosphere as an industry providing services for us. We are exploiting the Earth because of our economic thinking. We put ourselves right in the middle of the ecosystem and subordinate everything to our service. The problem is that the biosphere does not work as an industry and, beyond a certain point, it cannot be reproduced. As a result of increasing human pressure, we are reaching the tipping point of a global collapse. However, we cannot predict this tipping point, and we do not know much about the phenomena prior to collapses.

About 200 species extinct every day which is a rate of extinction comparable with past global mass extinctions. According to Newbold et al. [14], the level of natural biodiversity is so low on two-thirds of the world's land surface that it might already jeopardize normal ecosystem functioning and human well-being. We have only a rough estimation for the global number of species which is above 10 million, but we know only $15 \%$ of them [15]. Biodiversity loss is also an estimated number. Despite the possible inaccuracies of estimations, researchers agree that global biodiversity loss is significant. However, biodiversity loss cannot tell us how far we are from a possible collapse. The diversity levels before the big mass extinctions did not predict the points of the collapses, either.

High diversity is the sign of a healthy ecosystem; hence, its significant decline indicates an ecological crisis. A great diversity drop preceded the big mass extinctions; however, changes in diversity do not always show the severity of the ecological problem and a more advanced stage of a collapse. Diversity may remain constant before extinctions. This happened during the Early Jurassic (Toarcian) mass extinction according to Harries and Little [16]. Diversity does not necessarily have a nadir 
at the extinction boundary, for example, when mass extinction occur before the low point of the environmental perturbation or in case of delayed extinction when survivors and opportunistic invaders compose a transient mixed biota. Sometimes, the diversity remains constant during dominance shift when the collapse of the dominant elements does not cause significant structural changes in the ecosystem. It may also happen that the diversity level is still high but important ecosystem elements are already missing; hence, collapse is much closer than the hypothetical point suggested by biodiversity levels. Therefore, diversity values cannot necessarily tell how far we are from a collapse, and mass extinction can happen even in case of higher diversity. Spatial scales and taxonomical levels also affect diversity changes. Towards lower levels and scales, diversity loss is usually greater, though this rule is not set in stone.

The lowest diversity levels are usually at the beginning of the recovery phase $[17,18]$. Diversity starts to increase rapidly but gradually after a short gap following a dominance shift [19], except when environmental perturbation is prolonged. For example, after the Late Permian mass extinction, a series of volcanic bursts delayed the recovery for 10 million years [20]. However, a sharp diversity increase after the extinction does not always reflect the level of recovery, but a short-lived opportunist blooms [21]. The environment has a great role both in mass extinctions and recoveries, especially at global level. However, at local spatial scales, biotic factors may be as important as environmental factors.

In summary, diversity is an important indicator of ecological crisis, but it does not necessarily give reliable information on the advancement of a collapse. Because of the complexity of ecosystems, diversity does not always reflect the severity of a crisis.

Past mass extinctions and the recent ecological and biodiversity crisis must have some similarities, common points which can take use closer to understanding collapses. Hence, we should compare and combine our knowledge on recent biotic crisis and collapses with that of past mass extinctions.

The Late Ordovician mass extinction, about 445 million years ago, wiped out $57 \%$ of marine genera and $60-70 \%$ of marine species [22]. Two pulses of extinctions caused the massive loss of species. The Late Ordovician mass extinction is the only "big" which is explained by purely climatic reasons. The first wave of extinction was caused by glaciation and the second one by subsequent global warming. Glaciation exterminated warm-loving taxa with both small and large ranges. The tropical realm suffered the greatest loss. The global warming event mainly caused the extinction of wide-ranging, cosmopolitan, cold-loving taxa [23]. The Late Ordovician marine mass extinction probably started with no delay right at the beginning of environmental changes [24]. The pertained high temperature after the mass extinction, however, was likely to hinder the recovery at a global scale [23]. This does not mean that quick recoveries could not happen regionally [25]. The Late Ordovician mass extinction, which was the second largest, did not necessarily caused huge structural changes in the ecosystems [26, 27]. It must be noted that Erwin [27] debates the large magnitude of the Late Ordovician event.

The Late Devonian mass extinction began about 380 million years ago. $50 \%$ of the genera and at least $70 \%$ of species were lost [28]. It includes two events with different dynamics. The Kellwasser event showed the gradual turnover of the marine realm because of the gradual environmental changes presumably caused by tectonic movements [29]. It was not followed by great structural changes, and some researchers do not even consider it as a real mass extinction. The second event was larger and more destructive. The Hangenberg event resulted in a sudden faunal change. It affected all major vertebrate groups. Both the ecology and the environment were lost and caused the restructuring of the vertebrate ecosystems 
worldwide [29]. The recovery was probably delayed [27], and the fauna was very cosmopolitan at the beginning [30]. The cause of the second event is debated, but it must have been sudden and of large magnitude. Perhaps, the most likely reason for the Late Devonian crisis was the Siberian trap volcanism. De Vleeschouwer et al. [31] suggest that the Late Devonian events were astronomically forced.

The Late Permian event was the most devastating of all mass extinctions about 252 million years ago. More than $80 \%$ of genera and $90-95 \%$ of species died out [22]. It was probably triggered by a long series of volcanic outbursts of the Siberian Traps [32]. The environmental consequences were severe anoxia and acidification in the oceans, elimination of the ozone layer, and a prolonged greenhouse effect $[33,34]$. In the terrestrial ecosystems, the physical environment deteriorated: the erosion increased, the sediments and soils altered [32]. The authors suggest that the Late Permian mass extinction was not sudden and simultaneous [30, 35]. In the oceans, it was relatively faster. On the landmasses, plants and herbivores extinct later in time [32]. The recovery was considerably delayed: it took about 10 million years because of the constant environmental perturbation. However, it could be quicker locally in case of more favorable environmental conditions, for example, in well-oxygenated marine environment or under locally favorable climate $[36,37]$. The recovery was selective in terms of geographic location, as well. Higher altitudes, perhaps, recovered earlier than the tropical realm also because of quicker environmental improvements $[36,38]$. After the mass extinction, the marine community reorganized to a large extent, probably, because of the loss of dominant elements [27, 32].

The Late Triassic mass extinction happened about 201 million years ago and extirpated $48 \%$ of genera and $70-75 \%$ of species [22]. It was triggered by the sudden volcanism of the Pangaean Atlantic rifting. The volcanic outburst caused significant geochemical changes: it elevated atmospheric $\mathrm{CO}_{2}, \mathrm{SO}_{2}$, and $\mathrm{PAH}$ levels. The marine and terrestrial ecosystems collapsed immediately and simultaneously [39]. The Late Triassic event was quick and not as massive as the previous mass extinctions at genus level. The major elements of the ecosystem structures were preserved [27]. Boucot [30] debates this and suggests that the level-bottom marine ecosystems thoroughly reorganized. The extinction of competitors gave the opportunity for the dinosaurs to rise and dominate in the next period.

The youngest and publicly most well-known "Big Five" is the Late Cretaceous mass extinction which eliminated about $48 \%$ of genera and $70-75 \%$ of species 66 million years ago [22]. It belongs to less massive extinctions at genus level. An impact event was likely to initiate the global crisis with regional differences. Probably, widespread fire, sun-blocking dust cloud, perhaps climatic cooling, increased $\mathrm{SO}_{2}$ level, and the related acidification were the main consequences of the asteroid collision. The collapse was larger and more serious closer to the impact area with greater drop in diversity $[40,41]$. The extinction was sudden and simultaneous among diverse taxa, which refers to a common great and abrupt impact [42]. It was selective affecting specialized species and terrestrial plants more seriously [43, 44]. The recovery of the environment and the ecosystems was quick but gradual after the crisis [45, 46]. The diversity increased rapidly [47]. Most ecosystems did not go through thorough restructuring (e.g., [30]). The smaller magnitude of the event and the quick recovery might explain this [27]. The fire and the lack of sunlight hit the flora harder than most ecosystems, especially in regions closer to the impact zone. As a result, the flora became quite different from the one prior to the collapse at a regional scale [45]. After the extinction, mammals, birds, and flowering plants became dominant and long-term successful survivors.

Mass extinctions give the impression as if they had their own unique stories with some similarities and more differences. Similarities of mass extinctions are 
very important because they make collapses more predictable. Research questions related to similarities bring us closer to understanding the current global crisis. For example, is it possible that different causes of extinctions result in similar extinction mechanisms? Do events of different magnitudes lead to recoveries of different dynamics?

Besides the "Big Five," some smaller mass extinctions also provide valuable information on the characteristics of collapses. Less researched mass extinctions which were presumably caused by climate change (or climate change was an important contributor in the event) should get more attention. For example, during the Early Jurassic (Early Toarcian) mass extinction and the Paleocene-Eocene thermal maximum, increased $\mathrm{CO}_{2}$ level and temperature, acidification, and anoxia were typical accompanying phenomena of the global biotic crisis just like today; therefore, they could be used as an analogy. The Middle Permian (Capitanian) event which is a newly recognized major mass extinction and probably related to the large Late Permian mass extinction can also be linked to marine anoxia and acidification caused by volcanic eruptions. We have poor knowledge and inadequate data on periods before mass extinctions. It would be important to reveal more phenomena and patterns that preceded global past collapses to be able to create scenarios for the possible future biotic crisis.

\section{Author details}

Levente Hufnagel $^{1,2 *}$, Melinda Pálinkás ${ }^{1}$, Ferenc Mics $^{1}$ and Réka Homoródi ${ }^{2}$

1 Faculty of Agricultural and Environmental Science, Laboratory of Biometrics and Quantitative Ecology, Institute of Crop Production, Szent István University, Gödöllö, Hungary

2 ALÖKI Applied Ecological Research and Forensic Institute Ltd, Budapest, Hungary

*Address all correspondence to: leventehufnagel@gmail.com

IntechOpen

(C) 2020 The Author(s). Licensee IntechOpen. This chapter is distributed under the terms of the Creative Commons Attribution License (http://creativecommons.org/licenses/ by/3.0), which permits unrestricted use, distribution, and reproduction in any medium, provided the original work is properly cited. (cc) BY 
Introductory Chapter: The Present Global Ecological Crisis in the Light of the Mass Extinctions... DOI: http://dx.doi.org/10.5772/intechopen.90186

\section{References}

[1] Gro Harlem B. et al. Our Common Future - Report of the World Commission on Environment and Development, United Nations (Transmitted to the General Assembly as an Annex to document A/42/427 - Development and International Cooperation: Environment). 1987. Available from: https://www.are. admin.ch/are/en/home/sustainabledevelopment/internationalcooperation/2030agenda/ un-_-milestones-in-sustainabledevelopment/1987--brundtlandreport.html

[2] Gilián LD, Bódis J, Eszéki E, Illyés Z, Biró É, Nagy JG. Germination traits of adriatic lizard orchid (Himantoglossum adriaticum) in Hungary. Applied Ecology and Environmental Research. 2018;16(2):1155-1171

[3] Suel H, Mert A, Yalcinkaya B. Changing potential distribution of gray wolf under climate change in lake district, Turkey. Applied Ecology and Environmental Research. 2018;16(5):7129-7137

[4] Konrad L. Die acht Todsünden der zivilisierten Menschheit. Serie Piper, Auflage, München 1973;34. Auflage, München; 2009. ISBN 3-492-20050-8 (im Verlag Auditorium-Netzwerk auch als Hörbuch erschienen)

[5] Rüstemoğlu $\mathrm{H}$, Uğural S. $\mathrm{CO}_{2}$ emissions in Iran for 1990-2010: A decomposition analysis. Applied Ecology and Environmental Research. 2017;15(4):1833-1846

[6] Garamvölgyi Á, Hufnagel L. Impacts of climate change on vegetation distribution No. 1. Climate change induced vegetation shifts in the Paleartic region. Applied Ecology and Environmental Research. 2013;11(1):79-122
[7] Hufnagel L, Garamvölgyi Á. Impacts of climate change on vegetation distribution No. 2, climate change induced vegetation shifts in the New World. Applied Ecology and Environmental Research. 2014;12(2):255-422

[8] Pimm S, Jenkins CN, Abell R, Brooks TM, Gittleman JL, Joppa LN, et al. The biodiversity of species and their rates of extinction, distribution, and protection. Science. 2015;344(6187). DOI: $10.1126 /$ science. 1246752

[9] Barnosky AD, Matzke N, Tomiya S, Wogan GOU, Swartz B, Quental TB, et al. Has the Earth's sixth mass extinction already arrived? Nature. 2011;471(7336):51-57. DOI: 10.1038/ nature09678

[10] Ceballos G, Ehrlich PR, Dirzo R. Biological annihilation via the ongoing sixth mass extinction signaled by vertebrate population losses and declines. Proceedings of the National Academy of Sciences of the United States of America. 2017;114(30):60896096. DOI: $10.1073 /$ pnas.1704949114

[11] Dirzo R, Young HS, Galetti M, CeballosG, IsaacNJB, CollenB.Defaunation in the Anthropocene. Science. 2014;345(6195)

[12] Thomas CD, Cameron A, Green RE, Bakkenes M, Beaumont LJ, Collingham YC, et al. Extinction risk from climate change. Nature. 2004;427(6970):145-148. DOI: $10.1038 /$ nature 02121

[13] Hoekstra AY, Wiedmann TO. Humanity'sunsustainableenvironmental footprint. Science. 2014;344(6188): 1114-1117. DOI: 10.1126/science.1248365

[14] Newbold T, Hudson LN, Arnell AP, Contu S, De Palma A, Ferrier S, et al. Has land use pushed terrestrial 
biodiversity beyond the planetary boundary? A global assessment. Science. 2016;353(6296):288-291

[15] Chapman AD. Numbers of Living Species in Australia and the World-A Report for the Australian Biological Resources Study. 2nd ed. Toowoomba, Australia; 2009. Available at: http:// www.environment.gov.au/system/ files/pages/2ee3f4a1-f130-465b9c7a-79373680a067/files/nlsaw-2ndcomplete.pdf. ISBN 9780642568618

[16] Harries PJ, Little CTS. The early Toarcian (early Jurassic) and the Cenomanian-Turonian (late cretaceous) mass extinctions: Similarities and contrasts. Palaeogeography, Palaeoclimatology, Palaeoecology. 1999;154(1):39-66

[17] Foster WJ, Twitchett RJ. Functional diversity of marine ecosystems after the late Permian mass extinction event. Nature Geoscience. 2014;7(3):233-238. DOI: $10.1038 /$ NGEO2079

[18] Lowery CM, Bralower TJ, Owens JD, Rodríguez-tovar FJ, Jones H, Smit J, et al. Rapid recovery of life at ground zero of the end-cretaceous mass extinction. Nature. 2018;558(7709):288291. DOI: $10.1038 / \mathrm{s} 41586-018-0163-6$

[19] Cooper RA, Sadler PM, Munnecke A, Crampton JS. Graptoloid evolutionary rates track OrdovicianSilurian global climate change. Geological Magazine. 2014;151(2):349364. DOI: $10.1017 /$ S0016756813000198

[20] Hochuli PA, Sanson-Barrera A, Schneebeli-Hermann E, Bucher H. Severest crisis overlooked-Worst disruption of terrestrial environments postdates the Permian-Triassic mass extinction. Scientific Reports. 2016;6(28372):1-8. DOI: 10.1038/ srep28372

[21] Looy CV, Twitchett RJ, Dilcher DL, Cittert JHAVK, Visscher H. Life in the
end-Permian dead zone. Proceedings of the National Academy of Sciences. 2001;98(14):7879-7883. DOI: $10.1073 /$ pnas.131218098

[22] Benton MJ. When Life Nearly Died: The Greatest Mass Extinction of all Time. Thames and Hudson; 2003

[23] Darroch SAF, Wagner PJ. Responses of beta diversity to pulses of Ordovician-Silurian mass extinction. Ecology. 2015;96(2):532-549

[24] Sheehan PM, Coorough PJ, Fastovsky DE. Biotic selectivity during the $\mathrm{K} / \mathrm{T}$ and late Ordovician extinction events. Geological Society of America Special Paper. 1996;307:477-489

[25] Krug AZ, Patzkowsky ME. Geographic variation in turnover and recovery from the late ordovician mass extinction. Paleobiology. 2007;33(3):435-454

[26] Brenchley PJ, Marshall JD, Underwood CJ. Do all mass extinctions represent an ecological crisis? Evidence from the late Ordovician. Geological Journal. 2001;36(3-4):329-340

[27] Erwin DH. The end and the beginning: Recoveries from mass extinctions. Trends in Ecology and Evolution. 1998;13(9):344-349

[28] Briggs D, Crowther PR. Palaeobiology II. John Wiley \& Sons; 2008. p. 223 ISBN: 978-0-470-99928-8

[29] Friedman M, Sallan LC. Five hundred million years of extinction and recovery: A phanerozoic survey of large-scale diversity patterns in fishes. Palaeontology. 2012;55(4):707-742. DOI: 10.1111/j.1475-4983.2012.01165.x

[30] Boucot AJ. Phanerozoic extinctions: How similar are they to each other? In: Kauffman E, Walliser O, editors. Extinction Events in Earth History. Berlin: Springer Berlin; 1990. pp. 5-30 
[31] De Vleeschouwer D, Da Silva A-C, Sinnesael M, Chen D, Day JE, Whalen MT, et al. Timing and pacing of the late Devonian mass extinction event regulated by eccentricity and obliquity. Nature Communications. 2017;8(1):1-11. DOI: 10.1038/ s41467-017-02407-1

[32] Benton MJ, Twitchett RJ. How to kill (almost) all life: The end-Permian extinction event. Trends in Ecology and Evolution. 2003;18(7):358-365. DOI: 10.1016/S0169-5347(03)00093-4

[33] Lau KV, Maher K, Altiner D, Kelley BM, Kump LR, Lehrmann DJ, et al. Marine anoxia and delayed earth system recovery after the end-Permian extinction. Proceedings of the National Academy of Sciences of the United States of America. 2016;113(9):23602365. DOI: $10.1073 /$ pnas. 1515080113

[34] Petsios E, Thompson JR, Pietsch C, David J. Biotic impacts of temperature before, during, and after the endPermian extinction: A multi-metric and multi-scale approach to modeling extinction and recovery dynamics. Palaeogeography, Palaeoclimatology, Palaeoecology. 2019;513:86-99. DOI: 10.1016/j.palaeo.2017.08.038

[35] Shu-zhong AS, Shi GR. Paleobiogeographical extinction patterns of permian brachiopods in the Asian-Western Pacific region. Paleobiology. 2014;28(4):449-463

[36] Kidder DL, Worsley TR. Causes and consequences of extreme Permo-Triassic warming to globally equable climate and relation to the Permo-Triassic extinction and recovery. Palaeogeography, Palaeoclimatology, Palaeoecology. 2004;203(3):207-237. DOI: 10.1016/ S0031-0182(03)00667-9

[37] Twitchett RJ, Krystyn L, Baud A, Wheeley JR, Richoz S. Rapid marine recovery after the end-Permian massextinction event in the absence of marine anoxia. Geology. 2004;32(9):805-808. DOI: $10.1130 / G 20585.1$

[38] Wei H, Shen J, Schoepfer SD, Krystyn L, Richoz S, Algeo TJ.

Environmental controls on marine ecosystem recovery following mass extinctions, with an example from the early Triassic. Earth Science Reviews. 2015;149(October):108-135. DOI: 10.1016/j.earscirev.2014.10.007

[39] Götz AE, Ruckwied K, Pálfy J, Haas J. Palynological evidence of synchronous changes within the terrestrial and marine realm at the Triassic/Jurassic boundary (Csővár section, Hungary). Review of Palaeobotany and Palynology. 2009;156(3):401-409. DOI: 10.1016/j. revpalbo.2009.04.002

[40] Barreda VD, Cúneo NR, Wilf P, Currano ED, Scasso RA. Cretaceous/ paleogene floral turnover in Patagonia: Drop in diversity, low extinction, and a classopollis spike. PLoS One. 2012;7(12):1-8. DOI: 10.1371/journal. pone. 0052455

[41] Schueth JD, Bralower TJ, Jiang S, Patzkowsky ME. The role of regional survivor incumbency in the evolutionary recovery of calcareous nannoplankton from the cretaceous/ Paleogene (K/Pg) mass extinction. Paleobiology. 2015;41(4):661-679. DOI: 10.1017/pab.2015.28

[42] Harries PJ, Kauffman EG. Patterns of survival and recovery following the Cenomanian-Turonian (late cretaceous) mass extinction in the Western Interior Basin, United States. In: Kauffman E, Walliser O, editors. Extinction Events in Earth History. Berlin: Springer Berlin; 1990. pp. 277-298

[43] Harries PJ, Kauffman EG, Hansen TA. Models for biotic survival following mass extinction. Geological Society London Special Publications. 
1996;102(1):41-60. DOI: 10.1144/GSL.

SP.1996.001.01.03

[44] Longrich NR, Scriberas J, Wills MA. Severe extinction and rapid recovery of mammals across the cretaceous-Palaeogene boundary, and the effects of rarity on patterns of extinction and recovery. Journal of Evolutionary Biology. 2016;29(8):14951512. DOI: $10.1111 /$ jeb.12882

[45] Tschudy R, Pillmore C, Orth C, Gilmore J, Knight J. Disruption of the terrestrial plant ecosystem at the cretaceous-tertiary boundary, western interior. Science. 1984;225(4666):1030-1032

[46] Ksepka DT, Stidham TA, Williamson TE. Early Paleocene landbird supports rapid phylogenetic and morphological diversification of crown birds after the K-Pg mass extinction. Proceedings of the National Academy of Sciences of the United States of America. 2017;114(30):1-6. DOI: $10.1073 /$ pnas.1700188114

[47] Field DJ, Bercovici A, Berv JS, Lyson TR, Vajda V, Gauthier JA, et al. Early evolution of modern birds structured by global forest collapse at the end-cretaceous mass extinction. Current Biology. 2018;28(11):1825-1831. DOI: 10.1016/j.cub.2018.04.062 
Section 2

\section{Specific Aspects and Case Studies}





\title{
Valuing Caribbean Biodiversity Knowledge
}

\author{
Sylvia Adjoa Mitchell, Kimani A. Kitson-Walters and \\ Achsah Anna Mitchell
}

\begin{abstract}
Valuing Caribbean biodiversity for health and wealth requires knowledge of the bioresource so as to better appreciate the myriad of uses and services it provides. Increasing the knowledge base provides increasingly accurate valuation, which hopefully will lead to better management and sustainable use of this biodiversity. The Caribbean region comprises $229,540 \mathrm{~km}^{2}$ of land (only $10 \%$ of which is still in original forest cover) and $2,754,000 \mathrm{~km}^{2}$ of ocean. In the region there are about 13,000 identified plant species of which 205 genera and 6500 species are endemic. The marine area, with a maximum depth of $7686 \mathrm{~m}$, includes the world's second largest barrier reef. It is estimated that the region has $25.6 \%$ marine endemic species. Multiple uses have been found for both terrestrial and marine organisms of the Caribbean. Mass extinctions have occurred for Peoples, associated traditional knowledge, terrestrial and marine biodiversity. Sea level rise and increasing temperature are global problems that threaten this area. All this information cannot be covered in one chapter so this review, based on a wide range of publications including our own research, is to raise awareness of these issues and the need to know more while suggesting solutions for discussion.
\end{abstract}

Keywords: biotechnology, conservation, ethnobotany, hotspot, marine, medicinal plants, Nagoya protocol, terrestrial, traditional knowledge

\section{Introduction}

The greatest challenge facing Caribbean biodiversity is the relative lack of knowledge and analysis. Caribbean scientists have been and continue to be heavily engaged in gathering information on regional biodiversity. However, the region is large and diverse and there is much that is still unknown. Also, there is a need to synthesize and evaluate these findings, to set goals for future research and managed utilization. The biodiversity resource of the Caribbean is very rich but under threat, so the concern is real. While increasing population densities with associated issues of agriculture and urbanization, and climate change are important, lack of knowledge trumps them. Why? Because if we do not know what the Caribbean has and the worth of it, will we protect while sustainably using this bioresource? How can we protect what we do not even know we have?

Let us start with the fundamentals. When we say 'Caribbean', where in the world are we? Actually, there are two names for this area-'West Indies' and 'Caribbean'. The West Indies was so named to differentiate this area from the East Indies and includes all the islands in the Atlantic Ocean southeast of the Gulf of Mexico. The 


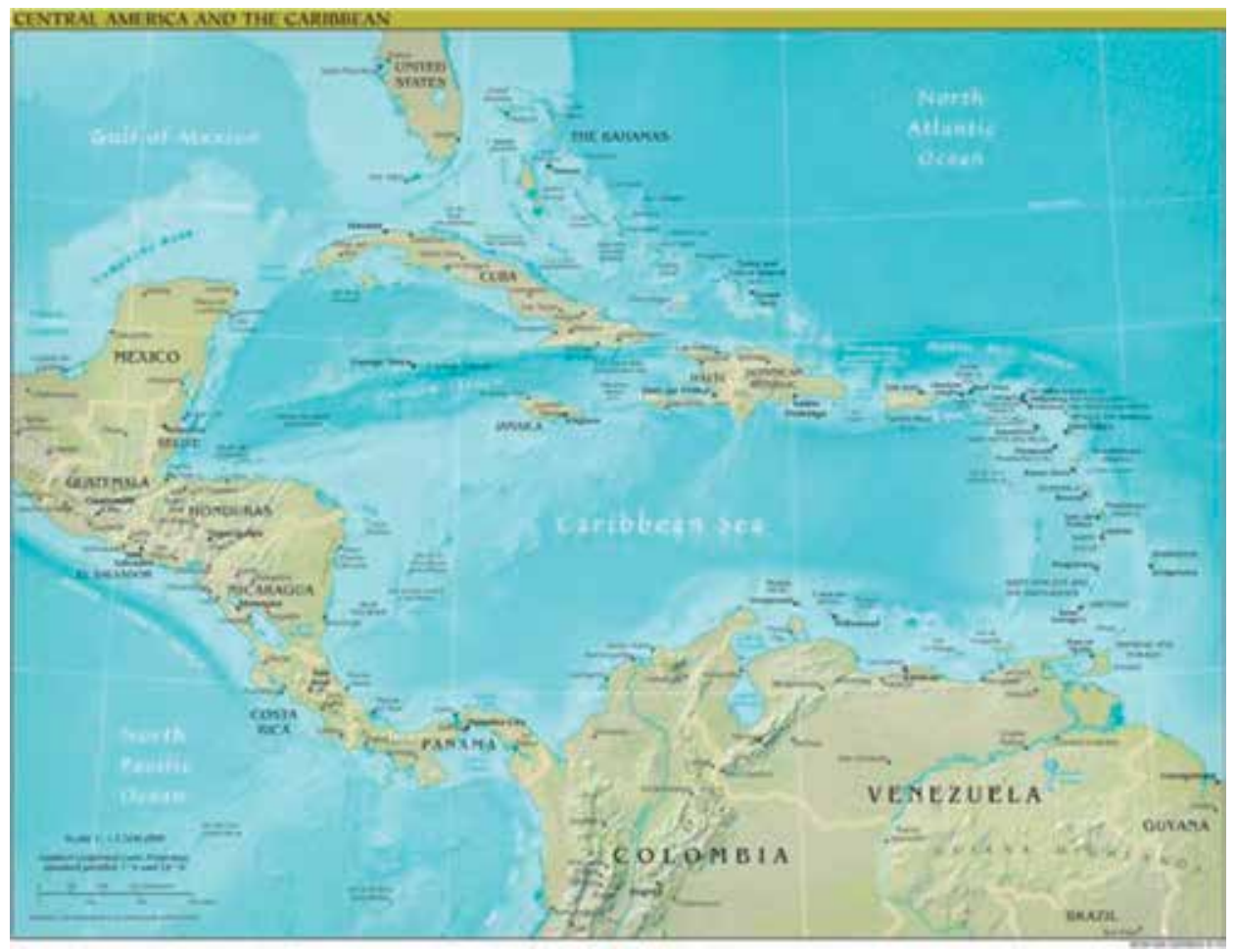

Figure 1.

Map showing the West Indies (all the islands in the Caribbean Sea), the Caribbean region (includes islands and bordering countries) and the Greater/Wider Caribbean (also includes the Gulf of Mexico, Florida, Bahamas and Bermuda). Source: https:/www.cia.gov/library/publications/the-world-factbook/attachments/ images/large/central_america-physical.jpg?1547145649.

Caribbean region encompasses a wider area, it includes the islands and the mainland countries whose shores are washed by the Caribbean Sea (eastern coast of Central America and northern coast of South America). Another term, the Greater or Wider Caribbean, is used to include the Gulf of Mexico, Florida, Bahamas and Bermuda (Figure 1).

What is better known is that the Caribbean is a tourist destination full of beautiful and rare plants and animals, many being unique to the region or parts thereof. Extensive work has been done to determine the biodiversity of this region. The Caribbean region comprises $229,540 \mathrm{~km}^{2}$ of land (with only $10 \%$ of original forest cover remaining) and $2,754,000 \mathrm{~km}^{2}$ of ocean. In this region, there are at least 13,000 identified plant species of which 205 genera and 6500 species are endemic [1]. Cuba, for example, has 6500 vascular plants of which $40 \%$ are endemic, and Jamaica has 2888 vascular plants and $28 \%$ endemism (Figure 2). Vertebrates also have a high rate of endemism of between 25 and 100\% [2]. Marine endemism is estimated to be $25.6 \%$ [3]. The marine area of the Caribbean is extensive, is $7686 \mathrm{~m}$ at its maximum depth and includes the world's second largest barrier reef, the Mesoamerican Barrier Reef, which runs $1000 \mathrm{~km}$ along the coasts of Mexico, Belize, Guatemala and Honduras. Many studies have been undertaken to determine and monitor the health of the Caribbean Sea. Multiple uses have been found for both terrestrial and marine organisms. All this information cannot be summarized in one chapter so the purpose here is to highlight the main points, to give awareness to issues of mass extinctions, biodiversity and global problems affecting this area, and to provide a SWOT analysis and valuation exercise, so as to suggest future research needs to strengthen our knowledge base for sustainable development. 


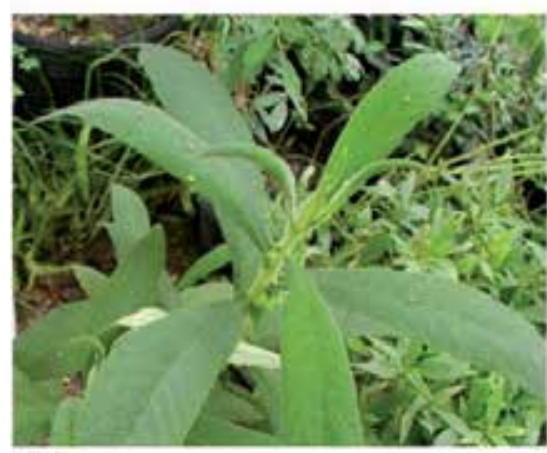

A)

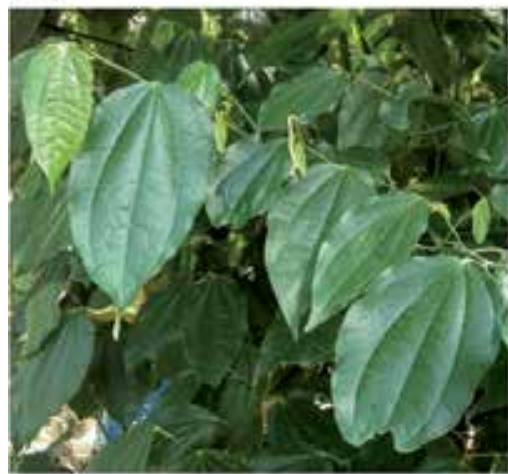

D)

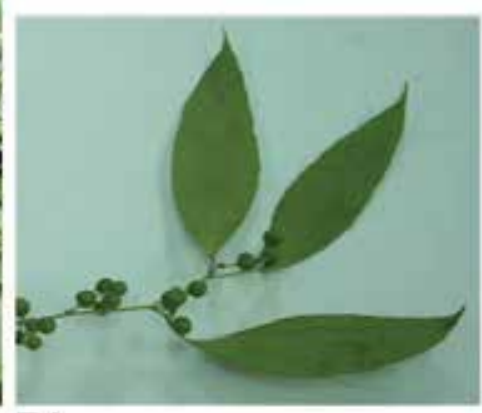

B)

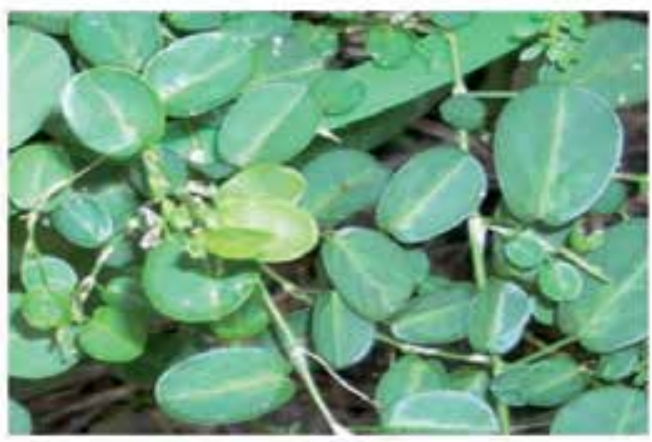

E)

Figure 2.

Endemic plants of the Caribbean: (A) search-mi-heart, Rhytidophyllum tomentosum; (B) leaf and fruit of Chaney root, Smilax balbisiana; (C) rhizome of Chaney root; (D) black jointer, Piper amalago; (E) medina, Alysicarpus vaginalis (plant not endemic but tonic use is endemic to the Caribbean). Pictures taken by Dr. Sylvia Mitchell.

\section{Methodology}

In the face of incomplete yet extensive data on Caribbean biodiversity, focus in this chapter is given to medicinal plants in order to estimate the extent of the resource, problems being experienced and some suggestions of what needs to be done to improve the situation. For Extinctions, the literature was searched for any estimates of extinctions. For Biodiversity, four areas were explored: (1) the Caribbean hotspot, (2) Caribbean medicinal plants where country of origin is mentioned, (3) Caribbean medicinal plant research and development highlighting commercial potential, (4) case studies to highlight different issues. For Global Problems, we consider the Caribbean as a region of a planet under pressure, to highlight what needs to be considered globally.

\section{Extinctions}

Extinctions in the Caribbean have to be considered in terms of Peoples, traditional knowledge and biodiversity-terrestrial and marine-whether endemic, native, indigenous, or imported. Extinction is a threat to every living organism on these small island development states (SIDS). Species considered abundant can suddenly become 
hard to find if they become commercially important to an island state. Such was the case of Cerasee (Momordica charantia) in Jamaica when it became a lucrative export crop. Species can also become overabundant and cause extinction of other species as happened to Coralita (Antigonon leptopus) on St. Eustatius and other islands. By review of literature, this was thought to be caused by: overgrazing by free-roaming livestock (16), anthropogenic disturbance (19) and climate change (six papers) [4].

Botanical work began early in the West Indies [5] but this historical data is not easily available. Not knowing what or how many species existed in the first place, makes analysis of extinction very difficult. When that question is asked of thousands of organisms, survival of all is often the best option. Extinction also has to be considered for the marine environment, as experienced when multiple consecutive coral bleaching events occurred in the mid to late-2000s. Warmer oceans are also implicated in the recent spread of coral diseases (Figure 4B) [6].

\subsection{Extinction of Caribbean peoples}

Due to the influx of many nations into the Caribbean, whether coerced or by free will, the earlier inhabitants of the Caribbean were thought to be extinct. However, in spite of tremendous forces against them, there are still pockets of Caribs and Tainos in the Caribbean [7]. In addition, DNA analyses have shown how the various nations have mingled in the region especially between Amerindian (from South America and the Yucatan Peninsula), African and European tribes [8, 9].

\subsection{Traditional knowledge (TK)}

Traditional knowledge (TK) of the early inhabitants (Tainos, Caribs) has been retained in pockets, and via intermingling of Amerindians, Europeans and Africans [7]. Such a connection was confirmed by analysis of a database of 2350 AfroSurinamese plant names-20\% of the Sranantongo and 43\% Maroon names were similar to those used in Gabon, Angola and Benin for related plants showing that the link between the Caribbean and Africa is strong [10].

A study comparing plants used in 35 African and the 117 Caribbean tonic mixtures indicated that few of the 324 ingredients (plant parts such as leaves, seeds, rhizomes, roots) were the same on both continents and the difference in genera and family increased with increasing distance from Africa indicating that new, unrelated plants with similar taste or properties were used; and while this suggests an African heritage, it also points to Amerindian and European influences [11]. Another study of 38 indigenous Jamaican root tonics indicates that the main forest plant ingredient is endemic to the island (Smilax balbisiana) suggesting that the Africans could utilize local plants to obtain the health outcome they desired [12]. This study uncovered several issues - there was no database to compare the common names to, there were no herbarium samples, and no scientific names for 20 of the 94 forest plants used in the root tonics. The only reference was the common name given on the tonic bottle [12] so the actual plants used are still unknown to science.

Caribbean traditional knowledge (TK) is extensive and includes both terrestrial and marine species [7]. Protection of biodiversity and its associated traditional knowledge is supported by the Nagoya Protocol. This is an international agreement which aims at sharing the benefits arising from the utilization of genetic resources in a fair and equitable way; it entered into force in 2014 (https://www.cbd.int/ abs/). Continued efforts to document Caribbean TK and associated plant knowledge, in order to preserve and sustainably use it for the benefit of the Caribbean, is strongly recommended. 


\subsection{Analysis of risk of extinction of Caribbean biodiversity}

The Caribbean region includes 35 island territories (17 independent and 18 dependent countries comprising about 700 islands, reefs and cays) and 12 continental bordering countries. The Caribbean population is estimated to be about 42.5 million while the region has over $27+$ million stay-over tourists each year. The risk of extinction of its biodiversity is due to several factors. Threats to flora, freshwater and marine biodiversity will be reviewed. These include the actions of waves of people starting from Amerindians who appear to have brought plant and animal species with them but who also lived in harmony with the natural world; through colonial times when great tracts of land were denuded of trees such as pimento (Pimenta dioica), logwood (Haematoxylon campechianum L), mahogany (Swietenia mahagoni) and bitterwood (Picrasma excelsa) to establish sugarcane plantations with immense associated damage to native biodiversity (to terrestrial and freshwater habitats) and who also imported new plant species; to the present time where destruction of local biodiversity and importation of new biodiversity has continued $[7,13]$. Tourism, though needed, has to be managed to reduce its threat to local biodiversity. More recent 'natural' threats include stronger hurricanes, rising ocean temperatures, drought, unpredictable seasons and rising sea levels. Local anthropogenic threats include increasing population densities in rural and urban areas, agriculture, roads (leading to habitat defragmentation and new settlements) and over-harvesting.

The Caribbean region is one of the world's hottest hot spots, with only just over $10 \%$ of its original forest cover remaining [14]. This aggravates the vulnerability of the region to hurricanes and other natural disasters. Of the 187 endemic mammals and birds in the Caribbean, at least 43 have become extinct over the last 500 years. Currently, it is estimated that 755 plants and vertebrate species are at risk of extinction [2]. A Lesser Antilles analysis found that of 263 seed plant taxa unique to these islands, $70 \%$ are threatened [15]. Of these endemics, most were found on only 1 $(37 \%), 2(14 \%)$ or $3(13 \%)$ islands while $25 \%$ were spread over 5 or more islands.

Globally, freshwater biodiversity accounts for 10\% [16] of all documented species, with about 167 freshwater fish occurring within the Caribbean [17]. Freshwater biodiversity is threatened by over-exploitation, water pollution, flow modification, destruction and degradation of habitat and invasion of exotic species [18]. Run-off from freshwater drainage leads to mangrove forests on the coast of Caribbean islands. These forests support more than 2000 species of fish, shellfish, invertebrates, and plants [19]. Suggested solutions to reduce risk of extinction for terrestrial ecosystems include protected areas that are well-managed and joined by 'corridors' of wild forest. Also there should be planned botanical collections (in situ, ex situ and in vitro) - held by farmers, institutions and government-recorded in a database registry. Databases and associated seed banks are needed for conservation of plant genetic material for food and agriculture (PGRFA) and for wild species (especially endemics). This information will help the region to determine species most at risk. Another recommendation is the development of an online, up-to-date, addable and searchable database for all Caribbean organisms-flora, fauna, microbes-and associated traditional knowledge-that is in the control of the Caribbean, for the benefit of its inhabitants. The time to act is now.

Marine biodiversity is also at risk. The Caribbean region is $92 \%$ sea and contains the largest concentration of marine species in the Atlantic Ocean [3]. The coastal area includes territorial waters up to 12 nautical miles from shore, some areas of these exclusive economic zones (EEZs) are still in dispute. The marine ecosystems in the Caribbean have three critical transboundary issues: (a) illegal, unreported and unregulated (IUU) fishing, (b) habitat degradation and (c) pollution. These are being exacerbated by climate variability and change. The Association of Marine 


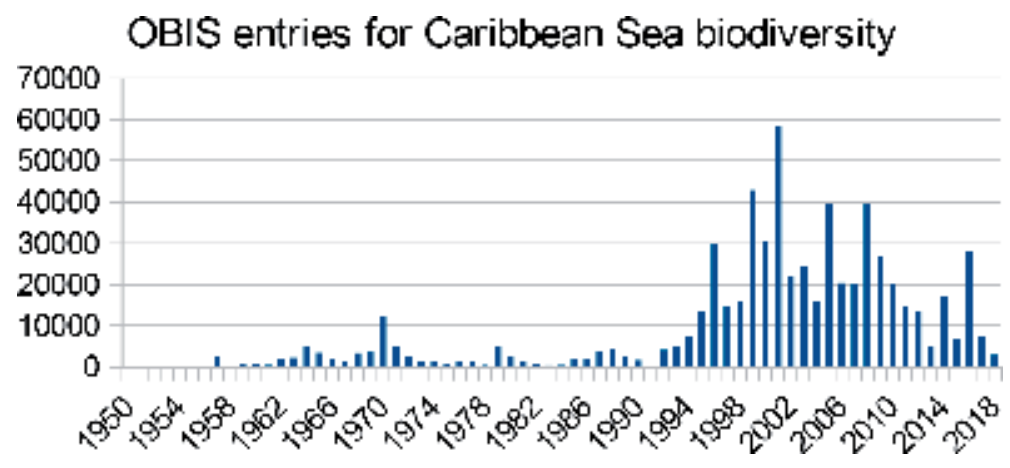

Figure 3.

Number of OBIS entries for species found in the Caribbean Sea.

Laboratories of the Caribbean was established in 1957 to facilitate regional collaboration and now includes 30 labs and over 300 members. Collection of data increased after mass mortality of the formerly ubiquitous sea urchin Diadema antillarum in 1983-1984 prompted several monitoring programs [20]. The census of marine life (CoML) became involved with the Caribbean in 2004. All the information gathered over the years has been fed into the Ocean Biogeographic Information System (OBIS), a dynamic, global, 4-dimensional (space and time) digital atlas [21]. Through these efforts, knowledge of marine biodiversity in the Caribbean is coming of age. OBIS has 663,339 records, 11,175 species and 15,659 taxa for the "Caribbean Sea" region (accessed August 02, 2019)—most of these were collected since 1992 (https://mapper.obis.org/?areaid=40012\#, Figure 3). The most wellknown marine ecosystems in the Caribbean are: coral reefs $\left(26,000 \mathrm{~km}^{2}\right)$, seagrass beds $\left(66,000 \mathrm{~km}^{2}\right)$, and mangroves $\left(11,560 \mathrm{~km}^{2}\right)$. Offshore and deep-sea habitats are slowly being documented as well [21].

In the last 30-40 years, anthropogenic impacts have led to degradation of water and land resources, increased sediment run-off, invertebrate extinction and habitat loss. The coverage of mangroves has decreased by an average of $1 \%$ per year since 1980. Coral cover in Jamaica was reduced to $10 \%$ by 2016, as a result of the concurrent effects of Hurricane Allen (1980), white band disease, reduced herbivory due to over-fishing and mass mortality of the urchin (Diadema antillarum) thus allowing algae overgrowth, and a major bleaching event in 2005 [22, 23]. For the future, here is a sobering thought-with blue biotechnology looking to the oceans for medical value-these marine species might be extinct before we even know they were there!

Incomplete information is still an issue. The known taxa for Caribbean coral reefs have been estimated to be only about $5-10 \%$ of total species inhabiting these communities. This hinders investigation into population dynamics and other studies [3]. Other issues highlighted were: heterogeneity of sampling effort, variability in collecting methods, relatively less sampling from off-shore and deep sea sites, under-sampling even of more accessible coastal areas, insufficient expert taxonomists, insufficient information guides, with many new species being discovered yearly, so while research and data collection has continued, marine biodiversity knowledge is still insufficient which hampers planning efforts. Another issue highlighted was that collected specimens remain scattered worldwide, with data largely in unavailable formats and sources with limited and inconsistent effort of some external researchers to make this data available. OBIS, is changing this narrative for the better and should be commended [3].

Yet another issue is marine invasive species that may enter the region via direct and indirect routes, possibly with multiple introductions. Most of these transfers 
are unintentional such as ballast water transfer and hull-fouling of international vessels [24-27]. Intentional releases usually entail the release of an animal one can no longer care for into the wild [28]. The invasive marine species gain access to resources needed by the native marine populations to survive. Without the usual checks and balances in their own native range, they often outcompete and overpopulate their new habitat, causing a nuisance. The zebra mussel, Dreissena polymorpha (Figure 4A), native to Europe, entered the USA Great Lakes in 1988 and then grew in numbers far greater that the native mussels causing substantial damage to industrial waterways with an annual maintenance cost of $\sim$ US\$ 1 billion [29]. The Caribbean wants to prevent such a disaster in its waters.

With increased movement of goods and people across oceans, the risk increases. If introduced species successfully establish, they begin to interrupt nature's delicate balance causing a cascading effect that can change entire ecosystems over time. Halophila stipulacea, a seagrass species native to the Red Sea and Indo-Pacific, was first observed in the Caribbean in 2002 and has rapidly spread [30-32]. H. stipulacea

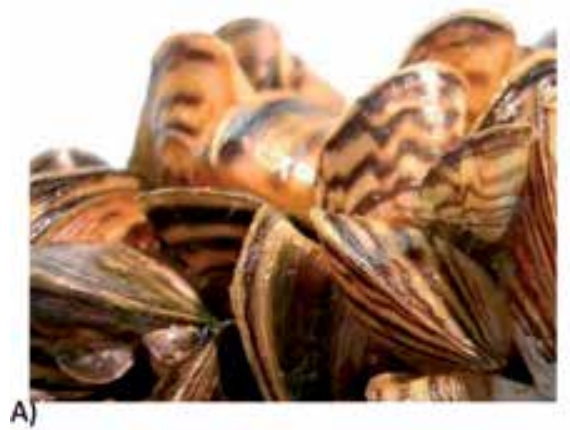

A

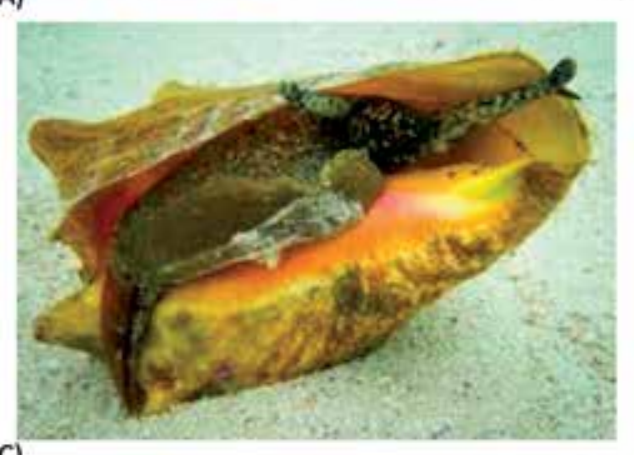

C)

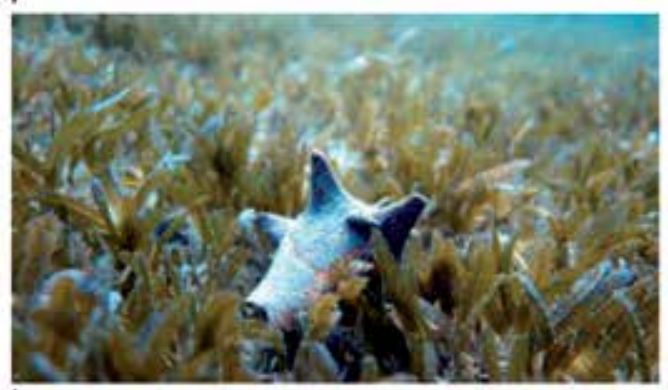

E)

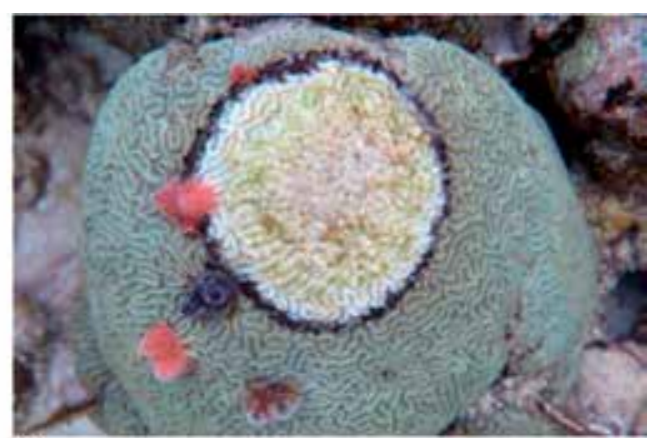

B)

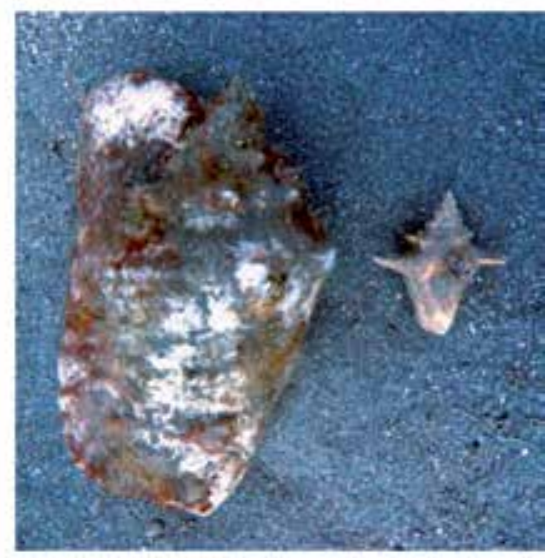

D)

Figure 4.

Marine pictures: (A) Zebra mussels (https://www.healthylake.ca/zebra-mussels), (B) Psuedodiploria strigosa brain coral infected with black band disease, (C) queen conch (https://www.keywestaquarium.com/queenconch), (D) juvenile and adult conch, (E) juvenile queen conch in invasive seagrass Halophila stipulacea. Pictures $(B, D, E)$ by Dr. Kimani Kitson-Walters. 
outcompetes Caribbean native seagrasses through its ability to rapidly expand and form dense mats which impacts native fish and epibenthic species [33]. The invasive seagrass has impacted the endangered queen conch (Lobatus gigas), a giant mollusk endemic to the Caribbean region, as it limits access of the juvenile conch to the sediment [34]. This has detrimental implications for this important species and countless others that use native seagrass meadows as a nursery habitat (Figure 4C-E).

Biotechnology is helping us better understand the magnitude of the marine bioresource and to monitor it, and thus propose solutions. Using DNA barcoding to identify Caribbean reef fish allowed processing of 3400 specimens of 521 reef fishes collected from six areas across the Caribbean between 2004 and 2009. By using these advanced methods, it is clear that tropical reef diversity has been underdetected and therefore underestimated [35]. This method was found especially useful for matching juveniles with adults and barcoding unknown specimens. This effort also resulted in the naming of new genera and resolution of taxonomic issues. Importantly, this database grows with each new set of barcodes making the information more and more robust [36].

The continued advancement of biotechnology provides new perspectives to age-old questions, providing solutions to problems that were unsolvable less than a decade ago. For example, the use of microsatellite DNA technology allowed for accurate distinction of populations and of individuals within populations and subsequently their genetic connectivity across temporal and spatial scales $[37,38]$. This is especially useful in informing management strategies of important species on a local and regional level, whether the goal is commercial or for conservation. In the case of the over-harvested queen conch, biotechnology has helped with both these goals. The multi-million US dollar conch trade has declined significantly throughout the Caribbean with little known about whether it can recover. It was found that genetic connectivity of the species across the region was limited by oceanic distance [39], making recovery of specific populations difficult due to complete reliance on self-recruitment or on upstream populations in the territorial waters of neighboring countries. The management practices, or lack thereof, on upstream populations therefore have a significant impact on the recovery of downstream populations [39, 40]. This serves as another reminder, that in the Caribbean we do not, and cannot, survive alone. This technology is applicable to all species and can be used to guide local and regional management and conservation, safeguarding biodiversity.

The use of single nucleotide polymorphisms (SNPs), another advanced genomics technique, can provide deeper insight into the connectivity of key species. SNPs allow for targeted research into specific aspects of a species' ecology on the molecular level. Questions about the effectiveness of marine protected areas, organism's response to climate change and anthropogenic stressors as well as identification of genetically distinct populations, can be answered using SNPs technology [41, 42]. SNP libraries can and have been developed for numerous species for conservation and management purposes. In the Caribbean, SNP technology has been applied across various taxa including endangered corals (Acropora palmata and Orbicella faveolata), fish (Nassau grouper), invertebrates (spiny lobster) and an invasive angiosperm (Halophila stipulacea) [42-46].

Along with gathering and analyzing knowledge, various methods are being used as counter-measures against possible extinctions. These include but are not limited to:

- Creating protected areas for biodiversity hotspots within the $\mathrm{CIBH}$

- Establishing protected heritage sites 
- In situ, ex situ (Figure 5) and in vitro plant collections (Figure 6)

- Wildcrafting, polyculture and permaculture practices

- Botanical gardens and seed banks

- Plant breeding and conservation efforts including by local communities

- Removal of top grazers (rats and goats) — see Redonda Island-the before and after pictures are awesome! [47]

- Reforestation/replanting of forest trees inland and mangroves along the coast

- Establishment of fish sanctuaries

- Coral reef restoration through multiple methods including micro-fragmentation, fertilization and coral larvae propagation $[48,49]$

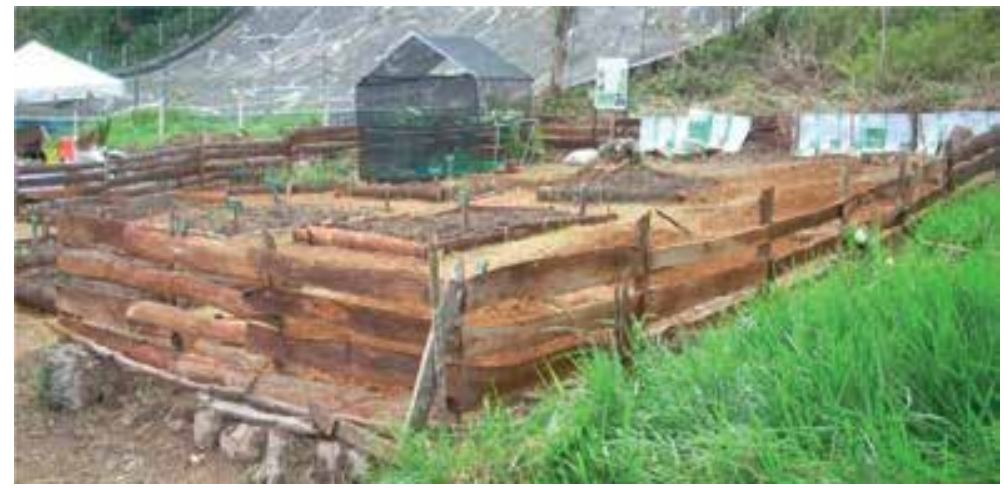

Figure 5.

Ex situ medicinal plant collection by a local community in Quickstep, Trelawny, Jamaica.

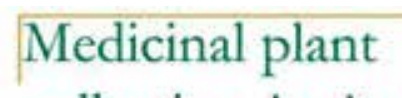
collection in vitro
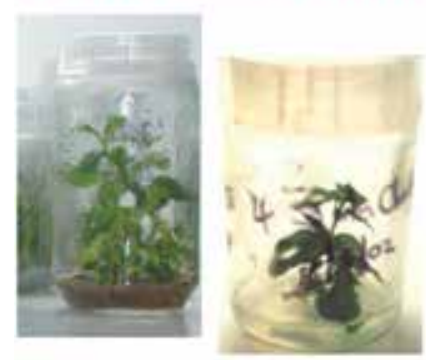

Leaf-of-life John Charles

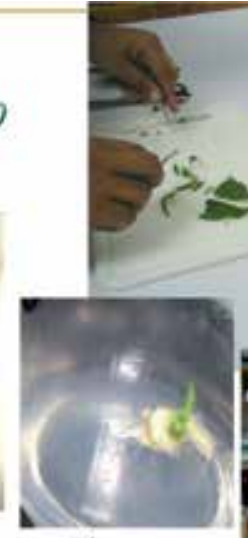

Ginger

For conservation and for multiplying elite planting material for farmers

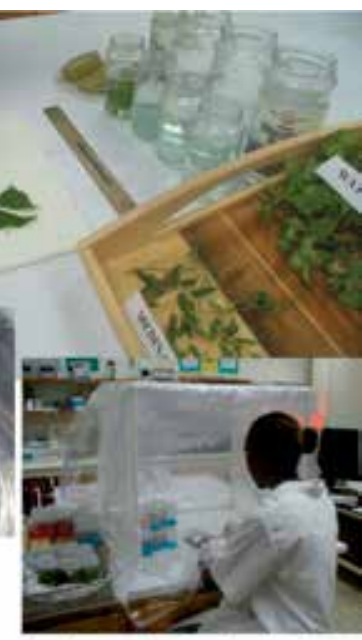

A good school project

Figure 6.

In vitro medicinal plant collection at the Biotechnology Centre, UWI, Mona Campus, Jamaica. 


\section{Biodiversity}

\subsection{Caribbean island biodiversity hotspot (CIBH)}

The Caribbean is one of 25 biodiversity hotspots worldwide (Table 1) [2]. Together these hotspots contain about 50,000 endemic species. As many as $44 \%$ of all known vascular plant species, and $35 \%$ of all species in four vertebrate groups, are confined to these 25 hotspots covering only $1.4 \%$ of the Earth's land surface. An area is designated as a hotspot when it contains at least $0.5 \%$ of the world's endemic plant species [50]. The Caribbean Islands are a known biodiversity hotspot (Figure 7), but this amazing biodiversity has been and is still being threatened by humans.

To further characterize the Caribbean Island Biodiversity Hotspot (CIBH): 294 Key Biodiversity Areas (KBA) were identified, these cover over $50,000 \mathrm{~km}^{2}$ or roughly $22 \%$ of the hotspot [2]. Of these, 144 (or 51\%) overlap partially or completely with protected areas. Cockpit Country, Litchfield Mountain-Matheson's Run, Blue Mountains (all Jamaica) and Massif de la Hotte (Haiti) were found to support exceptionally high numbers of globally threatened taxa, with more than 40 such species at each site. In total, 409 globally threatened plants and vertebrate species (trigger species) determined the vulnerability criterion to define KBAs. No data were available for the other 346 globally threatened species, most of which were plants [2].

The CIBH exhibits high endemism. It is seventh of the 25 global hotspots in terms of known plant species, and 6th in terms of known plant endemic species (Table 1). A total of 180 genera and 727 species are unique to this hotspot, these are the Caribbean endemics [51]. Type species of most of these were published between 1854 and 1928, but although molecular phylogeny has been available for 63, only 21 have robust data. Much work remains to be done. Conservation and management of resources requires an understanding of their taxonomy. This paper concluded that there is urgent need for (1) additional field studies to learn the conservation status of these genera, (2) effective protection of the habitats where the most endangered genera occur, and (3) additional biological and systematic studies of the least understood genera [51].

\begin{tabular}{lcccccc}
\hline Hotspots & $\begin{array}{c}\text { Plant species } \\
\text { number }\end{array}$ & $\begin{array}{c}\text { Endemic } \\
\text { plants }\end{array}$ & $\begin{array}{c}\text { \% of global } \\
\text { plants }\end{array}$ & $\begin{array}{c}\text { Vertebrate } \\
\text { species }\end{array}$ & $\begin{array}{c}\text { Endemic } \\
\text { Vertebrates }\end{array}$ & $\begin{array}{c}\text { \% of global } \\
\text { vertebrates }\end{array}$ \\
\hline 1. Tropical Andes & 45,000 & 20,000 & 6.7 & 3389 & 1567 & 5.7 \\
\hline 2. Sundaland & 25,000 & 15,000 & 5.0 & 1800 & 701 & 2.6 \\
\hline $\begin{array}{l}\text { 3. Mediterranean } \\
\text { Basin }\end{array}$ & 25,000 & 13,000 & 4.3 & 770 & 235 & 0.9 \\
\hline $\begin{array}{l}\text { 4. Mesoamerican } \\
\text { forests }\end{array}$ & 24,000 & 5000 & 1.7 & 2859 & 1159 & 4.2 \\
\hline $\begin{array}{l}\text { 5. Brazil's Atlantic } \\
\text { Forest }\end{array}$ & 20,000 & 8000 & 2.7 & 1361 & 567 & 2.1 \\
\hline $\begin{array}{l}\text { 6. Indo-Burma } \\
\text { Eastern Himalayas }\end{array}$ & 13,500 & 7000 & 2.3 & 2185 & 528 & 1.9 \\
\hline $\begin{array}{l}\text { 7. Caribbean } \\
\text { 8. Madagascar }\end{array}$ & 12,000 & 7000 & 2.3 & 1518 & 779 & 2.9 \\
\hline $\begin{array}{l}\text { 9. South-Central } \\
\text { China }\end{array}$ & 12,000 & 9704 & 3.2 & 987 & 771 & 2.8 \\
\hline \begin{tabular}{l} 
10. Brazil's Cerrado \\
\hline
\end{tabular} & 10,000 & 4400 & 1.5 & 1268 & 117 & 0.7 \\
\hline
\end{tabular}

Table 1.

Top 10 global biodiversity hotspots (in terms of plant species number) [2]. 


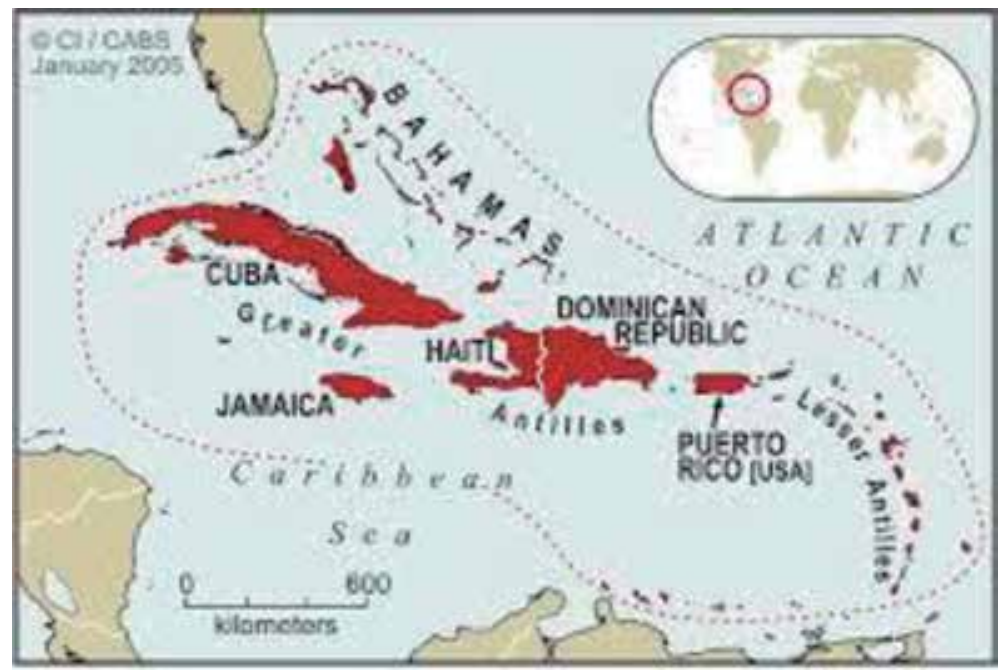

Figure 7.

Caribbean Island Biodiversity Hotspot (CIBH) showing its extent. Source: https://www.cepf.net/sites/default/ files/final_caribbean_ep.pdf.

In terms of biodiversity under threat, Conservation International identified 10 global priority regions in need of targeted funding, in order to build resilience and help adaptation to the impacts of climate change [52]. This would provide the greatest benefits to people and natural ecosystems necessary for life on Earth. These 10 areas intersect known global biodiversity hotspots and cover $13 \%$ of cultivated tropical land. The 10 areas include Central America, Caribbean, Andes and Atlantic coast of Brazil (South America), Guiana Highlands, Albertine Rift, Madagascar, Ghats (India), Philippines and Java (Indonesia) [52, 53]. However, there is no corresponding global fund or program to protect these resources at the level at which they need to be protected.

Understanding the biodiversity of the Caribbean is an ongoing process. Knowing where the hotspots are, where the KBAs are, where the global priority regions are, or even which organisms are endemic is not enough. Monographs for each species are needed. Understanding the life cycles, ecosystem interactions and the influences of threats such as population density and climate change are needed. Only then can viable management plans be made-for conservation and sustainable use.

Information for all 25 biodiversity hotspots can be found in source document [2].

\subsection{Caribbean medicinal plants}

An important part of biodiversity is the plants that have been found to be useful for health and wealth. The Caribbean medicinal plant industry is growing [54]. While there is still not a master list of all medicinal plants found in the Caribbean, an ethnobotanical database is being assembled. The first version of this database reviewed 21 books and included 2898 plant species and the country that identified them as being medicinal [6]. These books describe Caribbean medicinal plants and their folk uses, some are illustrated, and most have been published in the last 20 years (all since 1986 and 76\% (16/21) since 2001). Twelve new literature sources have since been added [12, 55-65]. This database (Version2) now includes 3566 plants growing in the Caribbean that have been identified with at least one ethnomedicinal use-some as tonics, some 


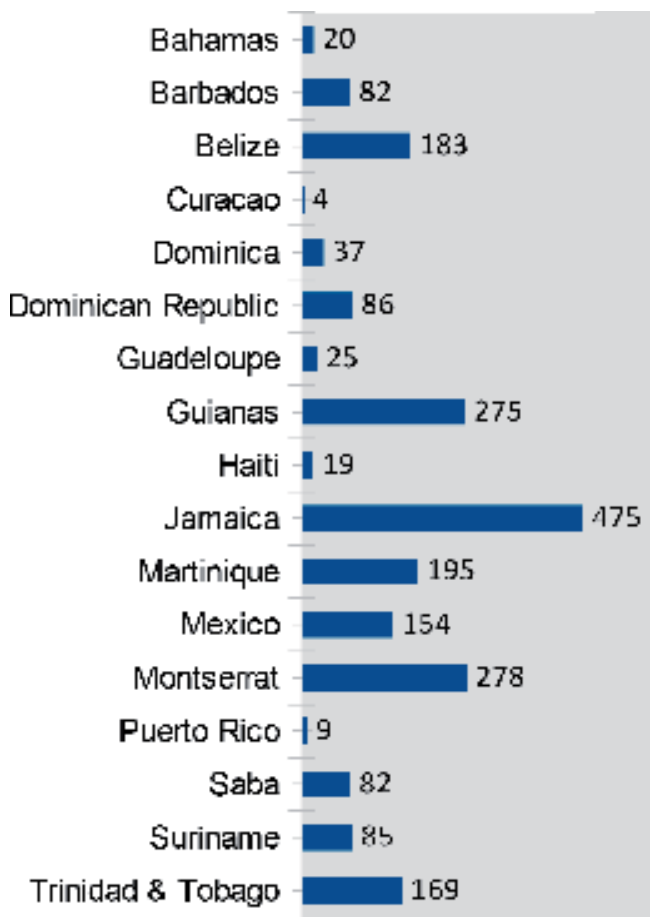

Figure 8.

Number of plants having at least one idientified ethnomedicinal use in 17 Caribbean countries as enumerated in 34 source documents. Of the total, 353 said 'Caribbean' so were not included in this figure. Another 1034 were identified only in Guianas and so were excluded so as not to overwhelm the graph.

preventative, some curative-for health and wellness purposes (Figure 8). Most of these plants (639) were identified as medicinal in only one country although they might be found in others (Table 2). The highest number of medicinal plants were identified in Jamaica (475) for the islands and the Guianas (1309) for the coastal countries. 'Guianas' includes Suriname, Guyana and French Guiana [6]. However, any island not yet represented in this database does not imply that it has no plants with identified medicinal properties, but rather that their information has not yet been added. A problem arises if the books are in different languages, in local publications or if they are out of print $[66,67]$. Not until the database is comprehensive will the comparative story of medicinal plants in the Caribbean be clearly seen.

\subsection{Medicinal plant research in the Caribbean}

The review of UWI research published between 1948 and 2001 listed 334 medicinal plants of which 194 had been studied in the lab [62]. Aphrodisiac root tonics described 152 mixtures from five Caribbean Islands, four South American and seven African countries that used ingredients from 324 plant species [11]. TRAMIL, which started in 1982 and under whose aegis several ethnobotanical studies have been carried out in the Caribbean, has monographs for 397 plant species (http://www. tramil.net). The second edition of the TRAMIL Caribbean Herbal Pharmacopeia had 99 species with 315 REC (recommended) and 5 TOX (found to be toxic) recipes [68]. The job now is to integrate these sources of Caribbean medicinal plant information into a searchable master database that acknowledges the countries from which this traditional knowledge emanates and returns benefit to the particular Caribbean ecosystem that needs this support to survive for perpetuity. 


\begin{tabular}{ll}
\hline $\begin{array}{l}\text { Number of countries in which the plant was } \\
\text { identified as being medicinal }\end{array}$ & Number of plants (based on scientific name) \\
\hline 1 & 639 \\
\hline 2 & 186 \\
\hline 3 & 87 \\
\hline 4 & 78 \\
\hline 5 & 43 \\
\hline 6 & 26 \\
\hline 7 & 15 \\
\hline 8 & 15 \\
\hline 9 & 13 \\
\hline 10 & 6 \\
\hline 11 & 11 \\
\hline 12 & 2 \\
\hline 13 & 1 \\
\hline 14 & 3 \\
\hline
\end{tabular}

Table 2.

Number of countries in which plant species were identified as being medicinal.

In temperate countries, single crops cover vast hectares. In the tropics, especially on small islands, this is not possible. In the Caribbean, the number of plants identified as being useful for one purpose or another continues to grow exponentially, for food, agriculture, horticulture and for medicinal uses [7, 11-13, 54-76]. It is no wonder then that there is a strong emphasis on the plant in the Caribbean [77, 78]. Many of the plants mentioned above have laboratory and clinical results indicating their antioxidant, anti-microbial and anti-cancer bioactivity. Indeed, to even attempt to summarize the research done on Caribbean plants would take a whole book. It is likely, that for whatever disease, there is probably a plant, or combination of plants in the Caribbean that can prevent or cure it! This includes very old diseases and new infectious diseases. To have such a rich heritage and not use it is like hanging a cheque on the wall because it looks pretty. We should find ways to conserve and use our rich heritage sustainably for health and wealth. The Caribbean has several Intellectual Property offices that can help with the transition from R\&D to business (https://www.ict-pulse.com/2012/08/protecting-intellectual-property-caribbean/) and the Nagoya Protocol to ensure benefit returns to the region. Associated with the protocol is the access and benefit-sharing clearing-house $(\mathrm{ABSCH})$, which is a key tool for enhancing legal certainty and transparency, and to monitor utilization of genetic resources along the value chain. The following medicinal plants have been suggested for further development, see Table $3[12,70]$.

\subsection{Case studies}

\subsubsection{Case study: Jamaica and Trinidad medicinal plants}

Jamaica has many publications describing local plants with ethnobotanical uses. A 1787 publication listed 89 medicinal plants and associated recipes [71]. A 1929 publication listed 41 medicinal plants [72]. Asprey and Thorton in 1953-1955 listed 250 medicinal plants [73-76]. A TRAMIL study carried out in 2008 and reported in 


\begin{tabular}{ll}
\hline Ackee (Blighia sapida) & Fever grass (Cymbopogon citratus) \\
\hline Bamboo (Bambusa vulgaris) & Guava (Psidium guajava) \\
\hline Bay tree (Pimenta racemosa) & Guinea hen weed (Petiveria alliacea) \\
\hline Bitterwood (Picrasma excelsa) & Lemon grass (C. flexuosus) \\
\hline Black jointer (Piper amalago spp. amalago) & Mauby (Colubrina arborescens) \\
\hline Bottlebrush (Callistemon viminalis) & Neem (Azadirachta indica) \\
\hline Cannabis (Cannabis sativa) & Nutmeg (Myristica fragrans) \\
\hline Carapa (Carapa guianensis) & Pimento (Pimenta dioica) \\
\hline Cerasee (Momordica charantia) & Sarsaparilla, Chaney root (Smilax spp.) \\
\hline Colic mint (Lippia alba) & Sorrel (Hibiscus sabdariffa) \\
\hline Cocoa (Theobroma cacao) & Turmeric (Curcuma longa) \\
\hline Fitweed (Eryngium foetidum) & Yam (Dioscorea spp.) \\
\hline
\end{tabular}

Table 3.

Caribbean medicinal plants with commercial potential.

2015 listed 116 plants of which 107 had herbarium vouchers and 8 were endemic [63]. A University of the West Indies review in 2006 identified 334 medicinal plants [62]. None of these publications are illustrated, neither is the Flora of Jamaica [79]. There is still no comprehensive illustrated document/database of plants used medicinally in Jamaica. The Manual of Dendrology describes 150 trees of Jamaica and is illustrated [80]. An article describing 30 medicinal plants of Jamaica is illustrated [69] while the Jamaica's Third National Report to the CBD has illustrations of 36 endemic plants and animals of Jamaica [81]. It would be sad to lose this biodiversity before even pictures are taken for prosperity. The Virtual Herbarium of Jamaica has 1638 specimens and is searchable (http://www.jamaicavirtualherbarium.com/). There are about 130,000 botanical specimens in the Institute of Jamaica's herbarium (representing over 3000 higher plant species and 600 fern species) and over 80,000 zoological specimens. There are also 30,000 botanical specimens at the University of the West Indies herbarium. There is no indication of how many of these are medicinal. These herbarium vouchers are useful but need to be supplemented with illustrations of the full plant, leaves, stems, flowers, fruit, under-ground parts and internal morphology.

Trinidad also has a history of medicinal plants. An ethnobotanical survey carried out in 1966 and reported in 1976 with 70 informants described 900 recipes and 186 common medicinal plants [82]. No earlier publication could be found. A 1994 study of the Cocoa Panyols listed 148 plants and 198 recipes [83]. All the plants were native to Trinidad but six species had African varieties and perhaps ten were native to Africa including Aframomum melegueta which may have been brought to the Caribbean by the Portuguese [83]. A 1995 study of plants for ethnoveterinary use reported on 12 plant species used for four categories of poultry health problems [84]. A more extensive TRAMIL survey covering 50 towns in 2007 and reported in 2015 listed 917 single plant remedies from 96 plant species. The number of multiple-plant remedies was not reported [58]. The herbarium of Trinidad and Tobago holds 50,000 specimens dating back to 1842 . This collection also includes samples from Belize, Guyana, Suriname and the Eastern Caribbean (https://sta.uwi.edu/herbarium/). An online database of this herbarium is hosted by the University of Oxford (https://herbaria.plants.ox.ac.uk/bol/trin).

\subsubsection{Case study: Montserrat}

Two studies will be highlighted-one on land and one at sea. On an 18-day trip, 13 scientists from Jamaica, Venezuela, Portugal, the United States Virgin Island and 
6 Montserrat divers visited 516 sites and completed 475 dives in Montserrat waters. This team counted 40,000 fish from 227 different species; 43 of the 65 species of Caribbean corals were seen including the rare Elkhorn and Staghorn corals. This represents a large investment towards biodiversity monitoring and revealed a sizeable resource that needs to be protected while it is enjoyed [85].

Montserrat is about 16 by $11 \mathrm{~km}$ with $40 \mathrm{~km}$ of shoreline. In 1989, Hugo as a Category 4 hurricane damaged more than $90 \%$ of the structures on the island. Then in 1995, the previously dormant Soufrière Hills volcano became active destroying $60 \%$ of the forest. Eruptions buried the capital city of Plymouth with more than $12 \mathrm{~m}$ of mud. From the 13,000 residents in 1994, most of the remaining population left (leaving less than 1200 people); this increased to 5200 by 2016 . The eruptions rendered the entire southern half of the island uninhabitable; it is now a designated Exclusion Zone with restricted access. Montserrat has several endemic species that are having to be rescued. The national bird is the endemic Montserrat oriole (Icterus oberi). Captive populations are held in several UK zoos. An ethnobotanical study in Montserrat reported in 2004 but carried out prior to the eruption identified 272 plant species (169 had folk medicinal uses); herbarium specimens of these were donated to several overseas herbariums [86]. Another publication in 1997 listed 256 medicinal and 24 poisonous plants [57]. Several criteria were suggested for prioritizing biodiversity in Montserrat: globally threatened species, areas of highest species richness, endemic species, optimal habitats, plants that are used by humans, conservation objectives, irreplaceability, and viability [87].

\subsubsection{Case study: Identification of Jamaican medicinal endemics}

In 2016, Jamaica measured itself against the Social Development Goals (SDG). Two of them are directly relevant: Goal 14: Conserve and sustainably use the oceans, seas and marine resources for sustainable development and Goal 15: Protect, restore and promote sustainable use of terrestrial ecosystems, sustainably manage forests, combat desertification, and halt and reverse land degradation and halt biodiversity loss. For Goal 14, none of the indicators were being calculated although data is available for $20 \%$. For Goal 15 , some (16.7\%) of the indicators were being calculated, $8.3 \%$ had available data but the indicators were not being produced while $75 \%$ were not being calculated and data was not available to produce them [88]. This by any indication is a poor report card.

While available literature indicates that the folk use of plants for health in Jamaica began a long time ago, even obtaining comprehensive botanical knowledge of this resource is elusive. In 1929, 41 medicinal plants were listed [72] and most are still being used. However, some problems were encountered: (1) the early literature was not illustrated, (2) scientific names were misspelt, (3) some common names did not match the scientific name known today, and (4) others were identified only to genus. Reconciliation of this early publication to existing knowledge is made more difficult as the only document on Jamaican flora is also not illustrated [79]. With the availability of cameras, we have no excuse. The only other reference to these plants is the herbarium voucher, but this includes only above ground plant parts, has no color, and is one dimensional, so is not useful in all cases. Without illustrations, how are we sure what plant they were referring to? This is important for while the author of this 1929 paper [72] thought 'such use of plants represents a rapidly passing phase of human healing', a 2008 ethnobotanical survey $[63,89]$ indicates that this practice is still being used.

Another issue arises when one tries to identify a plant species by what is referred to as a type species. In the annals of time, wisdom dictated that a herbarium voucher be 


\begin{tabular}{|c|c|c|c|c|c|}
\hline 54 & $\begin{array}{l}\text { Acanthospermum } \\
\text { camphoratum }\end{array}$ & & 197 & Alvaradoa jamaicensis & \\
\hline 183 & Amyris plumieri & Candlewood & 314 & Boerhavia scandens & Rat ears \\
\hline 245 & Cassia italica & Jamaica senna & 36 & Cassia jamaicensis & Jamaican broom \\
\hline 45 & Cinnamodendron corticosum & $\begin{array}{l}\text { Mountain } \\
\text { cinnamon }\end{array}$ & & & \\
\hline 174 & Coccoloba krugi & & 257 & Conyza karvinskyanus & Rockside daisy \\
\hline 22 & Cordia brownei & Black sage & 241 & Cordia jamaicensis & Black sage \\
\hline 274 & Croton wilsoni & Pepper rod & 299 & $\begin{array}{l}\text { Dendropemon } \\
\text { pauciflorus }\end{array}$ & Mistletoe \\
\hline 285 & Dryopteris sp. & White stick & 188 & Fagara elephantiasis & Yellow sanders \\
\hline 187 & Fagara martinicensis & Prickly yellow & 266 & Ipomea jamaicensis & Wild potato slip \\
\hline 43 & Lobelia accuminata & & 44 & Lobelia viridiflora & \\
\hline 262 & Pectis spp. & Stink weed & 40 & Peltophorum linnaei & Brazilletto \\
\hline 161 & Peperomia clusiifolia & & 163 & Peperomia proctorii & \\
\hline 120 & Phoradendron wattii & & 312 & Pimenta jamaicensis & Wild pimento \\
\hline 168 & Piperfadyenii & & 170 & Piper murrayanum & \\
\hline 171 & Piper verrucosum & & 286 & Polypodium exiguum & Hug-me-tight \\
\hline 99 & Rhytidophyllum tomentosum & Search-mi-heart & & & \\
\hline 144 & Sauvagesia brownei & Iron shrub & & & \\
\hline 201 & Smilax balbisiana & Chaney root & 104 & Clusia portlandiana & \\
\hline 190 & Spathelia glabrescens & & 191 & Spathelia sorbifolia & Mountain Pride \\
\hline 343 & Triumfetta sloanei & Bur weed & 71 & Vernonia acumiata & Bitter bush \\
\hline 72 & Vernonia pluvialis & & 74 & Wedelia gracilis & Consumption weed \\
\hline
\end{tabular}

Table 4.

Endemic plant species of Jamaica, common names are in blue [62].

designated the type species to which putative species would then be compared. This is problematic for plants such as Smilax species that cannot always be morphologically distinguished only by above-ground characteristics. Many Smilax species are in the islands and mainland countries; while transporting them to Europe, the origin of the different species has become muddled, and the type species are insufficient as a reference.

A total of 334 plants growing in Jamaica were identified as having medicinal properties [62]. Of these 37.2\% could also be found in Africa or Asia, 31\% species only in the Americas but genus elsewhere, $19 \%$ species and genus only in the Americas, and 13\% species found only in Jamaica. By comparison of these 334 medicinal plants of Jamaica with available flora databases, a list of 31 putative endemic medicinal species was assembled (Table 4).

\subsubsection{Case study: Cockpit country, Jamaica}

The Cockpit Country is a biodiversity hotspot within the Caribbean Island biodiversity hotspot (CIBH). It has karst geomorphology, which is an array of conical hills produced as the limestone erodes. Over 1500 different plant species grow naturally here [90]. Varied soil types on the different sections of the conical hills have resulted in a high rate of endemism. It has been estimated that 71 of Jamaica's endemic plants can 
Valuing Caribbean Biodiversity Knowledge

DOI: http://dx.doi.org/10.5772/intechopen.89016

\begin{tabular}{lcccc}
\hline Taxon & $\begin{array}{c}\text { \# of species resident } \\
\text { on Jamaica }\end{array}$ & $\begin{array}{c}\text { \# endemic } \\
\text { to Jamaica }\end{array}$ & $\begin{array}{c}\text { \# Jamaican endemics in } \\
\text { Cockpit Country }\end{array}$ & $\begin{array}{c}\text { \# endemic to } \\
\text { Cockpit Country }\end{array}$ \\
\hline Ferns & $\sim 600$ & $82(14 \%)$ & $15(18 \%)$ & 2 \\
\hline $\begin{array}{l}\text { Vascular } \\
\text { plants }\end{array}$ & 3304 & $923(28 \%)$ & $281(30 \%)$ & 71 \\
\hline
\end{tabular}

Source: https://www.cockpitcountry.com/plantsEndemicChecklist.html

Table 5 .

Jamaica endemics in the Cockpit Country.

only be found in the Cockpit Country (Table 5). The area is also a refuge for birds and butterflies. An interesting feature is that it has over 300 caves and 21 bat species. One of these bats can eat up to 1000 mosquitoes per hour [90]. The other hotspot within the CIBH in Jamaica, the Blue and John Crow Mountain, was designated a UNESCO World Heritage Site in 2015 for its natural and cultural heritage and is protected. However, the Cockpit Country unfortunately is still in turmoil as the borders of the Cockpit Country are still in dispute. The Cockpit Country Protected Area (CCPA) comprised of 74,726 ha that was established on November 2nd 2017, prevents mining within its borders (Figure 9B). However, it only covers $67 \%$ of the area proposed by the Cockpit Country Stakeholders Group (CCSG) (bordered by the outermost red line) (Figure 9A). The red line border was determined by those who live in the area and other stakeholders which includes the Maroons as being best to protect them, the natural biodiversity and Jamaica at large $[90,91]$. A proposed bauxite mining area, SML 173, is outside the CCPA but inside the CCSG boundary (Figure 9A, B). Mining bauxite in the Cockpit Country (as determined by the CCSG) could causes long-term loss of topsoil, disruption of social fabric, loss of water/climate regulation, loss of unique biodiversity and diminished use of the area as a biodiversity refuge.

\subsubsection{Case study: DCBD}

The Dutch Caribbean Biodiversity Database (DCBD, https://www.dcbd.nl/) is a central repository for biodiversity related research and monitoring data from the Dutch Caribbean. Research and monitoring data can be submitted to the Dutch Caribbean Nature Alliance (DCNA) secretariat for the DCBD. Material stored includes books, scientific articles, maps, charts, reports, biodiversity projects as well as portals to other global databases. Monitoring is continuous (www.dcnanature.org/ resources/research-monitoring). The historical and ongoing taxonomic collections from the Dutch Caribbean are held at Naturalis in Leiden, the Netherlands.

Understanding biodiversity changes requires comparison with historical collections. Fortunately, Naturalis houses 10,000 specimens from Saba, St Eustatius and St Maarten including those collected in 1908. However, by 2013, only $10 \%$ of this herbarium collection had been digitized. In the Netherlands, all Caribbean collections are housed in a single institute where about 100 scientists work on biodiversity [92]. The flora on Aruba, Bonaire and Curacao comprise 569 indigenous and naturalized species composed of South American, Central American and Caribbean species and 86 foreign species (imported accidentally or purposefully). Nine endemic species have been identified (Table 6). The flora is continually being updated. Local naturalists can email pictures taken by digital cameras to online photo-libraries to get plants identified or new ones added to the collection.

Coral reefs are an area of focus. Elkhorn (Acropora palmata) numbers have decreased by $97 \%$ since the 1980 s [93]. This is due to a multitude of issues such as disease, coral bleaching, hurricanes, human activity and collapse of the long-spined sea urchins (Diadema antillarum) populations that grazed the reefs keeping it clear 


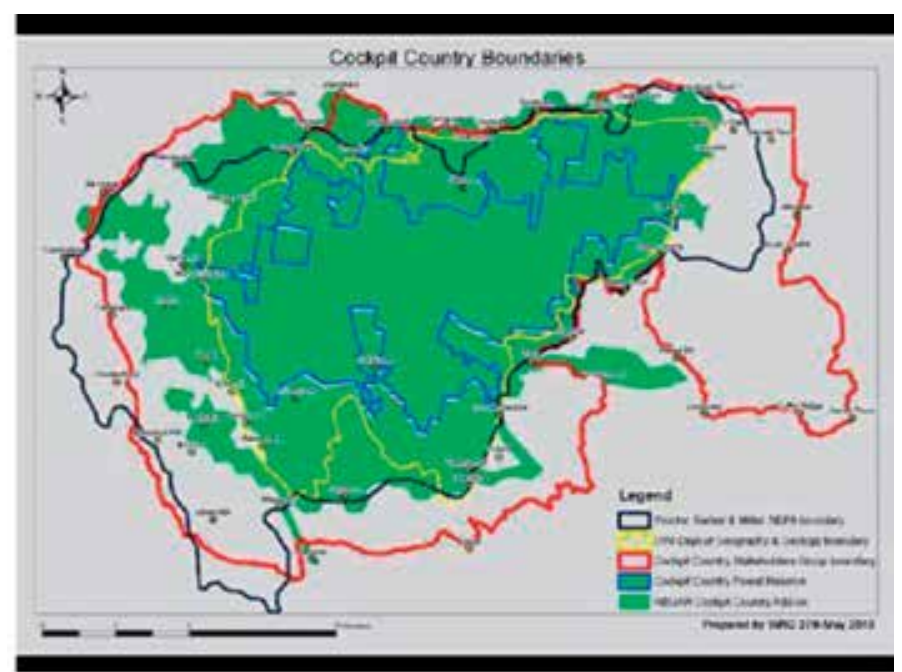

A)

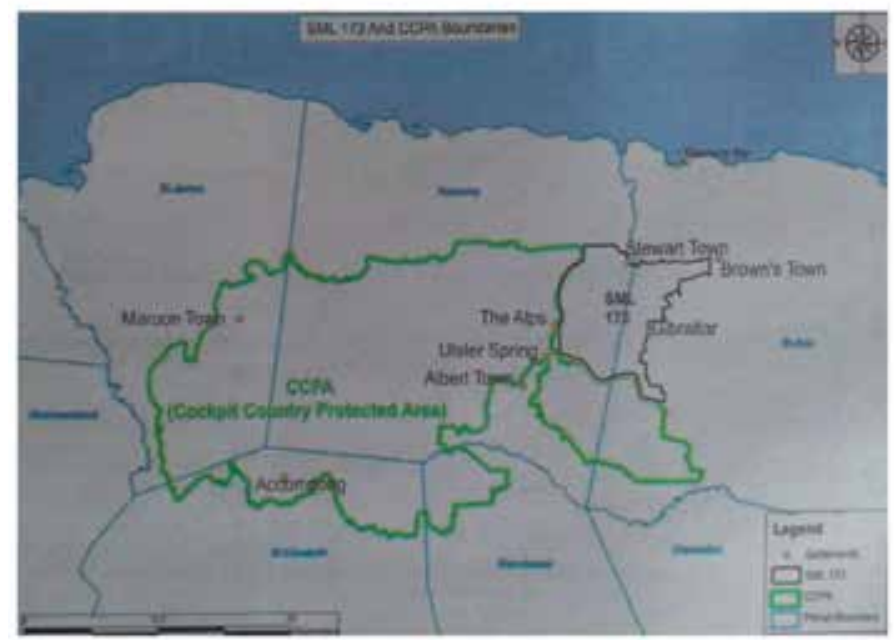

B)

Figure 9.

Cockpit Country: (A) proposed boundaries [78] and (B) CCPA and proposed bauxite mining area SML173 (Observer newspaper, p. 12, August 04, 2019).

of algae. Research includes outplanting of Acropora spp., identification of coral diseases, and growing coral on artificial structures.

The Bonaire Deep Reef Expedition I was carried out from May 30th to June 1st, 2013 when the deep reef of Bonaire was explored by researchers from IMARES Wageningen UR. The Dutch Ministry of Economic Affairs commissioned the research institute IMARES to study the deeper reef as part of the EEZ management plan for the Dutch Caribbean-they went down to 200-250 m. An interesting find was that lionfish were found as deep as $165 \mathrm{~m}$. More interesting information can be found on the DCBD website.

\subsubsection{Case study: TRAMIL}

TRAMIL is the 'program of applied research to popular medicine' which brings together Caribbean institutions interested in the traditional medicine of the islands. Ethnobotanical studies are followed by lab research on efficacy and toxicity of the 
Valuing Caribbean Biodiversity Knowledge

DOI: http://dx.doi.org/10.5772/intechopen.89016

\begin{tabular}{lll}
\hline \multicolumn{1}{l}{ Aruba } & Bonaire & Curaçao \\
\hline$\cdot$ Agave arubensis & $\bullet$ Agave boldinghiana & $\bullet$ Agave boldinghiana \\
\hline$\cdot$ Agave rutteniae & $\bullet$ Cynanchum boldinghii & $\bullet$ Cynanchum boldinghii \\
\hline$\cdot$ Cynanchum boldinghii & $\bullet$ Melocactus macracanthus & $\bullet$ Melocactus macracanthus \\
\hline$\bullet$ Melocactus macracanthus & $\bullet$ Maytenus versluysii & $\bullet$ Maytenus versluysii \\
\hline$\bullet$ Melocactus stramineus & $\bullet$ Myrcia curassavica & $\bullet$ Myrcia curassavica \\
\hline$\bullet$ Melocactus x bozsingianus & & \\
\hline Source: https://www.dcnanature.org/flora-of-aruba-bonaire-and-curacao/ & \\
\hline
\end{tabular}

Table 6.

Endemic plant species of the Leeward Dutch Caribbean Islands.

reported folk recipes. This information is then returned to the people. TRAMIL has the most comprehensive database on Caribbean medicinal plants (http://www. tramil.net/en - in three languages_-French, English and Spanish, Accessed: July $05,2019)$. Importantly the information in the TRAMIL library includes scientific and common names, several pictures, herbarium sample, scan, botanical description, thin section, territories with significant TRAMIL use, preparation, posology, chemistry, biological activities and recommendation. The database is online, available and searchable. The site also has links to publications, workshops, and a map of activities. It is important that this database, especially the illustrations, continues to serve Caribbean interests and remains accessible.

\subsection{Interregional and intraregional collections and databases}

Several herbariums are available in the Caribbean (Table 7). Also, there are many interregional and intraregional biodiversity institutions with Caribbean

\begin{tabular}{|c|c|c|c|}
\hline $\begin{array}{l}\text { Number/Name of } \\
\text { herbarium(s) }\end{array}$ & $\begin{array}{l}\text { Number of } \\
\text { specimens }\end{array}$ & Official acronym & Country \\
\hline Nassau Botanical Gardens & 7215 & $\mathrm{BNH}$ & Bahamas \\
\hline University of the West Indies & 5000 & BAR & Barbados \\
\hline $\begin{array}{l}\text { Ministry of Agriculture, } \\
\text { Fisheries, etc. }\end{array}$ & 10,000 & $\mathrm{BRH}$ & Belize \\
\hline $\begin{array}{l}\text { Natural Trust of the Cayman } \\
\text { Islands }\end{array}$ & 1369 & CAYM & Cayman Islands \\
\hline 22 herbaria & 807,527 & $\begin{array}{l}\text { AJBC, BSC, CSC, HABA, } \\
\text { HABE, HAC, HACC, HAJB, } \\
\text { HAJU, HANC, HFA, HMC, } \\
\text { HPC, HPPR, HPVC, IH, IM, LS, } \\
\text { MNHN, ROIJ, SV, ULV }\end{array}$ & Cuba \\
\hline Three herbaria & 175,000 & JBSD, UCMM, USD & $\begin{array}{c}\text { Dominican } \\
\text { Republic }\end{array}$ \\
\hline $\begin{array}{l}\text { Institut de Recherche pour le } \\
\text { Developpement, IRD }\end{array}$ & 170,000 & CAY & French Guiana \\
\hline $\begin{array}{l}\text { Institut National de la Recherche } \\
\text { Agronomique and Parc National } \\
\text { de Guadeloupe }\end{array}$ & 10,000 & GUAD & Guadeloupe \\
\hline Three herbaria & 57,850 & BRG, FDG, HJBG & Guyana \\
\hline Université d'Etat d'Haiti & 7216 & $\mathrm{EHH}$ & Haiti \\
\hline
\end{tabular}




\begin{tabular}{lccc}
\hline $\begin{array}{l}\text { Number/Name of } \\
\text { herbarium(s) }\end{array}$ & $\begin{array}{c}\text { Number of } \\
\text { specimens }\end{array}$ & Official acronym & Country \\
\hline $\begin{array}{l}\text { Institute of Jamaica (IJ) and } \\
\text { UWI (UCWI) }\end{array}$ & 161,600 & IJ, UCWI & Jamaica \\
\hline Seven herbaria & 167,430 & FPDB, MAPR, MSM, RPPR, SJ, \\
UPR, UPRRP & Puerto Rico \\
\hline University of Suriname & 37,000 & BBS & Suriname \\
\hline $\begin{array}{l}\text { The National Herbarium of } \\
\text { Trinidad and Tobago }\end{array}$ & 70,000 & TRIN & Trinidad \\
\hline None recorded & $?$ & $?$ & US Virgin \\
& & & Island \\
\hline External & $7,800,000$ & NY & USA \\
\hline $\begin{array}{l}\text { The New York Botanical } \\
\text { Gardens }\end{array}$ & $7,000,000$ & K & UK \\
\hline Royal Botanic Gardens at Kew & $6,900,000$ & L, Wag, U & Notherlands \\
\hline Naturalis-from 1829 & $6,600,000$ & USA \\
\hline Missouri Botanical Garden & & & \\
\hline
\end{tabular}

Table 7 .

Herbaria of the CIBH [94].

collections (http://sweetgum.nybg.org). Some of these collections are accessible to the Caribbean, but some are not. The 2007 Dominica ethnobotanical survey voucher specimens are deposited at the University of Missouri Dunn-Palmer herbarium [64]. The same situation happens to databases, so some of this information resides outside of the Caribbean and is not easily available (Table 8).

\subsection{SWOT analysis}

Valuation requires a SWOT analysis.

\subsubsection{Strength}

The strength of the Caribbean is its diversity-plants, animals, microbes, and people. All Caribbean countries have National Biodiversity Strategy and Action Plans (https://www.cbd.int/nbsap), FAO reports on PGRFA (http://www.fao.org/ plant-treaty/en/) and national environmental protection agencies. There are also many terrestrial (https://www.cepf.net/; https://www.thegef.org/) and marine initiatives for the Caribbean (http://caribbean.cepal.org/t/marine-resources). These reports carry a lot of information which are being under-utilized. The diversity of people has resulted in many innovations the rest of the world could benefit from. The databases on Caribbean medicinal plants are growing as is the research, development and innovation to develop useful products.

\subsubsection{Weaknesses}

Lack of appreciation of biodiversity for health and wealth; low level of development that hampers conservation, research and data gathering; and overdependence on imported fuel that uses foreign exchange that could otherwise be used for conservation projects. The status of Caribbean biodiversity is difficult to assess due to the wide extent of the bioresource, varied allegiances and languages, destruction 
Valuing Caribbean Biodiversity Knowledge

DOI: http://dx.doi.org/10.5772/intechopen.89016

\begin{tabular}{|c|c|}
\hline Database & Link to database \\
\hline \multicolumn{2}{|l|}{ Inter-Regional } \\
\hline TRAMIL & http://www.tramil.net/en \\
\hline Dutch Caribbean Biodiversity Database & www.DCNAnature.org \\
\hline Digital Library of the Caribbean & https://dloc.com/dloc1/collect \\
\hline Caribbean Database of Documentary Heritage & $\begin{array}{l}\text { http://nlj.gov.jm/caribbeanregister/docs/collections. } \\
\text { htm }\end{array}$ \\
\hline West Indian Drug Herb Interaction Database [95] & Not available online \\
\hline $\begin{array}{l}\text { International Union for Conservation of Nature } \\
\text { (IUCN) }\end{array}$ & $\begin{array}{l}\text { https://www.iucn.org/tags/regions/caribbean } \\
\text { Standardized methodology for creation of Caribbean } \\
\text { national registers of their marine and terrestrial } \\
\text { biological resources; Database is being populated [96]. }\end{array}$ \\
\hline \multicolumn{2}{|l|}{ Intra-Regional } \\
\hline Fairchild Tropical Botanic Garden & $\begin{array}{l}\text { http://www.virtualherbarium.org/Latham/ } \\
\text { Caribbean.htm }\end{array}$ \\
\hline New York Botanical Garden & $\begin{array}{l}\text { https://www.nybg.org/plant-research-and- } \\
\text { conservation/explore/caribbean/, Said to have over } \\
\text { 300,000 Caribbean plant and fungi specimens. }\end{array}$ \\
\hline Naturalis in Leiden, the Netherlands & $\begin{array}{l}\text { https://www.naturalis.nl/, Historical taxonomic } \\
\text { collections from the Dutch Caribbean }\end{array}$ \\
\hline The British Library & $\begin{array}{l}\text { https://www.bl.uk/collection-guides/ } \\
\text { caribbean-collections }\end{array}$ \\
\hline World Museum, Liverpool, UK & $\begin{array}{l}\text { https://www.liverpoolmuseums.org.uk/wml/ } \\
\text { collections/botany/seed-plants/trinidad-and-tobago/ } \\
\text { index.aspx, Trinidad and Tobago plant collection }\end{array}$ \\
\hline Kew Gardens, UK & $\begin{array}{l}\text { https://www.kew.org/kew-gardens/plants/islands- } \\
\text { flora-collection-Island flora collection—447 taxa, } \\
790 \text { accessions, includes UK Overseas Territories } \\
\text { (UKOTs) [97] and Caribbean samples }\end{array}$ \\
\hline Tropicos & $\begin{array}{l}\text { https://www.tropicos.org/ was originally created for } \\
\text { internal research but is now freely available. Includes } \\
\text { nomenclatural, bibliographic, and specimen data } \\
\text { accumulated in MBG's electronic databases during } \\
\text { past } 30 \text { years. This system has nearly } 1.3 \text { million } \\
\text { scientific names and over } 4.4 \text { million specimen } \\
\text { records. Specimen counts per country are available. }\end{array}$ \\
\hline $\begin{array}{l}\text { Smithsonian, National Museum of Natural History, } \\
\text { Flora of the West Indies }\end{array}$ & $\begin{array}{l}\text { https://naturalhistory2.si.edu/botany/WestIndies/ } \\
\text { Checklist of scientific names of seed plants from West } \\
\text { Indies, synonyms, common names, distribution by } \\
\text { island, images }\end{array}$ \\
\hline Ocean Biogeographic Information System & https://obis.org/ \\
\hline
\end{tabular}

Table 8.

Databases that include Caribbean biodiversity knowledge.

of local biodiversity, imports of new plant varieties, insufficient genotyping more so for terrestrial ecosystems and microbes than for marine; flora without illustrations; insufficient botanical data gathering due to insufficient taxonomists, researchers and custodians of local biodiversity. On one hand is insufficient information, on the other hand is volumes of raw data. Both issues need to be addressed using dedicated and trained personnel. The historical database is insufficient. Another weakness is that much information about the Caribbean resides outside of the region and needs 
to be repatriated or made more readily available. Although the biodiversity data gathered appears extensive, it is not robust enough. While every island has at least one herbarium or access to one, the floras of the region are inadequate. The Flora of Jamaica [79], which is the most comprehensive description of Jamaican flora is not illustrated and there is no other document that comes close to it in terms of the number of plants covered. Unfortunately it is out-of-print and unavailable. A similar situation can be found for flora of other Caribbean countries.

\subsubsection{Opportunities}

Since about the turn of the century, interest in medicinal plants has increased. Most islands now have annotated books on their medicinal plants. Many ethnobotanical surveys have been carried out with several databases being developed. TRAMIL, TROPICOS, and OBIS are important repositories of biodiversity information. Caribbean medicinal plants are reported to have multiple bioactivities. Island research can help to assess how communities are affected by different threats. Making use of these opportunities could bring health and wealth to the region that is sustainable. With more and more countries of the Caribbean signing onto the Nagoya Protocol, these benefits will be shared more equitably with the region.

\subsubsection{Threats}

Climate change, hurricanes, drought, volcanic eruptions, unsustainable agricultural practices, high population densities in rural areas, roads, urbanization, pollution overfishing and invasive species. The greatest threat is if insufficient action is taken to identify, catalog, rationalize, conserve assess and manage our biodiversity.

\subsection{Global problems}

Some of the problems the Caribbean has in terms of mass extinctions and biodiversity are the same as elsewhere. These include population pressure on biodiversity and climate change. On the other hand, there are fundamental problems that remain in the Caribbean that are not a priority elsewhere such as plant identification and conservation; for example, 20 of 94 root tonic forest plant species are still unknown to science [12]. Global funds have reached the Caribbean, but they are insufficient and not tailored to the needs on the ground. If the Caribbean hotspot is to be maintained for future generations, it is going to take researchers inside and outside of the region working together to determine the best way forward.

The Caribbean is affected by what happens elsewhere in the world. For example, the largest extent of Sargassum algae mats occurred in June 2018, when at least 20 million metric tons of the algae covered $8840 \mathrm{~km}$ of ocean from Africa to the Gulf of Mexico. Satellite tracking the algae mats over the last 19 years recorded a sudden and dramatic increase in summer 2011 when the algae changed from isolated groups to an extensive mat. The main cause for the dramatic increase has been linked to increased fertilizer use and deforestation of the Amazon resulting in increasing nutrients pouring into the ocean. Although the floating sargassum shelters turtles, fish and other marine species, too much is smothering corals, seagrass and wreaking havoc on the coasts across the Caribbean and the Gulf of Mexico as meter-thick seaweed covers the beaches and rots [98].

A big concern of the Caribbean is what will happen if we cannot keep global warming from passing $1.5^{\circ} \mathrm{C}$ above pre-industrial levels [99]. Hurricanes and droughts have caused billions of dollars in damage across the Caribbean especially in the last 20 years. Climate resilience is needed even now. However, the Caribbean 
needs '1.5 to stay alive' (https://www.ipcc.ch/sr15/). Capping global temperature rise at $2^{\circ} \mathrm{C}$-as some developed countries have suggested-would have catastrophic impacts on the Caribbean. This would cause extreme temperatures, increases in frequency, intensity and/or amount of heavy precipitation, increase intensity or frequency of droughts and incursion of sea water due to sea level rise. Climate smart agriculture is being recommended while climate and crop modeling is being developed. Identification, storage, sharing and utilization of climate-smart germplasm of important food crops is recommended for building climate resilience that safeguards food and nutrition security, and throughout the region institutions are developing biotechnology solutions for conservation and multiplication of germplasm. But even these efforts will be futile if global warming was to increase above $1.5^{\circ} \mathrm{C}$.

\section{Valuing our biodiversity knowledge}

A big threat to biodiversity is lack of respect for its value. We do not protect what we do not value. We need to spend more time in the garden and away from our computers. We need to ensure our children learn about our natural biodiversity; one way is by ethnobotanical school assignments [100]. Other activities recommended to help us value our biodiversity knowledge and ensure its perpetuity for future generations include:

- Identification of terrestrial, freshwater and marine biodiversity and production of illustrated flora, fauna and microbe monographs

- Ethnobotanical surveys

- Economic valuation of ethnobotanical knowledge to finished product

- Evaluation and conservation of rare, endemic and indigenous germplasm

- Interaction of scientists with rural communities to increase resilient choices

- Development of alternative and sustainable rural livelihoods

- Development of propagation protocols and provision of clean planting material

- Training farmers to conserve and use new (bio) technology

- Production and use of soil ameliorants and innovative machines that run on renewable energy_-solar pumps, bamboo charcoal, water harvesters

- Development of local agroprocessing solutions including essential oils, lotions, creams, soaps

- Development of educational material about useful and threatened biodiversity

- Increasing awareness of rural groups to intellectual property and the Nagoya Protocol and what it means for them

Given their conservation risks, small size, and high levels of endemism, islands offer particularly high returns for species conservation efforts and therefore 
warrant a high priority in global biodiversity conservation activities. The scientists who are working to conserve and sustainably use biodiversity in the islands need to be supported so that their efforts are not wasted.

\section{Way forward}

With a global understanding of the need to conserve biodiversity, especially key species, endangered, medicinal and economically important biodiversity, especially in hotspots, a dedicated initiative tailored to the needs of the region would help ease the pressure. The Caribbean has the following to offer:

- World-class universities and research institutions

- Quality publications highlighting the problem and offering solutions.

- Growing knowledge of Caribbean medicinal plants, freshwater and marine systems.

- Sought-after Caribbean traditional knowledge.

- Lots of sunshine and wind allowing for solar and wind energy.

- Climate change aware governments and scientists.

- Strong and flexible financial systems.

- A desire and understanding of what needs to be done.

- What works in one small island developing states (SIDS) can be applied to others.

Considering the wealth of Caribbean biodiversity knowledge, its presently recognized value and a SWOT analysis, the following areas are most in need of support:

- Identification of Caribbean organisms still unknown to science eg root tonic species, endemics, endangered species.

- Standardization of morphological descriptors and DNA fingerprinting of Caribbean biodiversity.

- Assessment of the interplay between terrestrial, freshwater and marine environments and their biodiversity.

- Education solutions that increase value placed on Caribbean biodiversity

- Annotated and illustrated floras and faunas. Online herbariums.

- A workable diffuse seed bank system (true seed and vegetative organs).

- Biofactory for production and conservation of elite planting material. 
- Long-term storage facilities for elite germplasm (cryopreservation/ biobanking).

- Research into biofarming and biopharming possibilities.

- Field studies to determine sustainable methods for producing high yield, high quality, high drought resistance, permaculture, climate smart crops.

- Permaculture and managed forest studies.

- Support for equipment access, data collection, overseas conferences and workshops, and publishing research outcomes in high impact journals.

- Access to labs, machines, methods, and educational material as needed.

- Repatriation of Caribbean biodiversity data and links to global databases.

- Establishing Caribbean pharmacopeia linked to online biological global databases.

- Plant monographs and Marine information sheets.

- Inclusion of Caribbean plants into Aquacrop, DSSAT and other modeling systems. Inclusion of Caribbean data into Statistica, FAO-stats, Knoema and other global statistical databases systems.

- Inclusion of Caribbean biodiversity custodians and scientists in global decision making endeavors.

- Use of access and benefit sharing systems for genetic resources, associated traditional knowledge holders and derived products.

- Robust Intellectual property systems.

- Robust plant variety protection.

- Biodiversity sensitive trading platforms.

\section{Conclusion}

All major countries of the world are represented in the Caribbean. In a region with so many forces that divide, plants and animals are a unifying force. This is because all biologists speak one language, an organism in any country will have the same unique scientific name. However, if we do not identify and value our biodiversity, it could be lost and we would not know. Increasing the knowledge base will provide increasingly accurate valuation of Caribbean biodiversity. Before we lose this precious and diverse bioresource to inaction, insufficiency, irresponsibility, rising sea levels and other vagaries of climate change, we have to act now. A big problem requires a big solution and those that perceive and understand have to lead the process. We hereby call on those with a conscience to support us in the region who are acting responsibly, to join forces, as we attempt to protect and sustainably use our biodiversity so the Caribbean can play its part in the welfare of the whole human race. 


\section{Websites on Caribbean biodiversity}

- https://www.telbba-plant-wiz.com/landscapes?fb_ref=Default

- https://naturalhistory2.si.edu/botany/WestIndies/

- http://legacy.cepf.net/resources/hotspots/North-and-Central-America/Pages/ Caribbean-Islands.aspx

- https://naturalhistory2.si.edu/botany/WestIndies/

- http://thecommonwealth.org/media/news/ caribbean-nations-prepare-maritime-boundary-talks-commonwealth-support

- http://atlas-caraibe.certic.unicaen.fr/en/page-122.html

- hull fouling: http://www.harsonic.com/harsonic-boats/ hull-fouling-is-highest-for-boats-that-remain-stationary/

- ballast water: http://www.imo.org/en/MediaCentre/HotTopics/BWM/Pages/ default.aspx

- invasive species that were brought in as pets: https://bcinvasives.ca/ commitments/dont-let-it-loose

\section{Acknowledgements}

I would like to thank all those who helped with this chapter.

\section{Author details}

Sylvia Adjoa Mitchell ${ }^{1 *}$, Kimani A. Kitson-Walters ${ }^{2,3}$ and Achsah Anna Mitchell ${ }^{4}$

1 The Biotechnology Centre, University of the West Indies, Mona Campus,

St. Andrew, Jamaica

2 Caribbean Netherlands Science Institute, St. Eustatius, Caribbean Netherlands

3 NIOZ Royal Netherlands Institute for Sea Research, Utrecht University, Texel, The Netherlands

4 St. Eustatius National Parks Foundation (STENAPA), St. Eustatius, Caribbean Netherlands

*Address all correspondence to: sylvia.mitchell@uwimona.edu.jm

\section{IntechOpen}

(C) 2019 The Author(s). Licensee IntechOpen. This chapter is distributed under the terms of the Creative Commons Attribution License (http://creativecommons.org/licenses/ by/3.0), which permits unrestricted use, distribution, and reproduction in any medium, provided the original work is properly cited. (cc) BY 


\section{References}

[1] Smithsonian National Museum of Natural History website, Flora of the West Indies page. Available from: http://legacy. cepf.net/resources/hotspots/Northand-Central-America/Pages/CaribbeanIslands.aspx [Accessed: 04 July 2019]

[2] Anadón-Irizarry V, Wege DC, Upgren A, Young R, Boom B, León $\mathrm{YM}$, et al. Sites for priority biodiversity conservation in the Caribbean Islands biodiversity hotspot. Journal of Threatened Taxa. 2012;4(8):2806-2844

[3] Miloslavich P, Dı’az JM, Klein E, Alvarado JJ, Di'az C, et al. Marine biodiversity in the Caribbean: Regional estimates and distribution patterns. PLoS One. 2010;5(8):e11916. DOI: 10.1371/journal.pone.0011916

[4] Heger WT, van Andel T. A socialecological perspective on ecosystem vulnerability for the invasive creeper coralita (Antigonon leptopus) in the Caribbean: A review. Global Ecology and Conservation. 2019;18:e0605

[5] Smithsonian National Museum of Natural History website, Flora of the West Indies page. Available from: https://naturalhistory2.si.edu/botany/ WestIndies/ [Accessed: 04 July 2019]

[6] Martin C. A mysterious coral disease is ravaging Caribbean reefs. ScienceNews. 3 August 2019;196(2). Available from: https://www. sciencenews.org/sn-magazine/ august-3-2019

[7] Mitchell SA, Lindsay K, Richards A. Bioprospecting in the Caribbean region: Caribbean ABS Traditional Knowledge Stocktaking Traditional Knowledge in the Caribbean Region. IUCN; 2018. 103p

[8] Moreno-Estrada A, Gravel S, Zakharia F, McCauley JL, Bymes JK, Gignoux CR, et al. Reconstructing the population genetic history of the Caribbean. PLoS Genetics. 2013;9(11):e1003925. DOI: 10.1371/ journal.pgen.1003925

[9] Torres JB, Kittles RA, Stone AC. Mitochondrial and Y chromosome diversity in the English-speaking Caribbean. Annals of Human Genetics. 2007;71:782-790

[10] van Andel TR. African names for American plants. American Scientist. 2015;103:268-275

[11] van Andel TR, Mitchell SA, Volpato G, Vandebroek I, Swier J, Ruysschaert S, et al. In search of the perfect aphrodisiac: Parallel use of bitter tonics in West Africa and the Caribbean. Journal of Ethnopharmacology. 2012;143(3):840-850

[12] Mitchell SA. The Jamaican root tonics: A botanical reference. Focus on Alternative and Complementary Therapies. 2011;16(4):271-280

[13] McGlashan D, Mitchell SA, Pryce M, Ryan J, McKenzie C, Burke A, et al. Jamaica: Country Report to the FAO International Technical Conference on Plant Genetic Resources for Food and Agriculture. FAO; 2008. 59p

[14] Brooks T, Smith ML. Caribbean catastrophes. Science. 2001;294:1469-1471

[15] Carrington CWS, Edwards RD, Kropnick GA. Assessment of the distribution of seed plants endemic to the Lesser Antilles in terms of habitat, elevation and conservation status. IN, Special Issue: Endangered and threatened species of the Caribbean. Caribbean Naturalist. 2018;2:30-47

[16] Dudgeon D, Arthington A, Gessner M, Kawabata Z, Knowler D, Lévêque $C$, et al. Freshwater biodiversity: Importance, threats, status and conservation 
challenges. Biological Reviews. 2006;81(2):163-182

[17] David CW, Doug R, Varty N, Anadón-Irizarry V, Pérez-Leroux A. Ecosystem Profile: The Caribbean Islands Biodiversity Hotspot. Critical Ecosystem Partnership Fund Donor Council, BirdLife International. 2 December 2009. 153p. Available from: https://www.cepf.net/sites/default/files/ finaldraft_caribbean_ep.pdf

[18] Pimm SL, Jenkins CN, Abell R, Brooks TM, Gittleman JL, Joppa LN, et al. The biodiversity of species and their rates of extinction, distribution, and protection. Science. 2014;344(6187):1246752-10p. DOI: $10.1126 /$ science. 1246752

[19] Biodiversity of the Caribbean: Protecting the Eastern Caribbean Region's Biodiversity Project. Organisation of Eastern Caribbean States. Victoria, British Colombia, Canada: Ekos Communications, Inc.; 2009. 18p

[20] Jackson JBC, Donovan MK, Cramer KL, Lam VV. Status and trends of Caribbean coral reefs. Gland, Switzerland: Global Coral Reef Monitoring Network, IUCN; 2014. 307p

[21] Miloslavich P. The census of marine life in the Caribbean: A biodiversity program. Revista de Biología Tropical. 2008;56(Suppl 1):171-181

[22] Gayle P. A new artificial reef design and partnerships towards coral reef restoration. CMS Newsletter. 2016;24:13

[23] Wilkinson C, Souter DN. Status of Caribbean coral reefs after bleaching and hurricanes in 2005. In: Global Coral Reef Monitoring Network; Vol. 148; 2008

[24] Bastrop R, Jürss K, Sturmbauer C. Cryptic species in marine polychaete and their independent introduction from North America to Europe.
Molecular Biology and Evolution. 1998;15(2):97-103

[25] Butterfield J, Diaz-Ferguson E, Silliman B, Saunders J, Buddo D, Mignucci-Giannoni A, et al. Rangewide phylogenetic structure of invasive red lionfish, Pterois volitans, reveals two regional clusters. Marine Biology. 2015;162:773-781

[26] Mitchell A. A study of ballast water stowaways entering a Jamaican port [MPhil thesis]. Life Science Department, Faculty of Pure and Applied Science, Mona Campus, University of the West Indies; 2012

[27] Mitchell A, Webber M, Buddo D, Webber D. Development of a protocol for sampling and analysis of ballast water in Jamaica. Revista de Biología Tropical. 2014;62:249-257

[28] Padilla DK, Williams SL. Beyond ballast water: Aquarium and ornamental trades as sources of invasive species in aquatic ecosystems. Frontiers in Ecology and the Environment. 2004;2(3):131-138

[29] Lovell SJ, Stone SF. The economic impacts of aquatic invasive species: A review of literature. In: NCEE Working Paper \#05-02; US Environmental Protection Agency; 2005. 66p

[30] Ruiz H, Ballantine DL. Occurrence of the seagrass Halophila stipulacea in the tropical west. Atlantic Bulletin of Marine Science. 2004;75(1):131-135

[31] Ruiz H, Ballantine DL, Sabater H. Continued spread of the seagrass Halophila stipulacea in the Caribbean: Documentation in Puerto Rico and the British Virgin Islands. Gulf and Caribbean Research. 2017;28:SC5-SC7

[32] Willette DA, Chalifour J, Debrot AOD, Engel MS, Miller J, Oxenford HA, et al. Continued expansion of the trans-Atlantic invasive 
marine angiosperm Halophila stipulacea in the Eastern Caribbean. Aquatic Botany. 2014;112:98-102

[33] Willette DA, Ambrose RF. Effects of the invasive seagrass Halophila stipulacea on the native seagrass, Syringodium filiforme, and associated fish and epibiota communities in the Eastern Caribbean. Aquatic Botany. 2012;103:74-82

[34] Boman EM, Bervoets T, de Graaf M, Dewenter J, Maitz A, Meijer MP, et al. Diet and growth of juvenile queen conch Lobatus gigas in native, mixed and invasive seagrass habitats. Marine Ecology Progress Series. 2019;621:143-154

[35] Plaisance L, Caley MJ, Brainard RE, Knowlton N. The diversity of coral reefs: What are we missing? PLoS One. 2011;6(10):e25026. DOI: 10.1371/ journal.pone.0025026

[36] Weigt LA, Baldwin CC, Driskell A, Smith DG, Ormos A, Reyier EA. Using DNA barcoding to access Caribbean reef fish biodiversity: Expanding taxonomic and geographic coverage. PLoS One. 2012;7(7):e41059. DOI: 10.1371/journal. pone. 0041059

[37] Shaklee JB, Bentzen P. Genetic identification of stocks of marine fish and shellfish. Bulletin of Marine Science. 1998;62(2):589-621

[38] Hellberg ME, Burton RS, Neigel JE, Palumbi SR. Genetic assessment of connectivity among marine populations. Bulletin of Marine Science. 2002;70(1):273-290

[39] Kitson-Walters KA, Candy AS, Truelove NK, Roye ME, Webber MK, Aiken KA, et al. Fine-scale population structure of Lobatus gigas in Jamaica's exclusive economic zone considering hydrodynamic influences. Fisheries Research. 2018;199:53-62. DOI: 10.1016/j.fishres.2017.11.010
[40] Truelove NK, Box SJ, Aiken K, Blythe-Mallett A, Boman EM, Booker CJ, et al. Isolation by distance and spatial genetic structure in an overharvested International Fishery. Diversity and Distributions. 2017;23:1-9

[41] Beltrán DM, Schizas NV, Appeldoorn RS, Prada C. Effective dispersal of Caribbean reef fish is smaller than current spacing among marine protected areas. Scientific Reports. 2017;7(1):4689, 10p

[42] Snelling J, Dziedzic K, Guermond S, Meyer E. Development of an integrated genomic map for a threatened Caribbean coral (Orbicella faveolata). Cold Spring Harbour Laboratory, bioRxiv. 2017:183467. 40p. Available from: https://www.biorxiv.org/content/ biorxiv/early/2017/10/03/183467.full.pdf

[43] Drury C, Schopmeyer S, Goergen E, Bartels E, Nedimyer K, Johnson M, et al. Genomic patterns in Acropora cervicornis show extensive population structure and variable genetic diversity. Ecology and Evolution. 2017;7(16):6188-6200

[44] Jackson AM, Semmens BX, Sadovy de Mitcheson Y, Nemeth RS, Heppell SA, Bush PG, et al. Population structure and Phylogeography in Nassau grouper (Epinephelus striatus), a massaggregating marine fish. PLoS One. 2014;9(5):e97508. DOI: 10.1371/journal. pone. 0097508

[45] Baeza JA, Umaña-Castro R, Mejia-Ortiz LM. Historical demography of the Caribbean spiny lobster Panulirus argus (Latreille, 1804) (Decapoda: Achelata: Palinuridae) in the Florida Keys, USA inferred using single nucleotide polymorphisms (SNPs). Journal of Crustacean Biology. 2019;39(4):378-385

[46] Chiquillo K, Campese L, Barber PH, Willette DA. Does the globally invasive 
marine angiosperm, Halophila stipulacea, have high genetic diversity or unique mutations? In: American Geophysical Union, Ocean Sciences Meeting 2016; Abstract\# ED14A-1611; 2016

[47] Anole Annals website, Redonda Island thrives after complex conservation project. Available from: https://www.anoleannals. org/2018/09/09/invasive-speciesremoval-aids-endemic-lizards-onremote-caribbean-island/ [Accessed: 04 July 2019]

[48] Chamberland VF, Petersen D, Vermeij MJA. Restoration of critically endangered Elkhorn coral (Acropora palmata) using sexually produced recruits. Global Ecology and Conservation. 2015;4:526-537

[49] Page CA, Muller EM, Vaughan DE. Microfragmenting for the successful restoration of slow growing massive corals. Ecological Engineering. 2018;123:86-94

[50] Myers N, Mittermeier RA, Mittermeier CG, da Fonseca GAB, Kent J. Biodiversity hotspot for conservation priorities. Nature. 2000;403(6772):853-858

[51] Francisco-Ortega J, SantiagoValentin E, Acevedo-Rodriguez P, Lewis C, Pipoly J III, Meerow AW, et al. Seed plant genera endemic to the Caribbean island biodiversity hotspot: A review and a molecular phylogenetic perspective. The Botanical Review. 2007;73(3):183-234

[52] Conservation International. Scientists Identify Top Ten Priority Regions for Climate Adaptation Funding to Secure Food Security and Biodiversity. 18 September 2013. Available from: https:// phys.org/news/2013-09-scientists-tenpriority-regions-climate.html

[53] Hannah L, Ikegami M, Hole DG, Seo C, Butchart SHM, Peterson AT, et al. Global climate change adaptation priorities for biodiversity and food security. PLoS One. 2013;8(8):e72590. DOI: 10.1371/journal.pone.0072590

[54] Mitchell SA, Jagnarine R-D, Simmonds R, Francis T, Picking D, Ahmad MH. A journey through the Medicinal Plant Industry of the Caribbean highlighting UWI Mona's contribution. Caribbean Quarterly. 2008;54(3):27-52

[55] Alvarado-GuzmanJA,Gavillan-Suarez], Germosen-Robineau L. TRAMIL ethnopharmacological survey: Knowledge distribution of medicinal plant use in the southeast region of Puerto Rico. Puerto Rico Health Sciences Journal. 2009;28(4):329-339

[56] Boulogne I, Germosen-Robineau L, Ozier-Lafontaine H, Fleury M, Loranger-Merciris G. TRAMIL ethnopharmacological survey in Les Saintes (Guadeloupe), French West Indies: A comparative study. Journal of Ethnopharmacology. 2011;133:1039-1050

[57] Brussell DE. Poisons and Panaceas: An Ethnobotanical Study of Montserrat. Carbondale and Edwardsille: Southern Illinois University Press; 1997. 196p

[58] Clement YN, Baksh-Comeau YS, Seaforth CE. An ethnobotanical survey of medicinal plants in Trinidad. Journal of Ethnobiology and Ethnomedicine. 2015;11:67, 29p

[59] Cohall D, Carrington S. A comparison of the chemical constituents of Barbadian medicinal plants within their respective plant families with established drug compounds and phytochemicals used to treat communicable and noncommunicable diseases. West Indian Medical Journal. 2012;61(1):17-27

[60] Flores KE, Quinlan MB.

Ethnomedicine of menstruation in rural Dominica, West Indies. Journal of Ethnopharmacology. 2004;153: 624-634 
[61] McClure SA, Eshibaugh WH. Love potions of Andros Island, Bahamas. Journal of Ethnobiology. 1983;3(2):149-156

[62] Mitchell SA, Ahmad MH. A review of Medicinal Plant Research at the University of the West Indies, Jamaica, 1948-2001. The West Indian Medical Journal. 2006;55(4):243-269

[63] Picking D, Delgoda R, Younger N, Germosen-Robineau L, Boulogne I, Mitchell SA. TRAMIL ethnomedicinal survey in Jamaica. Journal of Ethnopharmacology. 2015;169:314-327

[64] Ososki AL, Lohr P, Reiff M, Balick MJ, Kronenberg F,

Fugh-Berman A, et al. Ethnobotanical literature survey of medicinal plants in the Dominican Republic used for women's health conditions. Journal of Ethnopharmacology. 2002;79:285-298

[65] Quinlan MB, Quinlan RJ, Nolan JM. Ethnophysiology and herbal treatments of intestinal worms in Dominica, West Indies. Journal of Ethnopharmacology. 2002;80:75-83

[66] Benedetti M. Earth and Spirit: Medicinal Plants and Healing Lore from Puerto Rico. Orocovis, PR: Verde Luz; 1989. $272 \mathrm{p}$

[67] Nunez-Melendez E. Plantas Medicinales de Puerto Rico. San Juan, PR: Universidad de Puerto Rico Press; 1982. $498 \mathrm{p}$

[68] Germosén-Robineau L editor. Caribbean Herbal Pharmacopoeia, 2nd Ed. electronic book. Tramil; 2006. Available from: http://www. funredes.org/endacaribe/img/ PORTADAS-Publi-Tramil/CHP2bac

[69] Mitchell SA, Ahmad MH. Protecting our medicinal plant heritage: The making of a new national treasure. Jamaica Journal, Institute of Jamaica, Kingston. 2006;29(3):28-33
[70] Seaforth CE, Tikasingh T. Final Report: A Study for the Development of a Handbook of Selected Caribbean Herbs for Industry. CTA; 2005. 132p

[71] Wright W. An account of the medicinal plants growing in Jamaica. London Medical Journal. 1787;8(3):217-295

[72] Steggerda M. Plants of Jamaica used by natives for medicinal purposes. American Anthropologist. 1929;31:431-434

[73] Asprey GF, Thornton P. Medicinal plants of Jamaica. Part I. West Indian Medical Journal. 1953;2:233-252

[74] Asprey GF, Thornton P. Medicinal plants of Jamaica. Part II. West Indian Medical Journal. 1954;3:17-41

[75] Asprey GF, Thornton P. Medicinal plants of Jamaica. Part III. West Indian Medical Journal. 1955;4:69-82

[76] Asprey GF, Thornton P. Medicinal plants of Jamaica. Part IV. West Indian Medical Journal. 1955;4:145-168

[77] Mitchell SA, Lindsay K, Richards A. Bioprospecting in the Caribbean Region: Caribbean ABS Institutional Mapping. IUCN; 2018. 142p. Available from: http://www.abscaribbean.com/ resources/documents

[78] Mitchell SA, K Lindsay, A Richards (2018c) Bioprospecting in the Caribbean Region: Biodiversity Summary of Eight Caribbean Countries, IUCN; 2018. 62p. Available from: http:// www.abscaribbean.com/resources/ documents

[79] Adams CD. Flowering Plants of Jamaica. Jamaica: University of West Indies; 1972. 848p

[80] Parker T. Manual of Dendrology. Jamaica: Forestry Department, Ministry of Agriculture; 2003. 494p 
[81] NEPA. Summary of Jamaica's Third National Report to the Convention on Biological Diversity 2003-2004. Jamaica: NEPA; 2010

[82] Wong W. Some folk medicinal plants from Trinidad. Economic Botany. 1976;2:103-142

[83] Lans C. A review of the plantbased traditions of the Cocoa Panyols of Trinidad. GeoJournal; 2018;83(6):1425-1454

[84] Lans C, Brown G. Observations on ethnoveterinary medicines in Trinidad and Tobago. Preventive Veterinary Medicine. 1998;35:125-142

[85] DiscoverMNTTeam. Data from Scientific Assessment on Montserrat's Marine Coastal Environment Being Analysed. Discover Montserrat. April 14, 2016. Available from: https://discovermni. com/2016/04/14/data-from-scientificassessment-on-montserrats-marinecoastal-environment-being-analysed/ [Accessed: 29 July 2019]

[86] Brussell DE. A medicinal plant collection from Montserrat, West Indies. Economic Botany. 2004;58:S203-S220

[87] Young R. Biodiversity assessment of the Centre Hills, Montserrat. In: Pienkowski M, editor. Biodiversity That Matters: A Conference on Conservation in UK Overseas Territories and Other Small Island Communities. UK Overseas Territories Conservation Forum; 2007. pp. 318-326

[88] STATIN. Report on the National Consultations on the SDG Indicator Framework: Jamaica. Kingston, Jamaica: Statistical Institute of Jamaica; 2016

[89] Picking D, Younger N, Mitchell SA, Delgoda R. The prevalence of herbal medicine home use and concomitant use with pharmaceutical medicines in Jamaica. Journal of Ethnopharmacology. 2011;137(1):305-311
[90] Schwartz M. The Environmental Benefits of Current Land Use in Cockpit Country, Jamaica. Trelawny, Jamaica: Windsor Research Centre, Sherwood Content; 2010. 15p

[91] Cuff L. Maroons unhappy with Cockpit Country boundary proposal. Gleaner. 08 June 2013

[92] Wesselingh F, van Andel TR, van Proosdij A. Uncovering past Caribbean biodiversity: A look into the collections of Naturalis. BioNews. 2013;5:4-5.

Available from: www.DCNAnature.org

[93] Chamberland V. Research of the month: Coral reef restoration. BioNews. 2013;5:4-5. Available from: www.

DCNAnature.org

[94] Holmgren PK, Holmgren NH. Index Herbariorum: A Global Directory of Public Herbaria and Associated Staff. New York: New York Botanical Garden. On Wiki, List of herbaria in North America; 1998, continuously updated [Accessed: 04 July 2019]

[95] Cohall DH, Griffiths A, Scantlebury-Manning T, Fraswe HS, Carrington CMS. Drug-herb interactions: Database of medicinal plants of the Caribbean, their indications, toxicities and possible interactions with conventional medication. The West Indian Medical Journal. 2010;59(5):503-508

[96] Mitchell SA, Richards A, Lindsay K. Bioprospecting in the Caribbean Region: Standardized Methodology for Creation of Caribbean National Registers of their Marine and Terrestrial Biological Resources. IUCN; 2018. 45p. Available from: http://www.abscaribbean.com/ resources/documents

[97] Churchyard T, Eaton MA, Harvey S, Hall J, Millett J, Farr A, et al. The biodiversity of the United Kingdom's overseas territories: A stocktake of species occurrence and assessment of key knowledge gaps. 
Biodiversity and Conservation.

2016;25:1677-1694

[98] Gramling C. The largest seaweed bloom ever detected spanned the Atlantic in 2018. ScienceNews. 04 July 2019;196(2)

[99] https://caricom.org/media-center/ communications/news-from-thecommunity/the-caribbean-reiterates1.5-degrees-celsius-to-stay-alive

[100] van't Klooster C, Haabo V, van Andel T. Our children do not have time anymore to learn about medicinal plants: How an ethnobotanical school assignment can contribute to the conservation of Saramaccan Maroon traditional knowledge. Ethnobotany Research and Applications. 2019;18(11):1-477. DOI: 10.17348/era 



\title{
Acoustic Habitat Degradation Due to Shipping in the Indian Ocean Region
}

\author{
Arnab Das
}

\begin{abstract}
The Indian Ocean Region (IOR) is strategically emerging as the most important sea area in the twenty-first century and presents itself as a hub for maritime trade. The shipping traffic both due to merchant and naval vessels has increased manifold. The underwater radiated noise (URN) from marine vessels interferes with the perception of the marine ecosystem by the big whales, leading to acoustic habitat degradation. The global increase in the low-frequency ambient noise due to shipping is known to have doubled every decade, since the preindustrial era based on records available since the 1950s. The IOR has unique characteristics, in terms of geopolitical, socioeconomical, acoustical (tropical littoral waters) and more. The regulatory framework for managing the acoustic habitat degradation in the IOR will require understanding the unique challenges and opportunities. The frequent stranding of big whales in recent times is a manifestation of the severe acoustic habitat degradation in the region and demands urgent measures to be initiated. This chapter attempts to present the multiple dimensions of acoustic habitat degradation due to shipping in the IOR. Effective underwater domain awareness (UDA) framework proposed by the author could provide a comprehensive way forward to contain the noise pollution caused by increasing URN levels.
\end{abstract}

Keywords: acoustic capacity building, underwater radiated noise (URN), automated identification system (AIS), noise pollution, underwater domain awareness (UDA), sustainable blue economy, maritime capacity building

\section{Introduction}

Globally, there have been sustainability concerns due to the so-called development bogey which is slowly manifesting as a major cause of environmental degradation [1]. The oceans and other marine environments have been ignored so far because of perceived absence of direct impact on human well-being. However, in the recent times, we have been observing more and more attention being turned toward the oceans as it has been realized that marine ecosystems are a continuum of the universe and any disruptions there can impact human habitat on land as well [2].

The science and technology advances have made it more and more accessible to reach the deepest of the depths in the oceans, and we are realizing the challenges and opportunities that exist in the marine ecosystem. The vast undersea resources have significant potential for socioeconomic growth for mankind; however, the 
exploration and exploitation should be done in a calibrated manner to address sustainability concerns. Blue economy has become a buzz word in strategic discussions and vision formulations; however, the environment impact assessment (EIA) at times lacks multiple dimensions of the marine eco-concern due to the human intervention with the undersea ecosystem. Acoustic habitat degradation always escapes attention of the scientific and political community due to high resource requirement and the relative inaccessibility of the undersea domain [3].

The stressed resource on land is encouraging us to look at the oceans for economic growth and prosperity. The blue economy has emerged as the new buzz word with significant potential to complement economic development using the oceans and its resources. The blue economy has multiple dimensions, and the emphasis is on sustainable growth; however, on ground, the unregulated and unscrupulous rush toward oceans for economic gains has made it a serious cause of concern. The traditional blue economic activities include shipping, ports, oil and gas exploration, fishing, deep sea mining, marine tourism and other marine industries. In the recent times, we are also seeing massive growth in emerging industries like aquaculture, carbon sequestration (or blue carbon) and renewable energy production such as wind, wave and tidal energy. Figure 1 gives a broad pictorial representation of the multiple activities associated with the blue economy [4].

The availability of so-called modern science and technology tools has made the deepest of the oceans accessible, and thus, the humans are able to exploit and explore the vast resources of the undersea domain with ease. The uneven distribution of resources and know-how among the global powers coupled with the fragmented geopolitical approach toward regulating global commons are major obstacles for ensuring sustainability. There is vested interest among the global powers in ensuring complete lack of transparency and non-equitable extraction of the high-value resources available in the undersea domain. The environmental impact assessment (EIA) is skewed, and the real impact on the marine ecosystem never gets evaluated given the complex dimensions and dynamics of the marine ecosystem. Acoustic habitat degradation is one such issue that has escaped attention and attained monstrous proportion [5].

The ocean ambient noise or the background din in the seas has multiple sources both natural as well as anthropogenic. Theoretically, ambient noise cannot be directly linked to a specific identifiable source; however, it is attributable to general

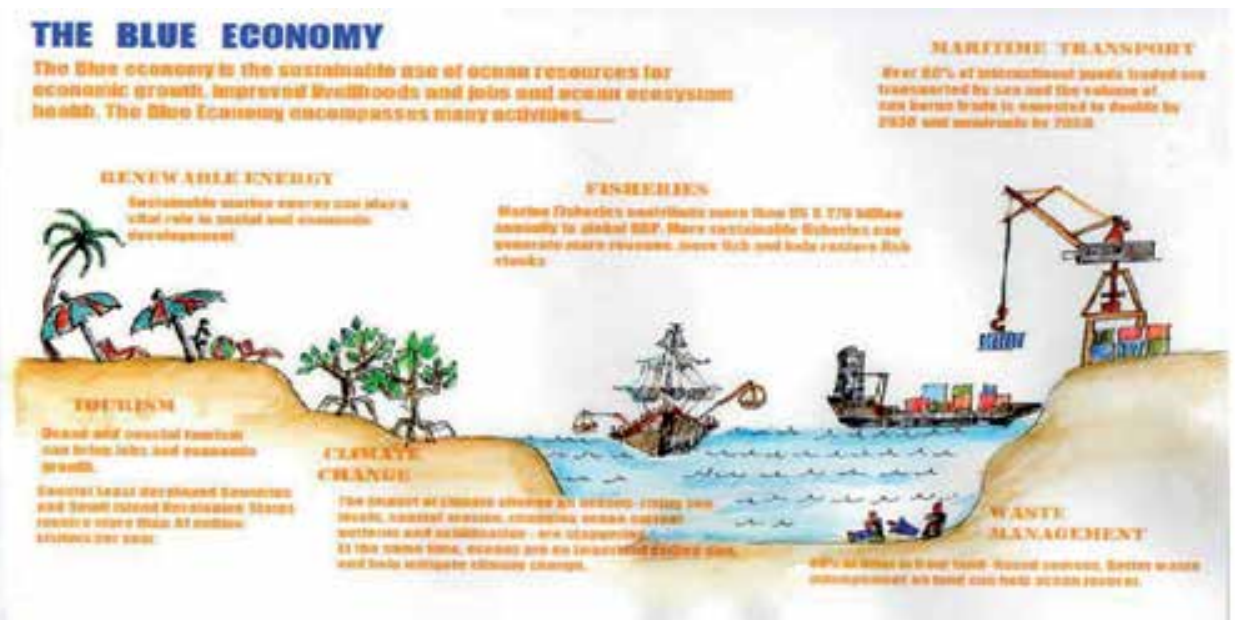

Figure 1.

Multiple activities associated with blue economy. 
types of sources. The natural sources include geophysical activities like windgenerated waves, earthquakes, precipitation, cracking of ice and many more as well as biological sources from marine species like whale songs, dolphin clicks and fish vocalizations. The anthropogenic noise originates from human-driven activities like shipping, geophysical surveys, oil and gas exploration, dredging and sonar transmissions. The classical ambient noise plot by Wenz GM, way back in the post Second World War period (valid even today), gives a clear segregation of the sources based on the frequency bands. The extreme low frequency $(<1 \mathrm{KHz})$ is dominated by distant shipping followed by wind-generated noise up to $15 \mathrm{kHz}$ [6]. Figure 2 gives the Wenz curve with clear domination of the shipping noise in the low frequency region.

Among the multiple activities under the blue economic umbrella, the shipping has some unique characteristics that merit attention while we want to analyze the sustainability concerns in the blue economy or the acoustic habitat degradation in the undersea domain [8]. These include the following:

a. The shipping is the single ubiquitous source of noise in the ocean. It forms the basic low-frequency background ambient noise across the oceans.

b.Shipping is directly linked to the global economic growth index, so there is minimal political motivation to regulate this sector.

c. The shipping noise is low frequency, so it suffers minimal attenuation in the underwater medium. This results in maximum impact across a large area.

d.The shipping noise is low intensity signal, however due to the well distributed nature of the shipping traffic the impact is wide spread across the entire global oceans.

e. The shipping noise acts like slow poison and does not cause instant impact. But, it contributes to gradual degradation of the ecosystem where the marine animals suffer profound psychoacoustic degradation leading up to fatalities and drastic species depletion.

f. The inability to establish direct linkages with the pollutant poses several regulatory challenges. Regulatory formulations demand clear cause and effect linkages.

The geostrategic relevance of the Indian Ocean Region (IOR) in the twenty-first century needs to be understood in a holistic manner. The economic development of any nation is closely linked to its trade and energy supply. The geostrategic location of the IOR ensures that it is the center of gravity for the sea lanes of communications (SLOCs) not only for the nations in the IOR but also for nations in the entire Indo-Pacific and beyond. The energy supplies from the middle-east, and the raw material from Africa to the growing economies in the South East Asia (China, Japan, Korea and others) and the return passage of finished goods from South East Asia to Africa and Europe put IOR in a very strategic position [9].

It is not only the commercial ships but also the naval ships that get deployed to protect the SLOCs given the volatile security situation in the region puts the number count of ships at an alarming level contributing to the high ambient noise. The socioeconomic conditions and also the socio-political situation of the nations in the IOR ensure poor design and manufacturing (with high radiated noise levels) of the ships in region and also limited regulatory provisions to be able to address the concerns of acoustic habitat degradation [10]. 


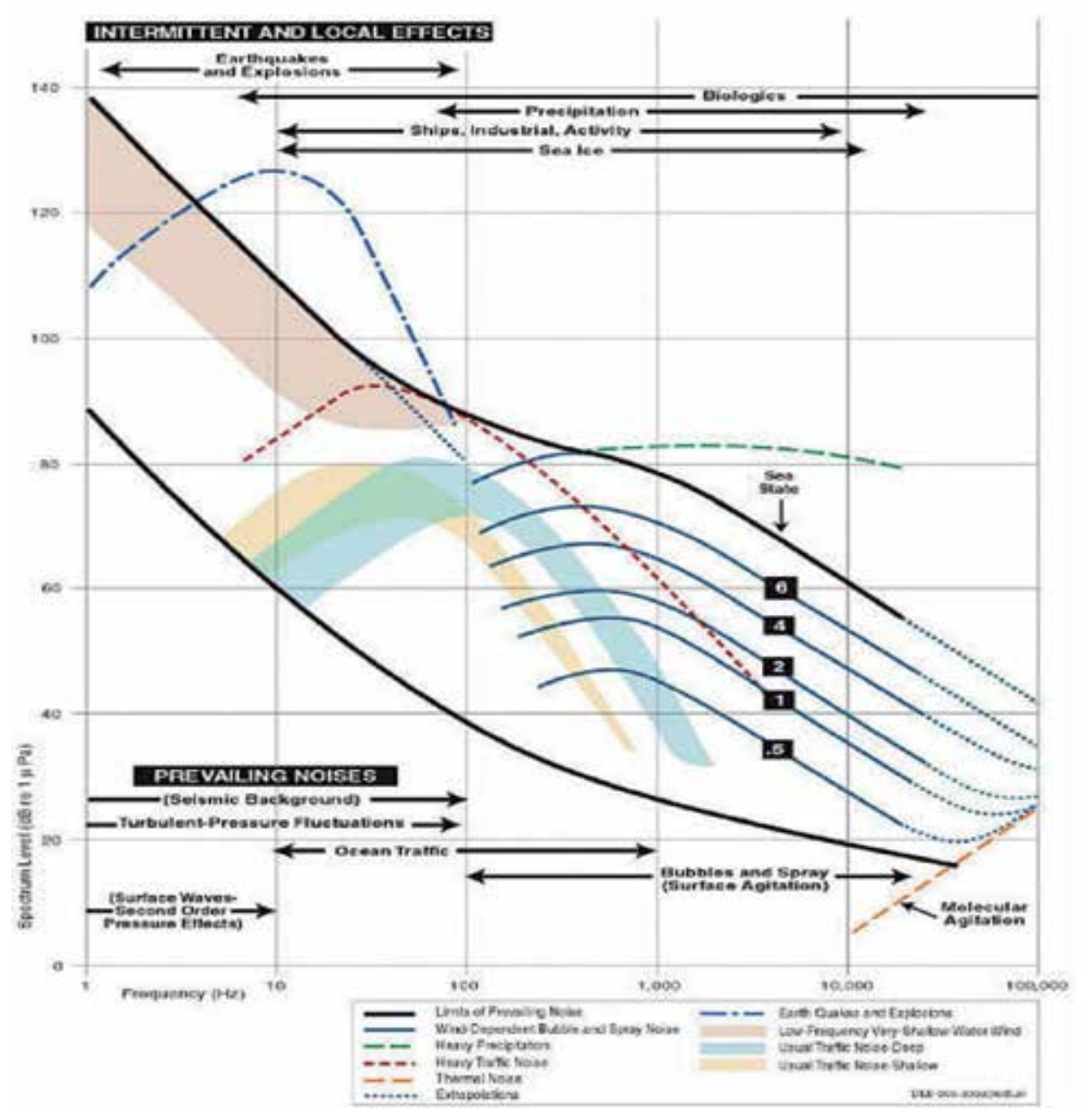

Figure 2.

Wenz curve [7].

The subsequent sections in the chapter attempt to address the larger issue of acoustic habitat degradation in the IOR due to shipping. In Section 2, we present the basics of underwater radiated noise (URN), the mechanism of generation of URN, acoustic stealth requirements for the naval platforms, ship design and management issues include, e.g., to contain URN, measurement and analysis aspects and more. Section 3 brings the challenges and opportunities in the IOR at all levels, geostrategically, geopolitically and geophysically. In Section 4, we discuss the use of sound by the marine species and articulate the relevance of sound for these species. Section 5 elaborates on the acoustic habitat degradation due to shipping noise. Section 6 enumerates the regulatory provisions that exist globally and the specific limitations in the IOR. In Section 7, we conclude by giving some way ahead and leads for addressing this serious concern of acoustic habitat degradation in the IOR due to shipping noise.

\section{Underwater radiated noise}

The underwater radiated noise (URN) is the acoustic signal emitted out of a marine platform as a by-product of its operations. These operations include 
propulsion, maintaining habitability on-board, any other mission specific activities and more. The platforms may be deployed in marine environment like the coastal waters or the high seas and the freshwater systems including rivers, lakes and reservoirs. Further, we could be looking at surface platforms like warships for naval deployments and merchant vessels for commercial deployments and also subsurface platforms including submarines for naval deployments and other sub-sea submersibles for undersea explorations.

The URN emissions are broadly categorized into three components including propulsion systems (comprising of the propellers and other machinery associated with the propulsion of the platform). The second component is the auxiliary machineries required for maintaining habitability on-board, power supply and distribution, mission specific activities and more. The third component is the hydrodynamic noise associated with the flow of fluids within and outside the hull of the platform. The spectral characteristics of the URN can be defined as narrow band due to the reciprocating (corresponding to the cylinder firing rate) and rotating machineries (corresponding to the rotation rate) and broad band due to the cavitation effect in the propellers and the non-laminar flow of fluids within and outside the hull of the platform. The URN spectrum is largely low frequency with narrow band tonals seen up to $500 \mathrm{~Hz}$; however, at higher propeller speed, the broadband cavitation spectrum masks the narrow band machinery tonals and is largely seen up to $1000 \mathrm{~Hz}$ [11].

The URN management comprises of three distinct communities. The first is the naval community for whom acoustic stealth is of paramount importance, and they are willing to deploy higher resources to achieve higher stealth standards. The second is the commercial merchant marine who need to maintain low levels of URN to comply with regulatory norms for acoustic habitat degradation. The third community comprises of the ship designers and shipbuilders who need to make sure that the newer marine platforms are compliant of the regulatory norms whether for acoustic stealth or for acoustic habitat degradation. They need to establish a direct link of every stage of the ship design and building activity to the overall URN value, at the end. The acoustic stealth has been a very well-developed area of science and technology for the naval community for a long time; however, it never percolated to the other communities as it remained a closely guarded secret for ensuring military supremacy [12].

The acoustic stealth requirement has multiple dimensions to it. The acoustic signature management as it is called comprises of three distinct stages-the first stage translates to measurement and analysis to be able to maintain enhanced levels of stealth or minimal levels of acoustic signatures to avoid detection. The second stage is the precise prediction of the acoustic signature of any platform (own or from the adversary) based on the available information in the open source regarding the design and machinery details. This can greatly enhance our tactical capabilities of initiating counter measures. The third is the deception, where we fake the actual signature of the platform and try to deceive the adversary given the advent of intelligent mines that can precisely target platforms. The acoustic signature management capabilities require high resource deployment right from infrastructure of an underwater range to measurement and analysis of hardware and software. The know-how is also highly specialized in terms of algorithm design for real-time implementation to advanced signal processing capabilities. The acoustic signature management will have similar corollary for the acoustic habitat degradation assessment as well. The measurement and analysis to minimize the URN is the first stage, and the second stage will be prediction that will be required for effective policy formulation and regulatory compliance. The third stage is the deception in some form, which will be required to ensure minimizing the acoustic habitat degradation for specific species $[8,12]$. 
The second dimension of acoustic stealth management is impact on the performance of our own sensors. The self-noise of the platform that has its origin in the noise and vibration on-board (similar to the URN) impacts the performance of the own sensors. Thus, containing the self-noise is equally important to enhance the effectiveness of the platform. The third dimension is the condition-based preventive maintenance (CBPM) that has its implication on the health of the equipment and fatigue failure. Regular noise and vibration measurement and analysis on-board the platform is an integral part of the planned maintenance schedule to enhance operational efficiency and minimize failures of running machineries. Thus, noise and vibration is an important prerequisite for all the three dimensions with its origin remaining the same; however, the manifestation is different for all the three. There is a need to establish clear linkages of the noise and vibration measurement data for each of the three dimensions, while we undertake the analysis [13].

The URN management needs to be ensured right from the design stage and beyond. The naval warship design has evolved over several decades of effort, and now most of the advanced navies have very mature design and manufacturing capabilities to ensure very high acoustic stealth of its platforms. The stealth requirements for naval platforms are so stringent that it is not enough to have a good design, but also during the operations as well, the regimes of operations are so chosen that the platforms emit minimal URN. The naval platforms undergo regular stealth assessments, to evaluate the exact status of the acoustic signature under multiple machinery regimes and also to monitor any deterioration due to mechanical wear and tear. The redundancies on-board are used effectively toward ensuring enhanced stealth standards during operations based on the exact stealth assessment. The maintenance schedules and routines are planned based on diagnostic ranging to identify causes of poor stealth during operations. Post refit, the effectiveness of the maintenance schedules is evaluated based on the stealth assessment. Any mid-life upgradation of equipment and systems on-board has to undergo acoustic stealth assessment to evaluate its impact on the overall acoustic signature of the platform.

The URN measurement and analysis, normally referred as underwater ranging, is a very complex and involved process, with significant infrastructure requirement and also analysis capabilities. The NATO Standard STANAG 1136 is a framework defined by the NATO for undertaking underwater ranging of warships. The URN measurement of naval platforms is a highly classified activity, and navies have defined their own protocols of measurement and analysis that are not available in open source. The STANAG 1136 is just a broad guideline [14]. The underwater measurement has its own complexities in terms of deployment of the sensors to far field measurement requirements. The Acoustical Society of America (ASA) has its own standards for vertical sensor arrays and the measurement protocols [15]. The underwater ranges in earlier days were the fixed over-run ranges where sensors were laid horizontally, and the vessels were made to pass over them at certain depth and specified regimes of operations. The regime-wise recordings are subsequently analyzed, and inferences were drawn. The fixed sensors have their advantages of high accuracy and effective mitigation of environmental distortions; however, the infrastructure cost is prohibitive. Portable vertical ranges are being increasingly used with the advantage of low cost and reasonable deployment ease [16].

Figure 3 presents a detailed framework for URN management. The three stakeholders, namely the navy with their interest in acoustic stealth, the marine conservation community with their requirement to contain acoustic habitat degradation and the blue economic entities related to ship building and ship design, are represented by the three horizontal faces of the prism. Policy, Technology and Innovation and the Human Resource Development will remain the pillars of any 


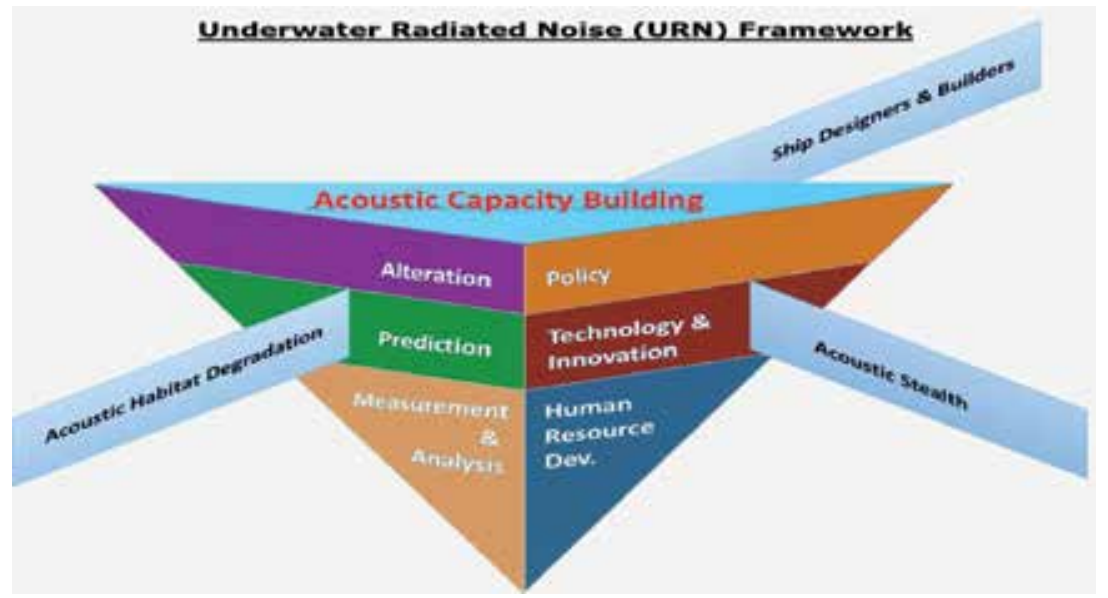

Figure 3.

URN management framework.

initiative toward URN management. The basic steps are measurement and analysis, prediction and alteration (naval community will call it deception as part of their acoustic signature management efforts). Acoustic capacity building will remain the core requirement.

\section{Indian Ocean region}

The Indian ocean region had become the strategic heartland of the 21st century, dislodging Europe and North East Asia which adorned this position in the 20th century ... the developments in the Indian Ocean region were contributing to the advent of a less Western centric and a more multi-polar world. [17]

—Donald L. Berlin, Head of Security Studies, Asia Pacific Centre for Security Studies, Honolulu, Hawaii

The twenty-first century is seeing massive strategic build up in the IOR, not just from the nations within the region but also from extra-regional powers to safeguard their strategic interests. These strategic interests range from political to economic and also militarily as a theater for great power rivalry being played out in the region. The IOR is the locus of important international SLOC for varied reasons and thus has a very unique strategic relevance [17].

Militarily, SLOC is a major maritime instrument of power, and the maritime geography dictates deployment of maritime forces. The security vulnerabilities in the IOR coupled with the strategic relevance of the SLOC ensures high deployment of maritime forces not just from the nations in the region but also by the extra-regional powers. The political interests originate from the fact that the SLOC signifies the state of relation with the nations along the sea route traversed. The choke points that govern the entry of SLOC into the region have a significant role in shaping the geopolitics of the region. Economically, the shortest route is the most important aspect for SLOC, and any disruption may call for strategic action. The socioeconomic status of nations in the region facilitates large-scale interference by the extra-regional powers, and thus rule-based regional framework is a big causality. The piracy and maritime terrorism in the region being on the rise has ensured huge presence of maritime forces to escort the SLOC, making it a high density 
shipping traffic zone. Anti-piracy measures also dictate rerouting of the SLOC, at times against the shortest route logic $[17,10]$.

The unique geography of India in the IOR and its position with respect to the international shipping lanes carrying bulk of the SLOC have not translated to having even a single transshipment hub in India. This is a major cause of suboptimal routing of shipping in the Indian subcontinent. The bulk of the seaborne trade to or from India, to or from America, East Asia, Africa, Europe and more passes through the Indian territorial waters. The ships carrying this cargo break their bulk in Colombo or in Singapore/Hong Kong. Further, the poor maritime infrastructure in terms of ports and shipyards has a significant impact on the shipping traffic in the region. The poor management of the shipping traffic is a serious cause of concern, in terms of distribution of the traffic that has a major impact on the crowding of the shipping lanes [18].

The shipbuilding industry in the Indian subcontinent has been a nonstarter for various reasons, in spite of having all the inputs necessary for a flourishing industry. Lack of strategic vision probably is the major cause of such a non-starter. Although India boasts of a glorious maritime past, but in the modern era, India has been termed as Sea Blind and has not displayed substantial maritime intent since Independence. The maritime infrastructure has been working in progress, and a huge potential is waiting to be explored and exploited. Right from specialized human resource to conducive policy framework has been a major cause of concern, and thus the contribution of the maritime sector to the GDP is in single digits. The sector not doing well also manifests as minimal investments on R\&D and strategic thinking [19].

The Indian shipbuilding industry currently accounts for only $1 \%$ of the global shipbuilding market. There are 27 shipyards in the country presently, and out of these, 19 are in the private sector. The current cumulative shipbuilding capacity of Indian shipyards is around 0.5 million deadweight tonnage. The order books of the public sector undertakings (PSUs) are completely skewed owing to high government protection enjoyed by them, whereas the private sector has been struggling due to lack of level playing field. Our shipyards are not competitive in the global market due to high cost and time overrun and archaic infrastructure and technology used. Some of the highly specialized components like the propellers and engines are still being imported at very high cost. Although we are in the major shipping routes, internationally, our shipbuilding and also ship repair industry has not been able to attract much business due to cost and quality concerns. There is serious gap in brand building and marketing as part of the national policy. As a nation, we were late in recognizing our maritime potential, and thus there is total absence of strategic vision [20].

The twenty-first century is certainly seeing a sea change in the maritime outlook for the IOR, both domestically and globally. The Indo-Pacific strategic construct is a recognition of the importance of the IOR in the global strategic space. More and more nations are deploying strategic assets in the region both militarily as well as for economic and political interests. India is being seen as a strategic partner for the global powers, specifically for the Indo part of the Indo-Pacific strategic construct. Domestically, as well, there is substantial strategic intent being displayed by successive governments. The Security And Growth for All in the Region (SAGAR) vision, announced by the Indian prime minister in May 2015, and the earlier mega initiative, named Sagarmala, are some of the critical policy announcements and affirmative action being aggressively pursued by the Indian establishment. Massive maritime capability and capacity building initiative are being given high priority including transshipment hubs, seamless multi-model connectivity and inland water transport across the river systems [21]. 
The tropical littoral waters in the IOR ensure significant challenges in the acoustic monitoring of the underwater domain. The sonars deployed for any attempt at underwater survey for effective underwater domain awareness (UDA) is grossly limited due to the sub-optimal performance. The tropical waters manifest as higher depth for the sound axis synonymous with the SOFAR channel that dictates the interaction of the acoustic propagation with the surface and the bottom. The depth of the sound axis at the equator is close to $2000 \mathrm{~m}$, in contrast to $50 \mathrm{~m}$ at the poles. Acoustically, the littoral waters are defined based on interactions with the surface and bottom boundaries; thus in the tropical waters even in water depths of $3000 \mathrm{~m}$, the underwater domain behaves like shallow waters. This means that the entire IOR is likely to be behaving like littoral waters acoustically due to tropical conditions. To top it all the tropical conditions also ensure higher surface and bottom fluctuations, and thus, the multipath propagation further translates to higher acoustic signal distortions. Thus, any attempt at acoustic habitat assessment to ascertain acoustic habitat degradation will subject to the tropical littoral limitations in the IOR [22].

The regional dynamics in the IOR has a profound impact on the geopolitical outcomes. The lack of synergy among the nations in the region and large-scale interference by the extra-regional powers have facilitated total absence of rulebased governance. The regulatory framework to manage acoustic habitat degradation and R\&D efforts to facilitate realistic acoustic habitat assessment have been a non-starter. The socioeconomic status of the nations in the region makes it politically unviable to bring regulatory frameworks to manage the marine environment effectively [23].

\section{Acoustic habitat}

The marine species use sound or acoustic signals for numerous biologically critical functions, and thus they can safely be said to possess acoustic vision as they perceive the world around them through sound. These biologically critical functions include communication (for group cohesion and coordination), navigation and exploration (for sensing the environment around), echolocation (for foraging and detection of prey), survival (avoiding predators) and many more. They may generate (vocalization) and receive (listen) sound, based on the soundscape of their habitat. Thus, acoustic habitat is critical for their well-being and survival. The vocalization and hearing is species specific and thus needs deeper understanding. The vocalization is relatively possible to monitor for varied range of species. However, the hearing of species is near impossible to monitor as the psychoacoustic study cannot be undertaken in the natural environment as the sound stimulus and its impact cannot be studied, without taking the animal into captivity. The auditory systems of smaller species that can be taken in captivity have been studied to some extent, but these animals in captivity may not respond in the same manner as in their natural habitat. Thus, such studies will have their own biases and may not reflect the true animal behavior. The vocalization in the large species like the big whales has been studied in their natural environment in a limited sense as their habitats are spread across the vast expanses of the oceans and also inaccessible in many cases. Out of the 126 sub-species of the whales (including dolphins and porpoises), only 25 have been studied for their acoustic characteristics, and most of them have only been studied for their vocalization as these are extremely large in size so cannot be taken in captivity in a lab environment [Chapters 2, 8].

Typically, it is assumed that the vocalization and the hearing have to be overlapping, with the hearing frequency band being much larger than the vocalization range. Further, it is interesting to note that some species may require hearing 
sensitivity far beyond their own vocalization to be able to detect any predatory threat through their vocalization. For example, a harbor seal may need to be able to detect the vocalization of a killer whale, though it may not vocalize in the same band. Thus, significant study is required to understand the acoustic habitat in the marine environment, both in terms of vocalization and auditory system (perception of sound) for varied marine species. The sound scape in their natural habitat will play a critical role in this study as these animals are known to adapt to their natural settings [Chapters 2, 8].

Marine animals have adapted to their acoustic habitat by developing specialized vocalization and hearing organs. The sound generated by fish is largely low frequency up to $1 \mathrm{kHz}$ that use multiple mechanisms for the same. These include [Chapters 2, 8] the following:

- Drumming that uses sonic muscles located on or near the swim bladder.

- Stridulation that uses striking or rubbing together of skeletal components.

- Hydrodynamics that uses quickly changing speed and direction while swimming.

The cetaceans have two major suborders namely Odontoceti (toothed whales) and the Mysticeti (Baleen whales) with a distinct and complex mechanism to generate and receive sound. The Odontocetes generate a variety of sounds using a complex system of air sacs and specialized soft tissues that vibrate as air moves through the nasal passage. The Mysticetes use the larynx (without the vocal cords) for sound generation. Marine vertebrates generate sound by closing their enlarged claws to create a bubble that cavitates. Snapping shrimps are known to generate sound with very high intensity using the cavitation process. Crabs are known to generate sound by drumming on the substrate with both their claws. Marine invertebrates use stridulation and rapid muscle contraction for sound generation like the spiny lobster [Chapters 2, 8].

The auditory system for acoustic perception of sound varies based on the fact that the particular marine species is exclusive water dweller or mixed. Cetaceans (exclusive water dwellers) and pinnipeds (seals, sea lions and walruses are mixed dwellers) show significant differences as the cetaceans have no external pinnae, and their ear canals are nonfunctional and narrow that are clogged with debris and dense wax. The narrow ear canal is not attached to the tympanic membrane (ear drum), thus not connected to the middle ear. In toothed whales, the lower jaw is surrounded by specialized fats which along with a thin bony area called the pan bone is known to play a critical role in channelizing the sound to the middle ear. The middle and inner ears of cetaceans are encashed in bones that are located in a cavity outside the skull. The complexity of the inner ear determines the sophistication of the auditory process [Chapters 2, 8].

In pinnipeds, the external ear flaps, or the pinnae are reduced or absent. Muscles and cartilage valve along the external ear canal function to close the ear canal to water. In general, the middle and inner ears in pinnipeds, polar bears and otters are similar to those of terrestrial mammals, and the mechanism for perception of sound is also similar. Depending on their lifestyles, some species hear best in air, whereas others hear better underwater.

The fishes have developed a unique mechanosensory (lateral line) system that senses vibration and water flow. The fish body is considered to be acoustically transparent as the density is approximately the same. The fish's body moves in concert with the traveling sound wave, and the sound gets picked up by bones in the inner ear called otoliths that are denser. The displacement/bend of the otoliths deforms 
the cilia on the hair cells located in the inner ear that is picked up by the brain as sound. Otoliths are the species-specific sensory organs, made of calcium carbonate, whose shape and size determine the acoustic characteristics of the sensed signal. The proximity of the swim bladder and the inner ear significantly determines the sensitivity to sound by the fish species. The density of the gas inside the swim bladder being lower than the fish's body and that of the seawater allows the swim bladder to deform due to sound pressure waves [Chapters 2, 8].

The acoustic characteristics of the vocalization by the marine animals that contribute to the soundscape in the underwater domain are highly species specific based on their intensity, frequency and time duration. The purpose for vocalization could vary from one-way communication signals to two-way echolocation signals for active sensing. The size of the animal also has a bearing on the acoustic characteristics, as bigger animals tend to generate low-frequency signals, whereas smaller animals tend to produce high frequency, sensitive to the mechanism of sound generation; size being comparable to the wavelength of the signal.

The large size Mysticetes produces sounds for communication over long ranges and senses the environment at low-frequency band ranging from 10 to $2000 \mathrm{~Hz}$. These large animals migrate over large areas and need to communicate over large ranges, thus use low frequency that attenuate far less. These signals are categorized as tonal calls, frequency-modulated sweeps, pulsed tonals for echolocation and broadband grunts. They use echolocation to sense the environment around them rather than for foraging. The Odontocetes use mid-to-high frequency sound in the frequency band of 1-200 kHz. These signals are categorized as broadband clicks with species-specific peak energy between 5 and $150 \mathrm{kHz}$, burst pulse click trains for echolocation used for foraging and other active sensing requirements and tonal and FM whistles for communication ranging from 1 to $25 \mathrm{kHz}$. Pinnipeds that are semi-aquatic breed produce a limited array of barks and clicks in the frequency range of $1-4 \mathrm{kHz}$ [Chapters 2, 8].

The non-toothed cetaceans have been found to be incapable of echolocation. The Odontocetes have very sophisticated sonar processing abilities with directed beams in space to locate, track and intercept prey. The fatty melon in the forehead acts as an acoustic lens to focus the acoustic beam. The freshwater dolphins like the Ganga river dolphins and harbor porpoises have been known to have very specialized clicks in the frequency range of above $100 \mathrm{kHz}$ for foraging. These animals have long beaks that form narrow beams to be able to direct high energy in the front for locating small fish for food. The sperm whales generate sonar pulses with intensity of the order of $223 \mathrm{~dB}$ underwater, which is equivalent to $160 \mathrm{~dB}$ in air, louder than a jet during take-off [Chapters 2,8].

The marine animals have evolved their vocalization and auditory system to be able to exploit the acoustic potential of the undersea domain, in spite of the severe limitation of the propagation conditions and low SNR. The natural sound from the animals is also complemented by the noise due to wind and others due to human intervention [Chapters 2, 8].

\section{Acoustic habitat degradation}

The sound scape in the marine environment is composed of two main sources. The natural source comprising of the physical activities like wind, wave, ice, rain and others and the biological sources as discussed above. The alternate source is the anthropogenic or manmade sources that primarily comprise of distant shipping, seismic surveys for oil and gas sector and the sonar transmissions for military and commercial applications. Additionally, there are industrial activities like deep sea 
mining, pile driving, dredging and many more that also contribute significantly to anthropogenic sources in the ocean [24].

The acoustic signals are the only signals that propagate effectively and efficiently underwater, so any disruption of the soundscape causes serious acoustic habitat degradation for the marine species. The marine species adapt very well to the natural sources of the soundscape in their habitat; however, the anthropogenic noise associated with the so-called human development index directly abets the acoustic habitat degradation. The rapid rise in the maritime activities has resulted in massive increase in the ambient noise having serious impact on the marine species' ability to adapt to the changes. The impact varies from minor discomfort to serious injuries and even fatalities and long-term species degradation [8].

The stressors impact the marine animal based on the acoustic characteristics of the noise ranging from the intensity, spectral content, duration, duty cycle and more. The sound propagation characteristics of the underwater medium also have a profound impact on the acoustic characteristics of the signal projected on the animal. The most important of all is the acoustic characteristics of the receptor (the marine animal likely to be impacted). Thus, a comprehensive source-path receiver model needs to be studied for a realistic assessment of the precise acoustic habitat degradation of any stressor on the marine environment. The IOR with its tropical littoral characteristics will have significant influence on the sound propagation. Certain marine species may be directly impacted, while others may get influenced through the ecosystem changes. Most of the conservation studies are species specific and have limited impact due to the dynamic interaction between the multiple components of the ecosystem and the stressors [12].

Among the stressors, the distant shipping, seismic activities due to the oil and gas industry and the sonar transmissions are considered among the primary sources of underwater noise that impact large-scale acoustic habitat degradation. Among these, the distant shipping is the single ubiquitous source of noise source that has widespread implications on the acoustic habitat degradation. The others are transient and localized in nature so can be managed to some extent. The distant shipping has the following characteristics that make it extremely complex, when we look at the management of the stressor:

a. The shipping traffic is extremely spread out to have a larger influence across multiple geographical regions and a very widespread impact as well.

b. The low frequency characteristics of the underwater-radiated noise from marine vessels suffer least attenuation while propagating in the underwater medium. Thus, the impact is spread over a large area covering thousands of kilometers. Coupled with the shipping traffic distribution, the influence is across the entire globe.

c. The shipping is directly linked to the economic growth index as over $90 \%$ of trade by volume and $70 \%$ of trade by value are carried by them. Thus, it is politically unviable for governments across the third world developing nations to bring regulations to limit underwater radiated noise (URN) from marine platforms.

d.The URN from shipping is like a slow poison that does not have any dramatic demonstration of catastrophic impact unlike the other transient sources. The increase in low-frequency ambient noise in the world oceans due to shipping has been recorded to have increased by $3.3 \mathrm{~dB}$ per decade since the $1950 \mathrm{~s}$. The 
so-called focusing event very essential for bringing regulatory provisions driven by strong public outcry does not get created due to the slow rise in the low-frequency ambient noise caused by URN [25, 26].

e. It is interesting to note that the acoustic stealth requirements for the naval vessels drives the same technologies and techniques required for managing acoustics habitat degradation. However, the absence of any regulatory provisions the profit hungry merchant marine has avoided implementing any such provisions. The humans being terrestrial animals do not see a direct impact of acoustic habitat degradation of the marine ecosystem on their well-being.

The global merchant marine fleet is directly connected to the economic engines, and so the enhanced global economic growth has translated to rise in the shipping traffic. The term "Noiseonomics" has been coined by Frisk to describe the relationship between ambient noise levels in the sea and global economic trends. His work is based on the assumption that distant shipping is the single ubiquitous source of ambient noise in the ocean, and these assumptions lead to the following hypothesis [27].

A. Hypothesis 1: Gross tonnage of the world fleet is directly correlated with lowfrequency ambient noise.

B. Hypothesis 2: The world GDP is directly proportional to the gross tonnage of the commercial shipping fleet.

C. Corollary: Ambient noise in the oceans is directly correlated with the world GDP.

The plots in Figure 4, as given by Frisk in his work, confirm that the rate of growth in all the three parameters, namely the world GDP, world fleet gross tonnage and the low-frequency ambient noise in the oceans. This closely matches with actual underwater recordings presented by Ross given above.

"Measurements of ambient noise levels, world fleet gross tonnage, and world gross domestic product are plotted as decibel (dB) quantities for the period 19502007. Linear fits to the data for all three quantities show similar slopes of $3.3 \mathrm{~dB}$ per decade with high goodness of fit $\left(\mathrm{R}^{2}\right)$ factors."

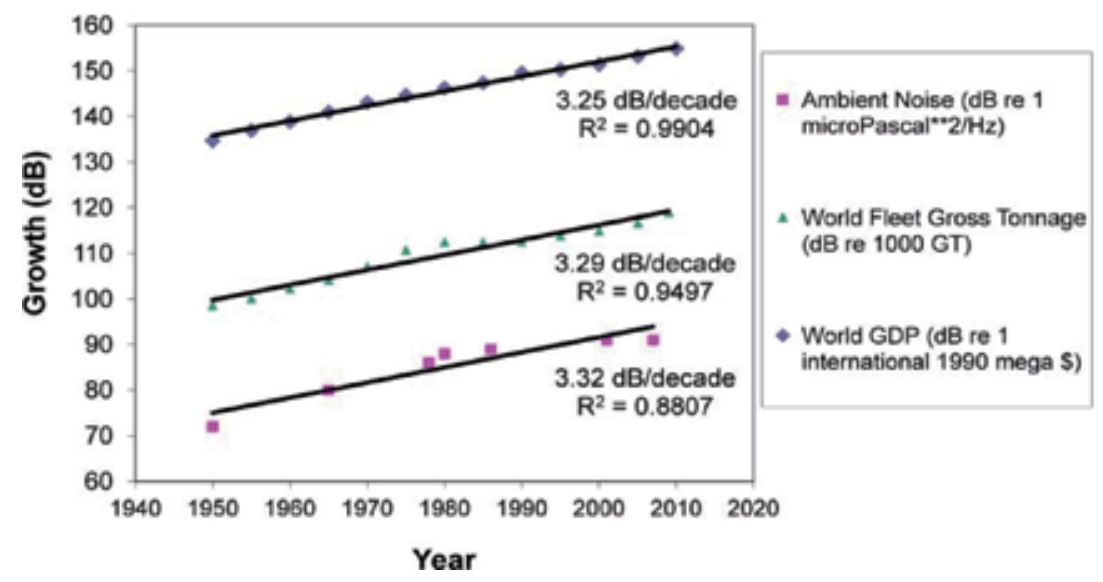

Figure 4 .

Long-term trends in ambient noise levels, gross tonnage of the world fleet, and world gross domestic product [27]. 


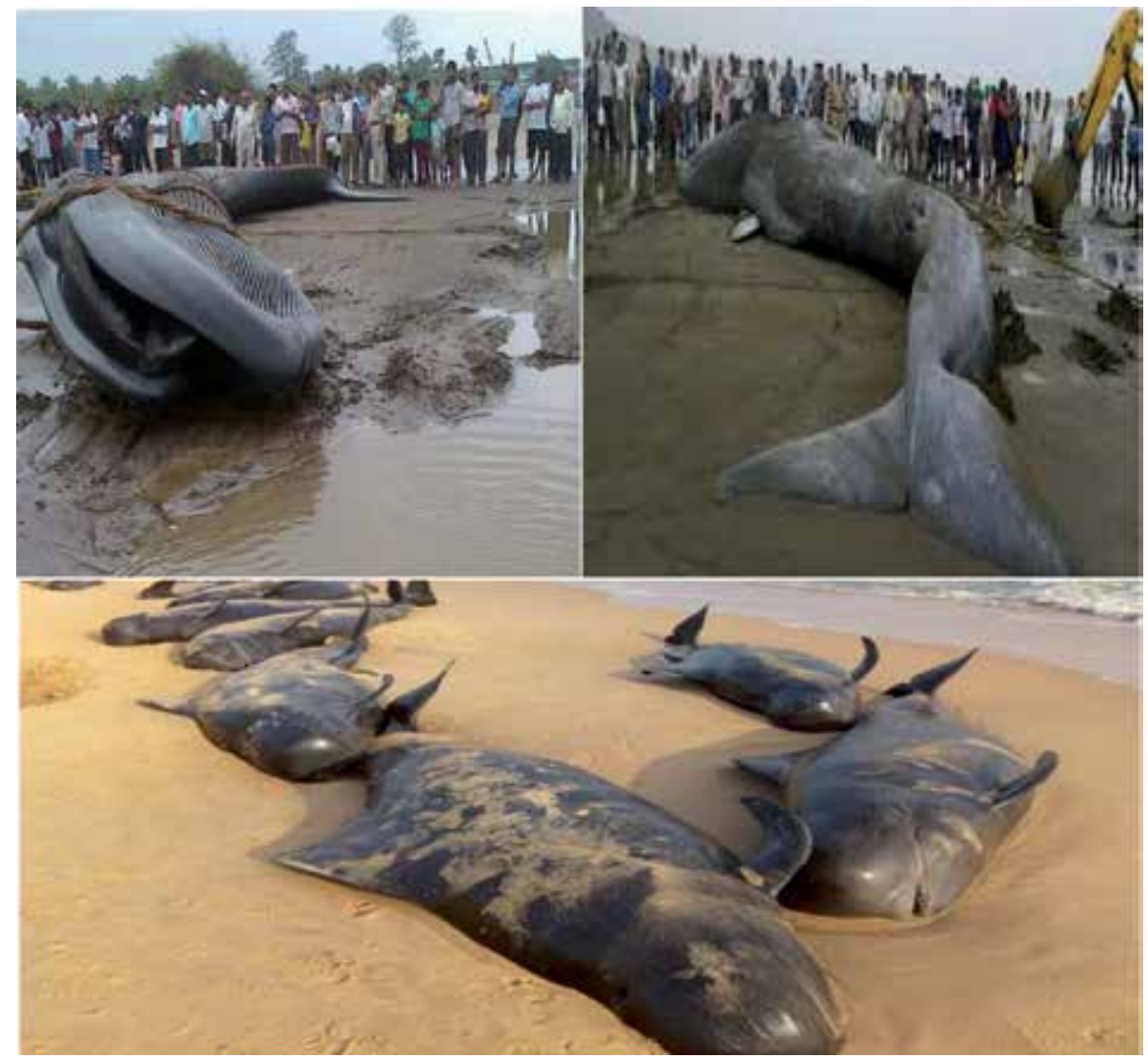

Figure 5.

Recent marine mammal stranding along the Indian coast [10]. Top left: $42 \mathrm{ft}$. Blue whale stranding off the Alibag coast in June 2015. Top left: $50 \mathrm{ft}$. Bryde whale stranding off the Mumbai coast in January 2016. Below: Over 90 short-finned pilot whales stranding off Tuticorin beach in January 2016.

The massive maritime infrastructure push in the IOR is creating unregulated activities both within and also on a regional level, thereby causing sustainability concerns in the IOR. The growing global consciousness on environmental degradation is bringing uniform regulatory frameworks across regions, and now India being a signatory to global norms may get constrained by these regulations. Acoustic habitat degradation is a major fallout of the rising maritime activities without comprehensive regulatory framework. The increasing maritime activities are also accompanied by higher noise levels in the ocean. The frequent stranding of marine mammals along the Indian coast is a manifestation of the catastrophic acoustic habitat degradation. Figure 5 presents recent incidents of stranding that is a manifestation of the severe acoustic habitat degradation. Such stranding is attributable to the navigation failure due to high ambient noise leading to disorientation [10].

\section{Regulatory framework}

The transboundary nature of the underwater noise and its variability across time and space and across the species have profound impact on any attempt at managing the acoustic habitat degradation in the underwater domain. Any attempt at regulation demands that we have precise information on the "cause and effect." While many stressors like seismic activities and sonar transmissions may 
be reasonably quantifiable to establish the cause and effect, but the URN from shipping is very complicated to establish this direct connect. The low-frequency ambient noise due to URN for distant shipping is spread across the entire ocean basin, so it is near impossible to define the jurisdiction of a nation or a region. The regional or global regulatory framework will require political consensus among all the stakeholders, which is a very difficult task given the diverse socioeconomic and geopolitical realities [28].

The URN has been recognized as a pollutant way back in 1982 under the United Nations Convention on the Laws of the Seas (UNCLOS). The substance vs. energy debate has also been put to rest under the UNCLOS that is ratified by 168 countries by now. The UNCLOS did declare the hazards of noise on the marine mammals and stated that it had a deleterious effect on them. However, even today, it has failed to announce regulatory framework on tackling noise in the ocean. The complexities of URN measurement and the infrastructure requirement for the same are extremely prohibitive for the developing world to accept it particularly when the shipping industry is going through a global down-turn [12].

The Marine Strategy Framework Document (MSFD) proposed by the European Union is by far the most forward looking international agreement to manage the acoustic habitat degradation issue so far. It considers multiple anthropogenic stressors and their potentially cumulative effect, giving more stress on ecosystem-based approach toward managing maritime activities. The stated objective is to achieve and maintain "Good Environmental Status" by 2020, measured by 11 descriptors, out of which the 11th one refers to underwater noise. URN management is getting far more attention under the MSFD, and more R\&D-based regulatory aspects are being encouraged. There are multiple other regional initiatives originating in Europe like the Helsinki Commission (HELCOM), OSPAR Convention, ASCOBANS, ACCOBAMS, etc., that do address the issue of noise in the oceans. However, it is important to recognize the trans-boundary nature of noise and the limited effect in the absence of larger regional and global initiatives [28].

The Marine Mammal Protection Act (MMPA) was probably the first regulation to recognize and implement the precautionary principle for the marine environment. In 1972, the MMPA in the United States recognized the harm caused by noise to marine mammals and mandated that activities in the oceans have to contain their energy (acoustic) emission into the water. The International Maritime Organization (IMO) in its protocol of 1978 (MARPOL) addresses the aspect of marine pollution from ships through its six annexures. The MARPOL fails to recognize noise as a pollutant being in energy form and only defines substance pollution (oil, noxious liquid substances, harmful packaged substances, sewage, garbage and air pollution). More recently, it has declared certain vulnerable areas as particularly sensitive sea areas (PSSA), where noise from the ships is recognized as a hazard and bars the ships from these areas in order to protect the acoustic habitat. However, in the open ocean, IMO fails to regulate the noise from the growing shipping traffic. The International Whaling Commission (IWC) does recognize the adverse impact of noise on the whales from the whale watching vessels and others. However, it fails to formulate an effective policy for protecting the whales from noise in the ocean [12].

The challenge of environmental conservation, rather management of the commons, has far greater complexities particularly in the developing world due to what we refer as the "Tyranny of Small Decisions." This concept was first explored in the context of economics by Alfred E Kahn, who highlighted the fact that a number of small decisions, individually small in size and time perspective, cumulatively generate an outcome that is neither optimal nor desired. He brought out that market economies commonly commit this, leading to market failure. The findings were extended to other areas like environmental degradation, political elections and 
health by many other scholars. The underwater environment more specifically the acoustic habitat degradation, a late entrant to the entire environmental debate, is a very fit case to apply these concepts for holistic management of the entire issue [8].

The ocean noise regulation has significant scientific uncertainties, management limitations and regulatory complexities. The Marine Mammal Protection Act (MMPA) 1972 was one of the most progressive regulations of its times with the precautionary principle as the guiding environmental framework. The MMPA covered whales, dolphins, porpoises and other marine mammal species; however, even after so many decades, over 20 species from the great blue whale to the Hawaiian monk seal are still considered endangered and threatened. The failure of any regulatory provision has multiple political, economic, social, scientific and managementrelated attributes [Chapters 5, 8].

The first and foremost issue that made the act meaningless was the exemptions, as the Defense Authorization Act gave far too many exemptions for multiple military deployments related to sonars and numerous other use of underwater sound in the name of national security. The peak of the Cold War ensured that the US Navy had numerous operational naval deployments and also research and training projects with heavy use of underwater transmissions for Anti-Submarine Missions against their adversary namely the Soviets. The second aspect was the noise criterion itself that could not cover the large number of marine species with very unique auditory features. The regulatory provisions necessitate robust noise criterion; however, the diverse marine species are very hard to map in terms of their hearing characteristics. Further, in the absence of detailed psycho-acoustic study across the species, the precise cause and effect cannot be established. The absence of firm noise criterion also makes it open to exemptions in the court of law even for commercial activities, especially in the developing nations with least political will for environmental concerns against the socioeconomic demands. The tropical littoral water in the IOR makes the medium impact far more severe to establish the source-path receiver model for formalizing the noise criterion. The resource limitations ensure that field experiments are too few and far in-between to be able to establish the noise criterion for the indigenous species in the local water. Ecosystem approach has always been a causality, as it is highly resource intensive and also requires high-end and sustained research efforts. Species-specific conservation efforts can never map the cause and effect in a complex and high biodiversity habitat with very intricate interplay of exchange among the species [Chapters 5, 8].

The regulatory provisions that exist so far have been able to address the instantaneous noise sources like seismic surveys, sonar transmissions, underwater explosions and others. However, the transboundary nature and the slow manifestation of the shipping noise have very unique challenges to establish the precise cause and effect and also the noise criterion. The cumulative impact is not only hard to prove but also impossible to implement. The time and resource constraint on the regulatory authority to undertake a scientifically logical experiment to establish biologically significant and population level impact is never enough. Further, in the absence of a credible noise criterion that addresses all species and all sources, it is a non-starter. The transboundary and the widespread impact (due to low frequency of the URN) brings complications of legal jurisdiction on regulatory provisions. National authorities cannot unilaterally bring regulations, and regional cooperation involves geopolitical challenges of diplomacy and international relations. Socioeconomic diversity, political factors, extra-regional power play and others complicate regional cooperation. The IOR is a mix of all kinds of physical, economic, political and geo-strategic factors making it a fragmented regional dynamics with significant interference by the extra-regional powers [Chapters 5, 8]. 


\section{Way ahead}

The formulation of way ahead for any crisis is the precise assessment of the degradation. In this case, we may refer as the environmental impact assessment (EIA) for the shipping in the IOR. The author has undertaken two critical work to establish the EIA, specific to this requirement. The first work pertains to the spatiotemporal low-frequency ambient noise mapping in the IOR using automatic identification system (AIS) data for shipping. The spatiotemporal low-frequency ambient noise map provides the precise levels of the anthropogenic noise due to shipping in the IOR. This is the first comprehensive assessment of the noise levels with a qualitative and quantitative description. The quantitative assessment provides the $\mathrm{dB}$ levels of anthropogenic noise in the IOR, based on the shipping traffic in the region and also keeping the medium fluctuations into account to make it an authentic in-situ assessment. The qualitative assessment pertains to the spatiotemporal changes based on the varying shipping traffic and the medium fluctuations across the entire region. The $\mathrm{dB}$ levels can be updated real time for any applications ranging from policy formulation, local management of the conservation efforts and more. The Figure 6 provides the spatiotemporal low-frequency ambient noise map for the IOR as discussed [12].

The second work pertains to the real impact assessment of the shipping traffic and some policy decisions pertaining to the security concerns namely the antipiracy measures. The on-ground assessment of the increase in the low-frequency ambient noise levels and the manifestation on the big whales have been presented in the work. The real recordings have been compared with previously reported work to present the precise ground situation and also correlation with the recent stranding incidents in the IOR. A detailed cause and effect assessment along with in-depth analysis has been presented to give a sense of the actual seriousness of the concern. Figure 7 above gives the recent hike in the stranding in the IOR and how it can be attributed to the increased shipping traffic in the region [10].

The two works above make it amply clear that all is not well, and very urgent steps are required to be initiated, to contain the crisis and manage the larger acoustic habitat degradation issue in the IOR. Given the specific challenges of the IOR - politically, socioeconomically, scientifically and otherwise-it is extremely important that we bring in a framework that addresses the entire issue very comprehensively. The author has been progressing a unique underwater domain awareness

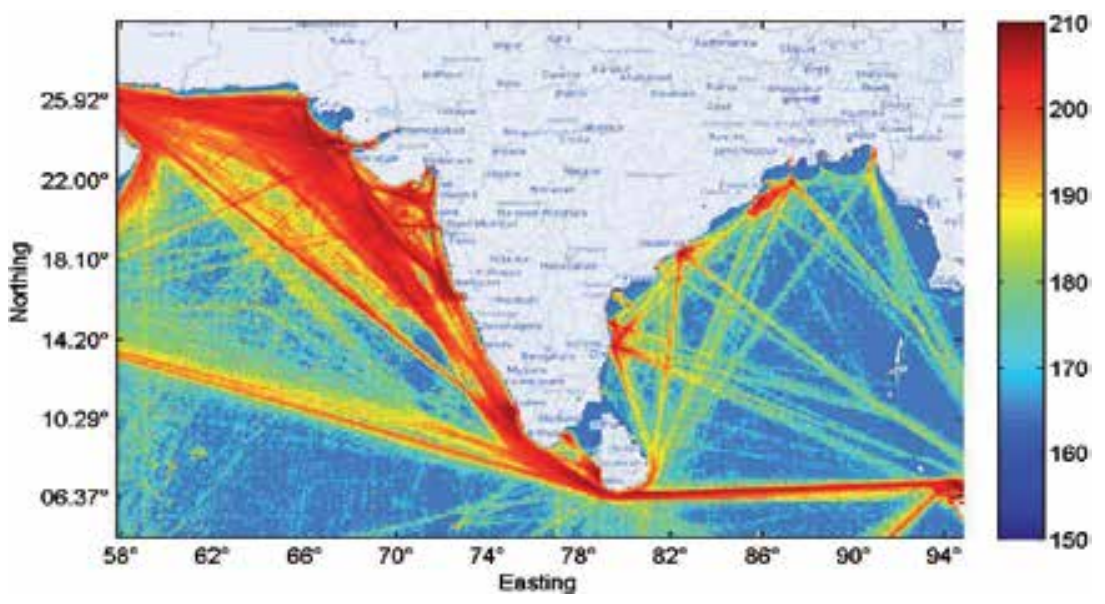

Figure 6.

Spatial noise mapping for IOR (noise in $\mathrm{dB}$ re $1 \mu \mathrm{Pa}^{2}$ ) [12]. 


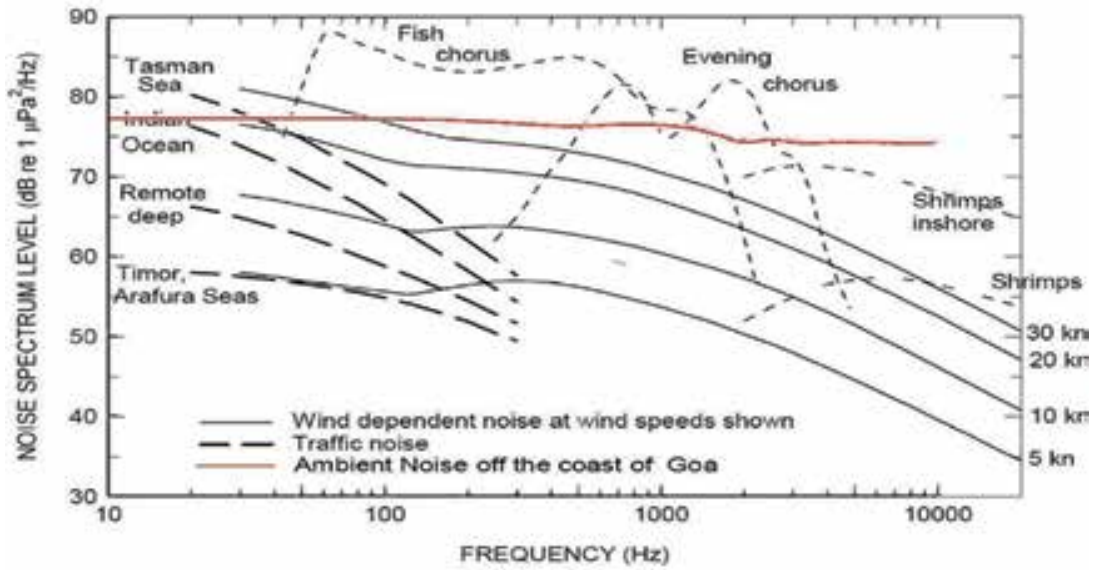

Figure 7.

Ambient noise comparison across different sea and Indian Ocean recordings over a decade. Recent data (in red) recorded off the west coast of India closer to the stranding area in 2010 post the anti-piracy measures is compared with recordings a decade earlier [10].

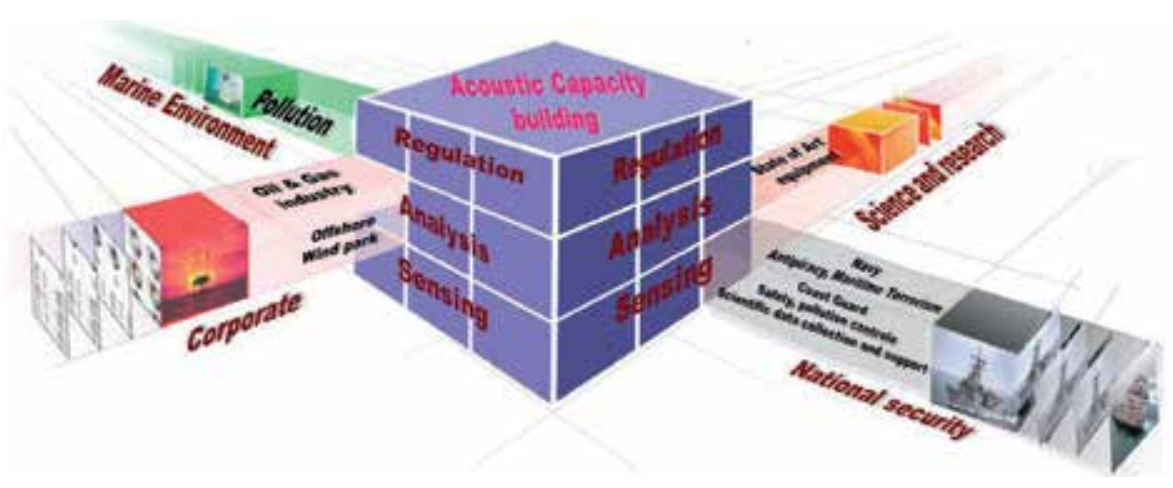

Figure 8.

Comprehensive perspective of undersea domain awareness [29].

(UDA) framework that could potentially address all the challenges mentioned above. The UDA framework largely addresses the critical issues of pooling of resources and synergizing of efforts across stakeholders to take care of the resource limitations in the developing world and also bring in efficiency and effectiveness. It is completely aligned with the local challenges and strategic vision of the dominant local authorities. Figure 8 gives a broad overview of the UDA framework as proposed by the author [29].

More specifically, there is a need to initiate an effective URN management plan that comprehensively takes care of all issues pertaining to the problem at large and also the local challenges of the IOR. It is ironical that the acoustic stealth is such a critical component of the military deployment in the underwater domain; however, the same has not percolated to the merchant marine for narrow commercial interests. The stealth technology has seen quantum jump during the Cold War era, and thus the know-how to undertake effective URN management does exist. However, in the absence of statutory regulatory provisions, the commercial shipping industry has managed to avoid these measures. Such actions (aptly described by the "Tyranny of Small Decisions") have brought us to a very critical state of affairs, and urgent measures are now required to save even the human kind. Acoustic habitat 
degradation has reached monstrous proportions. Hazards of underwater noise, though recognized way back in 1972, however concrete steps are still awaited more than 4 decades later. While we want to formulate the way forward, the following aspects merit attention:

a. Massive awareness drive is required across the stakeholders and policy makers. The humans being terrestrial animals feel that there is no direct impact on their well-being. However, it may be known that acoustic habitat degradation has grown in monstrous proportion to impact sustainable maritime growth for all.

b.URN management across the military community for stealth as well as the merchant marine community for acoustic habitat degradation in the IOR requires a very strategic approach. Synergizing technology development and human resource development for the two communities may have rich dividends. A national and regional URN policy is required to be formulated for India and the IOR. India being a dominant power in the region should take the lead and bring cogent regulatory framework to address the issue of URN management in a comprehensive manner.

c. The UDA framework as discussed could be the overarching concept to address the specific IOR challenges. The IOR has become a geo-strategic space not just for the nations in the region but also for global powers far removed geographically. Pooling of resources and synergizing of efforts as proposed in the UDA framework is the only way forward.

d.All three aspects of policy, technology and innovation and human resource development will require massive efforts to be able to address the serious concern of acoustic habitat degradation in the IOR. The massive maritime infrastructure development push for harnessing the blue economic potential needs to be equally backed by the efforts to manage the acoustic habitat degradation concerns, to facilitate sustainable growth.

e. Significant research efforts to understand the local characteristics in the IOR will be required to establish the source-path receiver model more accurately to be able to precisely ascertain the EIA due to the ever increasing shipping in the region.

f. The precautionary principle has to be the driving concept, as it is not possible to directly establish the cause and effect. Shipping, being the only ubiquitous source of ambient noise source in the ocean and being low frequency, has its own challenges and needs to be addressed accordingly. 


\section{Author details}

Arnab Das

Maritime Research Centre, Pune, India

*Address all correspondence to: arnabdas1972@hotmail.com

\section{IntechOpen}

(C) 2019 The Author(s). Licensee IntechOpen. This chapter is distributed under the terms of the Creative Commons Attribution License (http://creativecommons.org/licenses/ by/3.0), which permits unrestricted use, distribution, and reproduction in any medium, provided the original work is properly cited. (cc) BY 


\section{References}

[1] Environmental Degradation and Social Integration. UNRISD Briefing Paper No. 3 World Summit For Social Development. 1994. Available at: http:// www.unrisd.org/80256B3C005BCCF9/ (httpAuxPages)/52B8B9CA21978473802 56B65004C9CC9/\$file/bp3.pdf

[2] UNEP/GPA. The State of the Marine Environment: Trends and Processes. The Hague: UNEP/ GPA; 2006. Available at: https:// wedocs.unep.org/bitstream/ handle/20.500.11822/12469/global_soe_ trends.pdf? sequence $=1 \&$ is Allowed $=y$

[3] The Ocean and the Sustainable Development Goals under the 2030 Agenda for Sustainable Development, Regular Process for Global Reporting and Assessment of the State of the Marine Environment, Including Socioeconomic Aspects, A technical abstract of the First Global Integrated Marine Assessment. 2017. Available at: https://www.un.org/depts/los/ global_reporting/8th_adhoc_2017/ Technical_Abstract_on_the_Ocean_ and_the_Sustainable_Development Goals_under_the_2030_Agenda_for_ Susutainable_Development.pdf

[4] World Bank and United Nations Department of Economic and Social Affairs. The Potential of the Blue Economy: Increasing Long-Term Benefits of the Sustainable Use of Marine Resources for Small Island Developing States and Coastal Least Developed Countries. Washington DC: World Bank; 2017. Available at: https://sustainabledevelopment. un.org/content/documents/15434Blue EconomyJun1.pdf

[5] World Ocean Review 3, Living with the Oceans - 2014, Marine Resources Opportunities and Risks. Available at: https://worldoceanreview.com/ wp-content/downloads/wor3/WOR3_ english.pdf
[6] Harland EJ, Jones SAS, Clarke T. SEA 6 Technical Report: Underwater Ambient Noise. Produced by QinetiQ as part of the UK Department of Trade and Industry's offshore energy Strategic Environmental Assessment programme. 2005. Available at: https://assets.publishing.service. gov.uk/government/uploads/system/ uploads/attachment_data/file/197303/ SEA6_Noise_QinetiQ.pdf

[7] Available at: https://www.nap.edu/ openbook/0309085365/xhtml/images/ p20007774g195001.jpg

[8] Das A. Marine Eco-Concern and its Impact on the Indian Maritime Strategy. Pune, India: MRC Press; 2017. Available at: http://indianmaritimefoundation. org/mrcl

[9] Das A, Varma DSP. Ocean governance in the Indian Ocean region - An alternate perspective. Maritime Affairs: Journal of the National Maritime Foundation of India. 2015;11(1):47-65. DOI: 10.1080/09733159.2015.1029724

[10] Das A. Impact of maritime security policies on the marine ecosystem. Maritime Affairs: Journal of the National Maritime Foundation of India. 2016;12(2):89-98. DOI: 10.1080/09733159.2016.1246751

[11] Urick RJ. Principles of Underwater Sound. 3rd ed. New York: McGraw-Hill; 1983

[12] Das A. Underwater radiated noise: A new perspective in the Indian Ocean region. Maritime Affairs: Journal of the National Maritime Foundation of India. 2019;15(1):65-77. DOI: 10.1080/09733159.2019.1625225

[13] Crocker MJ. Handbook of Noise and Vibration Control. John Wiley \& Sons, Inc; 2007

[14] NATO - STANAG 1136 Standards for Use When Measuring and Reporting 
Radiated Noise Characteristics of Surface Ships, Submarines, Helicopters, etc. in Relation to Sonar Detection and Torpedo Acquisition Risk. 1995. Available at https:// standards.globalspec.com/std/165070/ STANAG\%201136

\section{[15] ANSI/ASA S12.64-2009/Part 1} (R2014). Quantities and Procedures for Description and Measurement of Underwater Sound from Ships - Part 1: General Requirements. Available at https://webstore.ansi.org/Standards/ ASA/ANSIASAS12642009PartR2014

[16] Vice Admiral GM Hiranandani (Retd), "Indian Navy: Underwater Ranges”, Issue Book Excerpt: Transition to Guardianship: The Indian Navy 1991-2000 | Date: 18 May 2018. Available at: http://www. indiandefencereview.com/spotlights/ indian-navy-underwater-ranges/

[17] Essays UK. Geostrategic Importance of Indian Ocean. 2018. Retrieved from: https://www.ukessays.com/essays/ history/geo-strategic-importance-ofthe-indian-ocean-region-history-essay. php?vref $=1$

[18] Velpula M. For a Transhipment Hub in India - Vizhinjam Holds the Maximum Potential to be the Next Big Transhipment Hub. Mumbai, India: The Economic Times, Opinion Piece; 2007. Available at: https://economictimes. indiatimes.com/for-a-transshipmenthub-in-india/articleshow/2461859.cms

[19] Sinha R et al. How India Can Capture $10 \%$ of World Shipbuilding Market in Next 10 Years", TERM PROJECT Gp 10 - SML 710. Delhi, India: Department of Management Studies, IIT Delhi; 2010. Available at: https://www.academia.edu/7743302/ How_India_can_Capture_10_of_World_ Shipbuilding_Market?email_work_ card=interaction_paper

[20] Krishnan SN. Prosperous Nation Building through Shipbuilding. National maritime Foundation as part of the Admiral A K Chatterji Fellowship. Available at: https://www.scribd.com/ book/311484549/Prosperous-NationBuilding-Through-Shipbuilding

[21] Das A. Underwater Domain Awareness in the Indo-Pacific. Perspective May 2019, Geopolitics. Available at: https://reader.magzter. com/preview/qb7e9bqxpj8xlr4vszqwul3 445780/344578\#page/2

[22] Das A. New perspective for oceanographic studies in the Indian Ocean region. Journal of Defence Studies. Jan 2014;8(1)

[23] Das A, Bangara S. Underwater Domain Awareness and Acoustic Capacity Building - A Maritime Security Perspective in the Indian Ocean Region. 2019. Available at: https://bharatshakti. in/underwater-domain-awareness-andacoustic-capacity-building-a-maritimesecurity-perspective-in-the-indianocean-region/

[24] Arnab Das, "Regulatory framework for acoustic habitat degradation in the Indian Ocean region", CASS Journal. 2016;3:11-23

[25] Ross D. Trends in Merchant Shipping (1969-1980). Report No. TT-SD-449-75-1. San Diego, CA: Tetra Tech, Inc; 1975

[26] McDonald MA, Hildebrand JA, Wiggins SM. Increases in deep ocean ambient noise in the Northeast Pacific west of san Nicolas Island, California. The Journal of the Acoustical Society of America. 2006;120:711-718

[27] Frisk GV. Noiseonomics: The relationship between ambient noise levels in the sea and global economic trends. Scientific Reports. 2012;2:437. DOI: $10.1038 /$ srep00437

[28] Erbe C. International regulation of underwater noise. Acoustics Australia. 2013;41(1):12-19 
Acoustic Habitat Degradation Due to Shipping in the Indian Ocean Region DOI: http://dx.doi.org/10.5772/intechopen.90108

[29] Das A. Underwater Domain

Awareness: A New Paradigm For The

Indian Ocean Region. Delhi, India:

Salute Magazine; 2018. Available at: https://salute.co.in/underwaterdomain-awareness-a-new-paradigmfor-the-indian-ocean-region/ 



\title{
Methane, Microbes and Models in Amazonian Floodplains: State of the Art and Perspectives
}

\author{
Dayane Juliate Barros, Marília de Souza Bento, \\ Murilo de Souza Ferreira, Janaina Braga do Carmo, \\ Rogério Hartung Toppa, Vania Neu, \\ Maria Bernadete de Amâncio Varesche, \\ Paula Benevides de Morais \\ and Acacio Aparecido Navarrete
}

\begin{abstract}
Amazon floodplain ecosystems include open water and intermittent flood forest and agricultural systems with different water types. They are a significant natural source of methane $\left(\mathrm{CH}_{4}\right)$ in the tropics. When soils are flooded and become anoxic, $\mathrm{CH}_{4}$ is produced by methanogenesis, while microbially mediated aerobic and anaerobic oxidation of $\mathrm{CH}_{4}$ serves as the primary biological sink of this greenhouse gas. Measurements of rates and controls on $\mathrm{CH}_{4}$ production and emission in the Amazon basin mainly come from studies on individual wetlands and floodplain lakes. Similarly, microbial communities in those Amazon floodplain habitats have been studied on individual lakes based on sequence-specific DNA analysis. Existing biogeochemical ecosystem models of $\mathrm{CH}_{4}$ from the Amazon floodplains focus on soil properties or involve factors such as $\mathrm{pH}$, redox potentials, or substrates. None of these models incorporate appropriate seasonal inundation; neither the microbiota does it as a component. In this sense, our chapter will highlight how the important efforts already contributed to understand the $\mathrm{CH}_{4}$ emission and its connections with abiotic and biotic factors in Amazon floodplains, as well as emphasize the need of encouraging cooperation and exchange of experience between research teams by using different approaches and scientific methods.
\end{abstract}

Keywords: methane emission, methanogenesis, methanotrophy, mathematical modeling

\section{Introduction}

The Amazon rainforest, well known for its vast biodiversity, is a unique ecosystem and plays an irrefutable role in the maintenance of global ecosystem services. The Amazon biome is one of the main contributors to the biogeochemical functioning of the terrestrial system [1]. A contributor to this functioning is the soil, which 
is considered one of the most complex and variable environmental compartments. The understanding of microbially mediated biogeochemical processes in this compartment is of particular interest in continental floodplains, where nutrient cycling is highly responsive for floating hydrology, and the gases produced in the soil may influence the global climate change [2].

Methane $\left(\mathrm{CH}_{4}\right)$ is one of the most important greenhouse gases (GHG). Amazonian wetlands are considered a significant source of $\mathrm{CH}_{4}$ emissions. In addition to the positive emission of GHG such as $\mathrm{CH}_{4}$, the wetlands provide a diverse range of vegetation that enables the sequestration of organic carbon.

Arguably, the most striking variation in the nature of the forests in the Amazon floodplains system is related to seasonal flooding. Variations in the level and flow of water, along with variations in temperature and sediment load, for example, are the most important factors to guide the structure and functioning of flood systems $[3,4]$. The flood pulse, responsible for the change in soil saturation, makes those areas predisposed to the activity of the anaerobic microbial community. In the absence of electron acceptors, $\mathrm{CH}_{4}$ is the final product of anaerobic decomposition of organic matter. The anaerobic oxidation of $\mathrm{CH}_{4}$ may occur in the presence of some of these electron receptors (iron, manganese, and sulfate) and nitrogenous forms (nitrite and nitrate).

Given the recent recognition of the importance of Amazonian floodplains for the global dynamics of the $\mathrm{CH}_{4}$ cycle, we emphasize the essential role of information from these systems as a key factor for the amelioration of $\mathrm{CH}_{4}$ emission models. Thus, microbiota data combined with in situ observations can successfully lead to new approaches of $\mathrm{CH}_{4}$ emission models for these ecosystems. This review first addresses the soil microbiota and the mechanisms related to them as part of the dynamics of the $\mathrm{CH}_{4}$ cycle. The initial topics include microbial characteristics, mainly of saturated systems (e.g., anaerobic metabolism and interactions with metals). The chapter synthesizes studies that assessed possible consequences regarding changes in hydrology caused by climate change. Subsequently, a synthesis of the different integrated approaches is reported: biogeochemistry, isotope, and soil metagenomics, revealing the importance of interfacing different methodologies to develop a more trustworthy representation of that system. The chapter ends by identifying the knowledge on the emission models in Amazonian floodplains, as well as suggests the incorporation of new variables into those models.

\section{Biogeochemical cycle of $\mathrm{CH}_{4}$}

Global biogeochemical cycles are mainly driven by microorganisms that feed on base compounds of carbon (C), such as $\mathrm{CH}_{4}$ or carbon dioxide $\left(\mathrm{CO}_{2}\right)$ [5]. The $\mathrm{CH}_{4}$ is the most abundant hydrocarbon in the atmosphere [6]. Due to its absorption characteristics, $\mathrm{CH}_{4}$ manifests positive radiative forcing, being a GHG that contributes to the regulation of temperature on the surface of the planet. It is believed that $\mathrm{CH}_{4}$ is responsible for $17 \%$ of global warming [7], taking into account the indirect chemical reactions of this gas with aerosols. The Global Warming Potential (GWP) of $\mathrm{CH}_{4}$ is estimated to be 25 times higher than the GWP of $\mathrm{CO}_{2}[8,9]$ on a 100 -year horizon.

The interest in estimates of $\mathrm{CH}_{4}$ emission in tropical forests has grown in recent years, particularly in wetlands such as the Amazon basin [10-15] and Pantanal [16-18]. This is due to the fact that the largest natural sources of $\mathrm{CH}_{4}$ are wetlands [19], contributing with 177-284 $\mathrm{Tg} \mathrm{CH}_{4}$ per year [7]. Humid areas are the largest and most uncertain sources of $\mathrm{CH}_{4}$ to the atmosphere [20]. Remote sensing techniques employing visible, infrared and microwave observations offer varying degrees of success in providing quantitative estimates of wetlands and inundation 
extent and monitoring natural and anthropogenic variations in these environments [21]. Another factor that may contribute to this uncertainty is the interannual variability of the water column associated to lakes and rivers, which directly influence the wetlands linked to them.

Wetlands have high $\mathrm{C}$ sequestration and store capacity, which justify the growing interest in studying the production and consumption of this gas in these ecosystems. The $\mathrm{C}$ sequestration refers to the removal of $\mathrm{CO}_{2}$ from the atmosphere, transfer, and accumulation of that gas in the flooded areas as soil organic matter. That is, the sequestration of $\mathrm{C}$ in wetlands is related to the photosynthetic removal of $\mathrm{CO}_{2}$ by producing organisms and its conversion into cellulose and other forms of $\mathrm{C}$, and subsequently the transformation of waste into soil organic matter [22]. This ability to act on the $\mathrm{C}$ cycling, in addition to all other ecosystem services performed by those environments, makes them critical components in understanding local, regional, and global $\mathrm{C}$ stocks, capable of influencing the balance of $\mathrm{CO}_{2}, \mathrm{CH}_{4}$, and other GHG.

Floodplains are defined as environments that are seasonally flooded or saturated due to rising groundwater or surface water and remain like that for a certain period of the year or throughout the year [3]. According to Junk et al. [3], flooding of plains along rivers tends to occur as a single annual flood pulse that lasts months. In these plains, flooding can also lead to an increase in allochthonous inputs of $\mathrm{C}$, making them essential to the food web and interesting to the scientific community.

The $\mathrm{CH}_{4}$ is produced mainly by microorganisms belonging to the domain Archaea in the final stage of organic matter fermentation in anaerobic environments [23], which play a crucial role in the biodegradation of organic matter [24]. However, only a fraction of the produced $\mathrm{CH}_{4}$ is emitted into the atmosphere. Microorganisms that oxidize $\mathrm{CH}_{4}$, which are known as methanotrophic bacteria use the other part. There is no consensus in the literature on the percentage of $\mathrm{CH}_{4}$ assimilated by these microorganisms. There are estimates that $10-100 \%$ of the $\mathrm{CH}_{4}$ produced by anaerobic microorganisms are oxidized into $\mathrm{CO}_{2}$ before reaching the atmosphere [25].

Part of the current understanding of the dynamics of $\mathrm{CH}_{4}$ in wetlands is based on the premise that most of the oxidation of $\mathrm{CH}_{4}$ occurs under aerobic conditions. However, recent studies indicate the action of several other electron acceptors (alternative to sulfate under aerobic conditions) in the anaerobic oxidation of $\mathrm{CH}_{4}$, including nitrate, nitrite, iron, and manganese [5, 26-32]. Studies also point to humic substances acting as a terminal acceptor for electrons in tropical flood areas [33]. In previous studies $[32,34]$, when attempting to justify the predominance of academic papers addressing the oxidation of $\mathrm{CH}_{4}$ exclusively by aerobic means, taking into account the fact that sulfate has been, for a long time, the only electron acceptor involved in the oxidation of $\mathrm{CH}_{4}$ in anoxic environments, the concentration of sulfate is generally too low in freshwater environments to play a role in the anaerobic oxidation of $\mathrm{CH}_{4}$. The contribution of anaerobic oxidation of $\mathrm{CH}_{4}$ to the methanotrophic processes is not fully elucidated, but the increasing number of papers validating the information shows that this mechanism seems to be more common than previously thought.

In turn, methanogenesis occurs when energetically favorable electron acceptors such as oxygen, nitrate, sulfate, and iron are absent or have been depleted [35]. In the absence of oxygen, the complete decomposition of complex organic compounds requires syntrophic system interactions in individual steps in the global process [36]. A sequential action involves hydrolysis, acidogenesis, acetogenesis, and methanogenesis steps [37]. Therefore, the many microbial guilds involved in those processes include hydrolytic, syntrophic fermentative, acetogenic, and methanogenic microorganisms. 
Bacteria and fungi are responsible for breaking down complex molecules during hydrolysis, such as polysaccharides, proteins, and their forming units (amino acids, fatty acids, and alcohols) [38]. In the acidogenesis stage, fermentative microorganisms convert simple substrates into volatile fatty acids (VFA) (e.g., acetate, propionate, and butyrate), alcohols (e.g., ethanol and butanol), $\mathrm{H}_{2}$, and $\mathrm{CO}_{2}$ [39]. In acetogenesis, the VFA and alcohols produced, such as propionate, butyrate, and ethanol, are converted into acetate, $\mathrm{H}_{2}$, and $\mathrm{CO}_{2}$ by acetogenic bacteria [39]. Finally, methanogens convert acetate, $\mathrm{H}_{2} / \mathrm{CO}_{2}$, formate, and methylated compounds into $\mathrm{CH}_{4}$.

\section{The microbiota involved in the cycling of $\mathrm{CH}_{4}$}

The amount of $\mathrm{CH}_{4}$ emitted from an ecosystem is the result of the balance between the production of $\mathrm{CH}_{4}$ (methanogenesis) and the consumption (oxidation) of this gas (methanotrophy). Therefore, the emission of $\mathrm{CH}_{4}$ into the atmosphere is determined by activity of methanogenic and methanotrophic microorganisms.

Methanogenic Archaea are widely ubiquitous in nature and have been detected in a wide range of environments, including freshwater sediments, hypersaline and rice lakes, anaerobic digesters, permafrost, and landfills, among others. They have a unique enzyme designed methyl-coenzyme $\mathrm{M}$ reductase (Mcr), which makes them specialized in producing $\mathrm{CH}_{4}$ [39]. This group of microorganisms presents high diversity in morphology and physiological parameters [40].

The methanogenic microorganisms belong to the Euryarchaeota phylum and until recently were classified into seven orders (Methanobacteriales, Methanococcales, Methanomicrobiales, Methanosarcinales, Methanocellales, Methanopyrales, and Methanomassiliicoccales). The discovery of the genes involved in methanogenesis in Bathyarchaeota and subsequently Verstraetearchaeota led to a paradigm shift, demonstrating that the evolutionary origin of methanogenesis is prior to the phylum Euryarchaeota [41].

The metabolism of methanogenic Archaea gains energy by reducing C compounds (e.g., $\mathrm{CO}_{2}$, formate, acetate, methanol, ethanol, methylamines, and methyl sulfides) to $\mathrm{CH}_{4}$ [23]. Thus, traditional methanogenic strains are widely characterized as hydrogenotrophic, acetoclastic, and methylotrophic based on the use of substrate. In most cases, the methane-producing pathways in the environment are determined by DNA sequencing of the corresponding methanogenic microorganisms [39]. The final step in all of these pathways is common and involves the conversion of methyl-S-CoM into $\mathrm{CH}_{4}$ by methyl-coenzyme $\mathrm{M}$ reductase (Mcr) [42].

Taking into consideration the production pathway (Figure 1), hydrogenotrophic methanogenic microorganisms are known as $\mathrm{H}_{2}$ oxidant, formate, or some simple alcohols and reduce $\mathrm{CO}_{2}$ to $\mathrm{CH}_{4}$ [43]. Most of the described methanogenic microorganisms are hydrogenotrophic. Acetoclastic methanogens divide acetate to form $\mathrm{CH}_{4}$ and $\mathrm{CO}_{2}$. They are found in habitats where hydrogenotrophic methanogenic microorganisms reduce $\mathrm{H}_{2}$ levels sufficiently to create the necessary conditions for the formation of high levels of acetate. Methylotrophic methanogenic microorganisms are common in sulfate-rich marine and hypersaline sediments, in which they use methylated compounds such as trimethylamine, dimethyl sulfate, and methanol [44]. In contrast, in sediments from freshwater environments, it is believed so far that methylotrophic methanogenesis is of little importance, although this is not what recent unpublished results have revealed for the floodable areas of the Amazon. However, the same reasoning used for anaerobic methanotrophy may be occurring in this case.

Methyl compounds, especially methanol, may play an underestimated role as contributors to the production of $\mathrm{CH}_{4}$ in wetlands [44]. Although the use of methanol in the presence of hydrogen has been observed among methanogenic Archaea, 


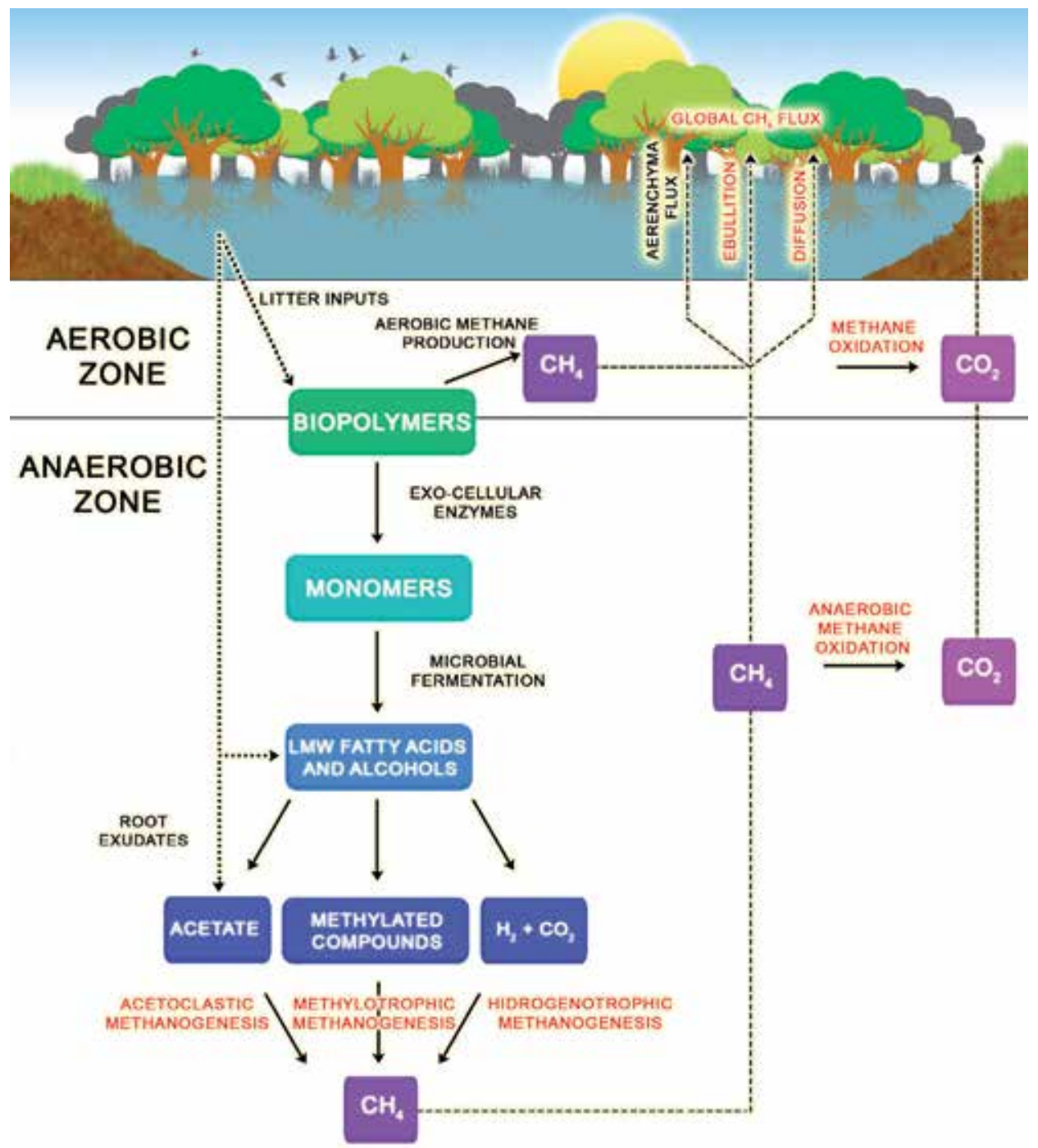

Figure 1.

Conceptual illustration of $\mathrm{CH}_{4}$ production and consumption prior to atmospheric release in wetland ecosystems. Microorganisms degrade complex organic material in anoxic system by a multistep process, leading to $\mathrm{CO}_{2}$ and $\mathrm{CH}_{4}$ as end products. Adapted from [34].

this substrate is rarely tested during the description of new species. This lack of information represents a serious obstacle to the analysis of metabolic abilities of methanogenic Archaea [45].

Meyer et al. [46] used a metagenomic approach to assess the relative abundance of genes involved in cycling $\mathrm{CH}_{4}$ in forest and pasture soils in Western Amazon and they revealed that genes involved in methanogenesis from methylated compounds were significantly more abundant in the pasture. Soil methylotrophs call attention to the central role of these organisms in global methanol conversions, which mainly originate from plants [47] released from both living and decomposing plant material [48]. Soil microbiota is an essential component of plant decomposition and formation of organic matter. Thus, the understanding about these communities, as well as the one regarding decomposed material, is essential to elucidate the dynamics of these environments. 
The literature mentions that in tropical alluvial plains the predominant microbial pathways in methane production are acetoclastic and hydrogenotrophic [49, 50]. However, Alves [51], when evaluating the enrichment of primary and secondary forest and pasture samples in the Amazon, indicated a higher production of $\mathrm{CH}_{4}$ by acetoclastic and methylotrophic pathways.

In flooded areas, known to have high methanogenic rates, methanotrophs are responsible for catalyzing the oxidation of $\mathrm{CH}_{4}$ at the aerobic-anaerobic interfaces. Methanotrophic bacteria are able to use $\mathrm{CH}_{4}$ as their sole source of $\mathrm{C}$ [52] and can be divided into four groups: Gammaproteobacteria (often referred as Type I or Type $\mathrm{X}$ ); Alphaproteobacteria (formerly known as Type II); Verrucomicrobia; and NC10 phylum members [53].

Methanotrophic activity is only viable because of an enzyme known as monooxygenase methane (MMO), which acts in two distinct forms: particulate (pMMO), within an intracellular membrane, or soluble (sMMO), in the cytoplasm. Both convert $\mathrm{CH}_{4}$ into the readily assimilated product, methanol [54].

The oxidations of $\mathrm{CH}_{4}$ have proven to be an important sink for this gas produced by sediments in the Amazon, reducing the amount of $\mathrm{CH}_{4}$ that reaches the atmosphere $[8,55]$.

The diversity of $\mathrm{CH}_{4}$ metabolizers or metabolizing organisms tends to increase in the near future due to additional findings in surveys using a metagenomic approach and other increasingly robust approaches to the study of microbial diversity. This can be the currently ambiguous evolutionary history of this important metabolic function [23].

\section{Influence of hydrology on tropical floodplains}

Alluvial plains are among the most dynamic ecosystems, consisting of a mosaic of habitats with high spatial-temporal turnover rates $[4,56]$. The complex interaction between the topography of the floodplain and the variation in river flow and sediment transport maintains a distinct gradient of lateral hydrological connectivity, which facilitates the coexistence of numerous aquatic, amphibian, and terrestrial species [4].

These sites exhibit highly heterogeneous stratigraphy produced by active river meanders and sediment deposition; dominant coarse-grained materials are interspersed with finer sediments, and organic matter is deposited, leading to distinct zones of oxic or anoxic conditions within the subsurface [57]. Regional variations in fresh water $\mathrm{CH}_{4}$ emissions are important factors that should be considered to ensure reliable global estimates. The C stocks, as well as the different classes of organic matter, still need to be elucidated in order to decrease our limitations in building $\mathrm{C}$ cycling models in those environments. Hydrological variations are responsible for determining the intensity and duration of aerobic conditions. Changes in these conditions can increase or decrease the rates of decomposition of organic matter [58].

The Colombian wetlands were evaluated and showed that the studied ecosystems are valuable $\mathrm{C}$ sinks, and hydrogeomorphology acts as an important factor for the storage of $C$ in these ecosystems [59]. Dalmagro et al. [18], when evaluating the largest tropical floodplain area in the world, Pantanal, revealed that they are potentially large $\mathrm{C}$ sinks and that the $\mathrm{C}$ balance was driven by the seasonal dynamics of precipitation and surface flooding that affected the anaerobic and aerobic phases of the soil. The assessment of the behavior of a freshwater flood area with a usual average flood period of 6 months per year, located in a park in the USA, showed that the environment become a source of $\mathrm{CO}_{2}$ when it went through a prolonged flood 
period (17 months). Such situations may occur more frequently in the future, as an intensification of rainfall is expected. Moreover, evidence suggests that the magnitude of wet and dry cycles can have significant effects on GHG emission [60].

Alluvial plains are environments adapted to variations in water level, and it seems that microbial communities can be adapted to these fluctuations and remain in a state of latency until the next flood. Hernández et al. [61] demonstrated that in Amazon forest soils the propensity to produce $\mathrm{CH}_{4}$ (at the laboratory) was best observed in relation to the duration of the lag phase. Soils that were never flooded (dry forest) presented this phase for a longer time than sites that were permanently flooded. In a laboratory study that imposed different levels of flood frequency, differences in composition have also been observed, but an increase in diversity under conditions of higher water saturation has been reported [62].

Alluvial plains are among the most threatened ecosystems in the world because of anthropogenic activities, especially in developing countries, where high demand from agricultural areas drives deforestation. An additional threat to those ecosystems is the increase in terrestrial temperatures due to global warming, generating a cycle of change in water regime that may consequently alter the storage capacity of $\mathrm{C}$ in wetland ecosystems [63].

\section{Sensitivity of floodplains to climate change}

Current projections suggest that rates of GHG emission from floodplains will increase as global average temperatures continue to rise, and this is of particular importance in temperate and tropical systems. The metabolism of $\mathrm{CH}_{4}$ in flooded areas is strongly influenced by environmental factors that have both spatial and temporal variability. The production and consumption of GHG are partially regulated by microbial processes, which are influenced by soil moisture and temperature [64]. In soils, the microbial production rate of $\mathrm{CH}_{4}$ generally shows an exponential relationship with air temperature, with the peak rate corresponding to temperatures of $25^{\circ} \mathrm{C}(77 \mathrm{~F})$ to $30^{\circ} \mathrm{C}(86 \mathrm{~F})$ [65].

Wetlands are likely to become the main net sources of $\mathrm{C}$ under the effect of warming climatic conditions in decades [64]. Sanches et al. [66] determined the crucial factors related to the emission of $\mathrm{CH}_{4}$ in lakes, on a large scale, observing emission patterns in different climate zones. The climate zones with the highest average air temperatures showed the highest emission rates.

Climate change in tropical wetlands is expected to cause an increase in temperature and a change in precipitation patterns, increasing the duration of the dry season, but also increasing the intensity of precipitation events. Given these predictions, the current and future balance of seasonally flooded tropical areas is still uncertain. A study conducted from 2014 to 2016 in the largest continuous wetland area in the world, the Brazilian Pantanal, demonstrated the response of $\mathrm{CH}_{4}$ and $\mathrm{CO}_{2}$ to the hydrological dynamics of this ecosystem [18]. Measurements revealed that $\mathrm{CH}_{4}$ emission increased rapidly as soon as anaerobic conditions were established, with the highest $\mathrm{CH}_{4}$ flow values having always been observed when soil redox potential values were less than $-100 \mathrm{mV}$. In summary, the data indicated that the seasonally flooded rainforests of Pantanal are potentially large $\mathrm{C}$ sinks, but significant sources of $\mathrm{CH}_{4}$ when anaerobic conditions dominate the soil (flood period). It is worth mentioning that the carried out measurements contemplate emission from tree trunks, soil flows, boiling, and diffusion from the water surface, since the methodology used was a $20 \mathrm{~m}$ (65.6 feet) high research tower, together with environmental sensors. A recent research suggests that $\mathrm{CH}_{4}$ emission from tree branches are the dominant source of regional $\mathrm{CH}_{4}$ emission to flooded tropical forest environments [11]. 


\section{6. $\mathrm{CH}_{4}$ emission in flooding areas: biogeochemistry, isotopic signature, and metagenomics}

Understanding the level of sensitivity of flooding areas as a response to climate change also requires efforts to be better achieved. This demands more knowledge at all levels, ranging from single-cell ecophysiology to in situ and ex situ biogeochemical functioning. Thus, efforts to cultivate recalcitrant microorganisms, evaluations of the microbiota with independent methods of cultivation, and the combination of these approaches with isotopic determinations and physical and chemical characterization of soil and water are necessary to achieve an understanding of the processes mediated by microorganisms in these environments [67].

It is a challenge for researchers to design experiments and adopt methods that can detect $\mathrm{C}$ cycling in alluvial plains. One of the approaches used is the characterization of microbial communities in space and time from the sequencing of DNA or RNA and the construction of correlation matrices of relative abundances of microbial taxa or functional groups with environmental variables [68]. Regardless of the study method, the characterization needs to reflect the correct scale for the issue and should contain enough replicates to provide meaningful data [69].

Metagenomic studies indicate high functional redundancy in flooding areas. Although we know that microbial communities are diverse, DNA-based methods can artificially inflate functional redundancy estimates [69]. This fact is due to the DNA-based approach not being able to distinguish between dormant and active cells [70].

Different responses have been found when assessing the effect of increased salinity on the composition of the total (DNA) and active (RNA) microbial community in an anaerobic reactor [71]. The concentration and exposure time most strongly affected the microbial community, and especially the Archaea phylotypes at the RNA level, both in terms of global diversity and specific phylotypes.

The evaluation of the survival conditions of Archaea methanogenic under aerated conditions in floodplains with rice crops revealed the composition of the active community, indicating that unknown mechanisms maintain the stability of the community in these environments until 1 year after the start of drainage [72].

Stable isotopes have long been used as a tool to investigate environmental processes and their relationships with microorganisms, which can be established through metabolic pathways [73]. The merit of C isotopes lies in their relatively slow exchange rate for many minerals containing $\mathrm{C}$ and in relatively large fractionations, even at high temperatures. These two properties make $\mathrm{C}$ isotopes an excellent recorder of geological processes and allow a better understanding of $\mathrm{C}$ sources and related-volatile flows in geological time scales [74]. We are undergoing a reformulation of isotopic approaches based on the increase in genomic and transcriptomic databases, the latest technologies with improved instrumental and mass spectrometric data acquisition, processing, and evaluation [73]. For Coyotzi et al. [75], the incorporation of stable isotopes into the microbial biomass allows the recovery of labeled nucleic acids from active microorganisms. The combination of stable isotopes with metagenomics provides access to the genomes of microorganisms involved in metabolic processes of interest.

The $\mathrm{CH}_{4}$ fluxes in terrestrial and aquatic environments have been evaluated in several ways, but in general, the monitoring of gas accumulation in flow chambers has been the predominant methodology to date. This methodology is conceptually simple and does not require expensive field equipment, but is laborious, based mainly on manual sampling [17]. 


\section{Modeling of $\mathrm{CH}_{4}$ emission}

To improve the prediction of climate models, it is important to understand the mechanisms by which microorganisms regulate the flow of terrestrial GHG. This involves considering the complex interactions that occur between microorganisms and other biotic and abiotic factors in the environment. The potential to mitigate climate change by reducing GHG emission through the management of terrestrial microbial processes is a perspective of high importance for the future [18].

Despite this importance, however, tropical flood areas are poorly represented in global models to predict global $\mathrm{CH}_{4}$ emission. A first step in the development of a process-based model of $\mathrm{CH}_{4}$ emission from tropical flood areas for global applications was documented in 2014. To this end, the LPX-Bern Dynamic Global Vegetation Model (LPX) was slightly modified to represent the hydrology of the floodplain, vegetation, and associated $\mathrm{CH}_{4}$ emission. The extent of tropical floodplains was prescribed using the production of the spatially explicit PCR-GLOBWB hydrology model. Several variables were introduced to this model, such as vegetation, ground cover (through remote sensing), not to mention that simulated $\mathrm{CH}_{4}$ flow densities were evaluated against field observations and regional flow inventories. However, soil microbiota was not considered as a component in the modeling. Simulated $\mathrm{CH}_{4}$ emissions at the Amazon basin scale were compared to simulations of previously performed models. Thus, it was found that this LPX model reproduces the average magnitude of the net flow densities of $\mathrm{CH}_{4}$ observed for the Amazon basin. However, the model does not reproduce the temporal and spatial variability between sampling sites, considering that site information is too limited to attest or refute some resources of the model. At the Amazon basin scale, the results obtained with the promotion of this model highlighted the great uncertainty in the magnitude of $\mathrm{CH}_{4}$ emission from floodable areas.

The sensitivity analysis provided clarification on the main drivers of $\mathrm{CH}_{4}$ emission from the floodplain and their associated uncertainties. Due to an intrinsic limitation of the LPX to consider seasonality in floodplain extension, the model failed to reproduce the total dynamics of $\mathrm{CH}_{4}$ emission, raising several scientific questions. Although this model includes more specific mechanisms for tropical floodplains, it was not possible to reduce the uncertainty in the magnitude of $\mathrm{CH}_{4}$ emission from the Amazon basin, thus justifying the need for further research to restrict $\mathrm{CH}_{4}$ emission and their temporal variability [15].

In the same year, Potter et al. [76] developed a new model that sought to seasonally estimate the carbon dynamics and $\mathrm{CH}_{4}$ emission of floodable ecosystems in the Amazon. The Amazon wetland simulation model took into account three main components: (a) details of the type of vegetation in the wetlands and changes in the level of water, temperature, and dissolved oxygen; (b) primary production, mass accumulation, and decay of the litter layer in soils and sediments; and (c) routes for production and transport of $\mathrm{CH}_{4}$ through the water column to the atmosphere.

The presented model is based on the input of the following data for simulations in a given flooded environment in the Amazon: latitude and longitude; vegetation types such as area cover fractions; daily surface temperature; solar irradiance flux; wind speed; precipitation; daily water depth; biomass production values for floating macrophytes; and satellite vegetation index data for flooded forest ecosystems. In order to improve the generality and use of this model, the incorporation of mechanical simulations of vertical mixing, horizontal exchanges, and various biogeochemical processes is necessary. In addition, the microbiota component is not directly reported. 
In 2016 [77], when evaluating the atmospheric concentrations of $\mathrm{CH}_{4}$ in the Amazon basin in 2010 and 2011, besides a 3D atmospheric chemical transport model (TOMCAT), two emission models in wetlands have been used [78-79] to reduce the uncertainty about $\mathrm{CH}_{4}$ emission. The first set of wetland and rice paddy emission derived from the Bloom et al. method [79]. The method uses a satellite to evaluate the carbon variation available for methanogenesis, which leads to a more accurate representation of the timing of $\mathrm{CH}_{4}$ emission. However, satellite data cannot distinguish between microbial $\mathrm{CH}_{4}$ emission from natural wetlands and anthropogenic emission from rice cultivation. The second model [the Joint UK Land Environment Simulator (JULES), version 3.4.1] [78] simulates the Earth's land surface in terms of carbon, water, and energy variations and includes a methane flux in wetlands as a component, based on Gedney et al. [80]. The flow of $\mathrm{CH}_{4}$ is dependent on the available carbon substrate, the temperature, and the fraction considered wet. The estimates used through the two wetlands emission models are based on processes and showed similar behaviors when the atmospheric model is compared to observations, regardless of which model was used [77].

In the same year (2016), another research on $\mathrm{CH}_{4}$ modeling was carried out, bringing to the fore the discussion of how beneficial the improvements in $\mathrm{CH}_{4}$ models would be for terrestrial system models and for the additional simulation of climatecarbon cycle feedbacks. Over the past four decades, several empirical models have been developed to quantify the magnitude, investigate spatial and temporal variations, and understand the underlying mechanisms and environmental controls of $\mathrm{CH}_{4}\left(\mathrm{CH}_{4}\right.$ flows in terrestrial ecosystems). These $\mathrm{CH}_{4}$ models are also used for the integration of multiple-scale $\mathrm{CH}_{4}$ data, such as laboratory-based incubation and molecular analysis, field observational experiments, remote sensing, and aircraft-based measurements in various terrestrial ecosystems. The authors noted that there are large discrepancies between models in terms of representation of $\mathrm{CH}_{4}$ processes and their environmental controls, and significant data, such as model incompatibilities, are partially attributed to different representations of landscape characterization and flood dynamics.

However, it should be noted that $\mathrm{CH}_{4}$ models should represent more explicitly the mechanisms underlying the exchange of Earth-atmosphere $\mathrm{CH}_{4}$, with emphasis on the improvement and validation of individual $\mathrm{CH}_{4}$ processes over depth and horizontal space, and models capable of simulating $\mathrm{CH}_{4}$ emissions at highly heterogeneous spatial and temporal scales, particularly in hotspots, should be developed; besides that, efforts should be made to develop benchmarking models (a modeling based on comparative analysis) that can be easily used for improvement, evaluation, and integration with data from molecular to global scales [81].

Widely applicable and robust prediction models should be developed from large data sets generated through collaboration with scientists around the world. To achieve high predictive accuracy, these data sets should cover a wide variety of information and variables at the most different scales of tropical floodplains within regions and globally.

\section{Closing remarks}

This chapter synthesizes the main progresses in scientific research applied to understanding the dynamics of $\mathrm{CH}_{4}$ in tropical floodplains. Here, we focused on an integrative approach to the main aspects of the $\mathrm{C}$ cycle, describing methods based on observations on the Earth's surface. However, a better understanding of the methylotrophic methanogenesis and anaerobic oxidation of $\mathrm{CH}_{4}$ still needs to be clarified for these environments. The next generation of models of $\mathrm{CH}_{4}$ emission should take into account seasonal water level fluctuation and the methanogenic and methanotrophic activity associated with it. This bold goal can only be achieved 
using a multianalytical approach based on a synergy of models, statistical methods for data integration, and scientific cooperation. This effort can help to create a unique design, in which not only the biosphere and the feedback of hydrological modeling but also the soil microbiota will be considered in the regional cycle of $\mathrm{C}$.

\section{Acknowledgements}

This study was supported by a grant from Fundação de Amparo à Pesquisa do Estado de São Paulo (Foundation for Research Support of the State of São Paulo) (FAPESP 2016/16687-3). DJB and MSF were supported by the CAPES Financial Code 001. MSB was supported by FAPESP 2017/06415-9 and FAPESP 2018/02277-3. AAN was supported by FAPESP 2017/03575-5.

\section{Author details}

Dayane Juliate Barros ${ }^{1}$, Marília de Souza Bento ${ }^{2}$, Murilo de Souza Ferreira ${ }^{3}$, Janaina Braga do Carmo ${ }^{4}$, Rogério Hartung Toppa ${ }^{4}$, Vania $\mathrm{Neu}^{5}$, Maria Bernadete de Amâncio Varesche ${ }^{6}$, Paula Benevides de Morais ${ }^{1}$ and Acacio Aparecido Navarrete ${ }^{1,4,7 *}$

1 Graduate Program in Biodiversity and Biotechnology - BIONORTE, Federal University of Tocantins (UFT), Palmas, Tocantins, Brazil

2 Graduate Program in Biotechnology and Environmental Monitoring (PPGBMA), Federal University of São Carlos (UFSCar), Sorocaba, São Paulo, Brazil

3 Graduate Program in Hydraulic and Sanitation Engineering (PPG-SHS) of the São Carlos School of Engineering, University of São Paulo (USP),

São Carlos, São Paulo, Brazil

4 Department of Environmental Sciences, Federal University of São Carlos (UFSCar), Sorocaba, São Paulo, Brazil

5 Social Environmental and Water Resources Institute, Federal Rural University of Amazonia (UFRA), Belém, Pará, Brazil

6 Department of Hydraulics and Sanitation, São Carlos School of Engineering, University of São Paulo (USP), São Carlos, São Paulo, Brazil

7 Graduate Program in Agronomy (PPGA), Federal University of Mato Grosso do Sul (UFMS), Chapadão do Sul, Mato Grosso do Sul, Brazil

*Address all correspondence to: acacionavarrete@gmail.com

\section{IntechOpen}

(C) 2019 The Author(s). Licensee IntechOpen. This chapter is distributed under the terms of the Creative Commons Attribution License (http://creativecommons.org/licenses/ by/3.0), which permits unrestricted use, distribution, and reproduction in any medium, provided the original work is properly cited. (cc) BY 


\section{References}

[1] Malhi Y, Roberts JT, Betts RA, Kileen TJ, Li W, Nobre CA. Cimate change, deforestation, and the fate of the Amazon. Science. 2008;319(5860):169-172. DOI: 10.1126/ Science.1146961

[2] Kotsyurbenko OR, Glagolev MV, Merkel AY, Sabrekov AF, Terentieva IE. Methanogenesis in soils, wetlands, and peat. In: Stams AJM, Sousa D, editors. Biogenesis of Hydrocarbons, Handbook of Hydrocarbon and Lipid Microbiology. Switzerland: Springer Nature; 2019. p. 1-18. DOI: 10.1007/978-3-319-53114-4_9-1

[3] Junk W, Bayley PB, Sparks RE. The flood pulse concept in riverfloodplain systems. In: Dodge DP, editor. Proceedings of the International Large River Symposium (LARS). Ottawa, Canada: Canadian Special Publication of Fisheries and Aquatic Sciences; 1989. pp. $110-127$

[4] Tockner K, Pusch M, Borchardt D, Lorang MS. Multiple stressors in coupled river-floodplain ecosystems. Freshwater Biology. 2010;55(Suppl 1):135-151. DOI: 10.1111/j.1365-2427.2009.02371.x

[5] Raghoebarsing AA, Pol A, Van De Pas-Schoonen KT, AJP S, Ettwig KF, WIC R, et al. A microbial consortium couples anaerobic methane oxidation to denitrification. Nature. 2006;440(7086):918-921. DOI: 10.1038/ nature 04617

[6] Caldwell SL, Laidler JR, Brewer EA, Eberly JEDO, Sandborgh SC. Critical review anaerobic oxidation of methane: Mechanisms, bioenergetics, and the ecology of associated microorganisms. Environmental Science \& Technology. 2008;42(18):6791-6799. DOI: 10.1021/ es800120b

[7] IPCC (Intergovernmental Panel on Climate Change). Summary for
Policymakers. In: Stocker TF, Qin D, Plattner GK, Tignor M, Allen S, Boschung J, Midgley P, editors. Climate Change 2013: The Physical Science Basis. Cambridge: Cambridge University Press; 2013. p. 465-570

[8] Crutzen PJ, Lelieveld JHI. Human impacts on atmospheric chemistry. Annual Review of Earth and Planetary Sciences. 2001;29:17-45. DOI: 10.1146/ annurev.earth.29.1.17

[9] Forster P, Ramaswamy V, Artaxo $\mathrm{P}$, et al. Changes in atmospheric constituents and in radiative forcing. In: Solomon S, Qin D, Manning M, Chen Z, et al., editors. Climate change 2007: The physical science basis.

Contribution of working group I to the fourth assessment report of the intergovernmental panel on climate change. Cambridge: Cambridge University Press; 2007

[10] Engle D, Melack JM. Methane emissions from an Amazon floodplain lake: Enhanced release during episodic mixing and during falling water. Biogeochemistry. 2000;51(1):71-90. DOI: 10.1023/A:1006389124823

[11] Pangala SR, Enrich-Prast A, Basso LS, Peixoto RB, Bastviken D, Hornibrook ERC, et al. Large emissions from floodplain trees close the Amazon methane budget. Nature. 2017;552(7684):230-234. DOI: $10.1038 /$ nature24639

[12] Barbosa PM, Farjalla VF, Melack JM, Amaral JHF, da Silva JS, Forsberg BR. High rates of methane oxidation in an Amazon floodplain lake. Biogeochemistry. 2018;137(3): 351-365. DOI: $10.1007 / \mathrm{s} 10533-018-$ 0425-2

[13] Sawakuchi HO, Bastviken D, Sawakuchi AO, Krusche AV, Ballester MVR, Richey JE. Methane 
emissions from Amazonian rivers and their contribution to the global methane budget. Global Change Biology. 2014;20(9):2829-2840. DOI: 10.1111/ gcb.12646

[14] Melack JNM, Hess LL, Gastil M, Forsberg BRF, Hamilton SHK, Lima IBT. Regionalization of methane emissions in the Amazon basin with microwave remote sensing. Global Change Biology. 2004;10:530-544. DOI: 10.1111/j.1529-8817.2003.00763.x

[15] Ringeval B, Houweling S, Van Bodegom PM, Spahni R, Van Beek R, Joos F, et al. Methane emissions from floodplains in the Amazon basin: Challenges in developing a processbased model for global applications. Biogeosciences. 2014;11(6):1519-1558. DOI: 10.5194/bg-11-1519-2014

[16] Bastviken D, Santoro AL, Marotta H, Pinho LQ, Calheiros DF, Crill $\mathrm{P}$, et al. Methane emissions from pantanal, South America, during the low water season: Toward more comprehensive sampling. Environmental Science \& Technology. 2010;44(14):5450-5455. DOI: 10.1021/ es1005048

[17] Peixoto RB, Machado-Silva F, Marotta H, Enrich-Prast A, Bastviken D. Spatial versus day-to-day within-lake variability in tropical floodplain lake $\mathrm{CH}_{4}$ emissions - developing optimized approaches to representative flux measurements. PLoS One. 2015;10(4): 1-11. DOI: 10.1371/journal. pone.0123319

[18] Dalmagro HJ, Lathuillière MJ, Sallo F d S, Guerreiro MF, Pinto OB, de Arruda PHZ, et al. Streams with riparian forest buffers versus impoundments differ in discharge and DOM characteristics for pasture catchments in Southern Amazonia. Water. 2019;11(2):1-20. DOI: 10.1111/ gcb.14615
[19] Saunois M, Bousquet P, Poulter B, Peregon A, Ciais P, Canadell JG, et al. The global methane budget 2000 - 2012. Earth System Science Data. 2016;8:697-751. DOI: 10.5194/essd-8-697-2016

[20] Kirschke S et al. Three decades of global methane sources and sinks. Nature Geosciense. 2013;6(10):813-823. DOI: $10.1038 /$ ngeo1955

[21] Prigent C, Papa F, Aires F, Rossow WB, Matthews E. Global inundation dynamics inferred from multiple satellite observations , 1993 2000. Journal of Geophysical ResearchAtmospheres. 2007;112(D12107):1-13. DOI: 10.1029/2006JD007847

[22] Lolu AJ, Ahluwalia AS, Sidhu MC, Reshi ZA. Carbon sequestration potential of macrophytes and seasonal carbon input assessment into the Hokersar wetland, Kashmir. Wetlands. 2019;39(3):453-472. DOI: 10.1007/ s13157-018-1092-8

[23] Evans PN, Boyd JA, Leu AO, Woodcroft BJ, Parks DH, Hugenholtz P, et al. An evolving view of methane metabolism in the Archaea. Nature Reviews. Microbiology. 2019;17(4):219232. DOI: $10.1038 / \mathrm{s} 41579-018-0136-7$

[24] Ghattas AK, Fischer F, Wick A, Ternes TA. Anaerobic biodegradation of (emerging) organic contaminants in the aquatic environment. Water Research. 2017;116:268-295. DOI: 10.1016/j. watres.2017.02.001

[25] Cronan CS. Ecosystem Biogeochemistry. Springer Textbooks in Earth Sciences, Geography and Environment. Switzerland: Springer Nature; 2018. 203p. DOI: 10.1007/978-3-319-66444-6

[26] Hu Z, Ma R. Distribution and characteristic of nitrite-dependent anaerobic methane oxidation bacteria by comparative analysis of wastewater treatment plants and agriculture fields 
in northern China. PeerJ. 2016;4:1-15. DOI: $10.7717 /$ peerj.2766

[27] Schubert CJ, Vazquez F, Lösekann-Behrens T, Knittel K, Tonolla M, Boetius A. Evidence for anaerobic oxidation of methane in sediments of a freshwater system (Lago di Cadagno). FEMS Microbiology Ecology. 2011;76(1):26-38. DOI: 10.1111/j.1574-6941.2010.01036.x

[28] Zehnder AJ, Brock TD. Anaerobic methane oxidation: Occurrence and ecology. Applied and Environmental Microbiology. 1980;39(1):194-204

[29] Ettwig KF, Butler MK, Le Paslier D, Pelletier E, Mangenot S, Kuypers MMM, et al. Nitrite-driven anaerobic methane oxidation by oxygenic bacteria. Nature. 2010;464(7288):543-548. DOI: 10.1038/ nature 08883

[30] Shen L, Ouyang L, Zhu Y, Trimmer M. Active pathways of anaerobic methane oxidation across contrasting riverbeds. The ISME Journal. 2019;13(3):752-766. DOI: 10.1038/s41396-018-0302-y

[31] Shi Y, Wang Z, He C, Zhang X, Sheng L, Ren X. Using $13 \mathrm{C}$ isotopes to explore denitrification-dependent anaerobic methane oxidation in a paddy-peatland. Scientific Reports. 2017;7(40848):1-8. DOI: 10.1038/ srep40848

[32] Segarra KEA, Schubotz F, Samarkin V, Yoshinaga MY, Hinrichs K, Joye SB. High rates of anaerobic methane oxidation in freshwater wetlands reduce potential atmospheric methane emissions. Nature Communications. 2015;6:1-8. DOI: $10.1038 /$ ncomms 8477

[33] Valenzuela EI, Prieto-Davó A, López-Lozano NE, Hernández-Eligio A, Vega-Alvarado L, Juárez K, et al. Anaerobic methane oxidation driven by microbial reduction of natural organic matter in a tropical wetland. Applied and Environmental Microbiology. 2017;83(11):1-15. DOI: 10.1128/ AEM.00645-17

[34] Bridgham SD, Cadillo-Quiroz H, Keller JK, Zhuang Q. Methane emissions from wetlands: Biogeochemical, microbial, and modeling perspectives from local to global scales. Global Change Biology. 2013;19(5):1325-1346. DOI: $10.1111 / g c b .12131$

[35] Thauer RK, Kaster AK, Seedorf H, Buckel W, Hedderich R. Methanogenic archaea: Ecologically relevant differences in energy conservation. Nature Reviews. Microbiology. 2008;6(8):579-591. DOI: 10.1038/ nrmicro1931

[36] Schink B. Energetics of syntrophic cooperation in methanogenic degradation. Microbiology and Molecular Biology Reviews. 1997;61(2):262-280. DOI: 1092-2172/97/\$04.0010

[37] Batstone DJ, Keller J, Angelidaki I, Kalyuzhnyi SV, Pavlostathis SG, Rozzi A, et al. The IWA anaerobic digestion model No 1 (ADM1). Water Science and Technology. 2002;45(10):65-73. DOI: 10.2166/ wst.2002.0292

[38] Nakayama CR, Penteado ED, Duarte RTD, Giachini AJ, Saia FT. Improved methanogenic communities for biogás production. In:

Treichel H, Fongaro G, editors. Improving Biogas Production. Cham: Springer; 2019. pp. 69-98. DOI: 10.1007/978-3-030-10516-7_4

[39] Zhang Y, Ma A, Zhuang G, Zhuang X. The acetotrophic pathway dominates methane production in Zoige alpine wetland coexisting with hydrogenotrophic pathway. Scientific Reports. 2019;9(1):9141. DOI: 10.1038/ s41598-019-45590

[40] Enzmann F, Mayer F, Rother M, Holtmann D. Methanogens: Biochemical 
background and biotechnological applications. AMB Express. 2018;8(1): 1-22. DOI: $10.1186 / \mathrm{s} 13568-017-0531-\mathrm{x}$

[41] Berghuis BA, Brian F, Schulz F, Blainey PC, Woyke T, Quake SR. Hydrogenotrophic methanogenesis in archaeal phylum Verstraetearchaeota reveals the shared ancestry of all methanogens. Proceedings of the National Academy of Sciences of the United States of America (USA). 2019;116(11):5037-5044. DOI: 10.1073/pnas.1815631116

[42] Borrel G, O'Toole PW, Harris $\mathrm{HMB}$, Peyret $\mathrm{P}$, Brugère JF, Gribaldo S. Phylogenomic data support a seventh order of methylotrophic methanogens and provide insights into the evolution of methanogenesis. Genome Biology and Evolution. 2013;5(10):1769-1780. DOI: 10.1093/ gbe/evt128

[43] Lyu Z, Shao N, Akinyemi T, Whitman WB. Methanogenesis. Current Biology. 2018;28(13):R727-R732. DOI: 10.1016/j.cub.2018.05.021

[44] Jiang Z, Xiao OT, Kuznetsov VL, Edwards PP. Turning carbon dioxide into fuel. Philosophical Transactions of the Royal Society A. 2010;368:33433364. DOI: $10.1098 /$ rsta.2010.0119

[45] Jabłoński S, Rodowicz P, Łukaszewicz M. Methanogenic archaea database containing physiological and biochemical characteristics. International Journal of Systematic and Evolutionary Microbiology. 2015;65(2015):1360-1368. DOI: 10.1099/ ijs. 0.000065

[46] Meyer KM, Klein AM, Rodrigues JLM, Tringe SG, Mirza BS, Tiedje JM, et al. Conversion of Amazon rainforest to agriculture alters community traits of methane-cycling organisms. Molecular Ecology. 2017;26(6):1547-1556. DOI: 10.1111/ ijlh.12426
[47] Stacheter A, Noll M, Lee CK, Selzer M, Glowik B, Ebertsch L, et al. Methanol oxidation by temperate soils and environmental determinants of associated methylotrophs. The ISME Journal. 2012;7(5):1051-1064. DOI: 10.1038 /ismej.2012.167

[48] Morawe M, Hoeke H, Wissenbach DK, Lentendu G, Wubet T, Kröber E, et al. Acidotolerant bacteria and fungi as a sink of methanol-derived carbon in a deciduous forest soil.

Frontiers in Microbiology. 2017;8(1361): 1-18. DOI: $10.3389 /$ fmicb.2017.01361

[49] Conrad R, Noll M, Claus P, Klose M, Bastos WR, Enrich-Prast A. Stable carbon isotope discrimination and microbiology of methane formation in tropical anoxic lake sediments. Biogeosciences. 2011;8(3):795-814. DOI: $10.5194 /$ bg-8-795-2011

[50] Conrad R, Ji Y, Noll M, Klose M, Claus P, Enrich-Prast A. Response of the methanogenic microbial communities in Amazonian oxbow lake sediments to desiccation stress. Environmental Microbiology. 2014;16(6):1682-1694. DOI: 10.1111/1462-2920.12267

[51] Alves KJ. Communities of methanogenic Archaea in different uses of Amazonian soils [dissertation]. Piracicaba: Luiz de Queiroz College of Agriculture (ESALQ); 2018

[52] Strong PJ, Xie S, Clarke WP. Methane as a resource: Can the methanotrophs add value? Environmental Science \& Technology. 2015;49(7):4001-4018. DOI: 10.1021/ es504242n

[53] Kalyuzhhnaya MG, Xing X, editors. Methane Biocatalysis: Paving the Way to Sustainability. Switzerland: Springer International Publishing; 2018. 312p. DOI: $10.1007 / 978-3-319-74866-5$

[54] Dalton H. The Leeuwenhoek lecture 2000: The natural and unnatural 
history of methane-oxidizing bacteria. Philosophical Transactions of the Royal Society B. 2005;360(1458):1207-1222. DOI: $10.1098 /$ rstb.2005.1657

[55] Sawakuchi O, Ward ND, Borges CD, Tsai SIUM, Richey JE, Centen A, et al. Oxidative mitigation of aquatic methane emissions in large Amazonian rivers. Global Change Biology. 2016;22(3):1075-1085. DOI: 10.1111/ gcb.13169

[56] Stanford JA, Lorang MS, Hauer FR. The shifting habitat mosaic of river ecosystems. SIL Proceedings, 19222010. 2005;29(1):123-136. DOI: 10.1080/03680770.2005.11901979

[57] Boye K, Noël V, Tfaily M, et al. Thermodynamically controlled preservation of organic carbon in floodplains. Nature Geoscience. 2017;10:415-419. DOI: 10.1038/ngeo2940

[58] Beringer J, Livesley SJ, Randle J, Hutley LB. Carbon dioxide fluxes dominate the greenhouse gas exchanges of a seasonal wetland in the wetdry tropics of Northern Australia. Agricultural and Forest Meteorology. 2013;182-183:239-247. DOI: 10.1016/j. agrformet.2013.06.008

[59] Pérez-rojas J, Moreno F, César J, Villa J. Catena soil organic carbon stocks in fluvial and isolated tropical wetlands from Colombia. Catena. 2019;179:139148. DOI: 10.1016/j.catena.2019.04.006

[60] Zhao J, Malone SL, Oberbauer SF, Olivas PC, Schedlbauer JL, Staudhammer CL, et al. Intensified inundation shifts a freshwater wetland from a $\mathrm{CO}_{2}$ sink to a source. Global Change Biology. 2019;25(10):3319-3333. DOI: $10.1111 /$ gcb.14718

[61] Hernández M, Klose M, Claus P, Bastviken D, Marotta H, et al. Structure, function and resilience to desiccation of methanogenic microbial communities in temporarily inundated soils of the Amazon rainforest (Cunia reserve, Rondonia ). Environmental Microbiology. 2019;21(5):1702-1717. DOI: 10.1111/1462-2920.14535

[62] Randle-Boggis RJ, Ashton PD, Helgason T. Increasing flooding frequency alters soil microbial communities and functions under laboratory conditions. MicrobiologyOpen. 2018;7(1):1-13. DOI: $10.1002 / \mathrm{mbo} 3.548$

[63] Mitsch WJ, Nahlik A, Wolski P, Bernal B, Zhang L, Ramberg L. Tropical wetlands: Seasonal hydrologic pulsing, carbon sequestration, and methane emissions. Wetlands Ecology and Management. 2010;18(5):573-586. DOI: 10.1007/s11273-009-9164-4

[64] Kayranli B, Scholz M, Mustafa A, Hedmark A. Carbon storage and fluxes within freshwater wetlands: A critical review. Wetlands. 2010;30(1):111-124. DOI: 10.1007/s13157-009-0003-4

[65] Dunfield P, Knowles R, Dumont R, Moore TR. Methane production and consumption in temperate and subarctic peat soils: Response to temperature and $\mathrm{pH}$. Soil Biology and Biochemistry. 1993;25(3):321-326. DOI: 10.1016/0038-0717(93)90130-4

[66] Sanches LF, Guenet B, Marinho CC, Barros N, de Assis Esteves F. Global regulation of methane emission from natural lakes. Scientific Reports. 2019;9(1):1-10. DOI: 10.1038/ s41598-018-36519-5

[67] Bodelier PLE, Dedysh SN. Microbiology of wetlands. Frontiers in Microbiology. 2013;4:1-4. DOI: 10.3389/ fmicb.2013.00079

[68] Boon E, Meehan CJ, Whidden C, Wong DHJ, Langille MGI, Beiko RG. Interactions in the microbiome: Communities of organisms and communities of genes. FEMS Microbiology 
Reviews. 2014;38(1):90-118. DOI: $10.1111 / 1574-6976.12035$

[69] Yarwood SA. The role of wetland microorganisms in plant-litter decomposition and soil organic matter formation: A critical review. FEMS Microbiology Ecology. 2018;94:1-17. DOI: $10.1093 /$ femsec/fiy175

[70] Lennon JT, Jones SE. Microbial seed banks: The ecological and evolutionary implications of dormancy. Nature Reviews. Microbiology. 2011;9(2):119130. DOI: $10.1038 /$ nrmicro2504

[71] De Vrieze J, Regueiro L, Props R, Vilchez-Vargas R, Jáuregui R, Pieper DH, et al. Presence does not imply activity: DNA and RNA patterns differ in response to salt perturbation in anaerobic digestion. Biotechnology for Biofuels. 2016;9(244):1-13. DOI: $10.1186 / \mathrm{s} 13068-016-0652-5$

[72] Liu D, Nishida M, Takahashi T, Asakawa S. Transcription of mcrA gene decreases upon prolonged nonflooding period in a methanogenic archaeal community of a paddyupland rotational field soil. Microbial Ecology. 2018;75(3):1-10. DOI: 10.1007/ s00248-017-1063-2

[73] Adrian L, Marco-Uurrea E. Isotopes in geobiochemistry: Tracing metabolic pathways in microorganisms of environmental relevance with stable isotopes. Current Opinion in Biotechnology. 2016;41:19-25. DOI: 10.1016/j.copbio.2016.03.018

[74] Kueter N, Lilley MD, Schmidt MW, Bernasconi SM. Experimental carbonatite/graphite carbon isotope fractionation and carbonate/graphite geothermometry. Geochimica et Cosmochimica Acta. 2019;253:290-306. DOI: 10.1016/j.gca.2019.03.020

[75] Coyotzi S, Pratscher J, Murrell JC, Neufeld JD. Targeted metagenomics of active microbial populations with stable-isotope probing. Current Opinion in Biotechnology. 2016;41:1-8. DOI: 10.1016/j.copbio.2016.02.017

[76] Potter C, Melack JM, Engle D. Modeling methane emissions from Amazon floodplain ecosystems. Wetlands. 2014;34:501-511. DOI: 10.1007/s13157-014-0516-3

[77] Wilson C, Gloor M, Gatti LV, Miller JB, Monks SA, McNorton J, et al. Contribution of regional sources to atmospheric methane over the Amazon basin in 2010 and 2011. Global Biogeochem. 2016;30:400-420. DOI: 10.1002/2015GB005300

[78] Clark DB, Mercado LM, Sitch S, Jones CD, Gedney N, Best MJ, et al. The joint UK land environment simulator (JULES), model description - Part 2: Carbon fluxes and vegetation dynamics. Geoscientific Model Development. 2011;4:701-722. DOI: 10.5194/ gmd-4-701-2011

[79] Bloom AA, Palmer PI, Fraser A, Reay DS. Seasonal variability of tropical wetland $\mathrm{CH}_{4}$ emissions: The role of the methanogen-available carbon pool. Biogeosciences. 2012;9(8):2821-2830. DOI: $10.5194 /$ bg-9-2821-2012

[80] Gedney N, Cox PM, Huntingford C. Climate feedback from wetland methane emissions. Geophysical Research Letters. 2004;31:1-4. DOI: 10.1029/2004GL020919

[81] Xu X, Yuan F, Hanson PJ, Wullschleger SD, Thornton PE, Riley WJ, et al. Reviews and syntheses: Four decades of modeling methane cycling in terrestrial ecosystems. Biogeosciences. 2016;13(12):3735-3755. DOI: $10.5194 /$ bg-13-3735-2016 



\title{
Impact of Disturbances on the Biodiversity of Ijala-Ikeren Wetland Ecosystem in Niger Delta
}

\author{
Michael Aigbe Uwagbae, Abdul-Rahman Dirisu, \\ Tambeke Nornu Gbarakoro, Eman I. El Surtasi, \\ Julia Ekenma Agwu, Martins S.O. Aisien and Johnny Rotimi
}

\begin{abstract}
An assessment of Ijala-Ikeren wetland in the Niger Delta of Nigeria was conducted for 9 months for biodiversity data comprising flora and specific aquatic fauna (amphibians and insects) in order to inventorise the species and ecosystem and to ascertain the effects of anthropogenic and natural disturbances on the wetland ecosystem. Five sites comprising three sites within the mangrove swamp and two ponds at the fringes of the mangrove ecosystem were sampled. Data collection methods include insect and amphibian sampling, and a few abiotic data. Empirical data on fish fauna was also obtained from fishermen. The $\mathrm{pH}$ value of the sampled sites in the mangrove ranged between 4.7 and 6.1, while temperature ranged from 28 to $29^{\circ} \mathrm{C}$. Red mangrove species (Rhizophora sp.) and few species of white mangrove (Avicennia sp.) were dominant plants. Only three insect species from three families were encountered and thirteen species of amphibians from three families were only encountered in ponds at the fringes of the wetland. Amphibians had the highest value of species richness index (d) (2.75) and diversity index $\left(\mathrm{H}^{\prime}\right)(2.08)$. The acidic $\mathrm{pH}$ values maybe attributed to the influx of effluent from the Warri refinery about $2.5 \mathrm{~km}$ away and the low insect diversity is due to the salinity.
\end{abstract}

Keywords: amphibian, biodiversity, environmental factor, insect, mangrove wetland, Niger Delta

\section{Introduction}

Nigeria has the largest mangrove forest in Africa and the third largest contiguous mangrove forest in the world. The mangrove region is widest on the sides of the Niger Delta, 35-45 km and narrows towards the centre to a width of $15 \mathrm{~km}$ except for the channel of the Brass River, which has extensive mangroves far upstream [1].

The mangrove forests of Nigeria comprise principally only three families and six species as follows: Family, Rhizophoraceae (the red mangrove): Rhizophora racemosa, $R$. harrisonii and $R$. mangle. Of these $R$. racemosa is the most abundant covering about $90 \%$ of the mangrove forest. Avicenniaceae (white mangrove), Avicennia africana and Combretaceae (Laguncularia racemosa and Conocarpus erectus [1] and alike have been reported in most parts of the West African coast [2]. The Ijala-Ikeren 
wetland is situated in the Niger Delta region of Nigeria. The Niger Delta region of Nigeria has four main ecological zones: Coastal Barrier Islands, Mangrove swamp forests, freshwater swamp and lowland rainforest. The mangrove swamp forest among these four ecological zones is the most affected by anthropogenic influences, as it has very poor regeneration potential [3].

Anthropogenic disturbances in the Niger Delta include oil spills which has been extensive, difficult to assess and often underreported. According to [3], oil spillages in the Niger Delta most especially in the mangrove wetlands are never reported or merely branded minor without minimum post-spill containment, recovery and remediation responses. Also, the World Commission on Environment and Development (WCED) as cited by [4] had reported that the mangrove deforestation and degradation are some of the greatest factors that would cause species extinction in the Niger Delta region in the next 50 years. Consequently, it is frightening that depletion of the mangrove forest could eliminate $5-15 \%$ of species by 2020 [5]. The Niger Delta biodiversity, including the Ijala-Ikeren wetland is very important for the concomitant presence of rainforests, mangroves, and many endemic flora and fauna, which are affected by oil pollution from oil spills, usually from bunkering and pipeline vandalisation of the petroleum refinery facilities situated less than $2 \mathrm{~km}$ to the East of the Ijala-Ikeren Wetland as well as solid waste pollution.

Oil pollution and its attendant impact on the creek ecology and the community are highly visible in the mangrove swamps due to proximity of the communities to refinery and oil pipelines criss-crossing the environment. The Ijala-Ikeren wetland has been affected by industrial activities, and pollution and this has affected the water quality in the community, and arthropods (insects) and amphibians [6]. Reported that the physical and sanitary quality of hand-dug well waters from communities around the Warri refinery including Ijala-Ikeren wetland was found slightly acidic at 6.04 and may be attributed to emissions from gas flaring and petroleum refining activities, which is common in the area. They also stated that the water quality from the community's surface water bodies and aquatic insect indicators are believed to be gradually deteriorating.

The Ijala-Ikeren wetland is well watered all the year round although the level of water in the creeks drops to about two meters during the dry season and varies daily owing to tides. The current ecological regime in the wetland is the amount of water in creeks and creeklets. This water is determined by tidal flow of sea water from the Atlantic Ocean at high tide and fresh water from the mainland into the Ocean at low tide. The continuous mixing of fresh and sea water gives rise to the brackish nature of water in the creeks and creeklets and in the mangrove swamp. Any change in the water regime either through the stoppage of sea water flowing into the wetland or fresh water flowing into the Ocean, will certainly change the ecology of the wetland and its current composition. The potential route of off-site contaminants to the ecosystem is by Ijala-Ikeren creeks and creeklets. The discharge of water from the creeks to the mangrove ecosystem is constant and runs all through the year but quantity and volume of water available in the mangrove and creeks are unstable [7]. Higher volumes of water are available in the rainy season due to runoffs and inter-tidal nature of the Warri River especially during high tide (personal communication).

Aquatic insects play very important role in food webs, and particularly in wetlands, the larval and adult stages provide a wholesome meal to fish [7], shorebirds [8] and other creatures in the Niger Delta mangroves. They are essential elements in food webs, essentially in energy flow and nutrient cycling [9]. This food source is key to the survival strategy of some fishes, amphibians and other animals. Selected aquatic insects are predators and in consuming their watery prey they help keep the insect population stable and functioning. Many species of aquatic insects are very 
sensitive to pollution and other environmental hazards, thus they reflect environmental changes and as a result are often used as indicators of the effects of human activity on water system and provide information on habitat and water quality [10]. Also some aquatic insects help keep the water clear by filtering it, others support in breaking down fallen dead leaves, while yet others clear the algae, allowing the water to produce more oxygen $[11,12]$.

Amphibians have important roles within nature and their sensitivity to changing environmental conditions may help determine the health of an ecosystem. They constitute an important part of food chain and contain important pharmaceutical compounds on their skin [13]. The International Union of Conservation of Nature (IUCN) Red List of threatened species has identified amphibians as being the most threatened vertebrate group, with about $40 \%$ at risk of extinction. The extinction and decline have been variously attributed to habitat loss, pollution, climate change, wild fire and over-exploitation [14].

Recent studies have documented the incidence and severity of sediment contamination by heavy metals in mangrove ecosystems $[15,16]$. Contaminants are released via industrial activities and ultimately enter aquatic ecosystems $[16,17]$.

Industrial effluent is a common anthropogenic impact on aquatic ecosystems including mangroves and this kind of pollution changes physical and chemical characteristics of aquatic systems, thus affecting the assemblage of aquatic fauna $[17,18]$.

The mangrove forests and salt marshes control the tidal wetland ecosystem dynamics and contribute to the development and condition of the tidal saline wetland ecological communities [19]. Mangrove forests and salt marshes are highly valued ecosystems; however, mangrove forests and salt marshes maintain divergent ecological communities and a different suite of goods and services [20]. Climate change, environmental stress and anthropogenic activities can cause the conversion of mangrove forest to salt marshes, with positive and negative expected and unexpected consequences (e.g., effects upon fish and wildlife populations, ecosystem resilience, nutrient cycling, and variation of texture and soil geochemistry). The physicochemical conditions and ecological implications of these mangrove forests to salt marshes conversions are poorly understood, but would likely include changes in soil, water, associated wildlife populations and supply of some ecosystem goods and services $[21,22]$.

The lack of publications on the biodiversity (particularly on the indicator species) - such as the insects and amphibians in Ijala-Ikeren wetlands of the Niger Delta, necessitated this study. Hence, this preliminary study was aimed at evaluating the abundance, community structure and diversity of biodiversity therein coupled with temperature, salinity and the $\mathrm{pH}$ levels of the ecosystem. We therefore, welcome future collaboration with available funding for a robust study.

\section{Materials and methods}

\subsection{Study area}

The study was conducted in Ijala-Ikeren wetland located within latitude $05.55^{\circ} \mathrm{N}$ and $05.57^{\circ} \mathrm{N}$ and longitude $05.68^{\circ} \mathrm{E}$ and $05.70^{\circ} \mathrm{E}$ in Warri, Delta State, Nigeria (Figure 1). The wetland is a brackish network of creeks and creeklets, and marshes with one or more relatively narrow connections to the sea.

The study area which covers a space of $1 \mathrm{~km}^{2}$ was divided into 2 regions: interior region bearing three sites; site 1, 2 and 3, and edges (fringes) region bearing sites 4 and 5 . Altogether, 5 sites were engaged. Site 1 is located at the position, $05.55940^{\circ} \mathrm{N}$, 


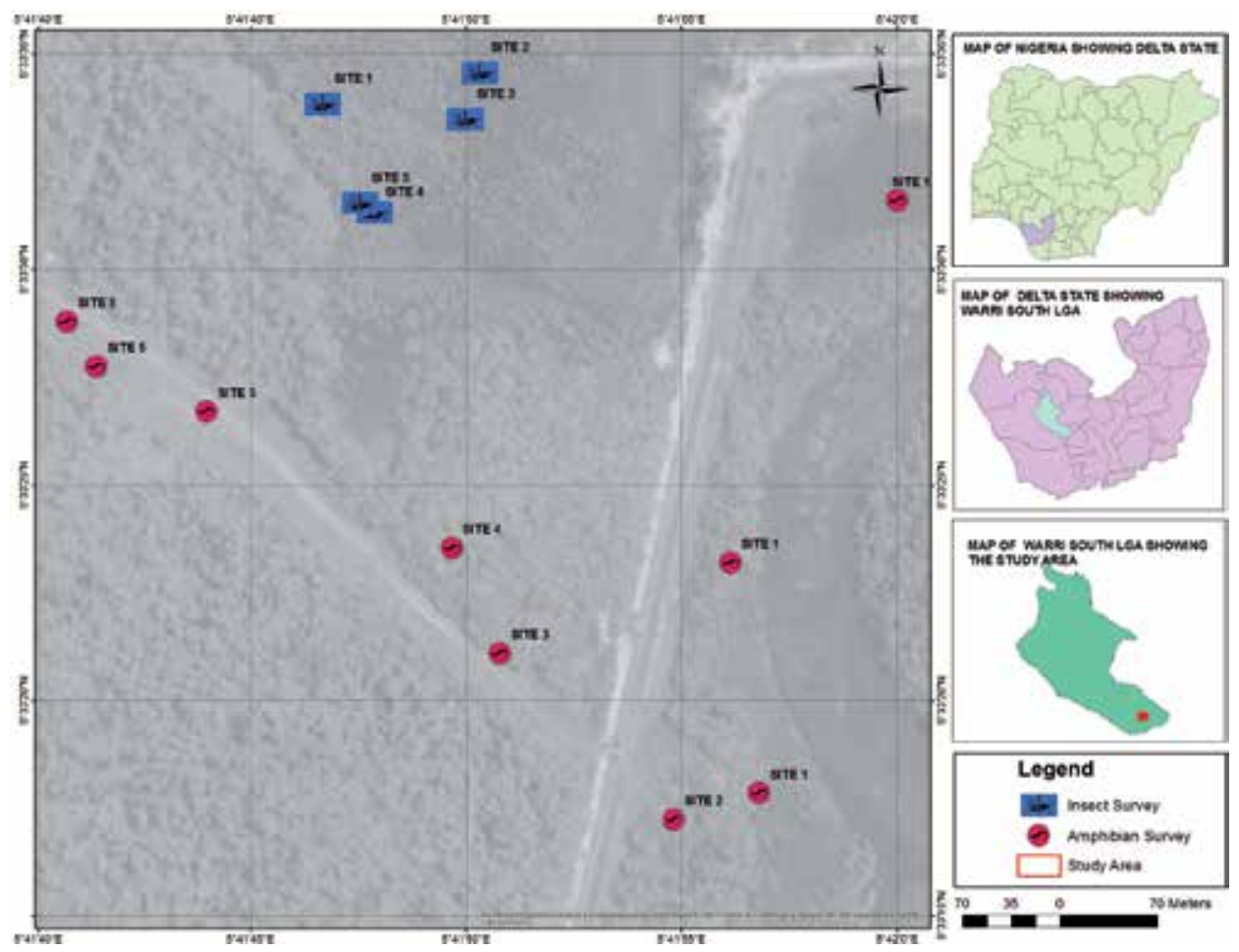

Figure 1.

Map of the study area.

and $05.69630^{\circ} \mathrm{E}$. The substratum here was covered with an admixture of black muddy and clayey sediment with an average depth of $0.2 \mathrm{~m}$. Tidal flow was low and was at a low transparency. Vegetation here includes Rhizophora racemosa, Rhizophora harrisonii and Rhizophora mangle. This site is situated immediately after edges. Meanwhile, site 2 has the same substratum coverage and depth with site 1 . The vegetation cover included thick stands of Rhizophora racemosa, Rhizophora harrisonii and Avicennia africana. The site is located at $05.44960^{\circ} \mathrm{N}$ and $05.69731^{\circ} \mathrm{E}$. This site was very close to the oil pipelines. The last site in interior region; site 3 , had the same substratum coverage and depth with sites 1 and 2 . The vegetation cover were; $R$. racemosa, $R$. harrisonii and Nymphaea lotus (Water lily). The site is located at $05.55930^{\circ} \mathrm{N}$ and $05.69722^{\circ} \mathrm{E}$. On the other hand, the two study sites representing the edges (fringes) region were sites 4 and 5. Site 4-the substratum was clayey with an average depth of $1.2 \mathrm{~m}$, stagnant water with high infestation of invasive species such as water hyacinth (Eichhornia crassipes) most importantly. While at site 5-the substratum was clayey too with an average depth of $<1 \mathrm{~m}$. Stagnant water and some grasses occurred at this site. It was located at $05.55876^{\circ} \mathrm{N}$ and $05.69654^{\circ} \mathrm{E}$. These sites (1-5) were selected on the strength of the tide and vegetation cover.

\subsection{Environmental condition}

Physicochemical parameters such as air temperature, water temperature, and $\mathrm{pH}$ were determined in situ. Temperatures were measured using the $0-100^{\circ} \mathrm{C}$ mercury in glass thermometer (Kurison Model-59). The $\mathrm{pH}$ was determined in situ using digital $\mathrm{pH}$ meter (consort 121, Belgium) adopted from [23]. While, salinity was determined in the laboratory by using HACHCO150 Model for total dissolved solid/ conductivity/salinity meter. 


\subsection{Vegetation cover}

A description of the vegetation cover in and around the wetland was undertaken. Diversity of species of mangroves was recorded from the two studied regions. We used a [24] sampling technique for rapid assessment of the mangal vegetation of the brackish ecosystem in the study area by walking around at low tide. This involved a reconnaissance survey of the study stations of the Ijala-Ikeren mangrove ecosystem where a systematic sampling along the directed transects was applied to conduct the flora survey of the study sites.

\subsection{Insect sampling}

Insect sampling was conducted in the dry season (October 2013-February, 2014) and in the wet season (March-June, 2014). It was a 9 month study. Collection of samples was carried out through the use of sweep and kicks nets, and hand collection. Access to the mangrove interiors was through Falcorp Mangrove Park. Hand collections were made from wetland (mangrove) plants and from ant hive (Figure 2). The sieve-like dip net was used to collect aquatic insects from a distance on the mangroves while small aquatic nets were used to collect specimens in the aquatic plant (Nymphaea lotus and Water lily) while in water. Specimens collected were placed in vials containing $70 \%$ ethanol solution $\left(\mathrm{C}_{2} \mathrm{H}_{6} \mathrm{O}\right)$.

Kick sampling method modified after [23] was used to collect aquatic insect larvae (macro-invertebrates) for $3 \mathrm{~min}$. We used $1 \mathrm{~min}$ to conduct searches before disturbing the water column and placing the net against the direction of the current for actual sampling. This method was also used to collect insects from water surface, from boulders, logs of wood and plants (Figure 3). All the collected specimens were identified using keys of [25-27]. The identified specimens were counted and placed into vials of $70 \%$ ethanol $\left(\mathrm{C}_{2} \mathrm{H}_{6} \mathrm{O}\right)$ which were well labelled indicating the location and date of collection.

\subsection{Amphibian fauna}

Sampling for amphibian was conducted using the Visual Acoustic Encounter Survey (VAES) method (i.e. listening to amphibians call and tracing the calls) at night and the anurans were captured by handpicking. The method was used along the trunk road (edges) traversing the area and in the interiors wetland (mangrove swamp) through the access to Falcorp Mangrove Park. Collection at the park was both during the day and at night.

\subsection{Fish study}

We used empirical method to ascertain the occurrences and diversity of fish species within Ijala-Ikeren wetland from the local fishermen at a few fish landings therein. A few fish species were equally sighted, observed and noted in-situ.

\subsection{Statistical analysis of data}

Overall diversity of soil insect was expressed as species richness, abundance, evenness and Simpson diversity index. Species richness and diversity patterns are a fundamental point for any scientific act in conservation biology [28]. Species richness represents the simplicity of describing communities at different scales and its broadly understood meaning. The complementary picture of overall diversity pattern of any community was documented by information about the abundance of 


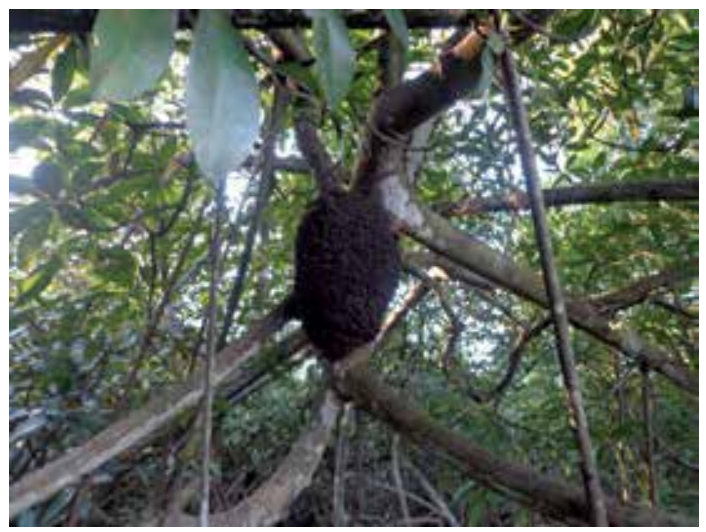

Figure 2.

An ant hive hanging on a mangrove plant in Ijala-Ikeren mangrove swamp where insect collection was made.
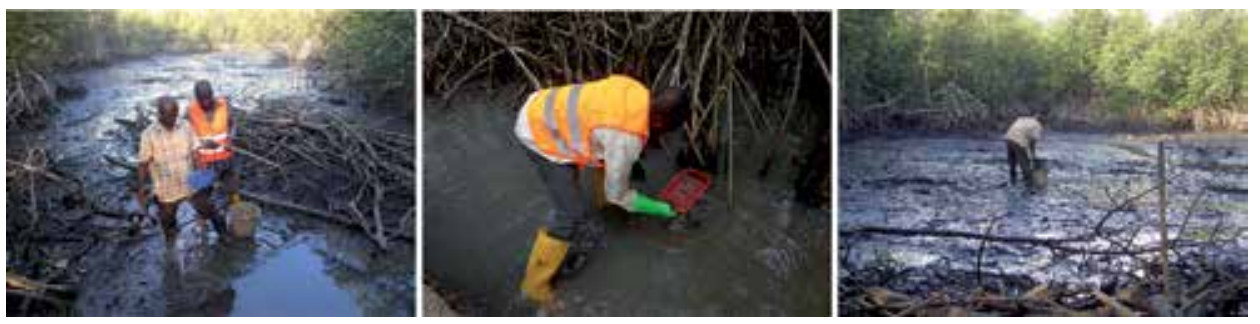

Figure 3.

Insect collection from under woods, logs and fallen leaves in Ijala-Ikeren mangrove.

species, the evenness of communities across the sampling region or the dominant species. Abundance is the kind of diversity measures that has inclusively been considered as equivalent to biodiversity per se [29] and referred to the sum of individuals in area. However, Simpson diversity index (D) is nearly the most tractable and statistically useful calculation [30]:

$$
\lambda=\sum p i^{2}, D=1-\lambda
$$

Where $\mathrm{D}$ is Simpson diversity index, $\lambda$ is an index of dominance. $\mathrm{p}_{\mathrm{i}}$ is the proportion of the community occupied by the ith species.

All parameters of diversity were calculated with PAST (version. 1.92) software running on Windows ${ }^{\circledR} \mathrm{XP},[31]$.

\section{Results}

\subsection{Environmental condition}

The mean values of physical parameters were recorded at the study sites. Air temperature ranged between 29 and $29.50^{\circ} \mathrm{C}$ in the mangroves (interior) and $30^{\circ} \mathrm{C}$ at the fringes (edges), while water temperature was between 28.50 and $29^{\circ} \mathrm{C}$ in the interior and $28-29^{\circ} \mathrm{C}$ at the edges (Table 1). On the other hand, the measured pH values ranged between 4.8 and 4.9 in the interior and 5.3-6.1 at the edges, and salinity values were between 1.50 and $1.70 \mathrm{ppm}$ (Table 1). 


\subsection{Vegetation cover}

The study also included the description of the vegetation in and around the wetland. It showed that the mangrove swamp in Ijala-Ikeren wetland is covered by three species of Rhizophora (red mangrove): Rhizophora racemosa, $R$. harrisonii and $R$. mangle. (Table 2). Other flora species found were Avicennia africana (white mangrove), Eichhornia crassipes (water hyacinth) which occurred on the fringes of mangrove swamp floating in the pond and Pandanus candelabrum (Table 2).

\subsection{Insect composition and diversity}

The sampled insects were identified into three orders: Hemiptera, Hymenoptera and Diptera. As shown in Table 3, Aquarius remigis, Formica sp. and Chironomus sp. were the identified species. Of these three species, only the order Hemiptera (Family: Gerridae) Aquarius remigis (Water strider) (adult)

\begin{tabular}{lccccc}
\hline Parameter & $\begin{array}{c}\text { Site1(Ijala- } \\
\text { Ikeren } \\
\text { mangrove) }\end{array}$ & $\begin{array}{c}\text { Site 2 } \\
\text { (Ijala- } \\
\text { Ikeren } \\
\text { mangrove) }\end{array}$ & $\begin{array}{c}\text { Site 3 } \\
\text { (Ijala- } \\
\text { Ikeren } \\
\text { mangrove) }\end{array}$ & $\begin{array}{c}\text { Site 4 (pond } \\
\text { infested } \\
\text { with water } \\
\text { hyacinth at } \\
\text { the fringe of } \\
\text { mangrove) }\end{array}$ & $\begin{array}{c}\text { Site 5 } \\
\text { (backhouse } \\
\text { pond close to } \\
\text { the boundary of } \\
\text { the mangrove } \\
\text { swamp) }\end{array}$ \\
\hline $\begin{array}{l}\text { Air } \\
\text { temperature } \\
\left({ }^{\circ} \mathrm{C}\right)\end{array}$ & 28.00 & 29.00 & 29.50 & 30.00 & 30.00 \\
\hline $\begin{array}{l}\text { Water } \\
\text { temperature } \\
\left({ }^{\circ} \mathrm{C}\right)\end{array}$ & 29.00 & 29.00 & 28.50 & 28.00 & 29.00 \\
\hline pH & 4.8 & 4.7 & & & \\
\hline $\begin{array}{l}\text { Salinity } \\
(\mathrm{ppm})\end{array}$ & 1.55 & 1.50 & 1.70 & & \\
\hline
\end{tabular}

Table 1.

Mean values of physical parameters of sampled sites in Ijala-Ikeren mangrove swamp and fringes.

\begin{tabular}{|c|c|c|c|c|}
\hline $\mathbf{S} / \mathbf{N}$ & Common name & Scientific name & Habitat & Uses \\
\hline 1 & Red mangrove & Rhizophora racemosa & Mangrove swamps & $\begin{array}{l}\text { Fuel wood, } \\
\text { timber }\end{array}$ \\
\hline 2 & Red mangrove & Rhizophora harrisonii & Mangrove swamps & $\begin{array}{l}\text { Fuel wood, } \\
\text { timber }\end{array}$ \\
\hline 3 & Red mangrove & Rhizophora mangle & Mangrove swamps & $\begin{array}{l}\text { Fuel wood, } \\
\text { timber }\end{array}$ \\
\hline 4 & White mangrove & Avicennia africana & Mangrove swamps & $\begin{array}{l}\text { Fuel wood, } \\
\text { timber }\end{array}$ \\
\hline 5 & Screw pine & Pandanus candelabrum & Mangrove swamps & - \\
\hline 6 & Water hyacinth & Eichhornia crassipes & $\begin{array}{l}\text { Fringes of mangrove } \\
\text { swamp } \\
\text { Floating in ponds }\end{array}$ & - \\
\hline
\end{tabular}

Table 2.

List of identified flora in Ijala-Ikeren mangrove swamp and fringes. 


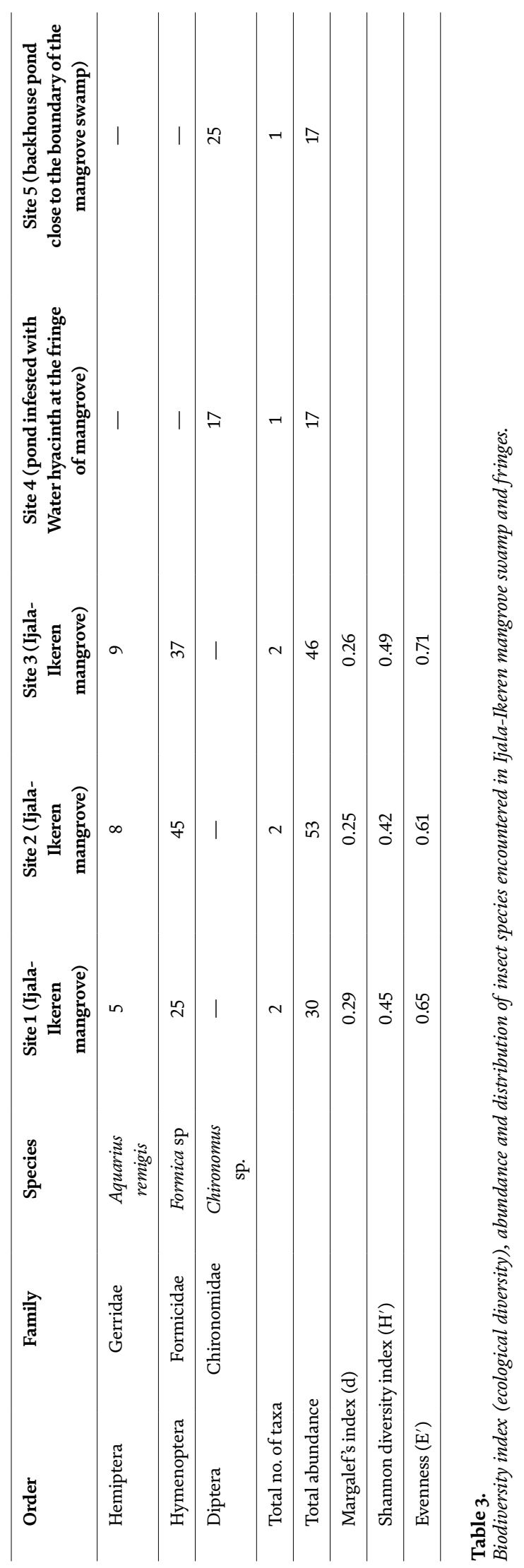


was found in the wetland. Meanwhile, Formica sp. (Hymenoptera: Formicidae) were handpicked from hives hanging from mangrove plants using forceps. No significant difference was detected among insect species $\left(\mathrm{F}_{(2,14)}=1.5, \mathrm{P}<0.3\right)$ in their abundance. The most specious abundant was Formica sp. (62.6\%) followed by the dipteran species; Chironomus sp. (24.6\%) in total catch of insect individuals (171 individuals).

Spatially, the three study sites in the interior (mangrove swamp) represented the highest percentage (75.5\%) of species abundance, where Aquarius remigis and Formica sp. were the only identified species there. Meanwhile, the other abundance percentage (24.5\%) was recorded at the edges (fringes) in the ponds (other two sites) in relating to the abundance of one species; Chironomus sp.

As shown in Table 3, the study sites at the mangrove swamp were the richest area with species number ( 2 species), site 1 had the greatest value in Margalef's species richness index (d) and diversity of species out of these sites. On the other hand, site 2 had the least value of both indices.

\subsection{Amphibian composition and diversity}

A total of ninety-one (91) individual amphibians were collected in this study. Thirteen amphibian species belonging to three different families were identified: Bufonidae, Hyperoliidae and Ranidae. All these species were collected from the edges (fringes) of the mangrove swamp (Table 4).

\begin{tabular}{|c|c|c|c|}
\hline Family & Species & Abundance & $\begin{array}{c}\text { Family } \\
\text { abundance \% }\end{array}$ \\
\hline Bufonidae & Amietophrynus maculatus & 3 & $3.30 \%$ \\
\hline \multirow[t]{8}{*}{ Hyperoliidae } & Afrixalus dorsalis & 23 & $60.40 \%$ \\
\hline & Afrixalus fulvoguttatus & 2 & \\
\hline & Afrixalus sp.? & 1 & \\
\hline & Hyperolius concolor & 13 & \\
\hline & Hyperolius fusciventris burtoni & 2 & \\
\hline & Hyperolius guttulatus & 1 & \\
\hline & Hyperolius sp. 1 & 12 & \\
\hline & Hyperolius sp. 2 & 1 & \\
\hline \multirow[t]{4}{*}{ Ranidae } & Hoplobatrachus occipitalis & 6 & 36.3 \\
\hline & Ptychadena bibroni & 4 & \\
\hline & Ptychadena oxyrhynchus & 9 & \\
\hline & Ptychadena pumilio & 1 & \\
\hline Total no. of taxa & & 13 & \\
\hline Total abundance & & 91 & \\
\hline Margalef's index (d) & & 2.75 & \\
\hline Shannon diversity index $\left(\mathrm{H}^{\prime}\right)$ & & 2.08 & \\
\hline Evenness $\left(\mathrm{E}^{\prime}\right)$ & & 0.08 & \\
\hline \multicolumn{4}{|c|}{$\begin{array}{l}\text { The 'E' which was very manifest in the unidentified Hyperolid (Hyperolius sp 1), Hyperolius occidentalis and } \\
\text { Afrixalus dorsalis (Figure A1). These could be cryptic colourations to enable them escape detection by predators in } \\
\text { their exposed habitats. }\end{array}$} \\
\hline
\end{tabular}

Table 4.

Abundance and distribution of amphibian fauna encountered in Ijala-Ikeren mangrove swamp and fringes. 


\begin{tabular}{|c|c|c|}
\hline $\mathrm{S} / \mathrm{N}$ & Common name & Scientific name \\
\hline 1. & Trunkfish & Gymnarchus niloticus \\
\hline 2. & African Bonny Tongue & Heterotis niloticus \\
\hline 3. & Characin & Alestes macrolepidotus \\
\hline 4. & Moonfish & Cuherinus cuherinus \\
\hline 5. & Cyprinit-African Carp & Labeo spp. \\
\hline 6. & - & Eutropius niloticus \\
\hline 7. & Catfish & Bagrus bayad \\
\hline 8. & Silver Catfish & Chrysichthys nigrodigitatus \\
\hline 9. & Catfish & Auchenoglanis occidentalis \\
\hline 10. & Electric Fish & Malapterurus electricus \\
\hline 11. & Niger Perch & Lates niloticus \\
\hline 12. & Tilapia & Tilapia galilaea \\
\hline 13. & Tilania & Tilapia aurea \\
\hline 14. & Tilapia & Tilapia zilli \\
\hline 15. & Snakehead & Channa obscura \\
\hline 16. & - & Hemichromis spp. \\
\hline 17. & Clarias & Clarias spp. \\
\hline 18. & - & Hemichromis fasciatus \\
\hline 19. & Elephant Snout Fish & Mormyrus macrophthalmus \\
\hline 20. & - & Polypterus senegalus \\
\hline
\end{tabular}

Table 5.

Indicative checklist of the fishes found in Ijala-Ikeren wetland.

Hyperoliidae was the most abundant one among the identified species (eight taxa) with an abundance of fifty-five individuals species. One feature of this group was the tendency to present different morphs (colour shade, pigmentation and design). Among this group, the dominant species was Afrixalus dorsalis (family: Hyperoliidae). The rare species were Hyperolius guttulatus and Ptychadena pumilio, Hyperolius sp. 2 and Afrixalus sp. About $30.8 \%$ of the identified species were grass frogs belonging to the family Ranidae, the genus Ptychadena had the dominant number of species (3 species); Ptychadena bibroni, P. Oxyrhynchus and P. Pumilio (Table 4). Meanwhile, only one species; Amietophrynus maculatus, was identified belonging to the family Bufonidae.

\subsection{Fish fauna diversity}

A checklist of the fish species is presented in Table 5. Catfish and Tilapia were the dominant species in the entire study area. A total of twenty representative species were recorded throughout.

\section{Discussion}

The study of vegetation in Ijala-Ikeren wetland clarified the richness of mangrove species, which is covered by about 95\% Rhizophora species (red mangrove) 
and Avicennia africana (white mangrove) with 5\% other species, mostly Pandamus candelabrum and Eichhornia crassipes. This vegetation community richness of biotic community is more present and stable [32]. The complete absence of Ephemeroptera, Diptera, Odonata, Coleoptera, Trichoptera and Arachnida especially mesofauna were observed which may be due to the brackish water predominantly. A significant change was also detected in the environmental condition with particular reference to $\mathrm{pH}$ value, which was estimated at between 6.3 in 2009 and decreased to 4.8 on the average (acidic value). This may be attributed to the absence of the above listed arthropod orders especially as insects cannot tolerate the slightest change in salinity values beyond the fresh water concentration. This same scenario could be playing out for the amphibians, as none were recorded or encountered in the wetland (within the mangroves). This phenomenon has certainly explained the very low occurrence of species diversity of insects and amphibians populations and occurrences in the wetland ecosystems. This is particular for insects, as no aquatic insect larvae were encountered or collected during the survey period. Similarly, no amphibian eggs/tadpoles or adult forms were encountered inside the mangrove habitats of Ijala-Ikeren wetland.

The acidity of water was explained by [6] who investigated the impact of refinery effluents around Warri Refinery and Petrochemical Company (WRPC) on surface waters of the creeks and soil qualities of host communities within and around Ijala-Ikeren wetland, and concluded the change in water $\mathrm{pH}$ to be 6.3, while the soil $\mathrm{pH}$ was 6.8 in Ijala-Ikeren wetland. This inference may be related to the discharge of these effluents from Warri Refinery and Petrochemical Company (WRPC) into Warri River which feeds the Ijala waters and also crude oil and its fraction seepages from numerous loading and off-loading jetties within the river which finds its way into the creeks in the Ijala-Ikeren wetland. They further stated that the Warri River is open to flooding which carries various contaminants. Contrary to our findings in water $\mathrm{pH}$, the sediments studies conducted elsewhere in the Mexican pacific and Thailand, recorded alkaline $\mathrm{pH}$ values ranging from 6.91 to $7.83[18,22]$.

Secondly, the discovery of illegal toxic waste dumpsites belonging to WRPC within these wetlands (pers. comm.) could increase the pollutant load of the study area. In turn, the highest concentration of calcium and salinity level was reported at the surface water within the wetland as reported by [6] though we did not analyse for calcium and heavy metals in this study. Also, heavy metals in varying concentrations and reasonable quantity from refinery effluents that resulted from Nigeria's crude oil could be one of the contributing factors to the acidic $\mathrm{pH}$ values. Especially, the metallic components in crude oil which are in the form of metalloporphyrin chelates, transition metal complexes, organometallic compounds, carbonyl acid salts of polar functional groups and colloidal minerals while other inorganic constituents of crude oil are sulphur, nitrogen, and oxygen [33].

Spatially, the study sites at the mangrove swamp was the richest habitat in terms of species number of insects, site 1 had the greatest value in Margalef's species richness index $(d)$ and diversity of species out of these sites. This result may relate to increasing the renewal of water during high tide as a common phenomenon in the area which could give rise to runoffs of debris from land into the mangrove. On the other hand, site 2 had the least value of both indices. As expected, this study site was characterised by its proximity to oil pipelines which over time had ruptured severely due to vandalisation and outlet that leads into the creeks. 
Among the sampled insects, the presence of Chironomus sp. and Aquarius remigis at low salinity $(<2 \mathrm{ppm})$ and acidic $\mathrm{pH}$ of surface water were detected. Chironomus sp. (Dipteran-Chironomidae) is tolerant of polluted water and an indicator of poor water quality with reduced oxygen concentration, and unhealthy ecosystem $[34,35]$. Therefore, this is a clear indication of the effect of the effluent on the biotic components of the water ecosystem.

Many amphibian species and their eggs are unable to tolerate and thrive in the brackish/salty environments of the mangrove (interior). One species, $H$. occipitalis was however an exception; this frog was encountered in several stagnant pools of water along the earth road leading to the wetland. Some individuals of this frog were sighted in a backhouse pond (edge) sharing boundary with the Ijala-Ikeren mangrove wetland.

So, the presence of Aquarius remigis and amphibian species; Hoplobatrachus occipitalis, at $\mathrm{pH}$ value of 4.1-4.9 indicates that the two species are indicator species of high acidic $\mathrm{pH}$ value. Those species whose presence occurred in acidic water bodies are tolerant of such environment and could be good candidate for monitoring changes in $\mathrm{pH}$ values in aquatic ecosystem especially brackish water including mangrove swamps. In accordance with the record of [36] these species of frog were found in some Nigerian waters at lower $\mathrm{pH}$ value which ranged from 4.1 to 4.2 .

The presence of the insect (Chironomus sp.) and amphibians (Hyperolius concolor, $H$. burtoni, $H$. guttulatus and two unidentified Hyperolius species of Afrixalus dorsalis, A. fulvovitattus and Afrixalus sp.) are indicators of high levels of contamination of water from petroleum refinery effluents, however, we did not analyse the content of the effluent. They are indicators of acidic water of $\mathrm{pH}$ value between 5.3 and 6.1. In addition, the absence of aquatic insects in the adjacent mangrove swamps within Ijala-Ikeren wetlands tells us of the high level of contamination trends in the mangrove and creeks/creeklets in the area which may have generally affected the density of fish catch (outside overfishing, and using the wrong fishing gears) in the area which is a major source of livelihood for the host communities (personal communication). This invariably has affected the income of the people and also their protein intake. Despite the diversity of fish fauna (20 individual species), the fishermen remarked that the population of fish per catch is fast dwindling a situation they attributed to human induced factor rather than natural. [23] asserted that fish and crustaceans species are well supported in an alkaline $\mathrm{pH}$ value of water greater than 7. Furthermore, the absence of amphibians in the mangrove equally raises concern as amphibians have important roles to play within nature and their sensitivity to changing environmental conditions may help determine the health of an ecosystem.

Species richness measures the number of different kinds of species present in a particular area. Margalef's Species Richness index (d) values range from 1 to 5 where the higher index indicates the greater diversity (Table 3). Shannon diversity index $\left(\mathrm{H}^{\prime}\right)$ takes into account the number of species and the evenness of the species. Diversity $\left(\mathrm{H}^{\prime}\right)$ values less than 1.0 are considered very low; between 1.0 and 3.0 have moderate diversity, while any value greater than 3.0 signifies high diversity and ecosystem stability (i.e. similar to a pristine ecosystem). Evenness ( $\left.E^{\prime}\right)$ refers to how evenly each species is represented in a given ecosystem. Equitability assumes a value between 0 and 1 with 1 being complete evenness.

The abundance was very evident in the order Hymenopteran (Formica sp.) (Appendix, Figure A2). These could be adduced to the fact that most arboreal ants 
are at least partially herbivorous-feeding on extra-floral nectaries, food bodies, pollen, epiphylls, and sap. They are also cryptic herbivores that feed on hemipteran honeydew [21, 37, 38].

\section{Conclusion/recommendation}

Oil pollution from oil spills usually from illegal bunkering and pipeline vandalisation of the petroleum refinery facilities situated less than $2 \mathrm{~km}$ to the East of the wetland, and solid waste pollution are the major threats to this unique wetland. The Ijala-Ikeren wetland ecosystem has been affected by industrial activities and pollution, and these have affected the insect species and the amphibians. Based on the findings of this study, it has been established that the wetland ecosystem is highly stressed from contaminants with records of high acidic $\mathrm{pH}$ values which has resulted in the absence of aquatic insects and reduced fishes. The study pointed out that over 5 years (between 2009 and 2014) drastic changes in $\mathrm{pH}$ values occurred in the wetlands, as it reduced from 6.3 in 2009 to 4.8 in 2014. This could deteriorate more to a very precarious situation in the next 5 years if the pollution source is still left unattended to.

The study has shown that amphibian population in Ijala-Ikeren wetland appeared not to be under threat or extinction in spite of their absence at the mangroves; as thirteen (13) species were encountered with some equally having preference for acidic ponds. The results also showed that degradation of the wetland is on-going and it will be recommended that wetland conservation should be encouraged to forestall further loss of biodiversity. In doing this, adequate channels to set up a national awareness campaign among coastal and marine communities in the Niger Delta in conserving wetlands be identified. This becomes necessary as there are over nine (9) enacted national legislation/Acts for the protection of wetlands but their enforcement has been very weak. So government needs to mobilise in order to save our wetlands.

Government and non-governmental agencies should encourage studies on the inventory of aquatic insect species of water bodies in the host communities around the refinery to determine the health and pollution status of the aquatic ecosystem via funding.

\section{Acknowledgements}

The funding for this research was provided by the Duke University Marine Laboratory/Oak Foundation Mini-Grant for marine conservation project to the first author (MAU). We are very much grateful to Duke University Marine Lab at Beaufort, NC USA. Thanks to Mr. Henry Erikowa, managing director of Falcorp Mangrove Park, Ijala-Ikeren in Warri for providing logistics for the team during the study. Special thanks also go to Messrs. Abiloye Erikowa and Festus Arijode for their various field assistance.

\section{Conflict of interest}

The authors have not declared any conflict of interests. 


\section{A. Appendixes}

(a)

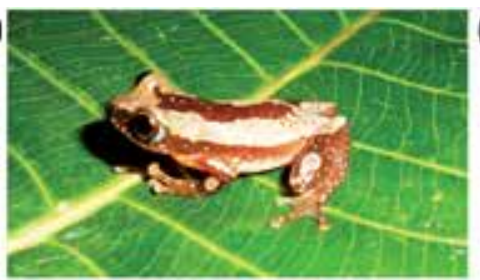

(c)

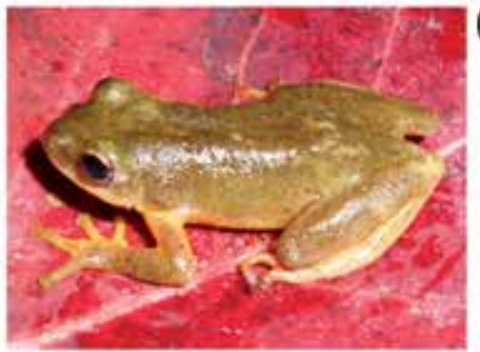

(e)

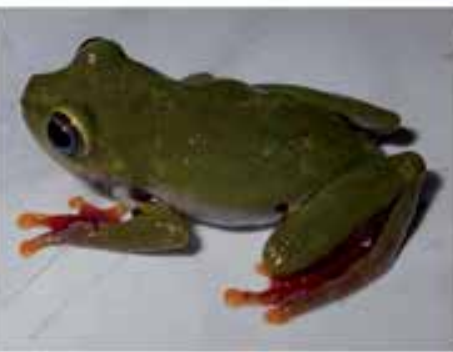

(g)

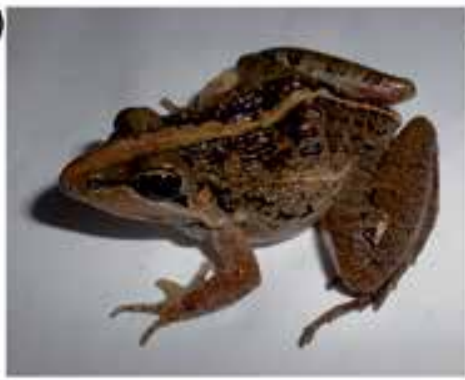

(i)

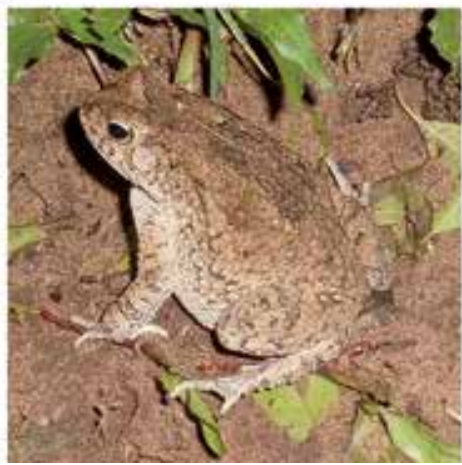

(b)

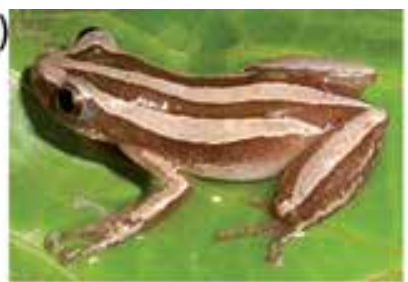

(d)

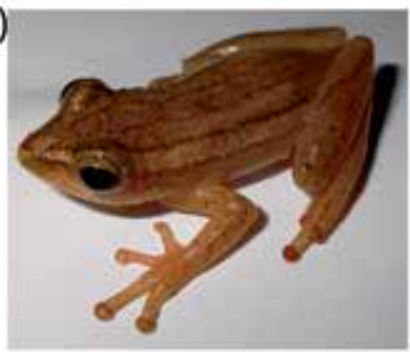

(f)

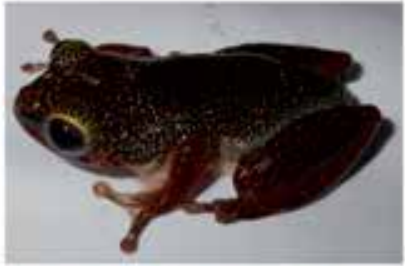

(h)

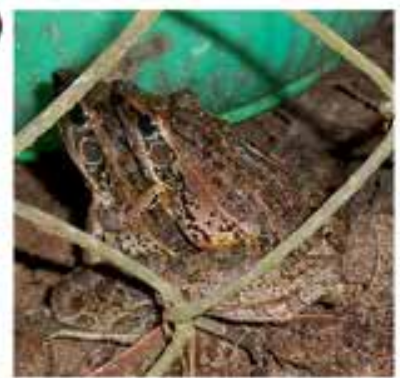

(j)

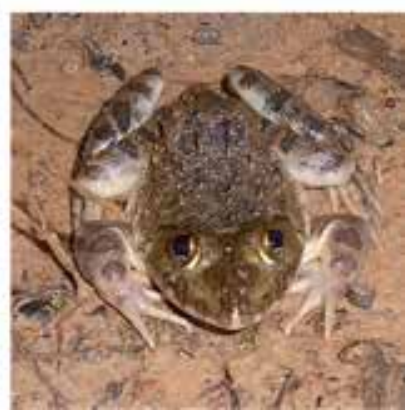

Figure A1.

(A-J) Anurans species encountered at Ijala-Ikeren community. (A) Afrixalus dorsalis; (B) Afrixalus fulvoguttatus; (C) Hyperolius concolor (phase C); (D) H. concolor (phase B); (E) Hyperolius fusciventris burtoni; (F) Hyperolius guttulatus; (G) Ptychadena bibroni; (H) Ptychadena oxyrhynchus; (I) Amietophrynus maculatus; (J) Hoplobatrachus occipitalis. 
Impact of Disturbances on the Biodiversity of Ijala-Ikeren Wetland Ecosystem in Niger Delta DOI: http://dx.doi.org/10.5772/intechopen.82604
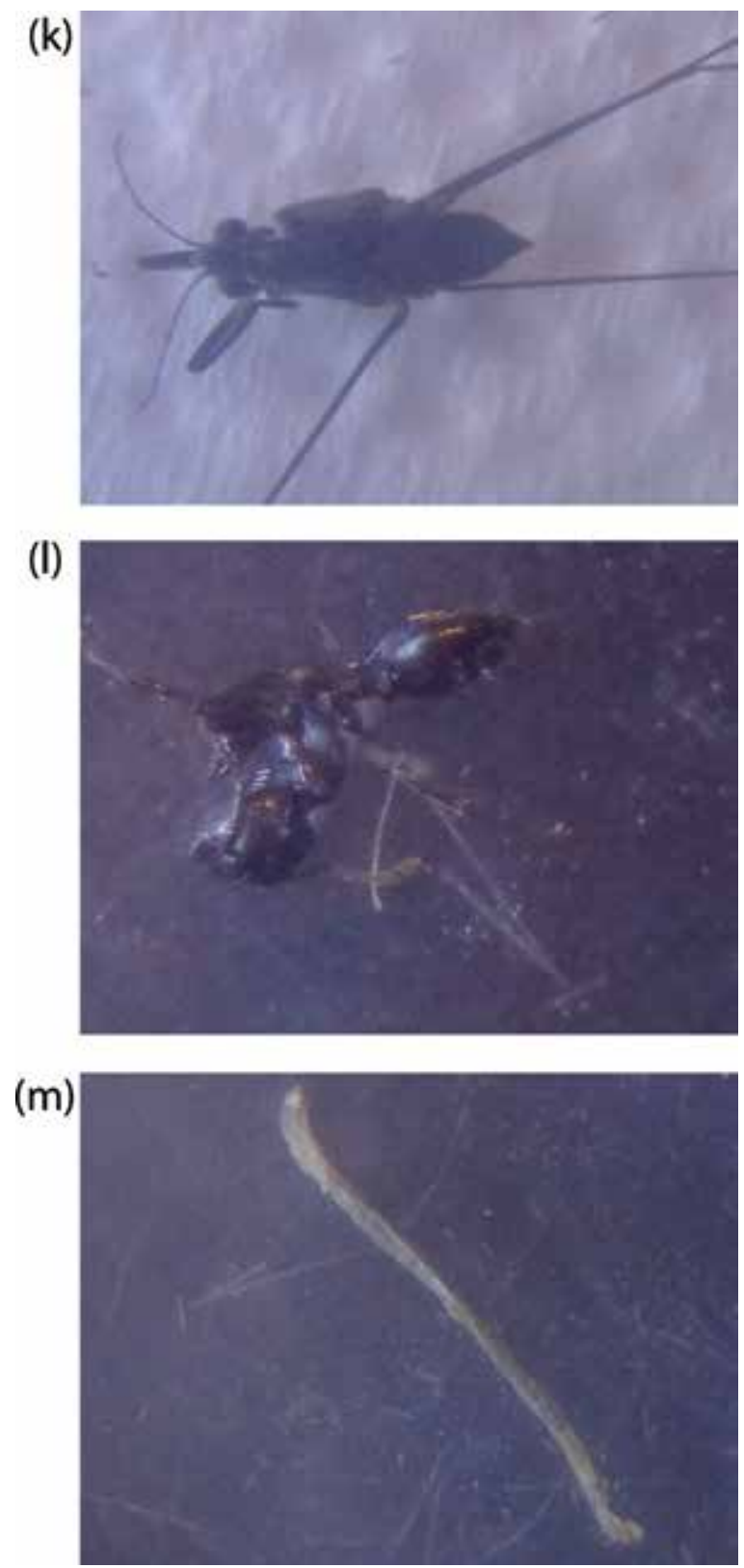

Figure A2.

(K-M) Insect species encountered at Ijala-Ikeren community. (K) Aquarius remigis; (L) Formica sp; $(M)$ Chironomus sp. 


\section{Author details}

Michael Aigbe Uwagbae ${ }^{1,2 *}$, Abdul-Rahman Dirisu ${ }^{1}$, Tambeke Nornu Gbarakoro ${ }^{3}$, Eman I. El Surtasi ${ }^{4}$, Julia Ekenma Agwu ${ }^{5}$, Martins S.O. Aisien ${ }^{1}$ and Johnny Rotimi ${ }^{1}$

1 Department of Animal and Environmental Biology, University of Benin, Benin City, Nigeria

2 Wetlands International, Port Harcourt, Nigeria

3 Department of Animal and Environmental Biology, University of Port Harcourt, Port Harcourt, Nigeria

4 Department of Zoology, Faculty of Science, Damietta University, Egypt

5 Department of Zoology and Environmental Biology, Faculty of Biological Sciences, University of Nigeria, Nsukka, Nigeria

*Address all correspondence to: mikeuwagbae@gmail.com

\section{IntechOpen}

(c) 2019 The Author(s). Licensee IntechOpen. This chapter is distributed under the terms of the Creative Commons Attribution License (http://creativecommons.org/licenses/ by/3.0), which permits unrestricted use, distribution, and reproduction in any medium, provided the original work is properly cited. $(\mathrm{cc}) \mathrm{BY}$ 


\section{References}

[1] Abere SA, Ekeke BA. The Nigerian mangrove and wildlife. In: Proceedings of the 1st International Technology, Education and Environment Conference. Human Resource Management Academic Research Society; 2011. pp. 824-834

[2] Longonje SN, Raffaelli D. Feeding ecology of mangrove crabs in Cameroon. Applied Ecology and Environmental Research. 2014;12(4):959-973. DOI: 10.15666/aeer/1204_959973

[3] Zabbey N. Impact of livelihoods in Nigeria. In: Paper Presented at the Conference on Petroleum and Pollution-How Does That Impact Human Rights? 27th April, 2009. Kulturhuset, Stockholm, Sweden: Amnesty International, Forum Syd and Friends of the Earth; 2009

[4] Bisong FE. Natural Resource Use and Conservation Systems for Sustainable Rural Development. Calabar: Baaj International; 2001. p. 55

[5] WRI. World Resources. New York: Basic Books; 1986. p. 348

[6] Nduka JK, Orisakwe OE. Effect of effluents from Warri refinery petrochemical company WRPC on water and soil qualities of "contiguous host" and "impacted on communities" of Delta state, Nigeria. The Open Environmental Pollution \& Toxicology Journal. 2009;1:11-17

[7] Sustainable Livelihoods and Biodiversity Study (SLBP). Ajaetan/ Ijala-Ikenren communities Ecological Survey Report. Wetlands InternationalAfrica; 2013. pp. 1-78

[8] Nagelkerken I, Blaber SJM, Bouillon S, Green P, Haywood M, Kirton LG, et al. The habitat function of mangroves for terrestrial and marine fauna: A review. Aquatic Botany. 2008;89:155-185
[9] Wallace JB, Webster JR. The role of macroinvertebrates in stream ecosystem function. Annual Review of Entomology. 1996;41:45-19

[10] Woodcock TS, Huryn A. The response of macroinvertebrate production to a pollution gradient in a headwater stream. Freshwater Biology. 2007;52(1):77-196

[11] Whiles MR, Wallace JB. Leaf litter decomposition and macroinvertebrate communities in headwater streams draining pine and hardwood catchment. Hydrobiologia. 1997;351(1-3):107-119

[12] Suter GW, Cormiery SM. Why care about aquatic insects: Uses, benefits, and services. Integrated Environmental Assessment and Management. 2014;11(2):188-194

[13] Hocking DJ, Babbitt KJ. Amphibian contributions to ecosystem services. Herpetological Conservation and Biology. 2014;9(1):1-17

[14] IUCN. The IUCN Red List of Threatened Species. Version 2016-2. Available from: http://www.iucnredlist. org [Accessed: 04 September 2016]

[15] Anouti FA. Bioaccumulation of heavy metals within mangrove ecosystems. Journal of Biodiversity and Endangered Species. 2014;2(2):1-2

[16] Ratheesh Kumar CS, Joseph MM, Gireesh Kumar TR, Renjith KR, Manju MN, Chandramohanakumar N. Spatial variability and contamination of heavy metals in the inter-tidal systems of a tropical environment. International Journal of Environmental Research. 2010;4(4):691-700

[17] Maiti SK, Chowdhury A. Effects of anthropogenic pollution on mangrove biodiversity: A review. Journal of Environmental Protection. 2013;4(12):428-1434 
[18] Kaewtubtim P, Meeinkuirt W, Seepom S, Pichtel J. Heavy metal phytoremediation potential of plant species in a mangrove ecosystem in Pattani Bay, Thailand. Applied Ecology and Environmental Research. 2016;14(1):367-382. DOI: $10.15666 /$ aeer/1401_367382

[19] Alongi DM. The Energetics of Mangrove Forests. New York: Springer; 2009

[20] Barbier EB, Hacker SD, Kennedy C, Koch EW, Stier AC, Silliman BR. The value of estuarine and coastal ecosystem services. Ecological Monographs. 2011;81(2):169-193

[21] Osland MJ, Enwright N, Day RH, Doyle TW. Winter climate change and coastal wetland foundation species: Salt marshes vs. mangrove forests in the southeastern United States. Global Change Biology. 2013;19:1482-1494

[22] Gutiérrez JCS, Ponce-Palafox JT, Pineda-Jaimes NB, Arenasfuentes V, Arredondo-Figueroa JL, CifuentesLemus JL. Comparison of the mangrove soil with different levels of disturbance in tropical Agua Brava Lagoon, Mexican Pacific. Applied Ecology and Environmental Research. 2016;14(4):4557. DOI: 10.15666/aeer/1404_045057

[23] Olomukoro JO, Dirisu AR. Macroinvertebrate community and pollution tolerance index in Edion and Omodo Rivers in derived Savannah wetlands in southern Nigeria. Jordan Journal of Biological Sciences. 2014;7(1):19-24

[24] Braun-Blanquet J.

Pflanzensoziologie, Grundzüge der Vegetationskunde. 3rd ed. Berlin: Springer Verlag, Wien; 1964. p. 865

[25] Merritt RW, Cummins KW, Berg MB. An Introduction to the Aquatic Insect of North America. 4th ed. 2008. p. 1158
[26] Abowei JFN, Ukoroije MBR. The identification, types, taxonomic orders, biodiversity and importance of aquatic insects. British Journal of Pharmacology and Toxicology. 2012;3(5):218-229

[27] Umar DM, Harding JS, Winterbourn MJ. Freshwater Invertebrates of the Mambilla Plateau, Nigeria. 1st ed. 2013. pp. 10-68

[28] Blüthgen N, Gebauer G, Fiedler $K$. Disentangling a rainforest food web using stable isotopes: Dietary diversity in a species-rich ant community. Oecologia. 2003;37:426-435

[29] Peet RK. The measurement of species diversity. Annual Review of Ecology and Systematics. 2003;5(1):285-307

[30] Lande R. Statistics and partitioning of species diversity, and similarity among multiple communities. Oikos. 1996;76:5-13

[31] Hammer $\varnothing$, Harper DAT, Ryan PD. PAST: Paleontological statistics software package for education and data analysis. Palaeontologia Electronica. 2001;4(1):9

[32] Mackie GL. Applied Aquatic Ecosystem Concepts. University of Guelph Custom Course back. Iowa, USA: Kendall Hunt Publishing Company; 2004. p. 724

[33] Achi SS, Shide EG. Analysis of trace metals by wet ashing and spectrophotometric techniques of crude oil samples. Journal of Chemical Society of Nigeria. 2004;29(11):11-24

[34] M'Erimba CM, Mathooko JM, Karanja HT, Mbaka JG. Monitoring water and habitat quality in six rivers draining the Mt. Kenya and Aberdare catchments using macroinvertebrates and qualitative habitat scoring. Egerton Journal of Science and Technology. 2014;14:81-104 
Impact of Disturbances on the Biodiversity of Ijala-Ikeren Wetland Ecosystem in Niger Delta DOI: http://dx.doi.org/10.5772/intechopen.82604

[35] Dirisu AR, Olomukoro JO.

Investigation of water quality of two rivers in Agbede wetlands in southern Nigeria. Global NEST Journal. 2015;17(3):451-462

[36] Taiwo IE, Amaeze NH, Adie PI, Adetoro OO. Heavy metal bioaccumulation and biomarkers of oxidative stress in the wild African tiger frog, Hoplobatrachus occipitalis. African Journal of Environmental Science and Technology. 2014;8(1):6-15

[37] Davidson DW, Cook SC, Snelling RR, Chua TH. Explaining the abundance of ants in lowland tropical rainforest canopies. Science. 2003;300:969-972

[38] Hunt JH. Cryptic herbivores of the rainforest canopy. Science. 2003;300:916 



\title{
An Economic Valuation and Mapping of Pollination Services in Ethiopia
}

\author{
Dawit Woubishet Mulatu
}

\begin{abstract}
An increasing degree of attention is being given to pollination ecosystem service. It has become a commonly mentioned example of how ecosystem services are economically valuable due to its linkage to the world food production. A notable bio-economic approach is applied to estimate the economic value of pollination and the production value loss attributable due to a decline in pollinator using the Ethiopian Annual Agricultural Sample Surveys (AgSS) data for the period 2003-2013. We are aiming to fill the research and knowledge gap with respect to spatial and temporal variation of economic valuation and mapping of pollination services in developing countries, by taking Ethiopia as an example. Result indicated that the mean economic value of pollination is about US\$81.3 million for this period. Our estimated crop vulnerability ratio was approximately $8.4 \%$, and pollination service contributes about $4.2 \%$ of the total farm gate value. The spatial analysis of our estimates revealed discrete patterns of zonal level variation in Ethiopia. Estimates and spatial analyses of pollination values and vulnerabilities provide vital information to determine suitable pollinator management strategies at different institutional and ecological scales. Accordingly, our findings have policy and management implications on the potential benefit of addressing pollinator decline at local level.
\end{abstract}

Keywords: pollination, ecosystem services, economic valuation, mapping and Ethiopia

\section{Introduction}

Pollination is an ecosystem service and a production practice [1]. At present, an increasing degree of attention is being given to pollination ecosystem service and its economic value due to its linkage to the world food production; on top, it has become a frequently mentioned example of how ecosystems services are economically valuable [2]. Pollination makes a very significant contribution for the production of a broad range of crops, in particular fruits, vegetables, fiber crops, and nuts. Its value is derived from its contribution to the maintenance of ecosystems as well as its impact on agriculture [3]. However, pollinators' decline all over the world has consequences in many agricultural areas and is a major global environmental concern [4]. Thus, it is necessary to assess the potential significant loss of economic value of pollination [5]. 
It is increasingly recognized that more studies are needed to enhance our understanding of pollination services $[3,6]$, their contribution to the ecosystem $[2,7,8]$, and agriculture productivity $[6,9,10]$. As well, there is a limited scientific evidence to explain the ongoing debate on pollination ecosystem service and valuation $[2,11,12]$, the spatial and temporal trends of pollination benefits $[1,13]$, landscape impacts on the stability of pollination ecosystem services [14], and the suitability of habitats for sustaining valuable pollinators [15]. There is also a wide variation placed in the economic value of pollinators, and the economic value of pollination services is still at its infancy stage $[2,7,10,16]$. Likewise, valuation of pollination services is useful to justify the allocation of resources toward conservation practices [17].

Economic valuation of pollination services not only provides information on the economic impacts of pollination decline but also contributes to decisionmaking process concerning selection of alternative mitigation strategies [6]. The first global estimate of the economic value of pollination was provided by Costanza et al. [18]. There is an increasing trend in pollination dependency in both the developed and the developing world $[19,20]$ and crop yields might also be declined due to pollination shortages [5]. The increasing pollination dependency led to a decline in agricultural production, thereby the demand for agricultural land expected to rise due to pollination absence or decline, particularly in developing countries [21]. In most developing countries, managing pollination services is also limited due to limited understanding of its economic value [22]. Accordingly, pollination is far beyond ecological-economical settings, but rather is a service of global importance threatened by land-use change and agricultural intensification [13, 23]. Therefore, we are aiming to fill the research and knowledge gap with respect to spatial and temporal variation of economic valuation of pollination services. Specifically, the major objectives of this study are: the first one is to quantify the economic value of pollination (EVP), the crop vulnerability ratio (CVR) or the potential relative production value loss attributable to lack of or disappearance of pollinators, and the pollination's contribution to total farm gate value $(\mathrm{PCV})$ or the potential relative agricultural sector production value loss attributable to lack of or disappearance of pollinators in Ethiopia. The second objective is to map and assess the temporal and spatial variation of EVP, CVR, and PCV in Ethiopia. Similar to Gallai et al. [5], our study is based on the hypothesis that the economic impact of pollinators on agricultural output is measurable through the use of dependence ratios quantifying the impact of a lack of or disappearance of pollinators on crop production value using a bio-economic approach. Thus, our study focuses on: the analysis of spatial and temporal variation in economic valuation of pollination services and the vulnerability of national economies on pollination benefits; and the use of zonal level data (at local level) to derive mapping of economic valuation pollination, pollination dependency, and vulnerability due to pollination decline.

\section{Methods}

A notable bio-economic approach is applied to estimate the economic value of pollination. It has been used to estimate the economic value of pollination, and the potential relative production and agricultural sector value loss attributable to lack of or disappearance of pollinators or the production value loss attributable to a decline in pollinator $[5,10]$. The total economic value of pollination (EVP) is calculated as follows: 


$$
E V P=\sum_{i=1}^{n} P_{i} * Q_{i} * D_{i}
$$

where for each crop i€ (1:n), (where $n=38$ in our study), $Q_{i}$ is the quantity produced, $D_{i}$ is the pollination dependency ratio, and $P_{i}$ is the price per unit of quantity produced. The potential production value loss attributable to lack of pollinators, which is the crop vulnerability ratio (CVR), is calculated as the ratio of EVP to economic production value of the crops in our study (EV). CVR is calculated as:

$$
C V R=\frac{E V P}{E V}=\frac{\sum_{i=1}^{n} P_{i} * Q_{i} * D_{i}}{\sum_{i=1}^{n} P_{i} * Q_{i}}(\%)
$$

We calculate the pollination contribution to total farm gate value (PCV). PCV measures the potential agricultural sector production value loss attributable to lack of pollinators. It is the ratio of EVP to total farm gate value (TFGV). In our case, the total farm gate value is reported for each zone and is a summation of values of all agricultural productions ( $m$ is the whole agricultural products). We did not include services and animal products in our total farm gate value calculation. PCV is calculated as:

$$
P C V=\frac{E V P}{T F G V}=\frac{\sum_{i=1}^{n} P_{i} * Q_{i} * D_{i}}{\sum_{i=1}^{m} P_{i} * Q_{i}}(\%)
$$

For Ethiopia, we estimate the EVP, CVR, and PCV for the period from 2003 to 2013. The spatial pattern and variation of EVP, CVR, and PCV of Ethiopia at the zone level for respective year are analyzed using geographical information systems (GIS). For a better understanding of the spatial and temporal pattern, maps were produced for the economic value of pollination, crop vulnerability ratio, and pollination contribution to total farm gate value. Spatially explicit analysis of these indices at local or national level show how pollination has fundamentally different regional significance and consequences in its absence [1].

\section{Data}

We used data of the Ethiopian Annual Agricultural Sample Surveys (AgSS) from 2003 to 2013 conducted by Central Statistical Agency (CSA) of Ethiopia [24]. The major part of the AgSS is the Main ("Meher") ${ }^{1}$ season postharvest survey which consists of area and production, land-use, farm management practices, and crop utilization of private peasant holdings. The specific objectives of main season postharvest survey are to estimate the total crop area, volume of crop production, and yield of crops for main agricultural season in Ethiopia. The data covered the entire rural parts of the country except some of the non-sedentary population zones in Ethiopia (i.e., Afar and Somali regional states). The agricultural products data collection in AgSS surveys cover all cereals, pulses, and oilseeds and the most commonly grown vegetables, root crops and permanent (perennial) crops. Holders growing at least one or more of these and/or other crops are enumerated, and data on crop area and yield condition are recorded; hence data on production of these crops are acquired.

For each year, quantities of various crops production were directly computed from the survey data. These values were aggregated to national, regional, and zonal

\footnotetext{
1 "Meher" is the local language in Ethiopia to indicate the main agricultural season.
} 


\begin{tabular}{|c|c|c|c|c|}
\hline Crop type & $\begin{array}{l}\text { Yield/seed increase } \\
\text { in the presence of } \\
\text { animal pollinators } 1\end{array}$ & $\begin{array}{c}\text { In the absence of } \\
\text { pollinators yield } \\
\text { maybe less by }\end{array}$ & Pollinators & $\begin{array}{c}\text { Mean } \\
\text { pollination } \\
\text { dependency }\end{array}$ \\
\hline Pumpkins & Essential & More than $90 \%$ & Honey bees & 0.95 \\
\hline Apples & Great & $40-90 \%$ & Wild bees & 0.65 \\
\hline Avocados & Great & $40-90 \%$ & Honey bees (Apis spp.) & 0.65 \\
\hline Cardamom & Great & $40-90 \%$ & Apis cerana Fabricius & 0.65 \\
\hline Coriander & Great & $40-90 \%$ & Apis cerana Fabricius & 0.65 \\
\hline Fennel & Great & $40-90 \%$ & Apis florea Fabricius & 0.65 \\
\hline Mangos & Great & $40-90 \%$ & Apis spp. & 0.65 \\
\hline Peach & Great & $40-90 \%$ & Apis mellifera $\mathrm{L}$. & 0.65 \\
\hline $\begin{array}{l}\text { Coffee } \\
\text { (Arabica) }\end{array}$ & Modest & $10-40 \%$ & Apis dorsata Fabricius & 0.25 \\
\hline Guava & Modest & $10-40 \%$ & Apis mellifera $\mathrm{L}$. & 0.25 \\
\hline Horse beans & Modest & $10-40 \%$ & Xylocopa aestuans $\mathrm{L}$. & 0.25 \\
\hline Sesame & Modest & $10-40 \%$ & Apis cerana Fabricius & 0.25 \\
\hline Rapeseed & Modest & $10-40 \%$ & Apis mellifera $\mathrm{L}$. & 0.25 \\
\hline Soybeans & Modest & $10-40 \%$ & Apis mellifera $\mathrm{L}$. & 0.25 \\
\hline Sunflower & Modest & $10-40 \%$ & Apis cerana Fabricius & 0.25 \\
\hline Cotton & Modest & $10-40 \%$ & Apis mellifera $\mathrm{L}$. & 0.25 \\
\hline Chickpeas & Little & $0-10 \%$ & Bumble bees & 0.05 \\
\hline Citron & Little & $0-10 \%$ & Apis cerana Fabricius & 0.05 \\
\hline Green pepper & Little & $0-10 \%$ & Honey bees & 0.05 \\
\hline Ground nuts & Little & $0-10 \%$ & Apis dorsata Fabricius & 0.05 \\
\hline Haricot beans & Little & $0-10 \%$ & & 0.05 \\
\hline Lemons & Little & $0-10 \%$ & Apis cerana Fabricius & 0.05 \\
\hline Line seed & Little & $0-10 \%$ & Apis mellifera $\mathrm{L}$. & 0.05 \\
\hline Mandarins & Little & $0-10 \%$ & Apis cerana Fabricius & 0.05 \\
\hline Oranges & Little & $0-10 \%$ & Apis cerana Fabricius & 0.05 \\
\hline Red pepper & Little & $0-10 \%$ & Honey bees & 0.05 \\
\hline Tomatoes & Little & $0-10 \%$ & Apis mellifera $\mathrm{L}$. & 0.05 \\
\hline Beans kidney & Little & $0-10 \%$ & & 0.05 \\
\hline Barley & $\begin{array}{l}\text { Does not show an } \\
\text { increase in yields }\end{array}$ & & Unspecified & 0 \\
\hline Lentils & $\begin{array}{l}\text { Does not show an } \\
\text { increase in yields }\end{array}$ & & Unspecified & 0 \\
\hline Maize & $\begin{array}{l}\text { Does not show an } \\
\text { increase in yields }\end{array}$ & & Unspecified & 0 \\
\hline Millet & $\begin{array}{l}\text { Does not show an } \\
\text { increase in yields }\end{array}$ & & Unspecified & 0 \\
\hline Oats & $\begin{array}{l}\text { Does not show an } \\
\text { increase in yields }\end{array}$ & & Unspecified & 0 \\
\hline Rice & $\begin{array}{l}\text { Does not show an } \\
\text { increase in yields }\end{array}$ & & Unspecified & 0 \\
\hline
\end{tabular}




\begin{tabular}{|c|c|c|c|c|}
\hline Crop type & $\begin{array}{l}\text { Yield/seed increase } \\
\text { in the presence of } \\
\text { animal pollinators } 1\end{array}$ & $\begin{array}{l}\text { In the absence of } \\
\text { pollinators yield } \\
\text { maybe less by }\end{array}$ & Pollinators & $\begin{array}{c}\text { Mean } \\
\text { pollination } \\
\text { dependency }\end{array}$ \\
\hline Sorghum & $\begin{array}{l}\text { Does not show an } \\
\text { increase in yields }\end{array}$ & & Unspecified & 0 \\
\hline Sugar cane & $\begin{array}{l}\text { Does not show an } \\
\text { increase in yields }\end{array}$ & & Unspecified & 0 \\
\hline Wheat & $\begin{array}{l}\text { Does not show an } \\
\text { increase in yields }\end{array}$ & & Unspecified & 0 \\
\hline Field peas & $\begin{array}{l}\text { Does not show an } \\
\text { increase in yields }\end{array}$ & & Unspecified & 0 \\
\hline
\end{tabular}

Table 1.

Crops identified in our study and their yield may decline in the absence or decline of pollinators (based on $[5,7,27])$.

levels. In order to get the value of each crop production, the volume of each crop production were multiplied by national average price of each crop item per year. The mean annual prices were computed for each crop item from the monthly producers' agricultural prices released by the CSA [25]. The dollar values of production were calculated by using data from the World Bank database [26]. Deflating the values of productions was also important for ease of comparing values across different years. We used information from the World Bank database [26] to correct the prices for inflation by considering 2011 as reference year. For all zones in respective years, the scope of our study is limited to 38 different types of crops (pulses, spices, vegetables, oilseeds, fruits, and cash crops). The detail on the type of crops, the crop pollinators, and the mean pollination dependency ratio of crops is presented in Table 1.

The crop pollination dependency ratio has been calculated based on the dependency ratio of the recently published for crops by $[5,7]$, and by using the FAO database $^{2}$ [27]. The mean value of pollination-driven yield reduction lying between 100 and $90 \%$ is $95 \%$ (i.e., pollination is reported as "essential"). The mean pollination-driven yield reduction ranging between 40 and $90 \%$ is $65 \%$ (i.e., pollination is reported as "great"). The mean pollination-driven yield reduction ranging between 10 and $40 \%$ is $25 \%$ (i.e., pollination is reported as "modest"). The mean pollination-driven yield reduction ranging between 0 and $10 \%$ reduction is $5 \%$ (i.e., pollination is reported as "little"). Pollination driven that does not show an increase in yields takes a zero dependency ratio $[2,7]$.

\section{Results and discussion}

Using the bio-economic approach, we estimate the economic value of pollination (EVP), the crop vulnerability ratio (CVR), and pollination's contribution to total farm gate value (PCV) for Ethiopia using the 2003-2013 zonal level production value data for 38 different type of crops. We calculate the annual mean value estimates of EVP, CVR, and PCV between 68 and 73 zones of the respective years from 2003 to 2013. For Ethiopia, the mean economic value of pollination, total farm gate value, and economic value of crops under study for the period of 2003-2013

\footnotetext{
2 The Food and Agriculture Organization of the United Nations (FAO's), Global Action on Pollination Services for Sustainable Agriculture. http://www.fao.org/pollination/pollination-database.
} 


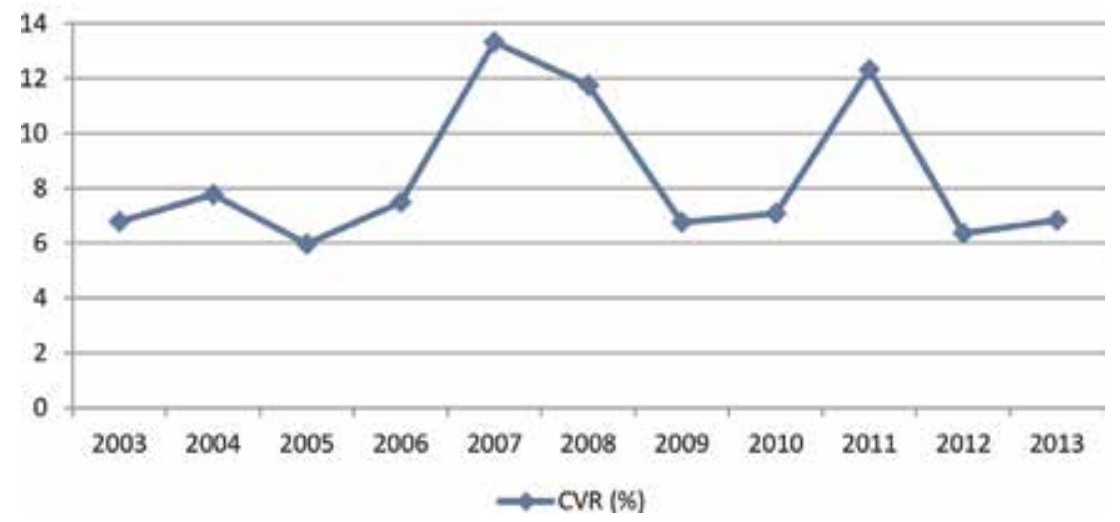

Figure 1.

Crop vulnerability ratio (CVR) (\%) for the period of 2003-2013.

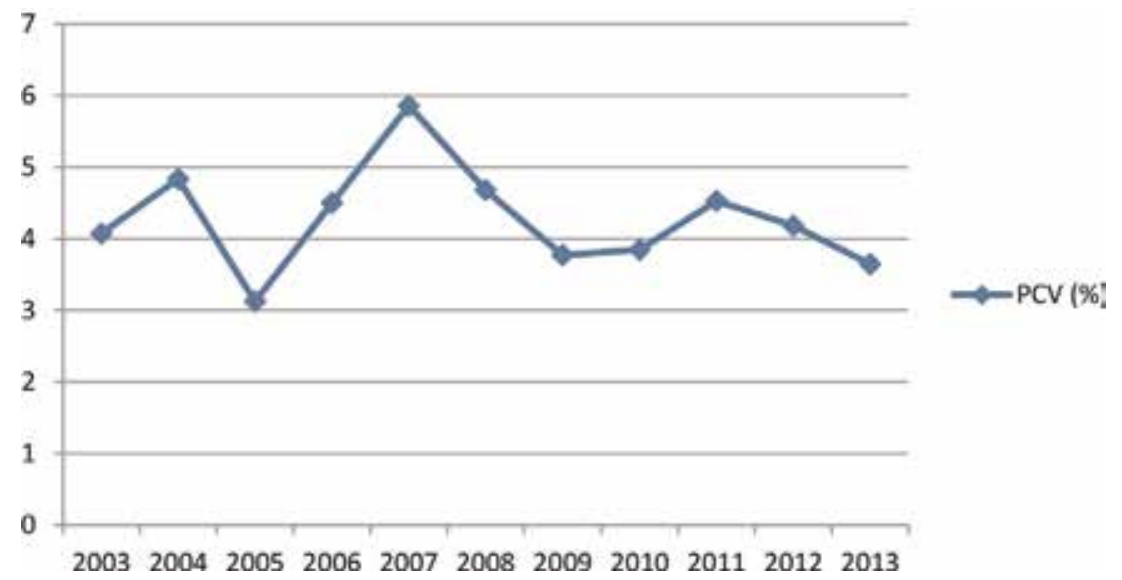

Figure 2.

Pollination contribution for farm gate value (PCV) (\%) for the period of 2003-2013.

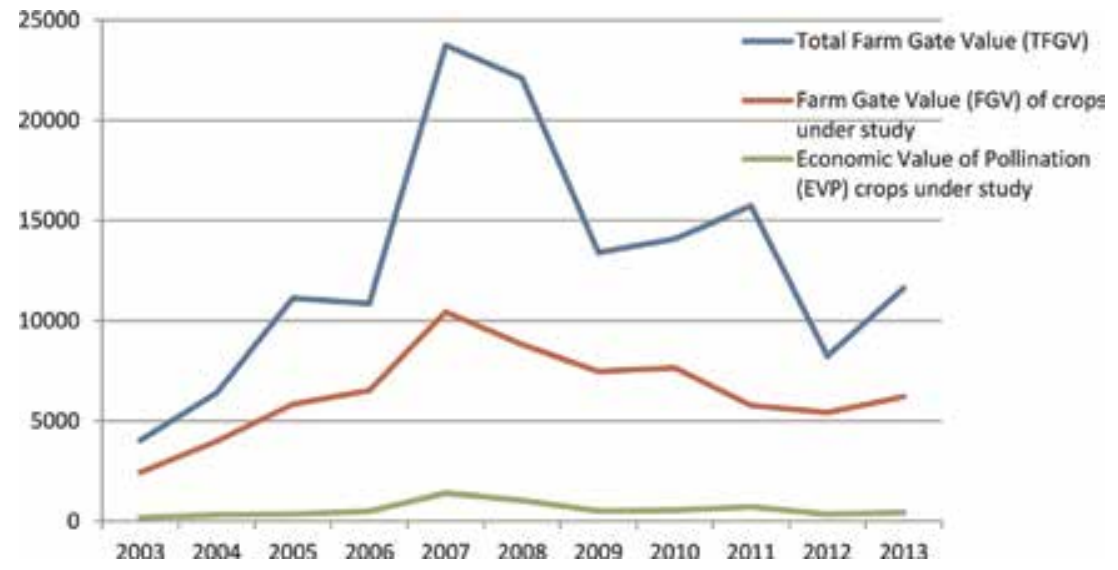

Figure 3.

Total farm gate value, farm gate value of crops under study and economic value of pollination in million USD for the period of 2003-2013. 
were $>$ US $\$ 81.3$ million, $>$ US $\$ 12.8$ billion, and $>$ US $\$ 6.41$ billion, respectively. Our estimated crop vulnerability ratio indicates a potential production value loss for the crops studied of roughly $8.4 \%$ in the absence of pollinators. The CVR for the period of 2003-2013 is presented in Figure 1 and it ranges between 6 and 13\% which is comparable with [13] that showed the national dependency of the agricultural GDP

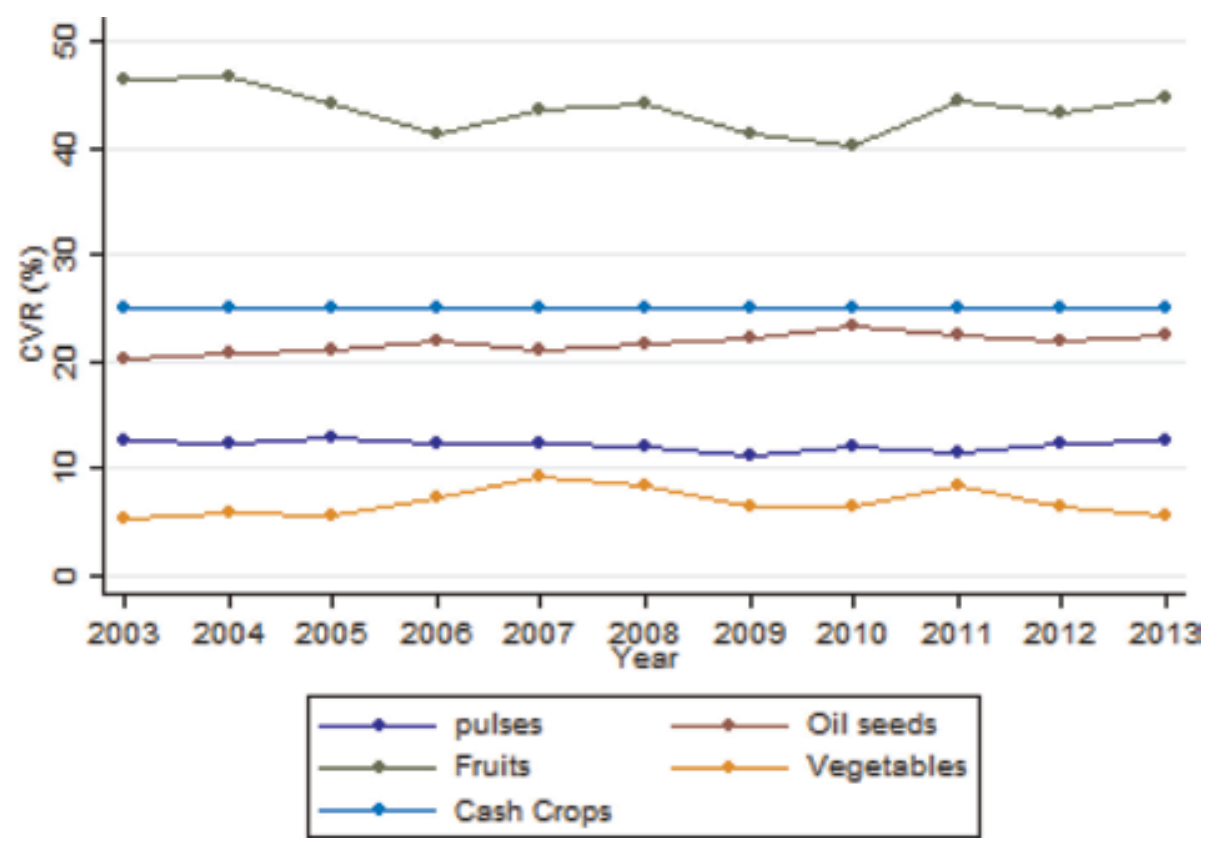

Figure 4 .

Crop vulnerability ratio (CVR) (\%) per crop category for the period of 2003-2013.
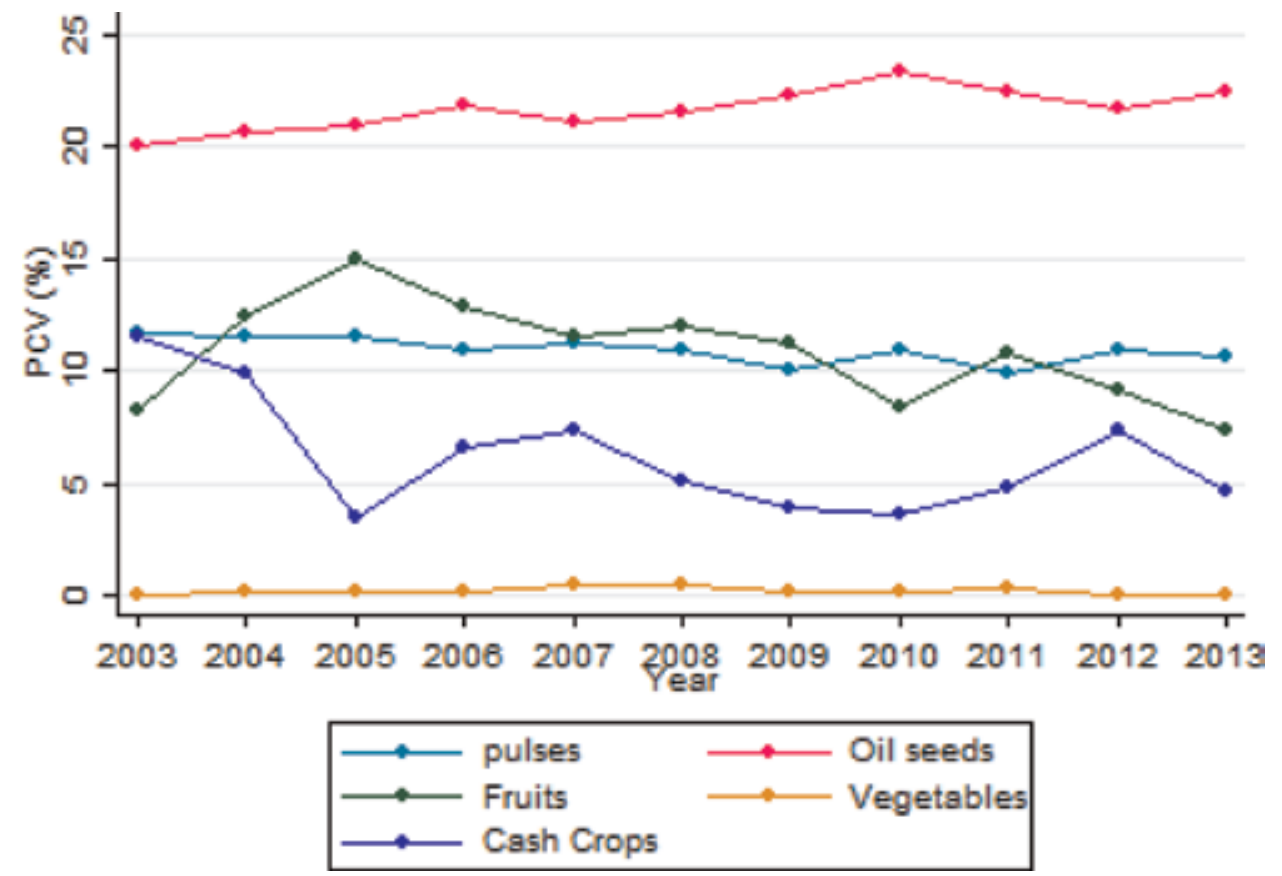

Figure 5 .

Pollination contribution to total farm gate value (PCV) (\%) per crop category for the period of 2003-2013. 
on pollination in east Africa (including Ethiopia) which ranges between 5 and 7.5\%. The mean PCV value indicated that the potential relative agricultural sector production value loss attributable to lack of or disappearance of pollinators in Ethiopia was $4.2 \%$ and the PCV values for respected year are presented in Figure 2. The highest value of CVR and PCV was found for the year 2007. Total farm gate values and economic value of pollination are presented in Figure 3. The CVR and PCV analyses have been done for different crop categories; fruits had highest CVR values due to their high pollination dependency followed by cash crops (e.g., coffee) and

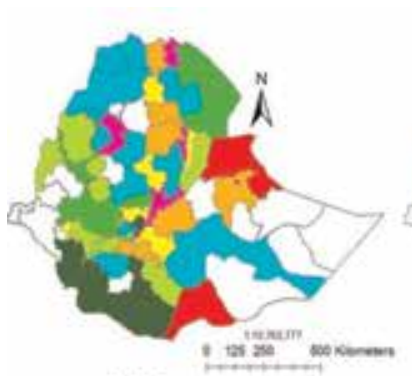

2003
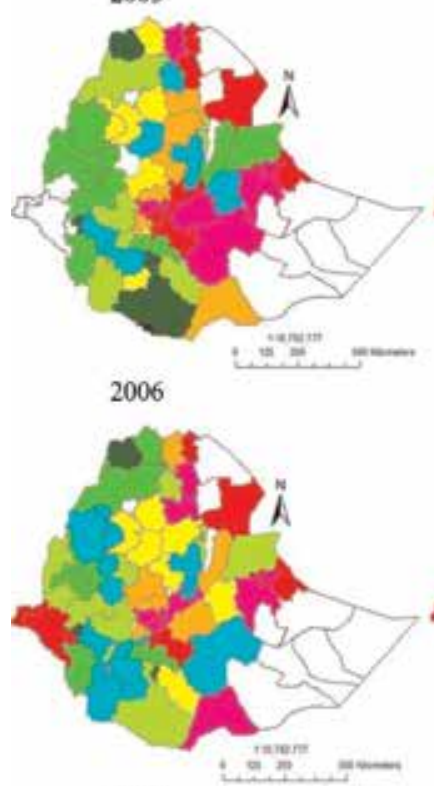

2009

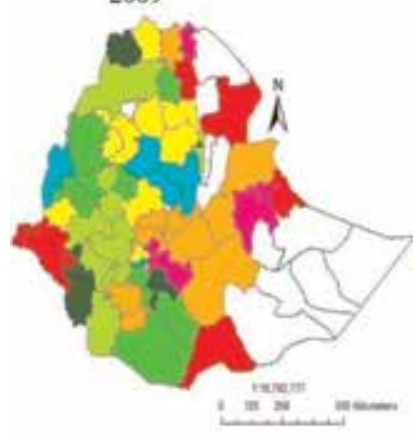

2012

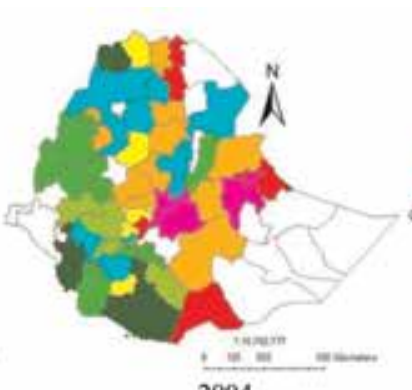

2004

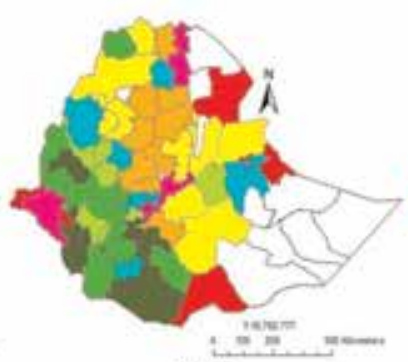

2007

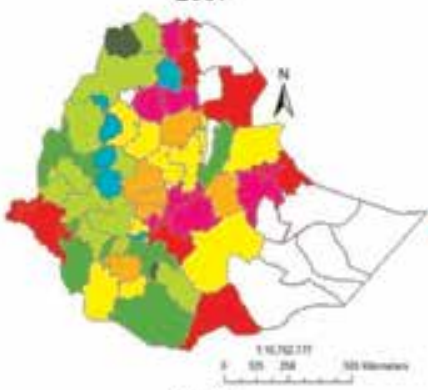

2010

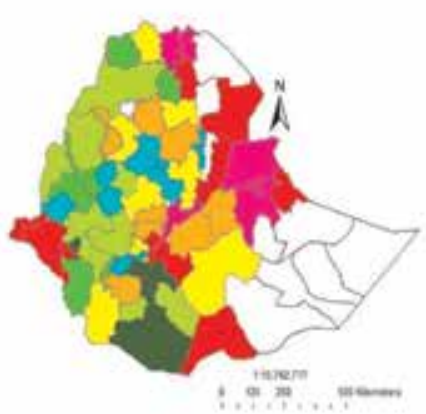

Legend

Ethiopia zonal level CVA

2013

Figure 6.

Ethiopia zone level mapping of the crop vulnerability ratio (CVR) (\%) for the period of 2003-2013. 
oil seeds (Figure 4). Alternatively, the pollination contribution to farm gate value indicated the highest percentage for oil seeds followed by relatively in similar pattern for fruits and pulses (Figure 5).

Our geographic information system (GIS) analysis revealed the spatial variation of the crop vulnerability ratio (Figure 6), the economic value of pollination (Figure 7), and the pollination's contribution to total farm gate value

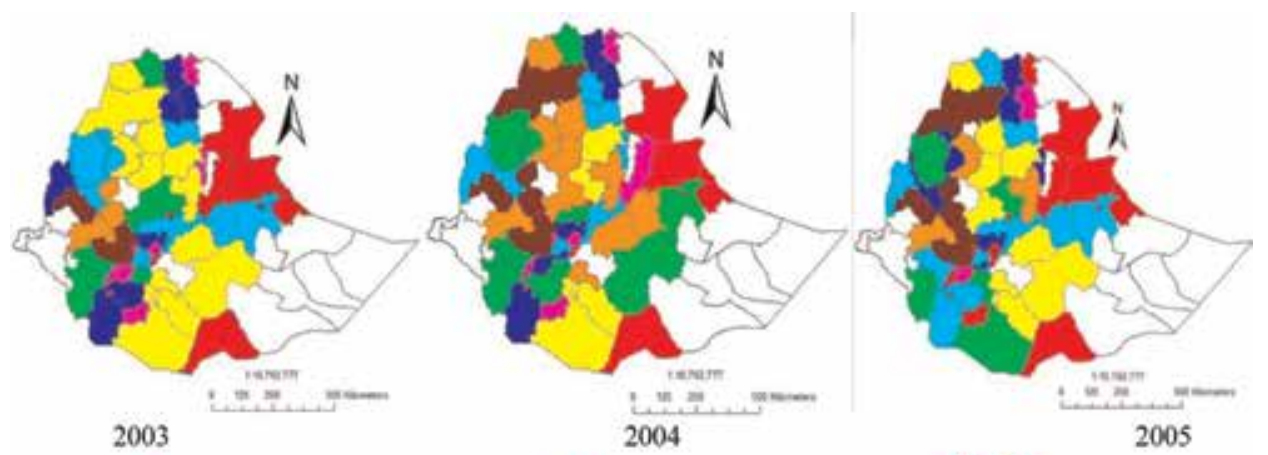

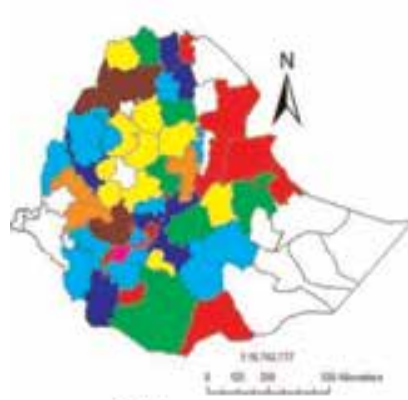

2006

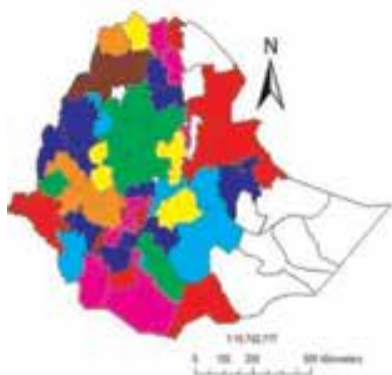

2009

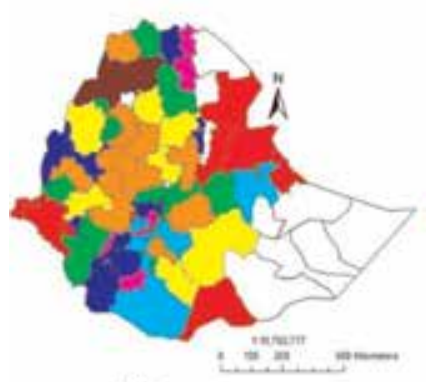

2012
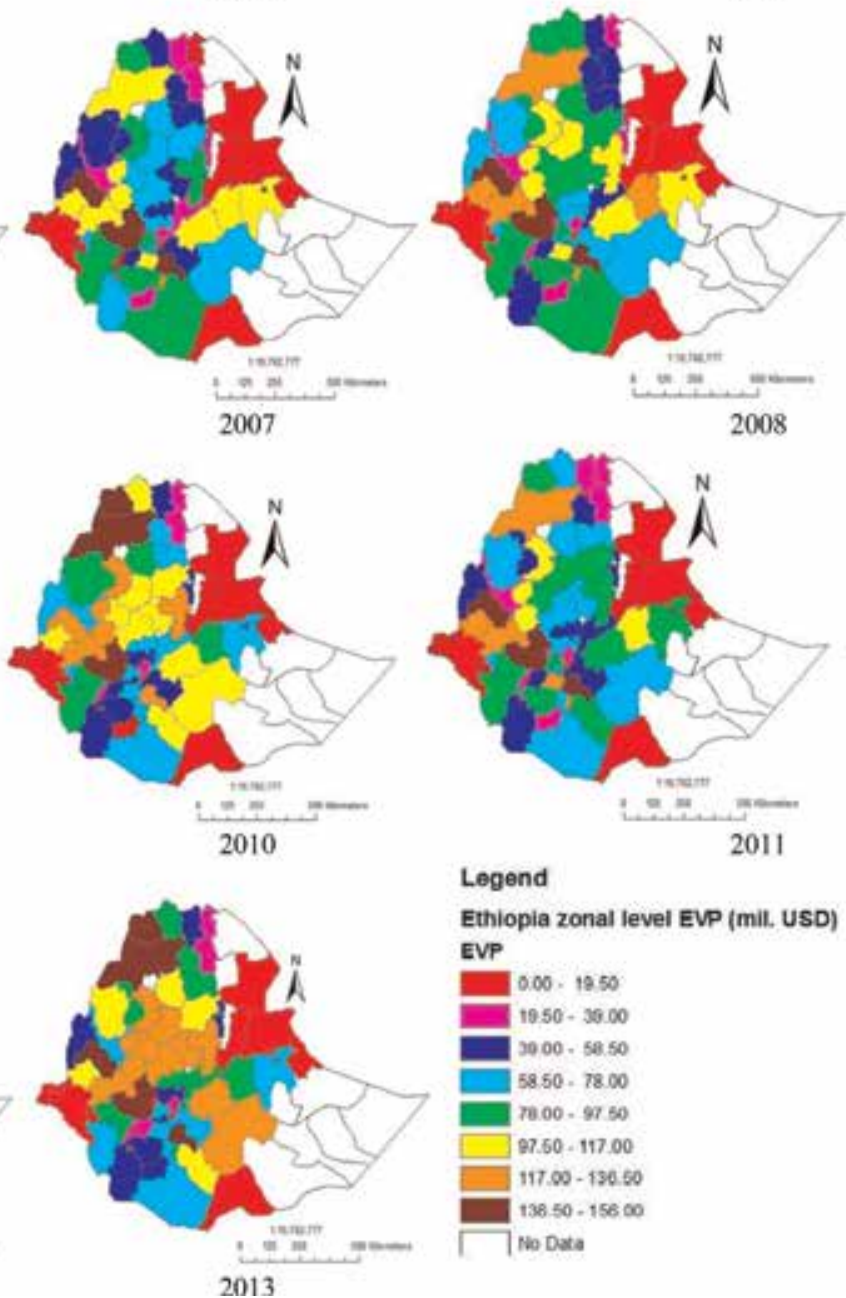

\section{Legend}

Ethiopia zonal level EVP (mil. USD) EVP

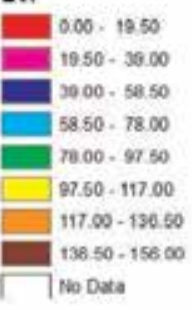

2013

Figure 7.

Ethiopia zone level mapping of the economic value of pollination (EVP) in million USD for the period of 2003-2013. 


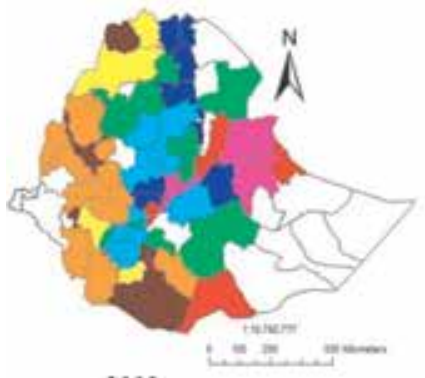

2003

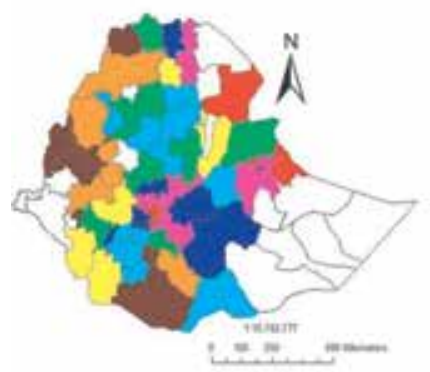

2006

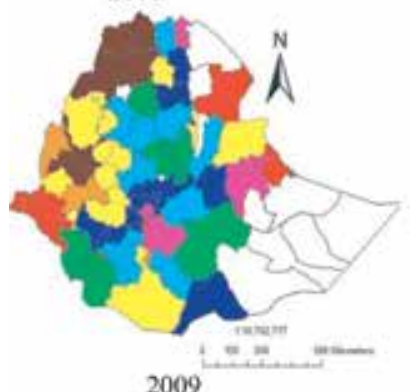

2009

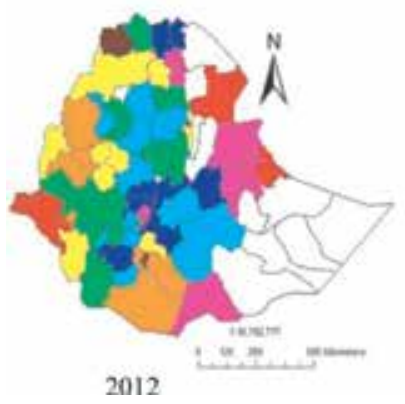

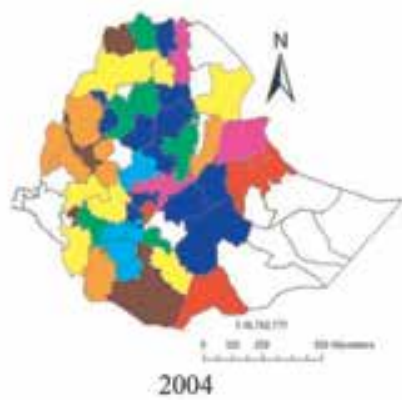
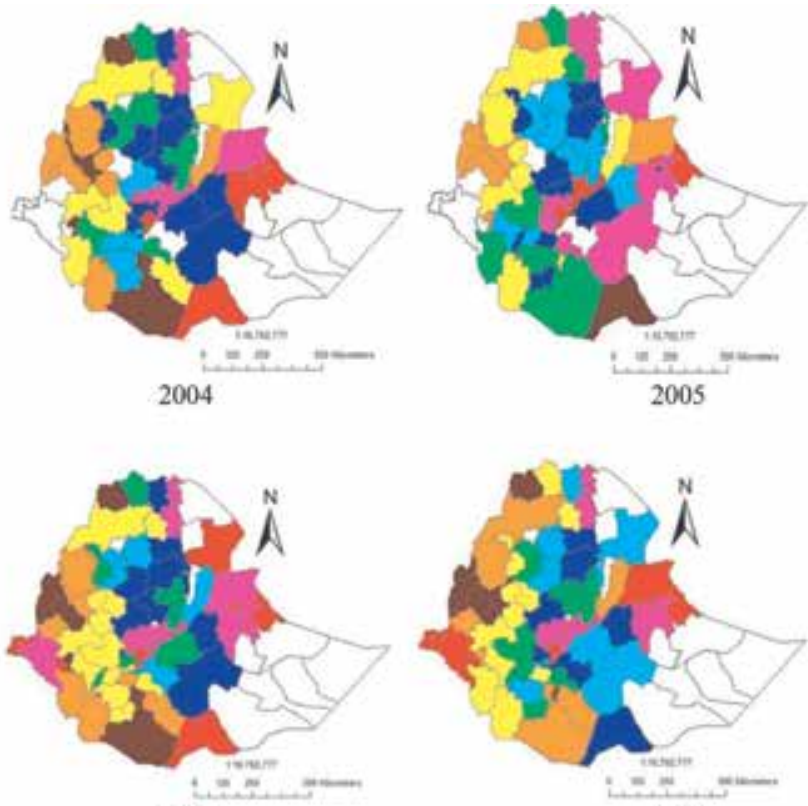

2007
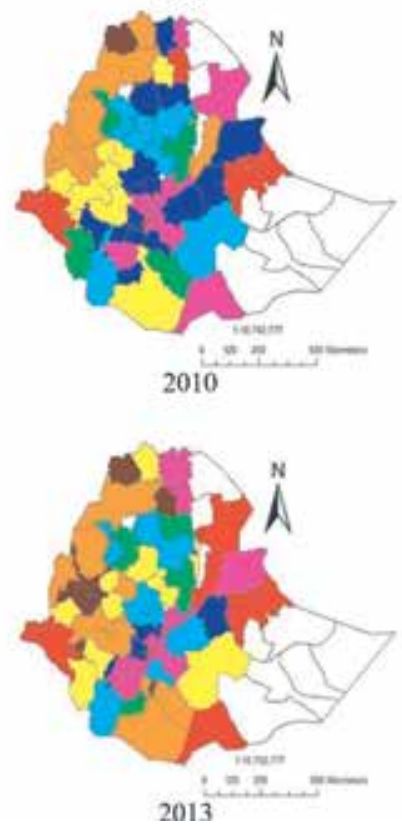
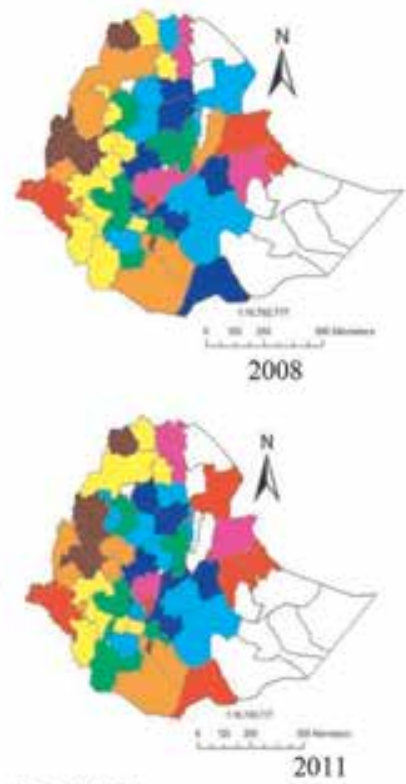

Legend

Ethiopia zonal level PCV (\%).

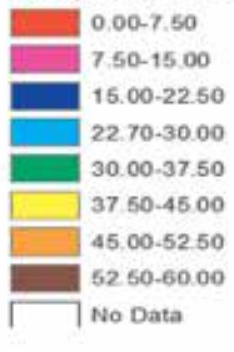

Figure 8.

Ethiopia zone level mapping of the pollination contribution to total farm gate value (PCV) (\%) for the period of 2003-2013.

(Figure 8). Zones with the higher CVR values appear to be clustered in the west-central part of the country. The north-western part of the country revealed the highest CVR value; these areas mainly produce oil seed products for export market. Some parts of the south and eastern zones show the lowest CVR value because these areas are dry land and mainly livestock production zones rather than crop production. The result for the spatial pattern of the economic value of pollination shown that it is comparable for most parts of the north-eastern and the south-western parts of the country while it had a highest value in the north-western and the central parts of the country which predominantly produced oil seeds and cash crops. 
Providing an estimate and spatial variation of the economic value of pollination is vital for cost-benefit analysis of planned interventions to perceived or anticipated pollinator decline [1]. The spatial analysis of our estimates revealed discrete patterns of zonal variation in pollination services and values within Ethiopia. Spatially explicit analysis of these indicators is important to support policies related to protection of abundant pollination sites for maintaining pollination services. Our results have policy and management implications on the potential benefit of addressing pollinator decline at local level. Similar to the findings of Barfield et al. [1], estimates and spatial analyses of pollination values and vulnerabilities provide information that is useful for the selection of the most appropriate pollinator management strategies at different institutional and ecological scales.

\section{Conclusion}

To understand the impact of pollinator decline on agriculture production in developing countries, empirical assessment of potential economic losses due to this decline is critical. As well, to support maintaining the pollination service in agriculture, there is a need to better understand the economic value generated by the pollination service. We estimated the economic value of pollination, and the potential relative production and agricultural sector value loss attributable to lack or disappearance of pollinators using bio-economic approach. We use the Ethiopian Annual Agricultural Sample Surveys (AgSS) data collected by Central Statistical Agency (CSA) for the period of 2003-2013. Result indicated that the potential production value loss attributable due to lack or decline of pollinators is nearly $8.4 \%$ and the potential agricultural sector production value loss attributable due to lack or decline of pollinators is about $4.2 \%$. In this chapter, we have shown that spatial analyses of pollination values and vulnerabilities due to a decline in population of pollinators provide information that is useful for the selection of the most appropriate pollinator management strategies at different institutional and ecological scales. Therefore, spatially explicit analysis of these indicators is also important to support policies related to protection of abundant pollination sites for maintaining pollination services at different scales.

\section{Acknowledgements}

This chapter is an output of the Ecosystem Services Accounting for Development (ESAfD) project, jointly conducted by the EfD initiative and the Swedish Environmental Protection Agency (SEPA) and funded by the Swedish International Development Cooperation Agency (Sida). We are very grateful to Ethiopia's Central Statistics Agency who assisted us in providing and coalition of the available data. 


\section{Author details}

Dawit Woubishet Mulatu

Environment and Climate Research Center (ECRC), Policy Studies Institute (PSI), Addis Ababa, Ethiopia

*Address all correspondence to: dawitwmulatu@gmail.com

\section{IntechOpen}

(C) 2019 The Author(s). Licensee IntechOpen. This chapter is distributed under the terms of the Creative Commons Attribution License (http://creativecommons.org/licenses/ by/3.0), which permits unrestricted use, distribution, and reproduction in any medium, provided the original work is properly cited. (cc) BY 


\section{References}

[1] Barfield A, Bergstrom J, Ferreira S. An economic valuation of pollination services in Georgia. In: Selected Paper Prepared for Presentation at the Southern Agricultural Economics Association Annual Meeting; February 4-7, 2012; Birmingham, AL; 2012

[2] Hanley N, Breeze TD, Ellis C, Goulson D. Measuring the economic value of pollination services: Principles, evidence and knowledge gaps.

Ecosystem Services. 2015;14:124-132

[3] FAO. Tools for conservation and use of pollination services. In: Economic Valuation of Pollination Services: Review of Methods; 2006

[4] Fukase J, Simons AM. Increased pollinator activity in urban gardens with more native flora. Applied Ecology and Environmental Research. 2015;14: 297-310

[5] Gallai N, Salles J-M, Settele J, Vaissière BE. Economic valuation of the vulnerability of world agriculture confronted with pollinator decline. Ecological Economics. 2009;68:810-821

[6] Bauer DM, Wing SI. Economic consequences of pollinator declines: A synthesis. Agricultural and Resource Economics Review. 2010;39:368-383

[7] Klein A-M, Vaissière BE, Cane JH, Steffan-Dewenter I, Cunningham SA, Kremen C, et al. Importance of pollinators in changing landscapes for world crops. Proceedings of the Royal Society of London B: Biological Sciences. 2007;274:303-313

[8] Ricketts TH. Tropical forest fragments enhance pollinator activity in nearby coffee crops (Fragmentos de Bosque Tropical Incrementan la Actividad de Polinizadores en Cultivos de Café Cercanos). Conservation Biology. 2004;18:1262-1271
[9] Çurur F, Çurur T. A study on the production and marketing of bee products providing biodiversity: Case study from Turkey. Applied Ecology and Environmental Research. 2019;17: 4707-4724

[10] Mwebaze P, Marris GC, Budge GE, Brown M, Potts SG, Breeze TD, et al. Quantifying the value of ecosystem services: A case study of honeybee pollination in the UK. In: 12th Annual BIOECON Conference 'From the Wealth of Nations to the Wealth of Nature: Rethinking Economic Growth'; 27-28 September 2010; Venice, Italy; 2010

[11] Costanza R, de Groot R, Sutton P, van der Ploeg S, Anderson SJ,

Kubiszewski I, et al. Changes in the global value of ecosystem services. Global Environmental Change. 2014;26: 152-158

[12] Garibaldi LA, Steffan-Dewenter I, Winfree R, Aizen MA, Bommarco R, Cunningham SA, et al. Wild pollinators enhance fruit set of crops regardless of honey bee abundance. Science. 2013; 339:1608-1611

[13] Lautenbach S, Seppelt R, Liebscher J, Dormann CF. Spatial and temporal trends of global pollination benefit. PLoS ONE. 2012;7:e35954

[14] Garibaldi LA, Steffan-Dewenter I, Kremen C, Morales JM, Bommarco R, Cunningham SA, et al. Stability of pollination services decreases with isolation from natural areas despite honey bee visits. Ecology Letters. 2011; 14:1062-1072

[15] Roubik DW. The value of bees to the coffee harvest. Nature. 2002;417:708

[16] Winfree R, Gross BJ, Kremen C. Valuing pollination services to 
agriculture. Ecological Economics. 2011; 71:80-88

[17] Allsopp M, de Lange W, Veldtman $\mathrm{R}$. Valuing insect pollination services with cost of replacement. PLoS ONE. 2008;3:e3128

[18] Costanza R, Ralph dA, Rudolf DG, Stephen F, Monica G, Bruce H, et al. Value of the world's ecosystem services and natural capital. Nature:

International Weekly Journal of Science. 1997;387:253-260

[19] Aizen MA, Garibaldi LA, Cunningham SA, Klein AM. Long-term global trends in crop yield and production reveal no current pollination shortage but increasing pollinator dependency. Current Biology. 2008;18: 1572-1575

[20] Aizen MA, Harder LD. The global stock of domesticated honey bees is growing slower than agricultural demand for pollination. Current Biology. 2009;19:915-918

[21] Aizen MA, Garibaldi LA, Cunningham SA, Klein AM. How much does agriculture depend on pollinators? Lessons from long-term trends in crop production. Annals of Botany. 2009;103 (9):1579-1588. DOI: 10.1093/aob/mcp076

[22] Kasina JM, Mburu J, Kraemer M, Holm-Mueller K. Economic benefit of crop pollination by bees: A case of Kakamega small-holder farming in western Kenya. Journal of Economic Entomology. 2009;102:467-473

[23] Potts SG, Biesmeijer JC, Kremen C, Neumann P, Schweiger O, Kunin WE. Global pollinator declines: Trends, impacts and drivers. Trends in Ecology \& Evolution. 2010;25:345-353

[24] CSA. Annual Agricultual Sample Survey Meher Season Microdata Files. Survey Years from 2013/2014 to 2003/
2004. Addis Ababa: Central Statistical Agency (CSA); 2014

[25] CSA. Monthly Agricultural Producer Prices for the years 2003-2013 [Data Files]. Addis Ababa: Central Statistical Agency (CSA); 2015

[26] WB. The World Bank, World Development Indicators. Ethiopia [Data file]. 2015. Retrieved from: http://data. worldbank.org/country/ethiopia.in [Updated: 22 December 2015]

[27] FAO The Food and Agriculture Organization of the United Nations. (FAO's) Global Action on Pollination Services for Sustainable Agriculture. 2015. Available from: http://www.fao. org/pollination/pollination-database [Accessed: December 2015] 


\title{
Biomimicry, Big Data and Artificial Intelligence for a Dynamic Climate Change Management Policy Regime
}

\author{
Vuyo Mjimba and Gamelihle Sibanda
}

\begin{abstract}
The adverse impacts of climate change are not always immediately discernible. Managing the impacts of this dynamic phenomenon demands an equally dynamic policy regime instead of the traditional and often static policy response mechanisms. The traditional policy responses are often a result of long consultative processes sometimes stretching over several years. Frequently, this generates obsolete policy responses. In this chapter, we propose the development of a dynamic policy and legislation formulation and implementation system that respond to dynamic disturbances such as climate change. The proposal draws from natural systems that have been constantly evolving over aeons. The proposed approach uses the systems lens of biomimicry positing that lessons from natural systems can be mimicked using models that rely on artificial intelligence (AI) to monitor changes through analysing and learning from Big Data and utilising rapid feedback loops to subsequently self-improve policy response mechanisms. Hypothetically under this approach, some key indicators for climate change and related hazards, exposure, risks and vulnerability can be tracked and material policy changes automatically made to appropriately to mitigate and/or adapt to climate change thus avoiding the pitfalls of the traditional protracted policy change routes.
\end{abstract}

Keywords: climate change, policy, biomimicry, Big Data, artificial intelligence

\section{Introduction and background}

Despite the near universally acknowledged, observed and predicted adverse impacts of climate change, a quandary in this space is the slow and inadequate policy and practice set of responses in climate change mitigation and climate change adaptation practices. One would expect a global and intense focus on managing the adverse impacts of this phenomenon across and between all governments, the private sector and virtually all of humanity. However, this is not the case. This is because managing climate change is a complex and continuous process whose effectiveness is determined by the actions of diverse groups of individuals, communities, governments, local and international agencies all with a wide variety and, very often, conflicting agendas. Nevertheless, the scope and sophistication of policies and practices seeking to manage the various aspects of climate change continues to advance. The management of climate change manifests through the dual policy 
approach that employs either/or and often both the market-based and the regulatory mechanisms of climate change management.

Market-based mechanisms involve creating economic instruments to direct the flow of finance, technology and capacity-building support towards innovations and actions that mitigate greenhouse gas (GHG) emissions to retard global warming and ultimately climate change [1]. The mechanisms are rooted in economic principles that seek to heighten the frugality of managing climate change through activities that do not compromise the efficacy of the embedded mechanisms. Two popular mechanisms under the market approach are the Kyoto Protocol rooted in the Clean Development Mechanism (CDM) and the International Emissions Trading (IET) [1]. The regulatory mechanisms, also called the command-and-control policies, invariably require polluters to take specific actions to reduce emissions [2]. Typically, these actions comprise the installation of particular technologies seeking to meet specific environmental management performance standards, that is, GHG emission reduction. While academics, policymakers and bureaucrats often make a distinction between these mechanisms, practice shows an overlap between the two. In fact, and largely, the two are mutually inclusive.

Although there is link between interventions related to climate change and economic indicators, there are other important indicators such as biodiversity that are difficult and perhaps not necessary to reduce to absolute monetary terms. For example, about $40 \%$ of the global economy relies on biological products, and $35 \%$ of the total jobs are dependent on ecosystem services that support sectors such as agriculture, construction, forestry, textiles and tourism $[3,4]$. This indicates the complexity of variables that need consideration in any effective and efficient strategy for managing climate change. Such management, its related policies and legislation need to balance the economic, social and environmental approaches. What is important in the irrespective approaches is the timely provision of relevant data and information about potential hazards and potential benefits of climate change, globally and in specific locations. This is critical to deliver appropriate, adequate and well-timed responses. Such a delivery system equally demands a rapid, flexible and dynamic policy formulation, implementation and revision system. An important input to this system is relevant, adequate and accurate (as much as possible) data to enable the development of appropriate policies. Policymaking based on such data is the essence of evidence-based policymaking. The basis of evidence-based policymaking in the public policy space is the quest to anchor social reform programmes on pertinent and practical knowledge provided by scientific research [5]. This approach elevates the importance of collecting and analysing the appropriate and adequate amount of data, both qualitatively and quantitatively.

A traditional complaint around managing climate change, climate change adaptation in particular has been the paucity of relevant quantities of data for processing to derive trustworthy information. However, this condition has and continues to improve rapidly and definitely. A combination of rapid and incessant increases, and improvements in the sophistication, affordability, compactness and use of technology are enabling the prompt generation and analysis of copious data sets. These large sets of both structured and unstructured heterogeneous data are known as Big Data. In principle, the timely (often in real time) processing of this data accompanied by appropriate policy responses can make a difference between the ability to rapidly as well as suitably respond to the climate change hazards and costly policy reform delays.

A challenge in the policy arena is that outside absolute dictatorships, contemporary and 'acceptable' policy formulation, adoption and implementation processes follow a routinely lengthy bureaucratic and linear approach. These processes often exclude the views of one or other concerned group(s) through a typical 
accentuating of internal bargaining among small, highly placed powerful groups [6]. Actors in the policy space bargain around their personal beliefs and preferences as well as those of interest groups they represent. These beliefs and preferences may initially vary widely but are narrowed by the give-and-take practices of the bargaining process. Consequently, the policy outcomes of the process rarely advance the absolute views of single individuals but instead are a mix of views from several individuals [6]. While this is the essence of democracy, the disadvantage is that the nature of bargaining processes usually delivers suboptimal policy outcomes and often belatedly. While the importance of democracy in policymaking is acceptable, the delivery of suboptimal and delayed policy responses is problematic in dealing with dynamic and deleterious effects of phenomena such as climate change, economic development and human health, among others. Ideally, the desired policy responses must be dynamic, and more importantly, they must deliver systemic changes for efficient policy implementation, monitoring and evaluation that may lead to either to policy entrenchment or revision.

Nature is replete with forms of order and seemingly systemic changes in large complex systems. In principle, the policy formulation, implementation and revision space can draw important lessons from the collective and individual units of biological systems such as cell colonies, schools of fish, ant colonies and bird flocks. A protuberant characteristic of collective behaviour in such natural systems is the appearance of global order in which individuals harmonise their states to an extent of giving a striking impression that the group behaves as one [7]. While it is posited that group formations in systems such as insect swarms are a mere epiphenomenon of the independent interaction of each individual with an external landmark and stimuli, what matters is that the resultant order remains impressive and individual actions culminate in a collective benefit. While group formations are impressive, nature also shows deeper and long-lasting systemic changes that confer adaptation of individuals and entire ecosystems to external conditions.

Looking at how nature both rapidly and gradually but systemically adjusts to a plethora of stimuli and eventually achieves a 'dynamic equilibrium', it is arguable that managing climate change, that is, adjusting both mitigation and adaptation strategies and regimes, can learn from biological systems. A timeous and appropriate adjustment of relevant policy levers is critical for managing climate change. To this end, this chapter proposes a dynamic policy based on a learning, self-improving and self-adjusting policymaking approach that draws lessons from biological systems and it components - the essence of biomimicry. Ideally, the proposed approach was appropriate and should seek to avoid the lengthy policy cycle stages but still deliver a systemic and responsive policy to manage climate change narrowly and sustainable development broadly. The suggested and futuristic policymaking approach is cognisant of the fact that there is limited clarity around the concept of global order in many biological systems. It is also aware of fears around artificial intelligence/machine-learning phenomena as well as the contests and power dynamics in the policymaking space. Nevertheless, we posit that lessons from how natural systems both as individual and most relevantly as a system have and still evolve to adapt to changing environmental conditions carry important learning points for the proposed policymaking approach. As stated earlier changes in natural systems are both immediate as in the case of a school of fish avoiding predators and slow, for example, how the ecosystems have adapted to ionising radiation from Chernobyl [8]. Even slower is that birds of flight have evolved to have hollow bones strengthened by struts to reduce dead weight, whereas flightless birds like ostrich have more solid bones. In the case of birds of flights, bones in places with higher stresses are more solid. This principle informs the building of the shells of modern aircraft to optimise weight and strength of designs. Eliminating unrequired 
material means less dead weight, less fuel consumption and thus a lesser carbon footprint. Indeed Mother Nature can be a model, measure and mentor.

\section{Methodology}

The need for the proposed dynamic policy model arises from a process of critical reflection focusing on policymaking and adjusting to unpredictable phenomenaclimate change in this case. The reflection draws from the biggest teacher of survival tactics under challenging, unpredictable and dynamic conditions-Mother Nature.

As a methodology, critical reflection informs on ways that improve practice. It involves the ability to unearth, examine and change firmly entrenched assumptions leading to central changes in perspectives [9]. In seeking to challenge established positions and change them, critical reflection pays attention to the power dimensions of assumptive thinking. It examines how power dimensions affect the envisaged or proposed changes that may deliver desired outcomes [10]. In this chapter, the focus is challenging some tenets of the policy cycle arguing that in making or amending policy, not all components of a policy need to go through the cycle. Some important technical components can avoid the cycle if the policymaking process has mechanism to analyse and interpret relevant data that has a bearing on policy specifics, that is, codes and standards. This is the essence of the proposed learning and self-adjusting policy. In principle, such a policy can deliver an optimal policy regime provided the adjustments are driven by adequate and appropriate data.

Four traditions of thinking guide critical reflection as applied here. The first is reflexivity. This relates to how a researcher is aware of biases of analytic focus on his or her relationship to the field of study and the ways that cultural practices involve consciousness and commentary on themselves [11]. In this research, it was important to be reflexive considering our experiences as authors specifically as researchers, practitioners and concerned citizens in the climate change, sustainable development and broader social development spaces. Also important is our preference for the trans-, inter- and multidisciplinary research-a desirable approach in the sustainable development discourse. As a result, the concepts that inform the proposed policymaking approach are eclectic drawing from climate change, policymaking, biological science and computer technology. This reflects our academic training, experiences and practice.

A second consideration is reflective practice. This pertains to an awareness of the gap between theory and practice [12]. As authors, we are aware of this, often with first-hand experience on observing policymaking and its implementation and sometimes lack of implementation because of power dynamics in the policy space. The third component of critical reflection is deconstructionism. This relates to questioning the notion of generating knowledge in a progressive and nonconflictual manner [13]. Critical reflection interrogates power relations and in this case questions (and even threatens) the role of politicians, lobbyists and public service bureaucrats in the policy cycle. The fourth and final tradition of thinking in this methodology is critical social theory. Its importance to the arguments in this chapter is the argument that the use and interpretation of knowledge are social constructed [10]. This means it is possible to change or improve the same knowledge as well as its use and interpretation. This is important as the proposed model involves the use of artificial intelligence-a largely feared and in some cases a politically unpopular practice [14].

Despites these and other advantages, critical reflection also has weaknesses. Among the many weaknesses, a relevant one is that reflection is centred on 
individuals and not groups. Proposing a new approach to policymaking that in some cases eliminates the human element may not be everyone's cup of tea. Nevertheless, we advance such a model noting the urgency of policies that rapidly react to both the present and potential drivers and adverse impacts of climate change avoiding some sometimes misplaced human reluctances to deal with the problem head-on. Now, it is important to emphasise that we are not in any way suggesting humans make a wholesale delegation of their role to technology. Instead, we seek to improve policymaking for the benefit of humanity, and technology has a role in that endeavour. In advancing this view, a glimpse into the dynamics of policymaking is critical.

\section{Conventional policymaking}

Policies are essentially government or private organisation statements of what these entities intend to do or not to do, including laws, regulations and decisions designed to achieve defined goals [15]. Public policies essentially are government statements that outline public plans of dealing with societal problems in terms of the relevant laws, regulations or orders that seeks to influence behaviour for longterm societal collective benefits [15]. However, despite stating their objectives and the enacting of laws, public policies in particular are often late and regularly deliver suboptimal outcomes. Such outcomes and associated delays result from compromises that are necessary to accommodate the diverse views of critical and powerful/ influential stakeholders active in the policymaking arena. With reference to public policy, the outcomes reflect the prevailing political system. The policy cycle is a conceptual model that outlines the formulation, implementation and revision of these plans $[3,16,17]$. The cycle comprises five political activities, namely, (i) agenda setting, (ii) policy formulation, (iii) policy adoption, (iv) implementation and (v) evaluation.

Agenda setting deals with selecting societal problems that require addressing through public policy interventions. Such problems could be local issues such as discernible crime levels, public transport concerns or global issues such environmental degradation and international trade and standards. Power dynamics and asymmetries in the cultural, political, social, economic or ideological arenas are important for either including or excluding societal issues in and from policy agendas $[18,19]$. This implies that some important societal problems may not make it to the policy agenda especially those not championed by powerful constituencies as individuals and/or groups of elected or bureaucracy public officials, the media and the interest groups $[18,20]$. An issue that makes it to the policy agenda then proceeds to the next process of policy formulation. This is the stage at which discussions seek to define the courses of action for dealing with particular societal challenges.

The related discussions take place in government bureaucracies, legislative bodies (i.e. parliament) interest group offices and public meetings, that is, special commissions, among other platforms [21]. Visible activities of policymaking inter alia include parliamentary debates, exchange between parliament and the executive and public policy enquiries. Power dynamics remain in play at this stage. For example, interest groups may work with the executive, parliament or even the senior civil servants to formulate policy. Some parliamentary representatives may owe the success of their campaigns to the financial backing of interest groups who expert particular policy positions as a return on their investment. This approach excludes other groups that may have different interests and views on the policy agenda. After policy formulation, policy adoption, which essentially is the official recognition of a policy, follows. This essentially is an exclusive domain of explicit actions of government institutions. Adoption is dependent on the majority of relevant actors such 
as parliamentarians, either as individuals, representatives of particular groups or along party lines accepting the proposed policy [22]. The political systems play an important role in the policy adoption process. Absolute dictatorship, veto or other forms of executive powers can be used either to accept or reject a policy as earlier formulated or with modifications.

Accepted policies proceed to the implementation stage with the conversion of new laws and programmes into practice. A critical component of public policy implementation is capable and capacitated civil service in the bureaucratic structures of government. Implementation involves the interpretation of policy documents into operational frameworks. To this end, there is a need of clarity of policy objectives particularly where are the contestations around a particular. Ambiguity and conflict result in policy implementation challenges [23]. In addition, an accurate translation of policy documents into operational frameworks avoids the bureaucratic drift phenomenon [24], which is the shifting of policy away from its objective and towards the preference of the bureaucracy. After a period of implementation, it becomes necessary to evaluate the efficacy of the policy. This serves to ascertain if or not a policy has or is attaining its stated objectives. Evaluation examines if a policy has resulted in changes in practices and behaviours, satisfied needs such as increasing financial savings, addressing traffic congestion or addressing environmental concerns or has systematically addressed core societal problems and not mere symptoms of the problem(s). More important is that evaluation serves as feedback mechanism to either modify the existing policy for improved efficacy and identifying new challenges that in turn enter the policy cycle commencing with agenda setting. This gives rise to an interminable policy cycle. Alternatively, policy evaluation can lead to the termination of some policies.

The journey from agenda setting to policy adoption can be long. For example, in the international arena, the contribution of different countries in mitigating GHG is a hotly contested issue. The glimmer of hope that emerged after the Paris Agreement (COP 21) has somewhat been extinguished by the Donald Trump administration in the United States of America. Meanwhile GHG emissions continue to grow and with that global warming and ultimately climate change with its adverse impacts. In an ideal world, climate change needs the rapid development of a policy regime that manages climate change. More importantly, the policy must be evidence-driven and be flexible to rapid changes as dictated by emerging knowledge. Even more important is that the policy regime must confer systemic changes. This is a tall order in a globe with diverse interests and views. Nature often delivers on systemic changes that deliver widespread optimal outcome. Can policymaking learn from nature?

\section{Biomimicry and climate change}

The growing severity of the impacts of climate change demands a rapid and vast array of policy actions that both mitigate and adapt humanity and indeed all other flora and fauna to the impacts of these changes. The focus of mitigation is reducing or eliminating the increase of anthropogenic GHG emissions into the atmosphere. Adaption seeks to assist the world live with the inevitable climate change adverse events arising from global warming due to historic and present high GHG emissions. The question for many who seek to manage the climate change challenge is how to navigate the highly contested mitigation and adaptation policy and practice space. Contestations in this arena arise because managing climate change carries a mix political, economic and environment considerations around which humans rarely share similar views concerning the best options in maximising utility. 
As debates continue, contestation sharpen and diminish, there is a growing focus on how humans can emulate nature's ability to heal itself as well as to adapt to environments both harsh and otherwise. This mimicking is the essence of the science of biomimicry. The term biomimicry emerges from a combination of the word bios, meaning life, and mimesis, meaning to imitate. Biomimicry is a discipline that studies nature's strategies and how humans can emulate these strategies to solve contemporary challenges in a sustainable manner. Benyus captures the essence of biomimicry stating:

The core idea is that nature, imaginative by necessity, has already solved many of the problems we are grappling with. Animals, plants, and microbes are the consummate engineers. They have found what works, what is appropriate, and most important, what lasts here on Earth. After 3.8 billion years of research and development, failures are fossils, and what surrounds us is the secret to survival [25].

The essence of this assertion is that nature is replete with examples that can inform human activities, in this case on climate change mitigation and adaptation. This biomimicry operates in three distinct but interlinked levels of (i) organism level mimicry, which mimics a specific organism; (ii) the behaviour level, which focuses on how an organism behaves to its larger environment and (iii) ecosystem level mimicry [26].

An example of organism level biomimicry is that of the Teatro del Agua outdoor theatre in the Canary Islands, which mimics the Namib desert beetle Stenocara in condensing moisture in sea breeze to generate fresh water that is collected and used in this theatre [27]. The focus of behaviour level biomimicry is not the organism per se but rather how that organism behaves in changing both the biotic and abiotic material and systems in its environment [26, 28, 29]. For example, the behaviour of the North American beaver (Castor canadensis) of blocking water flow in rivers creates wetlands that retain nutrients, which in turn leads a diversity in both the resident flora and fauna generating a resilient ecosystem [30].

While mimicking individual organisms or their behaviour may benefit efforts seeking to manage climate change, greater benefits accrue if the mimicry is systemic, that is, it covers an entire ecosystem. This approach is concerned with how systems in all individual organisms, the environment and its resources work and interact as a collective. Any important theoretical construct of the ecosystem level biomimicry is the ecosystem principle. The principles (Table 1) are an overly simplified representation of how ecosystems operate.

An important point from the table is that an ecosystem is a function of all individual organisms in a locale, their behaviour as individuals and relative to other organisms both of their kind and not of their kind within that system. More important and relevant to this chapter is the point that ecosystems seek to optimise the entire system rather than its components. This is important because it many mean that one component of the system may have to compromise its individual absolute efficiency to deliver a system-wide optimal outcome. The key to such an outcome is using limited resources only for functions that are critical and leaving the rest for others to do the same [4]. Mjimba [31] refers to such an approach as the concept of separating real needs and wants in redefining a new path to sustainable development.

Mimicking ecosystems can focus on both the function and process strategies of ecosystems. The functions of ecosystems relate to services that include the provision of food and medicines, soil formation, detoxification of gases and liquids and climate regulation, among others [32]. The focus on process strategies relates to ecosystem aspects that confer resilience to these systems. This pertains to how ecosystems work both at individual and collective levels, the inherent relationships in the system with the related feedback loops that deliver the capacity and capability of an ecosystem to self-correct and self-heal [4]. 


\begin{tabular}{|c|c|}
\hline Ecosystem principle & Ecosystem components \\
\hline Ecosystems are dependent on sunlight & $\begin{array}{l}\text { Energy is drawn from sunlight } \\
\text { The sun carries spatial and time management means }\end{array}$ \\
\hline $\begin{array}{l}\text { Ecosystems optimise the system and not its } \\
\text { individual components }\end{array}$ & $\begin{array}{l}\text { Matter is cycled } \\
\text { Energy is transformed } \\
\text { Materials and energy are applied for multiple functions }\end{array}$ \\
\hline $\begin{array}{l}\text { Ecosystems carry various apparatuses, } \\
\text { associations and information }\end{array}$ & $\begin{array}{l}\text { Diversity enables resilience } \\
\text { Relationships are complex and are arranged and work in } \\
\text { varied hierarchies } \\
\text { There is complementarity and cooperation in ecosystems } \\
\text { Ecosystems are subject to emerging trends and events } \\
\text { Ecosystems self-organise }\end{array}$ \\
\hline $\begin{array}{l}\text { Ecosystems are in harmony to and hinge on } \\
\text { local conditions }\end{array}$ & $\begin{array}{l}\text { Ecosystems often use local materials } \\
\text { Ecosystems exploit locally available and abundant } \\
\text { prospects }\end{array}$ \\
\hline Ecosystems adapt and evolve & $\begin{array}{l}\text { The rates and levels of ecosystem adaptation and } \\
\text { evolution differ } \\
\text { Ecosystem are in a constant flux of a balanced } \\
\text { non-equilibrium } \\
\text { Ecosystems self-correct and self-heal }\end{array}$ \\
\hline Ecosystems create conditions that sustain life & $\begin{array}{l}\text { Functional ecosystems enhance biospheres } \\
\text { Ecosystem functions and outputs are environmentally } \\
\text { benevolent }\end{array}$ \\
\hline
\end{tabular}

Table 1.

Ecosystem principles.

An understanding of the theories of evolution and/or adapting suggests that the self-correction and self-healing manoeuvres of an ecosystem make use of past and present data such as the weather (i.e. temperature, humidity and wind currents) to ensure that the ecosystem remains optimal. An analogous situation to such adjustments is the behaviour of animals like fish, birds and locusts moving in large numbers.

Moving group of such animals have to balance the need (or nature) to maintain close proximity simultaneously with their ability to change both direction and speed as a unit while avoiding colliding with both other group members and physical structures in their environment $[7,33]$. This type of behaviour resides in the biological driven response of the individual animals, which manifest as a self-organised system [7]. The formations of these self-organised systems differ between and within the different types of birds, fish or insects as determined by the reasons for their movement and the population size of the group. For instance, in birds, a turn may or may not result in changes in the shape, density and volume of the flock and the positions individual birds take up in the flock [7]. Similarly, schools of fish change their formations based on the size of the schools. Very large schools of up to and more than 10,000 fish have subformations within the entire group. The entire school formations and its subformations change in response to predators and other external influences [33]. An important and relevant observation is that the reaction of individuals that actually sense either danger or an opportunity triggers similar reactions by other group members that may not have sensed the hazard or opportunity [33]. Humans too sometimes conform to this coordinated collective behaviour [34]. For example, the etiquette on the escalators up or down the City of London underground railway network is that as the escalator moves one can stand on the right-hand side and walk on the left-hand side. Largely this enhances the overall 
human traffic movement efficiency by decreasing the number of movements to avoid collisions. This is also apparent in the flows of people moving in opposite directions in a street or other constricted spaces. Often the people extemporaneously organise themselves into lanes of uniform walking direction to enhance easier movement. What is interesting is that such arrangements develop without particular individuals either managing or broadcasting these activities or relevant information about them so that others may follow.

In all these forms of self-organised systems, the observed changes are (often) systemic and seek to optimise efficiencies for the entire system rather than its components. This is different from the aforementioned compromises that deliver suboptimal outcome in the conventional policymaking process of democratic societies. Another important feature of such systems is their ability to receive data continually, process this data to generate information that triggers adjustments that deliver rapid changes again seeking at attaining (eventually) optimal outcomes for the systems. Based on these and other observation propose the development of a policymaking machinery that learns and self-adjusts. Such machinery would be appropriate for managing some aspects of dynamic challenges such as those of climate change. This proposal rests on using recent technological developments to drive some aspects of policymaking. We focus on two developments here, Big Data and artificial intelligence, and use these to propose a biomimicry-based policy cycle model for managing the challenges presented by the climate change phenomenon.

\section{Artificial intelligence, Big Data and dynamic policy: Policies inspired by natural systems}

Before we proceed to the model, a minor detour is inevitable as a foundation for the proposal. This detour briefly outlines the concept of artificial intelligence (AI). A growing discussion in the world of computer science is around the types of computer intelligence. Terms that include, cognitive computing, machine learning and deep learning, are the focus of this chapter around artificial intelligence (AI). Often, there is an interchangeable use of these terms in daily language. However, the terms differ although refer to related things.

Cognitive computing refers to the sensory subdivision of machine intelligence that is used. Sensors and algorithms are used to enable computer to 'see', 'hear' and 'feel' [35]. Through image sensors computers can see, microphones facilitate their hearing ability and the text-to-speech and speech-to-text technologies permit computers to interconnect with humans using natural (human) language through programmes such as Alexa, Siri, Cortana and Google Assistant.

Simplified, machine learning is knowledge computers gain from old data and historical trends identifying patterns that humans cannot identify [36]. This form of machine intelligence uses colossal amounts of data to generate patterns recognised by computers and thereafter used to differentiate objects from each other, for example, distinguishing between male and female humans or cats and dogs including the different breeds of these animals. The deep learning branch of machine intelligence involves using neural networks that mimic the physiology and function of the human brain $[36,37]$. The networks include several layers of neurons that permit computers to learn from historical data and thereafter apply in a way similar to how a human brain thinks [36]. This is the most advanced form of machine learning which is increasingly becoming the favoured approach in training computers.

AI refers to machines acting in ways that seem intelligent [35]. This is through enabling decision-making capabilities to computers. The intention of AI is for 
computers to make decisions that address specific problems just as humans do every day [35]. Computers use recommendation engines for this purpose, whereas narrow $\mathrm{AI}$ is a machine-based system designed to address a specific problem such predicting election results $[15,35,37]$. AI applications work in several branches that include machine learning, natural language processing and robotics. Our proposal is to extend the application of AI into the policymaking space to inform climate change mitigation and adaptation based on models adapted from natural systems through the process of biomimicry. This is a proposal for a dynamic policymaking model. The quintessential proposition of the model is the sequence of quick interventions that incorporate rapid and automated feedback loops that reinforce learning in the policy cycle so that the policy remains in a state of dynamic self-improvement as shown in Figure 1 (the Mjimba-Sibanda dynamic policy model).

The first stage of the model entails an analysis of natural biological systems using the biomimicry lens in order to understand the strategies that nature has evolved over aeons. The appropriate and relevant strategies are turned into design principles that are no longer limited to the biological context. These general design principles are used to inspire the development of a base policy. To update the policy continually, whenever defined factors change, the abstracted principles are modelled to produce algorithms that mimic the behaviour of the natural biological system, including in terms of having specific variables for the algorithm. The algorithm's input is Big Data from both the public domain and relevant databases for public policy. Artificial intelligence leverages the sensing of relevant data input, computing the historical and live data in order to adjust the policy and to provide feedback to improve the modelling of the algorithm. Most attractive is that computing the Big Data can enable the prediction of future scenarios. In principle, this means avail an opportunity to anticipate future challenges and adjust the policy to avoid or adapt to those changes before they even manifest. Adjusting to avoid such changes is the essence of climate change mitigation, and adjusting to manage the impacts of the changes relates to climate change adaptation- anticipatory adaptation. The desired policy adjustment can either be automatic, which is desirable in some cases, or be an outcome of debates that are characteristic of the democratic policymaking process.

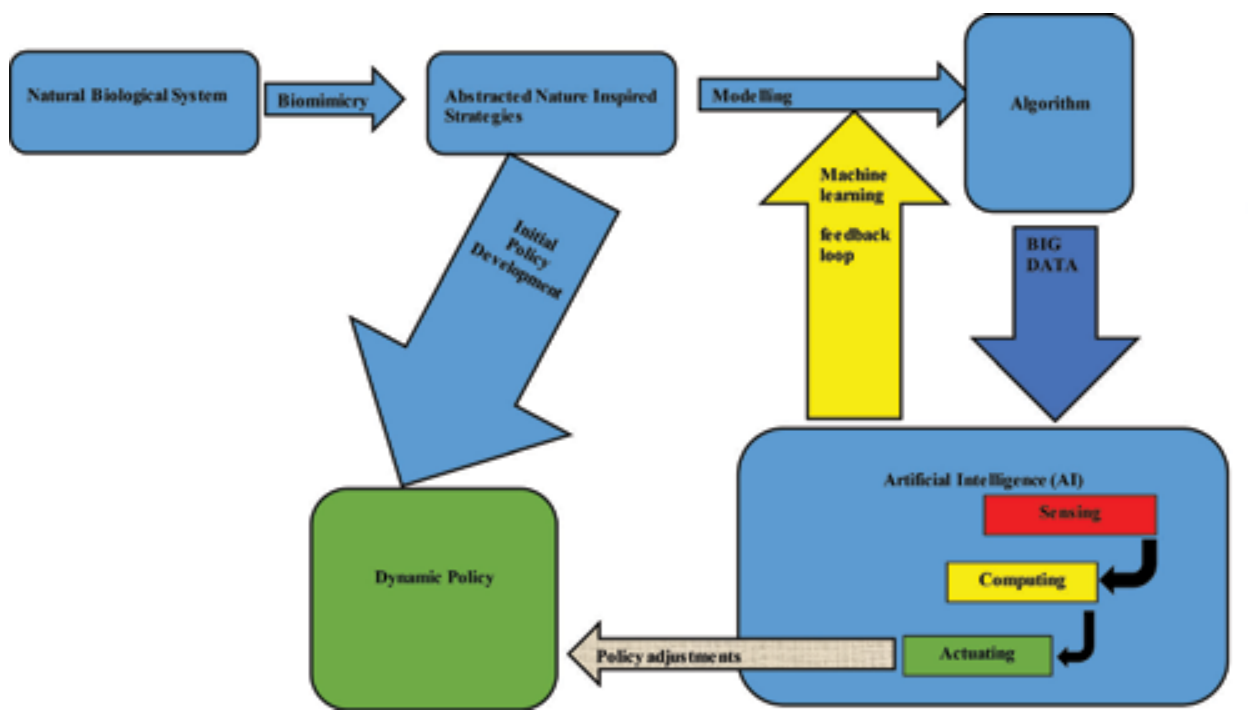

Figure 1.

The Mjimba-Sibanda dynamic policy model. Source: Authors. 


\section{Applying the model}

New ideas and innovations often struggle to gain traction particularly when benefits around them are obscure or disputed both rightly or wrongly. Cognisant of this fact, two examples illustrate plausible applications of the proposed model in both climate change mitigation and climate change adaptation. Before presenting the examples, a brief recap of some tenets of the biomimicry-policymaking nexus that informs the Mjimba-Sibanda dynamic policy model may be in order.

First, it is important to remember that biomimicry applies to three main typologies: mimicking form, process or system. Mimicking form entails emulating (not exact copying) a particular shape in order to achieve a particular function. Second, mimicking a system requires understanding of dynamics of complex interactions. In nature, an ecosystem illustrates such complex system. In natural ecosystems, the concept of waste does not apply because everything is either raw material or food for another and everything is recyclable in a closed resource loop. In such systems, there is co-evolution and co-development. The analogous human concept is the circular economy [38]. The Kalundborg Industrial Park in Denmark illustrates this concept through the co-location of complementary industries that exchange resources that include water, heat, gas, fertiliser and fly ash [39]. Here, we take the view of policy development as being analogous to co-evolving mutualistic relationships in a thriving ecosystem. In that regard, policy development has to seek greater benefits of systems and not components of systems. Let us now revert to the examples of two cases relating to climate change mitigation and adaptation.

Carbon sequestration is a plausible intervention of climate change mitigation. Forests such as the Amazon forests are significant and natural sequestration arenas. However, since the 1970 s, over $18 \%$ of the Amazon rainforests have been destroyed mainly for agricultural, timber logging and mining, among other activities. This has removed a significant carbon sink. In addition, these forests provide habitat for about a quarter of the world's terrestrial species and account for about $15 \%$ of terrestrial photosynthesis, whose by-product is the oxygen that humans and other animals breathe. Part of climate change mitigation seeks to retard and halt the further destruction of these forests. AI can help understand the relationships among various parameters such as rainfall, humidity, wind, temperature and floods. In addition, AI can also project changes in the acreage of critical forests projecting how these changes affect ecosystem services such as carbon sequestration. The relative changes in these parameters can be used for policy modelling seeking to enact automatically more stringent policy and legislation prescripts that can reduce the rate of depletion and promote regeneration of natural forests. The optimisation of natural systems such as the hydrological cycle, natural runoff, percolation and evaporation rates could provide benchmarks for what ideal conditions policy may seek to foster. An advantage of applying the proposed model in such a scenario is that the policy relies on both current and predicted possible conditions based on current deforestation rates. In addition, the generation of stringent conditions relies less on human judgement with AI generating the interrelations among species and components and, most important, making specific policy adjustments seeking to halt or mitigate present and future hazards.

Regarding climate change adaptation, machine intelligence such as AI and machine learning can predict possible future scenarios including the timing of their manifestation. Big Data fed into machine learning could help predict, for example, the areas with the likelihood of coastal flooding associated with climate change-related sea level rises. A dynamic policy could prescribe future actions such as land rezoning to stop further construction or the introduction of new building codes in areas with highest exposure to natural hazards and high probability of such 
risks manifesting. Similarly, the policy could define insurance models and levels of disaster preparedness triggered automatically should sea levels reach specified thresholds. This would enable various groups such as residents, investors, insurance providers and emergency services such as the police, hospitals and disaster units to be better prepared.

At first glance, the two examples may appear far-fetched and impractical. However, the plethora of late but well-intended and sometimes incoherent policies in many disciplines suggest that a systemic and self-adjusting policy regime is ideal to deal with the dynamics and nuances of issues such climate change. This holds in majority of policies that relate to climate change adaptation. Traditionally, these have often appeared after adverse events have occurred, instead of manifesting pre-the event to minimise damage. Even in the mitigation drive, the various actions arguably react to events that are avoidable, that is, driving reforestation instead of avoiding deforestation. The Mjimba-Sibanda dynamic policy model seeks to avoid this by taking a proactive policy approach to managing climate change. The approach takes the 'evidence-based' policymaking position by using large amounts of data to change both timeously and appropriately the relevant policy standards, codes and other parameters. The advantages of such dynamic policies are available elsewhere. Although the advantages do not necessarily use machine learning and do not draw from biomimicry, they nevertheless apply in this argument.

One important example of dynamic policy is in Kenya. Following the disputed 2007 elections, the feuding parties in the country eventually agreed to a negotiated settlement that culminated in a Government of National Unity (GNU) that comprised representatives of the various political parties. The political parties designed reforms for a more democratic political dispensation. Due to the prevailing mistrust at the time, the parties agreed that the implementation of the new Constitution, which came into effect in 2010, would include self-executing mechanisms. For example, certain provisions that required the President to ratify Bills by a specific date were set to become the responsibility of the Chief Justice if the President did not act accordingly. Similarly, if the Chief Justice reneged in signing the same within a defined period, the said provisions could automatically become law. Compelled by these conditions, on 27 August 2011 the then President signed 15 out of 27 Bills that were to meet the 1-year deadline [40]. Elsewhere, and using computer technology, the development of the blockchain-based smart contracts phenomenon offers interesting cases for the proposed Mjimba-Sibanda model. A blockchain is a distributed data structure replicated and shared among the members of a network [41]. Smart contracts are instruments that coded to automatically execute when certain criteria are met [41]. Merging the blockchain and smart contracts innovations gives rise to decentralised self-executing and self-enforcing contracts. Similarly, the proposed Mjimba-Sibanda model envisages future-oriented self-executing mechanisms aiming to manage climate change. Its criteria for executing changes will be a continuous computation of biological, climatic, physical and other data to generate policy that drives best practice concerning both climate change mitigation and adaptation.

\section{Conclusion}

Tying it all up, it is important to note that the current state of affairs in the management of climate change is in part because of human frailties in the process of making policy that can respond effectively to this challenge. Most concerning in this regard is that sometimes humans are reluctant to take decisions that may interrupt established but destructive practices and adopt new and seemingly inconvenient 
practices that may present long-term benefits. In addition, sometimes humans struggle to gather, analyse and link varied and vast amounts of data to generate information that appropriately informs policy and practice. This condition extends to many disciplines of social and economic development. The Mjimba-Sibanda dynamic policy model seeks to avoid some of these human shortcomings. The model proposes to combine lessons from biological systems, with the new concepts of Big Data and machine learning/artificial intelligence to define critical policy components that can aid the management of climate change.

As stated earlier nature learns and adapts both in the short and long terms. Mother Nature is the biggest teacher on earth. Through biomimicry, humans learn to emulate nature both at individual and system levels. However, lessons from nature are numerous and nuanced to an extent that the human mind may not adequately decipher the relations in these lessons. Modern computer technology serves to address this shortcoming, and the rise of artificial intelligence, especially machine learning, among other related concepts, offers an opportunity for improved decision-making to improve human conditions on earth. At this point it is important to allay fears of machines taking over the human-decision function.

Our belief is that humans working with machines, each contributing what it is good at, can produce outcomes that are much better than when humans and machines working separately. Furthermore, our position is that even in democratic societies, there are policy shifts that need to, can and must avoid the bargaining vagaries of the policy cycle and shift automatically when the relevant and adequate amounts of data accurately and appropriately generates credible information to develop fair, transparent and equitable policies. This is important in an environment which data generation and analysis are happening with greater speeds, the severity and frequency of climate change-linked extreme weather events are increasing and political expediency is sometimes overriding genuine environmental concerns with long-term detrimental effects. In such a scenario, rapid and to an extent automatic policy shifts are important. What is critical is that automatic changes in one area or department should in turn trigger relevant policy changes across government departments, private, public sectors and industries to deliver a system-wide change that avoids policy incoherencies and conflicts. Where human intervention can override machine decisions, the process should be transparent to all relevant stakeholders to prevent abuse by those with the overriding capability and authority. More important is that all overrides must always leave an auditable and public trail log of who effected the changes and the corresponding rationale.

The journey towards a new policymaking approach begins! 


\section{Author details}

Vuyo Mjimba* and Gamelihle Sibanda ${ }^{2}$

1 Human Sciences Research Council-Africa Institute of South Africa, South Africa

2 International Labour Organisation, South Africa

*Address all correspondence to: vmjimba@yahoo.com

\section{IntechOpen}

(C) 2019 The Author(s). Licensee IntechOpen. This chapter is distributed under the terms of the Creative Commons Attribution License (http://creativecommons.org/licenses/ by/3.0), which permits unrestricted use, distribution, and reproduction in any medium, provided the original work is properly cited. (cc) BY 
Biomimicry, Big Data and Artificial Intelligence for a Dynamic Climate Change Management... DOI: http://dx.doi.org/10.5772/intechopen.84406

\section{References}

[1] Goers SR, Alexander F, Wagner AF, Wegmayr J. New and old market-based instruments for climate change policy. Environmental Economics and Policy Studies. 2010;12(1-2):1-30

[2] Keohane RO, Victor DG. The regime complex for climate change. Perspectives on Politics. 2010;9(1): 7-23. Nunes PALD, Nijkamp P (2011). Biodiversity: Economic perspectives, Research Memorandum 2011-2, Faculty of Economics and Business Administration

[3] Demir A. The concept of economic value: The importance of biodiversity. Wulfenia. 2015;22(10):320-339

[4] Nunes P, Nijkamp P. Biodiversity: Economic Perspectives, Research Memorandum 2011-2. Faculty of Economics and Business:

Administration; 2011

[5] Head BW. Three lenses of evidencebased policy. The Australian Journal of Public Administration. 2008;67(1):1-11. DOI: $10.1111 /$ j.1467-8500.2007.00564.x

[6] Knill C and Tosun J. Policy-Making. In: Caramani Daniele, ed. Comparative Politics. 2. Oxford, UK: Oxford University Press; 2011:373-388

[7] Hemelrijk CK, Hildenbrandt H. 2012 schools of fish and flocks of birds: Their shape and internal structure by selforganization. Interface Focus. 2012;2: 726-737. DOI: $10.1098 /$ rsfs.2012.0025

[8] British Ecological Society (BES). Chernobyl's birds adapting to ionizing radiation; 2014

[9] Mezirow J. How critical reflection triggers learning. In: Mezirow J, editor. Fostering Critical Reflection in Adulthood. Jossey-Bass: San Francisco, CA; 1991

[10] Fook J. Developing critical reflection as a research method.
In: Higgs J, Titchen A, Horsfall D, Bridges D, editors. Creative Spaces for Qualitative Researching. Practice, Education, Work and Society, Vol. 5. Rotterdam: Sense Publishers; 2011

[11] Daley A. Reflections on reflexivity and critical reflection as critical research practices. Affilia. 2010;25(1):68-82

[12] Fook J. Beyond reflective practice: Reworking the "critical" in critical reflection. Keynote paper presented at Professional Lifelong Learning: Beyond reflective practice, a one-day conference held at Trinity and All Saints College, Leeds: University of Leeds; 3 July 2006

[13] Hickson H. Critical reflection: Reflecting on learning to be reflective. International and Multidisciplinary Perspectives. 2011;12(6):829-839

[14] Berghel H. Through the PRISM darkly. IEEE Computer Society. 2013;7(46):1-5

[15] Newton K, Van Deth J. Foundations of Comparative Politics (Cambridge Textbooks in Comparative Politics). Cambridge: Cambridge University Press; 2005. DOI: $10.1017 /$ CBO9780511806810

[16] Lasswell HD. The Decision Process: Seven Categories of Functional Analysis. College Park, MD: University of Maryland; 1956

[17] Lasswell HD. A Pre-View of Policy Sciences. New York, NY: Elsevier; 1971

[18] Everett S. The policy cycle: Democratic process or rational paradigm revisited. Australian Journal of Public Administration. 2003;62(2):65-70

[19] Howlett M, Ramesh M. Studying Public Policy. Policy Cycles and Policy Subsystems. Canada: Oxford University Press; 2003 
[20] Gerston LN. Public Policy Making: Process and Principles. Armonk, New York: ME Sharpe.|| Inc; 2004

[21] Dye TR. Understanding Public Policy. 3rd ed. Englewood Cliffs, New Jersey: Prentice-Hall; 2005

[22] Anderson J. Public Policy-Making. 5th ed. New York: Houghton Mifflin; 2003

[23] Maitland RE. Synthesizing the implementation literature: The ambiguity-conflict model of policy implementation. Journal of Public Administration Research and Theory: J-PART. 1995;5(2):145-174

[24] Grossman SJ, Hart OD. An analysis of the principal agent problem.

Econometrica. 1983;51(1):7-46

[25] Benyus JM. Innovation Inspired by Nature. New York, NY: Harper and Perennial; 1997

[26] Pedersen Zari M. Biomimetic approaches to architectural design for increased sustainability. In: SB07 New Zealand Paper Number: 033. New Zealand: School of Architecture, Victoria University, Wellington; 2007

[27] Garrod RP, Harris LG, Schofield WC, McGettrick J, Ward LJ, Teare DO, et al. Mimicking a Stenocara beetle's back for microcondensation using plasmachemical patterned superhydrophobic-superhydrophilic surfaces. Langmuir. 2007;23(2):689-693

[28] Pedersen Zari M. Biomimetic design for climate change adaptation and mitigation. Architectural Science Review. 2007;53:172-183

[29] Pedersen Zari M and Storey JB. An ecosystem based biomimetic theory for a regenerative built environment. Centre of Building Performance Research, School of Architecture. Wellington, New Zealand: Victoria University of Wellington; 2007
[30] Rosemond AD, Anderson CB. Engineering role models: Do non-human species have the answers. Ecological Engineering. 2003;20:379-387

[31] Mjimba V. Relearning our wants and needs for sustainable development. In: Nhamo G, Mjimba V, editors. Sustainability, Climate Change and the Green Economy. Pretoria: Africa Institute of South Africa; 2016

[32] Eastwood A, Nijnik M, Brooker

R, Pakeman R, Artz R, Norton

$\mathrm{L}$, et al. Nature conservation and ecosystem service delivery. Joint Nature Conservation Committee. Peterborough: Joint Nature Conservation Committee; JNCC Report No. 492; 2013

[33] Lecheval V, Jiang L, Tichit P, Sire C, Hemelrijk CK, Theraulaz G. Social conformity and propagation of information in collective U-turns of fish schools. Proceedings of the Royal Society B. 2018;285:1-9

[34] Helbing D, Molnar P, Farkas I, Bolay K. Self-organizing pedestrian movement. Environment and Planning B. $2001 ; 28: 361-383$

[35] Koch C, Tononi G. A test for consciousness. Scientific American. 2011;304(6):44-47

[36] McKinsey Global Institute (MGI). The Age of Analytics: Competing in a Data-Driven World. McKinsey \& Company. 2016. Available from: https://www.mckinsey.com/ /media/ McKinsey/Business\%20Functions/ McKinsey\%20Analytics/Our\%20 Insights/The $\% 20$ age $\% 20$ of $\% 20$ analytics\%20Competing\%20in $\% 20 \mathrm{a} \% 20$ data\%20driven\%20world/MGI-The-Ageof-Analytics-Executive-summary.ashx [Accessed: 30 December 2018]

[37] Ransbotham S, Kiron D, Gerbert P, Reeves M. Reshaping business with 
Biomimicry, Big Data and Artificial Intelligence for a Dynamic Climate Change Management... DOI: http://dx.doi.org/10.5772/intechopen.84406

artificial intelligence. Closing the gap between ambition and action. MIT Sloan Management Review. 2017;59(1):1-17

[38] Geissdoerfer M, Savaget P, Bocken NMP, Hultink E. The circular economy-A new sustainability paradigm? Journal of Cleaner

Production. Jan. 2017;143(1):757-768

[39] Jacobsen NB. Industrial Symbiosis in Kalundborg, Denmark A quantitative assessment of economic and environmental aspects. Journal of Industrial Ecology. 2006;10(1-2):239-255

[40] Ng'etich P. Kibaki Signs Key Bills Daily Nation 28 August 2011; 2011. Available from: https://www.nation. co.ke/news/politics/Kibaki-signs-keyBills-/1064-1227002-12n8rpaz/index. html [Accessed: 30 December 2018]

[41] Christidis K, Devetsikiotis M. Blockchains and smart contracts for the internet of things. IEEE Access. 2016; 4:2292-2303 


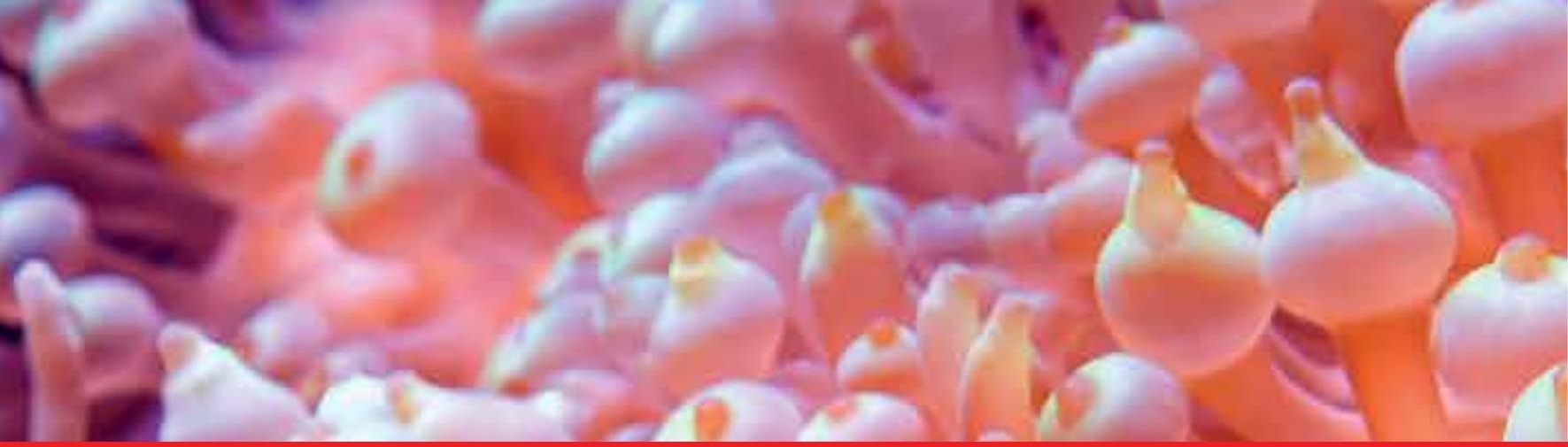

\section{Edited by Levente Hufnagel}

Changing Ecosystems and Their Services provides a very interesting account of the frontiers of biodiversity and ecological research. It consists of seven chapters covering mass extinctions: the "Big Five" and "The Sixth", which are recent global ecological crises, Caribbean biodiversity, acoustic habitat degradation due to shipping in the world's oceans, methane production of microbes in Amazonian floodplains, African mangrove forests, pollination as ecosystem services in Ethiopia, and climate change management. I am sure that this book will be very useful for everybody-researchers, teachers, students, or others interested in the field-who would benefit from insight into biodiversity research.

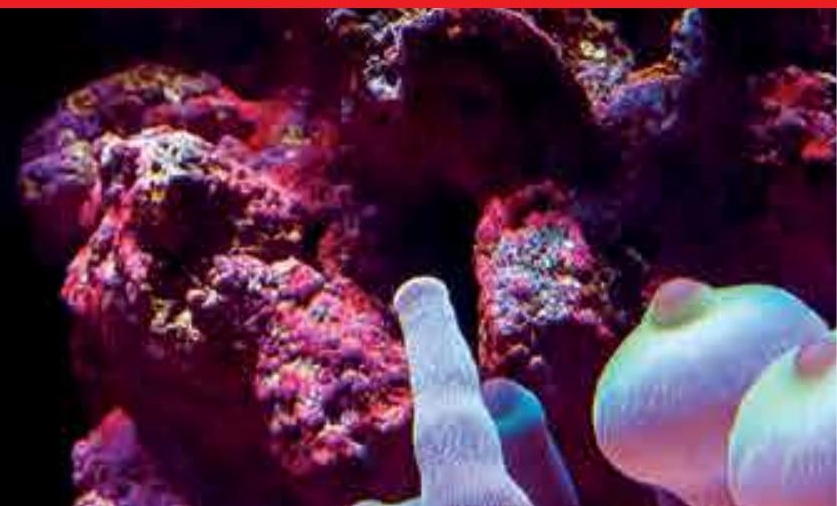

